\title{
Mechanism of Action of Liver Growth Induced by Peroxisome Proliferators
}

\author{
by
}

Abeer H. A. Amer B.Sc., M.Sc.

Thesis submitted to The University of Nottingham for the degree of Doctor of Philosophy 


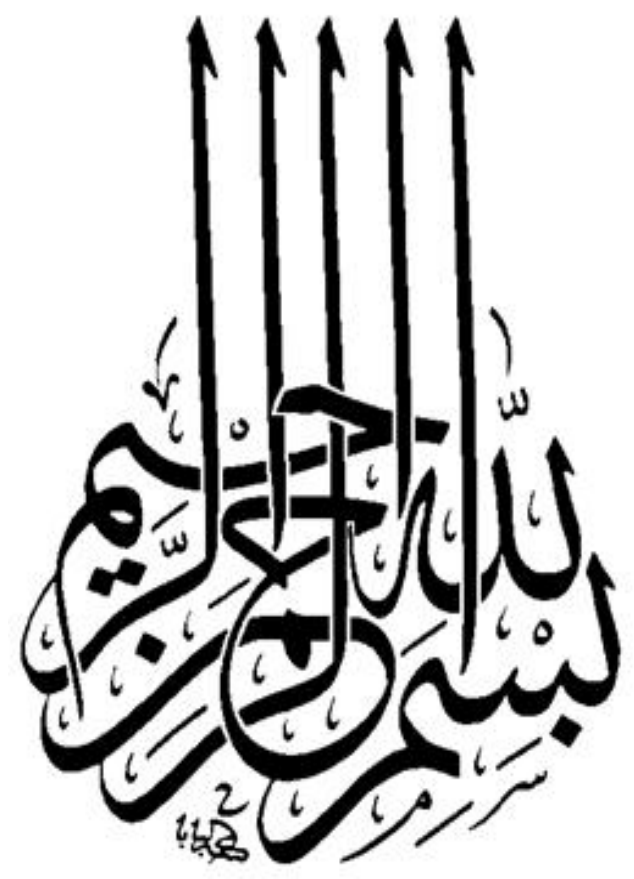

In The Name Of God (Allah) The Most Merciful The Most Gracious 


\section{Abstract}

Humans are ubiquitously exposed to peroxisome proliferators including hypolipidemic agents, industrial solvents and natural products. Because of this and the fact that peroxisome proliferators cause non-genotoxic hepatocarcinogenesis in rodents, it is of importance to elucidate the mechanism of action of the peroxisome proliferators in order to provide an assessment of the hazard, if any, of these compounds to humans. It is also known that the peroxisome proliferators begin their actions by inducing hepatic DNA synthesis. Thus, the aim of this thesis was to find genes that could be responsible for triggering the induction of hepatic DNA synthesis caused by peroxisome proliferators, specifically ciprofibrate.

First, it was important to indicate when the induction of hepatic DNA synthesis actually happens. This was done with BrdU immunohistochemical procedures. The induction of hepatic DNA synthesis with ciprofibrate in mice was observable only after 4 days making it difficult to specify when the induction actually happened. In rats the induction of hepatic DNA synthesis was found to peak at 24 hours and this system gave the better opportunity to find the genes responsible. The difference in the timing of induced hepatic DNA synthesis between mice and rats implied that there could be a species difference in the mechanism of each species' response to PPAR. With immunohistochemistry it was noticed that there was a difference in the lobular localization of hepatic DNA synthesis in the liver tissues of rats and mice dosed with different inducers, with the rat livers exhibiting periportal distribution while hepatic DNA synthesis in the mice seemed to be distributed throughout the liver tissue.

The effects of ciprofibrate or cyproterone acetate on liver gene expression in rats were studied, using cDNA microarrays, transcriptome sequencing and quantitative real- time PCR. A 1- 5 hour treatment period was chosen to detect the immediate early gene response, while a 24 hour time point was chosen to elucidate the confounding effects from the hepatic DNA synthesis seen 
during the 24 hour stimulation. The results showed that ciprofibrate altered the expression of numerous genes including previously known PPAR $\alpha$ agonist-responsive genes involved in processes such as PPAR signalling pathways, fatty acid metabolic pathway, cell cycle, palmitoylCoA hydrolase activity, lipid metabolism, inflammatory responses, and stress responses, in addition to a large number of novel candidate genes.

Three novel induced genes GOs2, Ccndl and Scd1, (and two marker genes CYP4Al and CYP3A1) were confirmed with quantitative real- time PCR. The G0s2, Ccndl and Scdl were found to be up-regulated at the hours 1 and 3 after dosing and not 24 hours, and the G0s 2 and Scdl were specific for the ciprofibrate suggesting they were involved in a distinct PPAR $\alpha$ pathway responsible for the hepatic DNA synthesis. The complete database of the transcriptional response provided here opens doors of opportunity for further research to identify genes responsible for the liver growth induced by peroxisome proliferators. 


\section{Acknowledgments}

I can not thank enough my former supervisor, Dr David Bell who supervised me for over 3 years for his advice and guidance. Even after he left he was always happy to support me and to reply to my e-mails even on his holidays! He will always be my role model for his passion about science and his dedication to his students and work. I would also like to thank my supervisor Dr Simon Avery for his help in correcting my thesis and whose advice and encouragement got me through to the end of my PhD.

I would like to thank Dr Abdullah Al-kholaifi for his instructions and help with the immunohistochemistry and for his generosity with his slides that gave me the insight to explore and study. I would like to show my gratitude to Dr Tim Gant from Leisecter University for allowing me to use his microarray scanner and for his help with the analysis, and to Kate Phillips for providing me with the microarray slides and for training me to use the microarray scanner. I would also like to show my appreciation to Dr Aboobaker Aziz from the University of Nottingham QMC for his help with the transcriptome analysis, and for letting me take over his computer for the duration of my work in his lab.

I especially would like to thank Richard Wall and Himanshu Kharkwal who were a great help in training me to conduct and analyse the qRT-PCR, and for all the BBQs and meals they were always keen on organizing for the group. And a big thank you to Mr. Declan Brady who was always there for help and advice.

Finally, I would like to thank the Libyan people for providing financial support for my study and thank you to all my family and friends for their help and support in making this $\mathrm{PhD}$ a pleasurable time of my life. 


\section{Dedication}

This thesis is dedicated to

my Wother and Father, my Fusband Wail and to my Grisdren

Monder, 落a and Moriammed

This thesis is dedicated to

the memory of my grandfatier 花yad $\mathscr{\mathscr { t }}_{\text {mer }}$

and to the

Martyrs of the Libyan Gause 


\section{Declaration}

I declare, that this work was achieved in the duration of my PhD studies at the University of Nottingham, and is my original effort unless otherwise stated. Information from other resources has been fully recognized. No part of this thesis has been submitted for assessment leading to a degree.

Abeer Amer

17th Febuary 2011 


\section{TABLE OF CONTENTS}

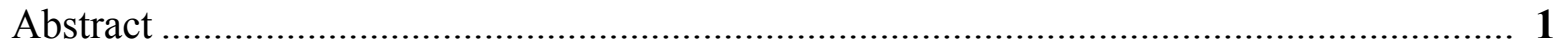

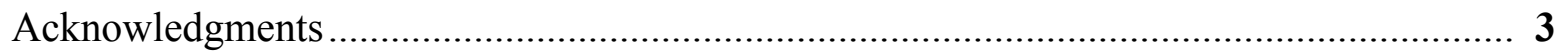

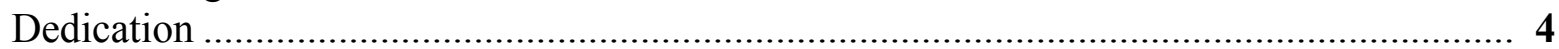

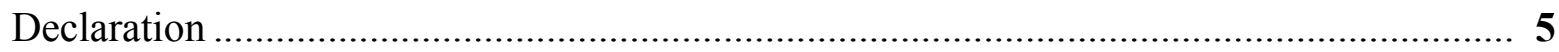

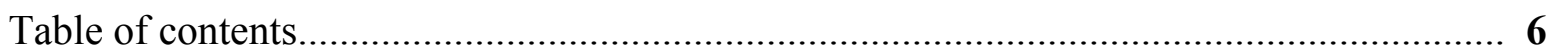

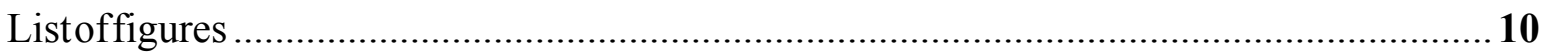

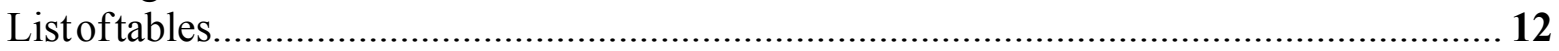

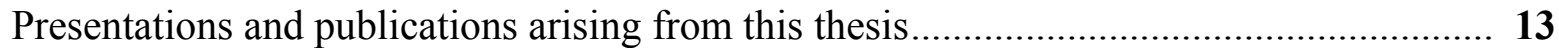

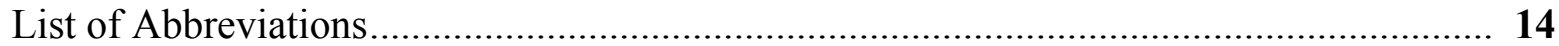

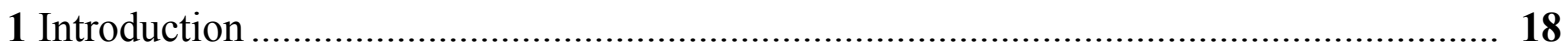

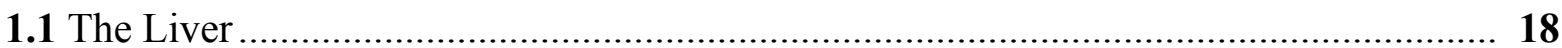

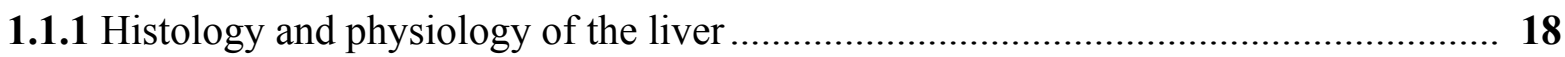

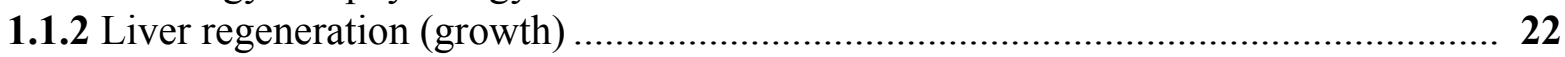

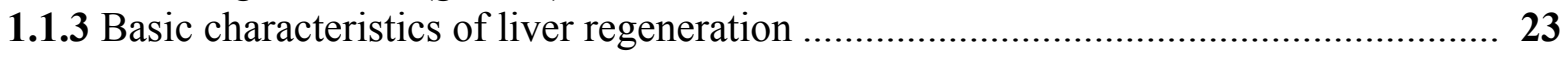

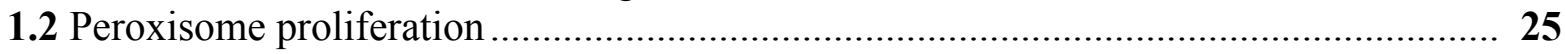

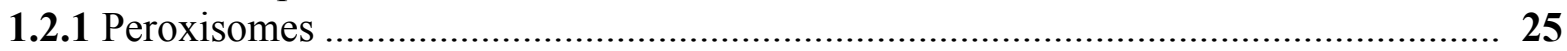

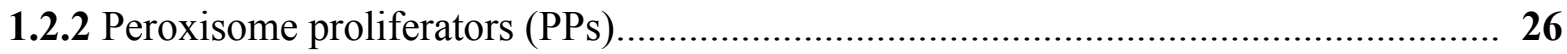

1.2.3 Ciprofibrate, cyproterone acetate and pregnenolone- $16 \alpha$-carbonitrile ....................... 28

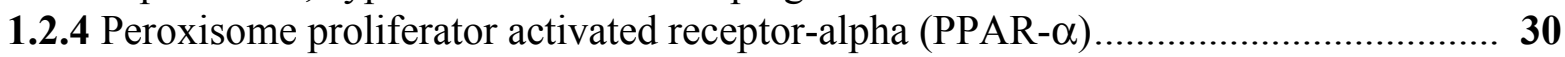

1.2.5 Toxicological changes induced by peroxisome proliferators.................................. 31

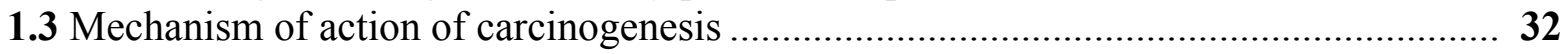

1.3.1 Peroxisome proliferators induce liver cancer in rodents ..................................... 33

1.3.2 Peroxisome proliferators are non-genotoxic carcinogens .................................... 33

1.4 Induction of hepatic DNA synthesis by peroxisome proliferators .............................. 35

1.4.1 Acute and chronic effects of peroxisome proliferators on hepatic DNA synthesis .... 35

1.5 Gene expression in response to peroxisome proliferators........................................... 36

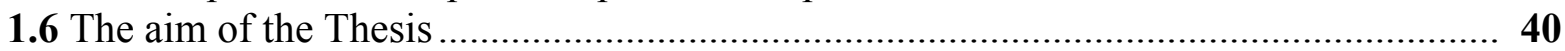

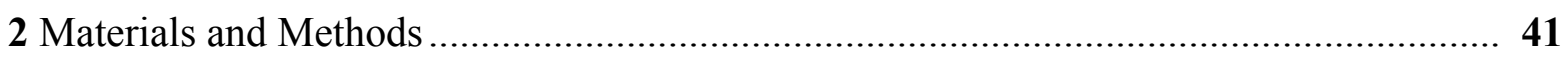

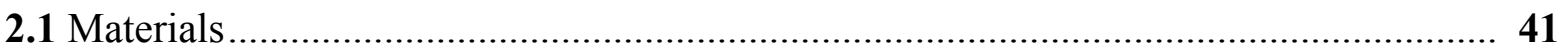

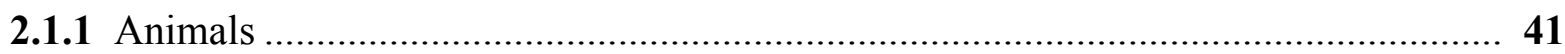

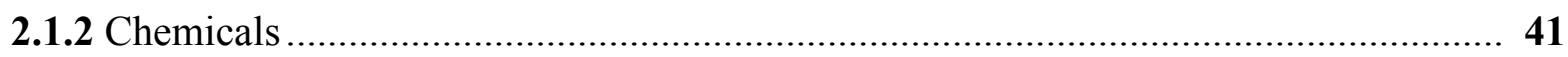

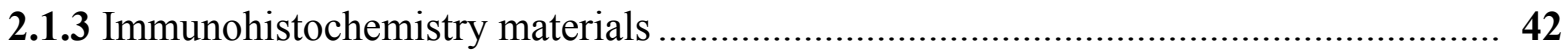

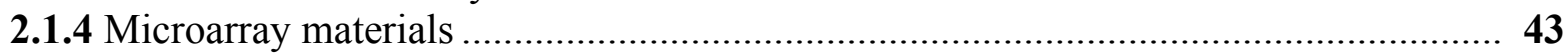

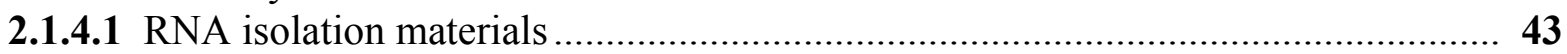

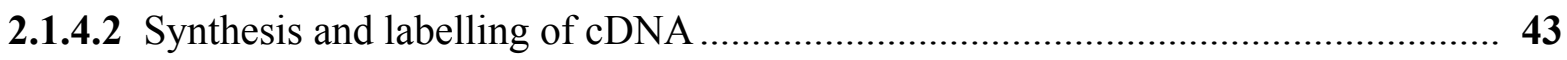

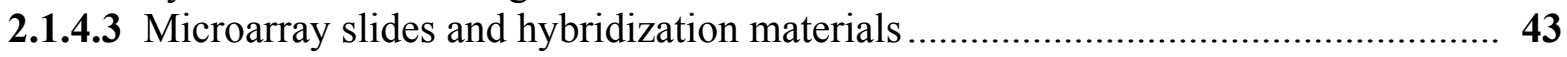

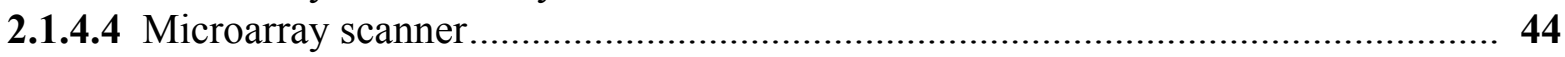

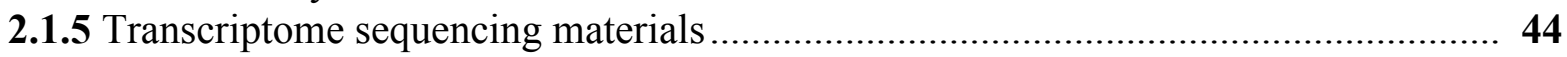

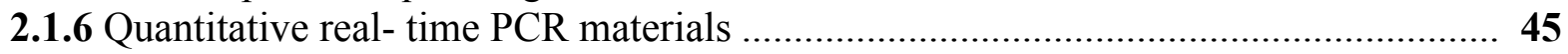

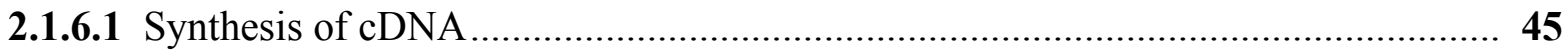

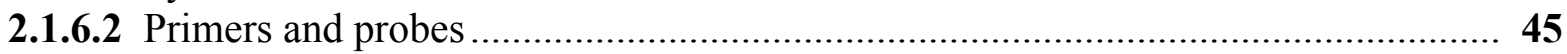

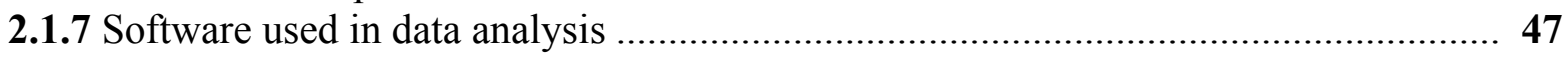

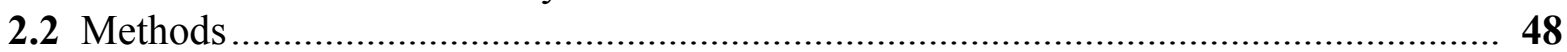

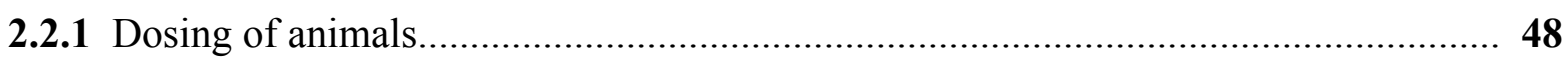

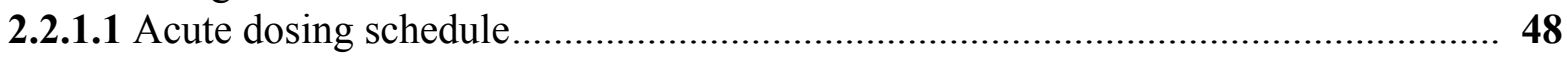

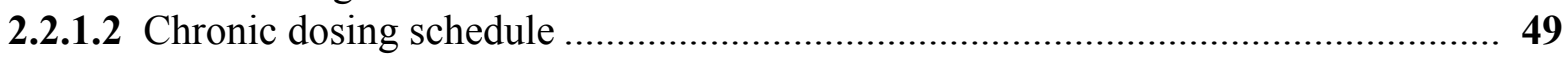

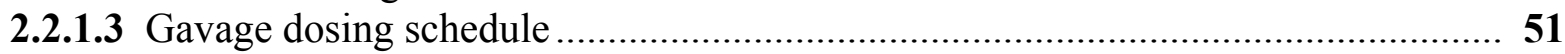


2.2.2 Animal observations and tissue collection

2.2.3 Immunohistochemistry technique for BrdU paraffin sections ...............................52

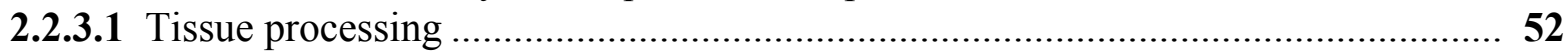

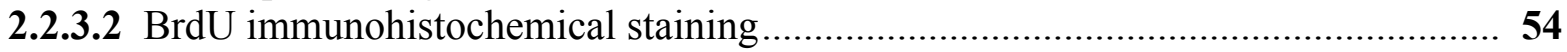

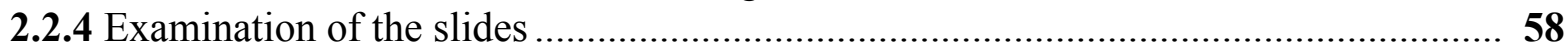

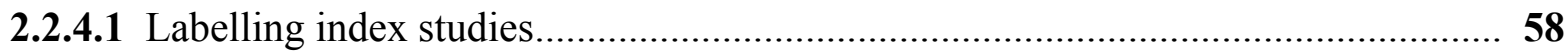

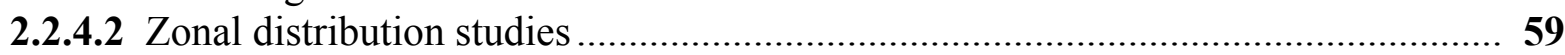

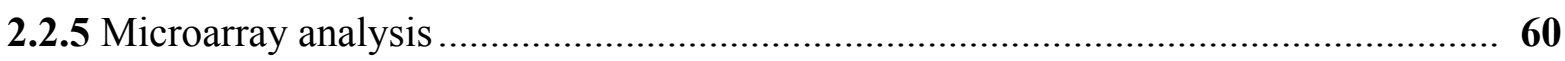

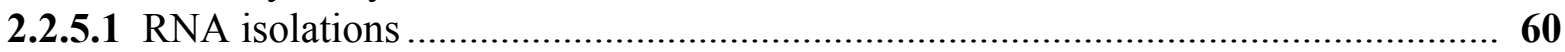

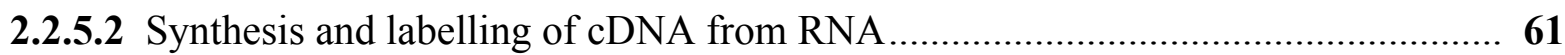

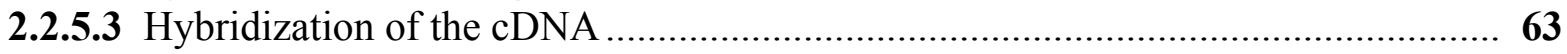

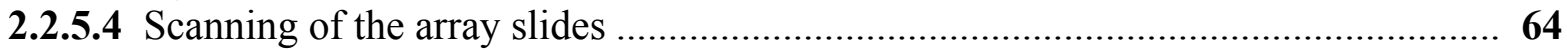

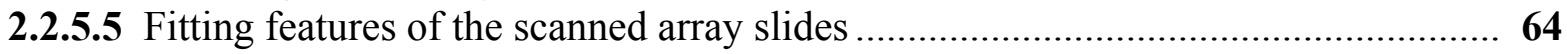

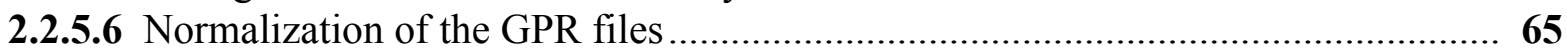

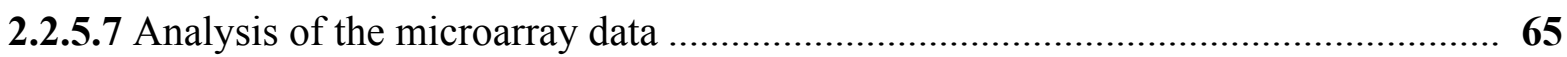

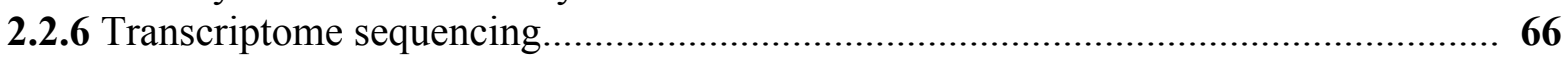

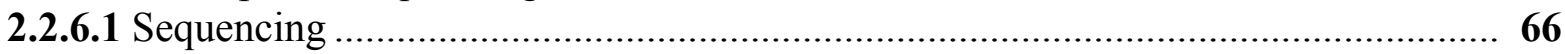

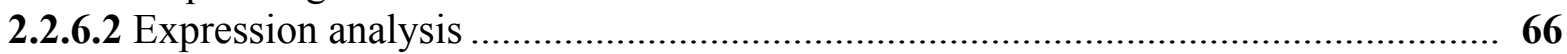

2.2.7 Quantitative real-time reverse transcriptase polymerase chain reaction (qRT-PCR) .. 67

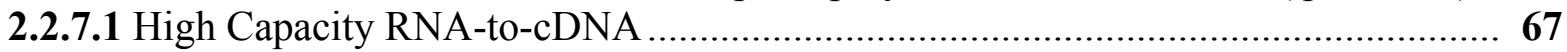

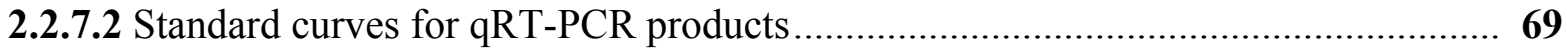

2.2.7.3 Quantitative real-time PCR using TaqMan ${ }^{\circledR}$ gene expression .............................. 69

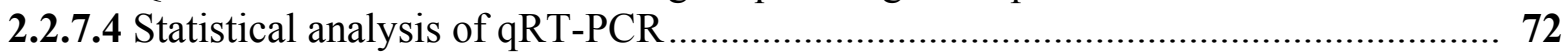

2.2.8 Quantity and quality measurement of RNA and cDNA ....................................... 72

2.2.9 Measurement of serum Alanine Aminotransferase ALT ........................................ 72

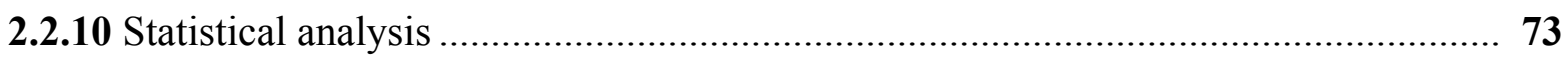

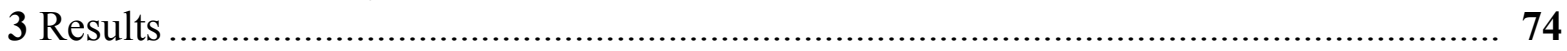

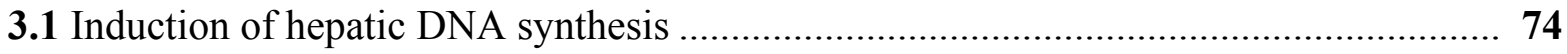

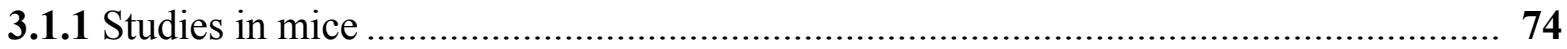

3.1.1.1 Optimization of immunohistochemical technique ............................................ 74

3.1.1.2 Effect of ciprofibrate on hepatic DNA synthesis in mice .................................... 78

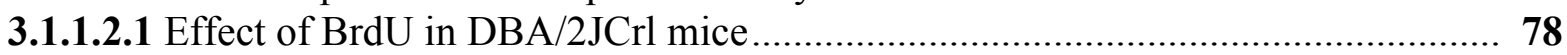

3.1.1.2.2 Effect of ciprofibrate in DBA/2JCrl mice ....................................................... 80

3.1.1.3 Effect of ciprofibrate in C57BL/6JCrl mice................................................... 84

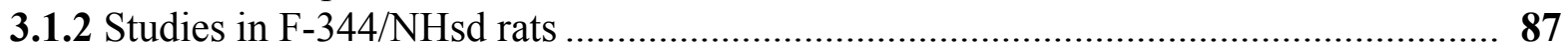

3.1.2.1 Effect of ciprofibrate on hepatic DNA synthesis in F-344/NHsd rats .................... 87

3.1.2.1.1 Time course of ciprofibrate effect in F-344/NHsd rats ...................................... 87

3.1.2.1.2 Dose response for ciprofibrate in rats ............................................................. 91

3.1.2.2 Effect of pregnane $X$ receptor (PXR) ligands on hepatic

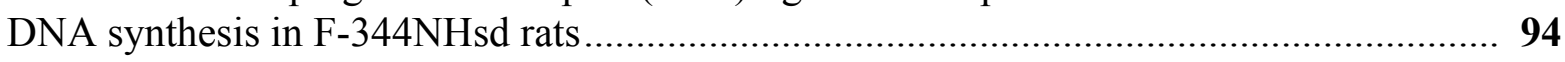

3.1.2.2.1 PXR ligands in male and female rats: Pilot study .............................................. 94

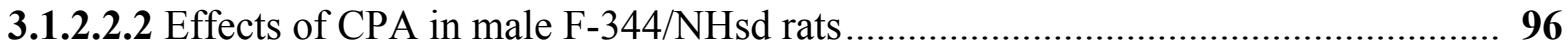

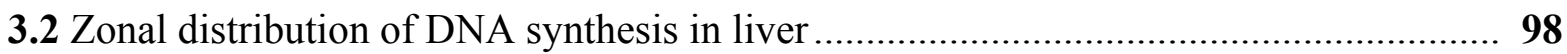

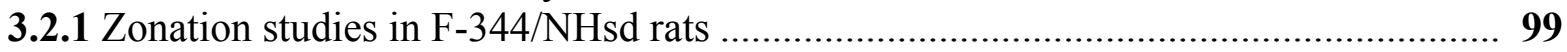

3.2.1.1 Induction of hepatic DNA synthesis by PPAR $\alpha$ ligands (ciprofibrate) ................... 99

3.2.1.2 Induction of DNA synthesis by the PXR ligand cyproterone acetate (CPA)......... 103

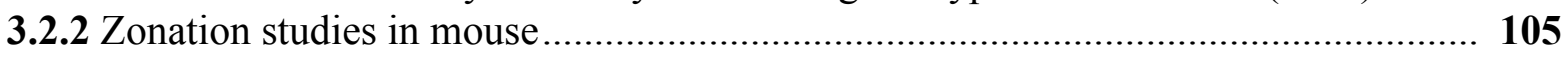

3.2.2.1 Induction of hepatic DNA synthesis by the constitutive

androstane receptor (CAR) agonist TCPOBOP in 129S4/SvJae mice ............................. 105 
3.2.2.2 Induction of hepatic DNA synthesis by PPAR $\alpha$ ligands (ciprofibrate) ................ 109

3.2.2.2.1 Zonation in $129 \mathrm{~S} 4 / \mathrm{SvJ}$ Je mice treated with ciprofibrate. ................................... 109

3.2.2.2.2 Zonation in $129 \mathrm{~S} 4 / \mathrm{SvJae} P P A R \alpha-$ null $\left(129 \mathrm{~S} 4 / \mathrm{SvJae}-\right.$ Ppara $\left.^{\text {tm } 1 \mathrm{Gonz} / \mathrm{tm} 1 \mathrm{Gonz}}\right)$ mice treated with ciprofibrate.

3.2.2.2.3 Zonation in $\mathrm{C} 57 \mathrm{BL} / 6 \mathrm{JCrl}$ mice treated with ciprofibrate.

3.2.2.2.4 Zonation in $\mathrm{DBA} / 2 \mathrm{JCrl}$ mice treated with ciprofibrate.

3.2.2.3 Induction of hepatic DNA synthesis by the PPAR $\alpha$ methylclofenapate. .............. 115

3.2.2.3.1 Zonation in 129S4/SvJae mice treated with MCP ............................................. 115

3.2.2.3.2 Zonation in Alderley park (AP) mice treated with MCP................................ 117

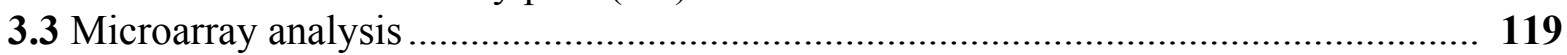

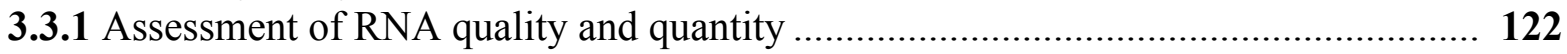

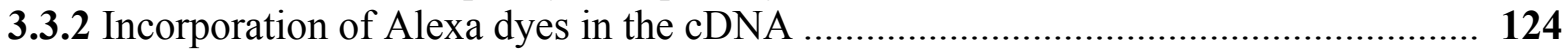

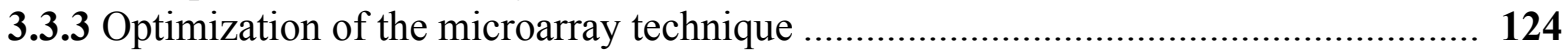

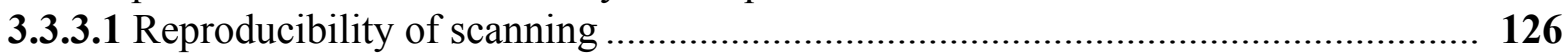

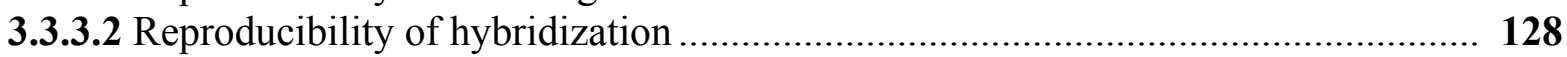

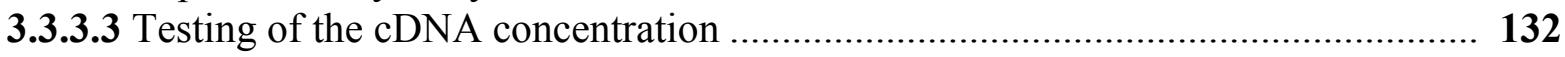

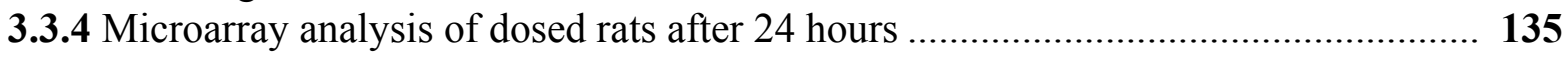

3.3.5 Microarray analysis of ciprofibrate dosed rats after 1,3 , and 5 hours .................... 143

3.3.6 Microarray analysis of CPA dosed rats after 1,3 , and 5 hours ............................. 157

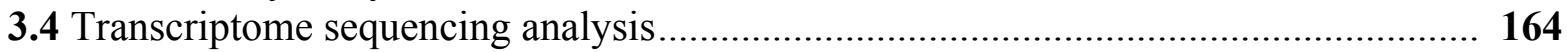

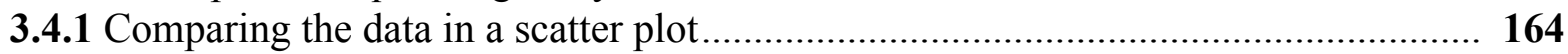

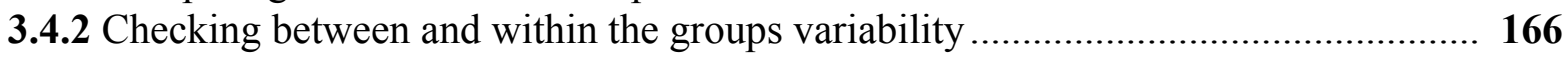

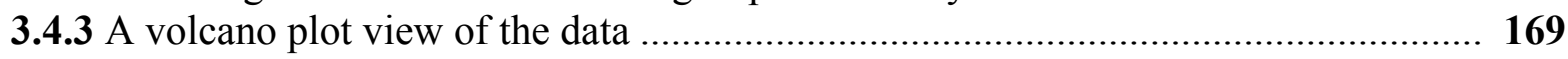

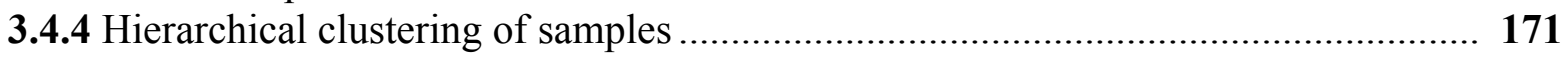

3.4.5 Hierarchical and K-means clusters of features.................................................. 173

3.4.6 Induced genes by ciprofibrate after 3 hours with RNAseq ................................. 174

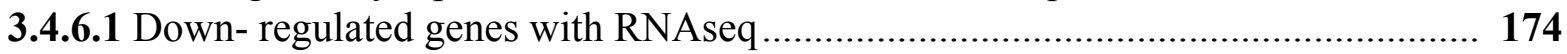

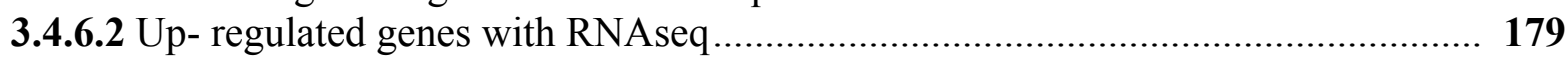

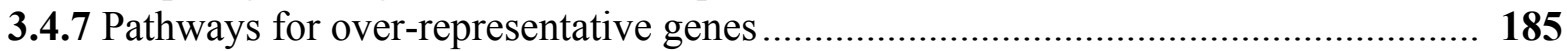

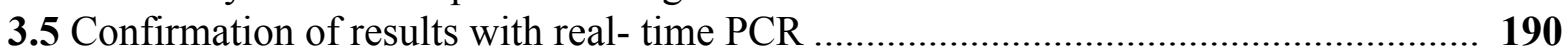

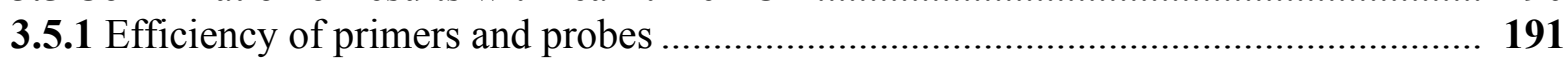

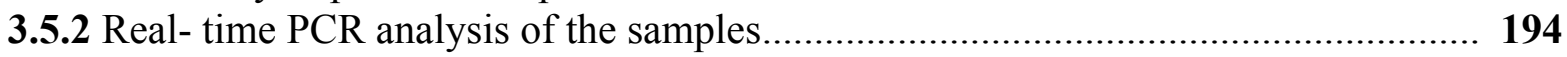

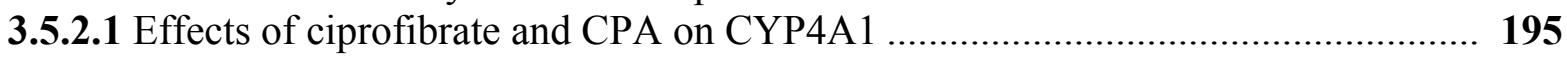

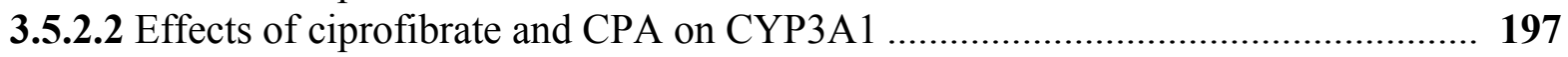

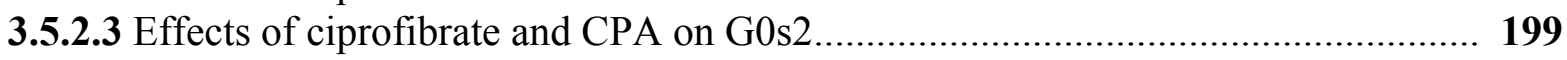

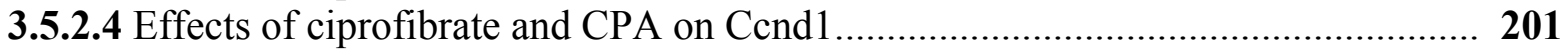

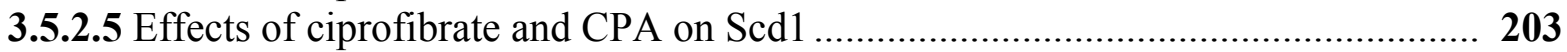

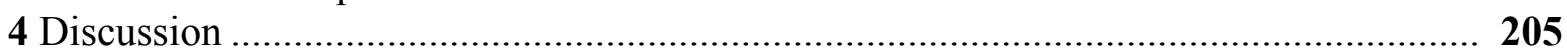

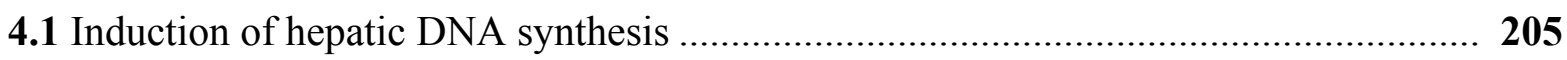

4.1.1 Effect of ciprofibrate on hepatic DNA synthesis in mice ................................... 205

4.1.2 Effect of ciprofibrate on hepatic DNA synthesis in rats ..................................... 207

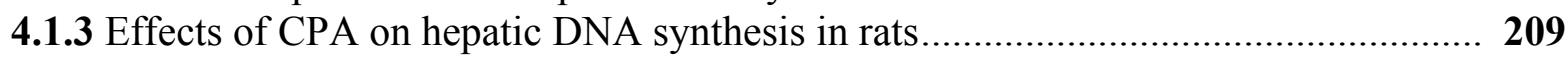

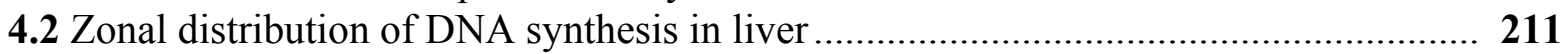

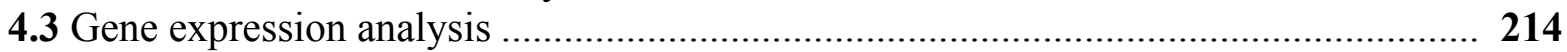

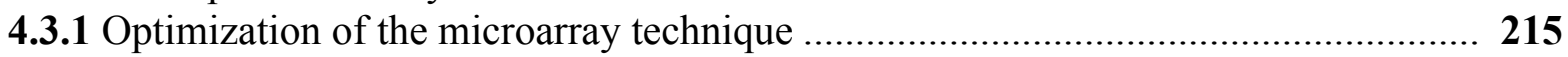

4.3.2 Microarray analysis of rats dosed with ciprofibrate ........................................... 216

4.3.3 Transcriptome sequencing of rats dosed with ciprofibrate for 3 hours..................... 218

4.3.4 Ciprofibrate pathways of over-represented genes ............................................ 219

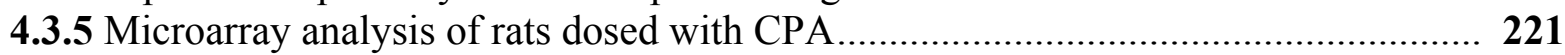


4.3.6 CPA pathways of over-represented genes........................................................... 222

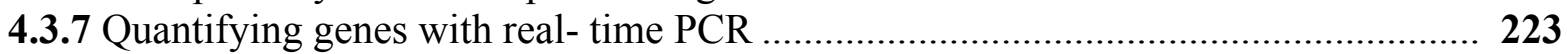

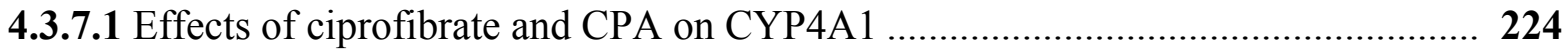

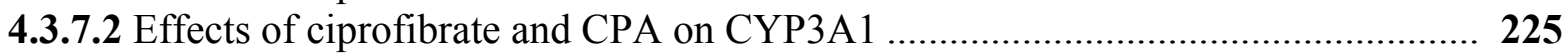

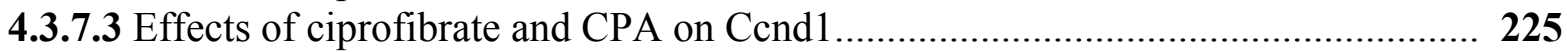

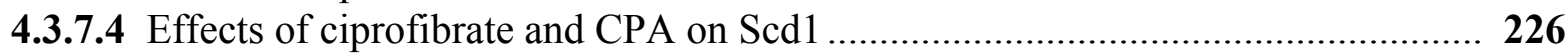

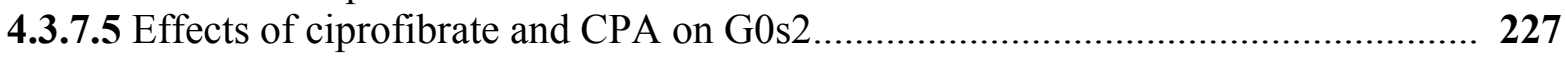

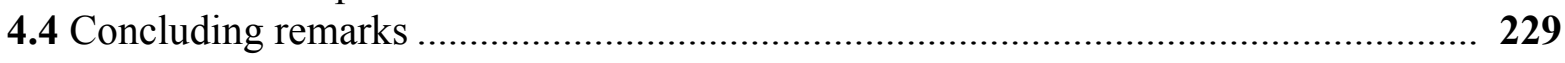

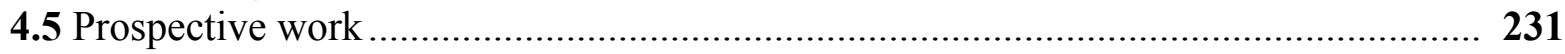

Appendix RNA, cDNA and dye yields of the microarray samples ............................. 233

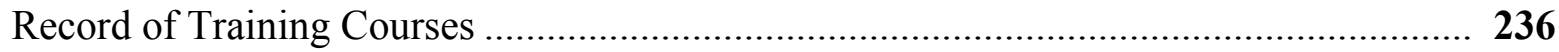

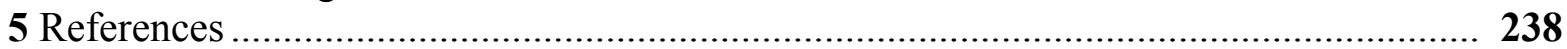




\section{LIST OF FIGURES}

Figure 1.1 Histological view of the classic liver lobules .............................................. 19

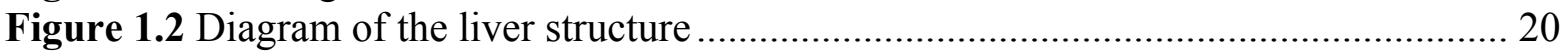

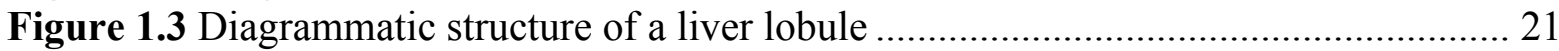

Figure 1.4 Histological section of liver cells.................................................................. 22

Figure 1.5 Diagrammatic illustration showing patterns of DNA synthesis

and induction of gene expression during rat liver regeneration ............................................ 24

Figure 1.6 Schematic diagram of the PPAR mechanism of action ................................... 37

Figure 2.1 Schematic representation of acute and gavage dosing protocols........................ 49

Figure 2.2 Schematic representation of chronic dosing protocol alone ............................. 50

Figure 2.3 Schematic representation of chronic and gavage dosing protocols .................... 50

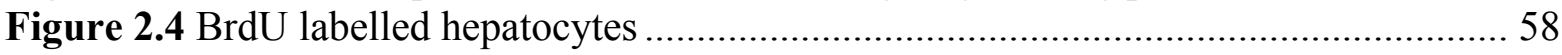

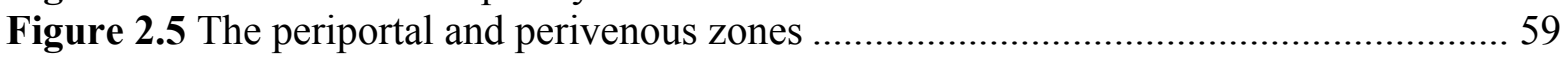

Figure 3.1 Optimization of secondary antibody concentration for immunohistochemistry.. 75

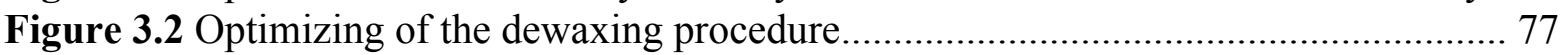

Figure 3.3 Effects of BrdU on body weight in DBA/2JCrl mice ..................................... 79

Figure 3.4 Effect of ciprofibrate on body weight in DBA/2JCrl mice............................... 81

Figure 3.5 Effects of ciprofibrate on liver growth in DBA/2JCrl mice. ............................ 83

Figure 3.6 Effects of ciprofibrate on body weight in C57BL/6JCrl mice............................ 85

Figure 3.7 Effects of ciprofibrate on liver growth in C57BL/6Jcrl mice............................ 86

Figure 3.8 Time course of effects of ciprofibrate on liver weight in F-344/NHsd rats........ 89

Figure 3.9 Time course of effects of ciprofibrate on hepatic DNA

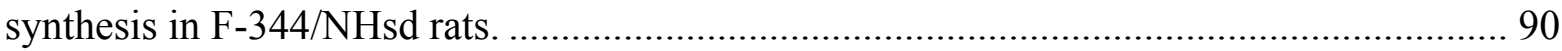

Figure 3.10 Dose response of ciprofibrate on liver growth in F-344/NHsd rats................. 92

Figure 3.11 Effect of ciprofibrate on serum aminotransferase (ALT) …......................... 93

Figure 3.12 Effects of PXR ligands in male and female rats: pilot study .......................... 95

Figure 3.13 Effects of CPA on liver growth in F-344NHsd rats...................................... 97

Figure 3.14 Zonal distribution of hepatic replication in F-344/NHsd rats ........................ 100

Figure 3.15 Central vein and portal space of liver sections in F-344/NHsd rats. ............... 101

Figure 3.16 Hepatic zonal distribution of cell proliferation in rats

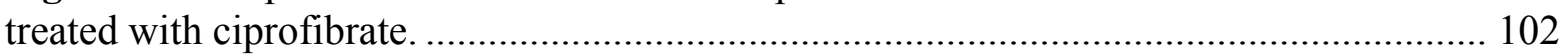

Figure 3.17 Hepatic zonal distribution of cell proliferation in rats treated with CPA....... 104

Figure 3.18 Zonal distribution of hepatic replication in 129S4/SvJae mice ....................... 106

Figure 3.19 Central veins and portal spaces of liver sections in 129S4/Svae mouse.......... 107

Figure 3.20 Zonal distribution of hepatic DNA synthesis in

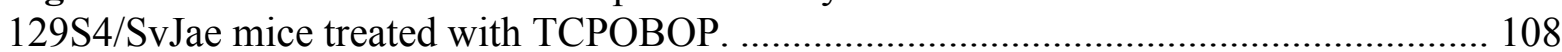

Figure 3.21 Lobular distribution of hepatic DNA synthesis in

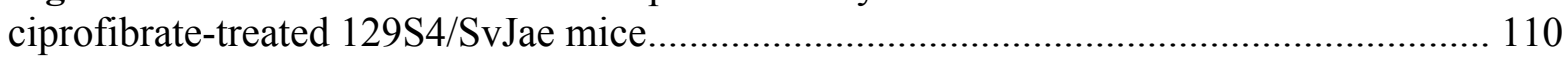

Figure 3.22 Lobular localization of DNA labelling in 129S4/SvJae

(Ppara $^{\text {tm1Gonz/tm1Gonz) male mice }}$

Figure 3.23 Lobular localization of hepatic DNA labelling in

C57BL/6JCrl mice treated with ciprofibrate

Figure 3.24 Lobular localization of hepatic DNA labelling in

DBA/2JCrl mice treated with ciprofibrate

Figure 3.25 Zonal distribution of hepatic DNA synthesis in

129S4/SvJae mice treated with MCP.

Figure 3.26 Zonal distribution of hepatic DNA synthesis in AP mice

treated with MCP. 
Figure 3.27 Time course of hepatic DNA synthesis in F-344NHsd rats 120

Figure 3.28 Effects of ciprofibrate and CPA on hepatic DNA synthesis in F-344NHsd rats after 24 hours of dosing 121

Figure 3.29 Effects of ciprofibrate and CPA on liver weight in F-344NHsd rats. 121

Figure 3.30 Optimizing RNA isolation from rat liver. 123

Figure 3.31 Agarose gel with RNA from F-344NHsd rat liver....................................... 123

Figure 3.32 More examples of agarose gels loaded with RNAs from F-344NHsd rats...... 123

Figure 3.33 Images of the scanned microarray slide..................................................... 125

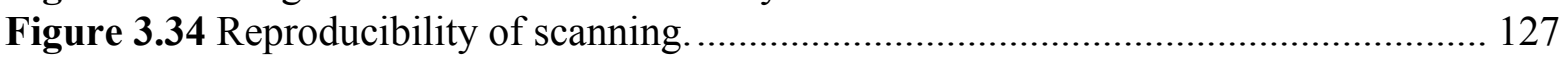

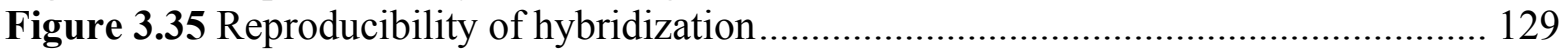

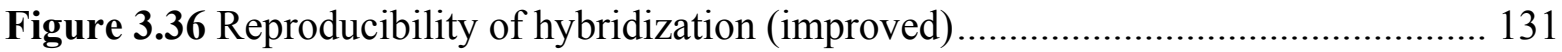

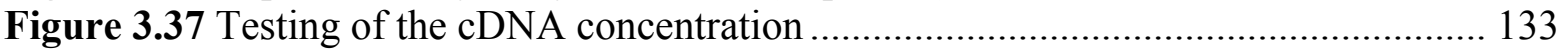

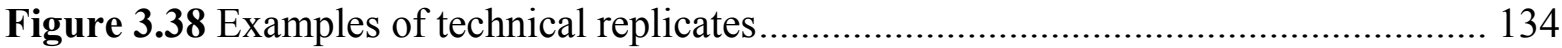

Figure 3.39 Effect of ciprofibrate on gene expression after 24 hour ................................ 140

Figure 3.40 Effect of CPA after 24 hour on gene expression .......................................... 142

Figure 3.41 Heatmap for microarray analysis of ciprofibrate gene

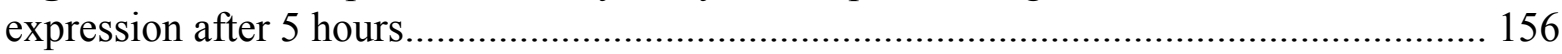

Figure 3.42 Heatmap for microarray analysis of CPA treated samples after 3 hours ........ 163

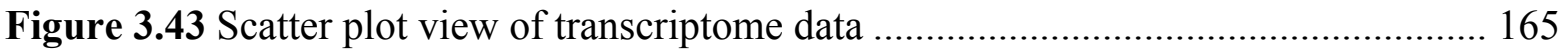

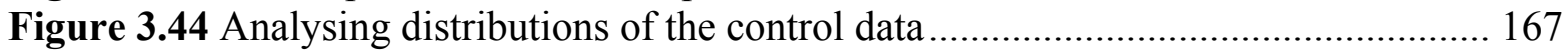

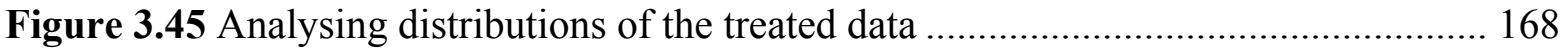

Figure 3.46 Analysing distributions of all the transcriptome data .................................. 169

Figure 3.47 volcano plot view of transcriptome data (Student's t- test) ............................ 170

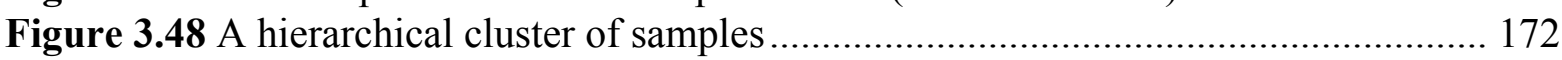

Figure 3.49 Amplification efficiencies for AhR, Scd1 and CYP3A1.............................. 192

Figure 3.50 Amplification efficiencies for Ccnd1, CYP4A1 and G0s2 .......................... 193

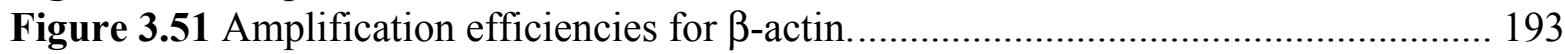

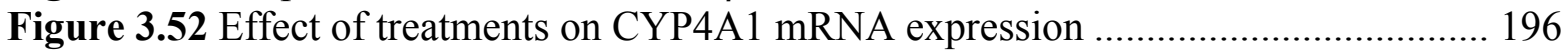

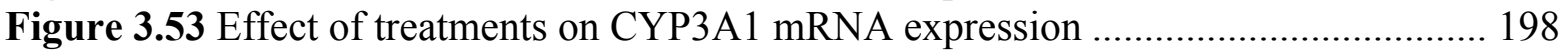

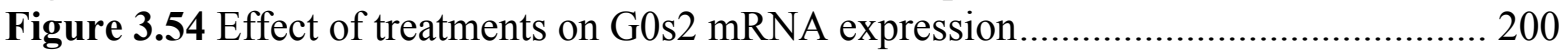

Figure 3.55 Effect of treatments on Ccnd1 mRNA expression....................................... 202

Figure 3.56 Effect of treatments on Scd1 mRNA expression .......................................... 204 


\section{LIST OF TABLES}

Table 1.1 Chemical formula and structure of ciprofibrate, cyproterone acetate and pregnenolo-

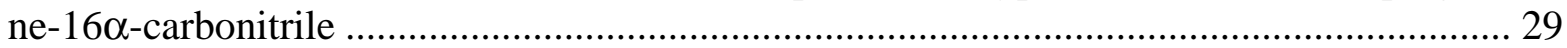

Table 2.1 RT-PCR oligonucleotides primers and probes for rat genes.............................. 46

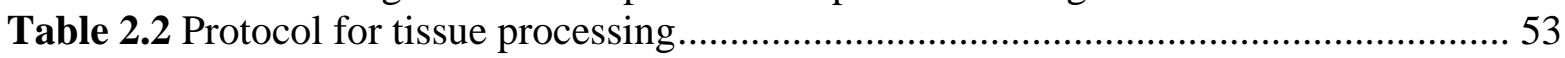

Table 2.3 Protocol for BrdU immunohistochemical staining ............................................. 56

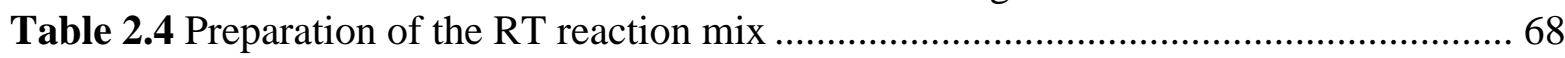

Table 2.5 Optimal conditions for use with high capacity RNA-to-cDNA kit. ...................... 68

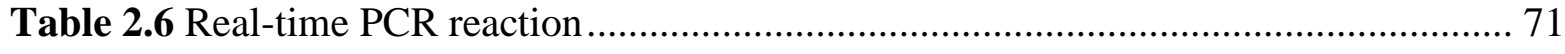

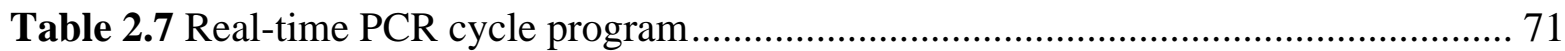

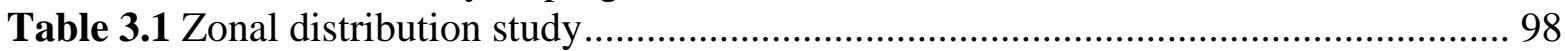

Table 3.2 Known up- regulated genes at 24 hour in ciprofibrate dosed Fisher rats............ 136

Table 3.3 Known up- regulated genes at 24 hour in CPA dosed Fisher rats...................... 137

Table 3.4 Known down- regulated genes at 24 hour in ciprofibrate dosed Fisher rats...... 138

Table 3.5 Known down- regulated genes at 24 hour in CPA dosed Fisher rats................. 138

Table 3.6 Up- regulated genes at 1 hour in ciprofibrate dosed Fisher rats......................... 144

Table 3.7 Down- regulated genes at 1 hour in ciprofibrate dosed Fisher rats.................... 146

Table 3.8 Up- regulated genes after 3 hours in ciprofibrate dosed Fisher rats................... 149

Table 3.9 Down- regulated genes after 3 hours in ciprofibrate dosed Fisher rats............... 151

Table 3.10 Up- regulated genes after 5 hours in ciprofibrate dosed Fisher rats................. 152

Table 3.11 Down- regulated genes after 5 hours in ciprofibrate dosed Fisher rats............ 154

Table 3.12 Up- regulated genes at 1 hour in CPA dosed Fisher rats................................ 158

Table 3.13 Down- regulated genes at 1 hour in CPA dosed Fisher rats............................ 159

Table 3.14 Up- regulated genes after 3 hours in CPA dosed Fisher rats........................... 160

Table 3.15 Down- regulated genes after 3 hours in CPA dosed Fisher rats...................... 160

Table 3.16 Up- regulated genes after 5 hours in CPA dosed Fisher rats........................... 161

Table 3.17 Down- regulated genes after 5 hours in CPA dosed Fisher rats....................... 162

Table 3.18 Named down- regulated genes in ciprofibrate dosed rats treated for 3 hours... 175

Table 3.19 Novel down- regulated genes in rats dosed with ciprofibrate for 3 hours........ 178

Table 3.20 Named up- regulated genes in ciprofibrate dosed rats treated for 3 hours........ 180

Table 3.21 Novel up- regulated genes in rats dosed with ciprofibrate for

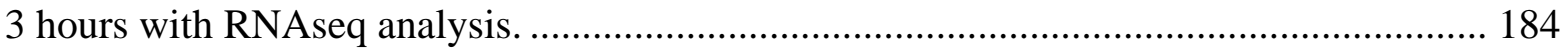

Table 3.22 Some pathways represented by named up- regulated genes in

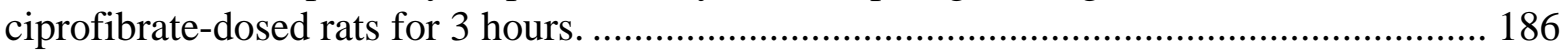

Table 3.23 Quantitation data of real- time RT-PCR for the genes used............................. 194 


\title{
Presentations and publications arising from this thesis
}

\section{Platform presentations}

1- A. H. Amer, A. M Al Kholaifi, T. Gant and D. R. Bell. (2010). Induction of liver growth by peroxisome proliferators. At the British Toxicology Society, Edinburgh. UK.

\section{Poster presentations}

1- A. H. Amer, A. M. Al Kholaifi and D. R. Bell. (2008). Effects of peroxisome proliferators on zonated DNA synthesis in rat and mouse liver. At the British Toxicology Society, Surrey.

\begin{abstract}
s
1- A. H. Amer, A. M Al Kholaifi, T. Gant and D. R. Bell. (2010). Mechanism of action of liver growth induced by peroxisome proliferators. Toxicology. 278, (3), 350-351.

2- A. H. Amer, A. M. Al Kholaifi and D. R. Bell. (2008). Effects of peroxisome proliferators on zonated DNA synthesis in rat and mouse liver. Toxicology. 253, (1), 26-27.
\end{abstract}

\section{Papers}

1- A. Al Kholaifi, A. Amer, B. Jeffrey, T. J. Gray, R. A. Roberts and D. R. Bell. (2008). Species-specific kinetics and zonation of hepatic DNA synthesis induced by ligands of PPAR alpha. Toxicol Sci. 104 (1) 74-85.

2- A. Amer, F. Aboshofa, A. Al Kholaifi, T. Gant and D. Bell. (2011). Mechanism of action of liver growth induced by peroxisome proliferators. (manuscripts in progress). 


\section{List of Abbreviations}

$\mathrm{ACO}$

AhR

ALT

ANOVA

AP-mice

$\beta$-actin

BrdU

BSA

$\mathrm{C} / \mathrm{EBP} \alpha$

CAR

$\mathrm{CCl}_{4}$

Cend1

cDNA

CPA

$\mathrm{Ct}$

CV

CYP3A1

CYP4A1

DAB

DECP
Acyl-CoA

Aryl hydrocarbon receptor

Alanine aminotransferase

Analysis of variance

Alderley park mice

Beta actin

5-Bromo-2-deoxyuridine

Bovine serum albumin

CCAAT-enhancer-binding protein alpha

Constitutive androstane receptor

Carbon tetrachloride

Cyclin D1 a cell cycle

Complementary DNA

Cyproterone acetate

Cycling threshold

Central vein/ perivenous

Cytorochrome P450, family 3 subfamily A, polypeptide 1

Cytorochrome P450, family 4 subfamily A, polypeptide 1

3,3' diamino-benzidine tetrahydrochloride

Diethyl pyro carbonate 


\begin{tabular}{|c|c|}
\hline DEHP & Di-(2-ethyl-hexyl) phthalate \\
\hline DMSO & Dimethyl sufoxide \\
\hline DPX & Distyrene, plasterine and xylene \\
\hline EdU & 5-ethynyl-2'-deoxyuridine \\
\hline $\mathrm{F}$ & Forward primer \\
\hline F-344/NHsd & Fisher-344/NHsd rats \\
\hline FDA & Food and drug administration \\
\hline FDR & False discovery rate \\
\hline G0 & Gap zero \\
\hline G0s2 & G0/G1 switch 2 \\
\hline GAL & GenePix Array List \\
\hline GPR & GenePix results \\
\hline GstYb4 & Glutathione S-transferase mu 3 \\
\hline $\mathrm{H}$ & Hepatocytes \\
\hline HEPES & 4-(2-hydroxyethyl)-1-piperazineethanesulfonic acid \\
\hline HGF & Hepatocyte growth factor \\
\hline $\mathrm{HNF} 4 \alpha$ & Hepatic nuclear factor- $4 \alpha$ \\
\hline IGFBP1 & Insulin-like-growth-factor-binding protein-1 \\
\hline IP & Intra-peritoneal \\
\hline IQR & Inter quartile range \\
\hline KEGG & Kyoto encyclopedia of genes and genomes \\
\hline
\end{tabular}


LI Labelling index

MAPK/ERK Mitogen-activated protein kinase/extracellular signal-regulated kinase

MCP Methylcyclopentane

MEEBO Mouse exonic evidence based oligonucleotide

MIAME Minimum information about a microarray experiment

NCTR National centre for toxicological research of the U.S. A

NF-kB Nuclear factor kappa beta

NP Non-parenchymal cells

NTC No template control

OD Optical density

P Probe

PBS Phosphate buffer saline

PCN Pregnenolone-16 $\alpha$-carbonitrile

PCR Polymerase chain reaction

PPAR Peroxisome proliferator activated receptor

PPRE Peroxisome proliferator hormone response element

PS Portal space/ periportal

PXR Pregane X receptor

$\mathrm{R} \quad$ Reverse primer

RGD Rat genome database

RNAseq Transcriptome sequencing analysis 
RPKM

RT

RXR

S phase

Scd1

SD

SDS

SSC

STAT 3

T3

TBE

TBS

TCPOBOP

TGF $\alpha$

TGF $\beta$

TIFF

$\mathrm{TNF} \alpha$

Tween-20

WY-14,643
Reads per kilobase of exon model per million mapped reads

Reverse transcriptase

Retinoid X receptor

Synthesis phase

Sterol-coenzyme A desaturase 1

Standard deviation

Sodium lauryl (dodecyl) sulfate

Saline-sodium citrate buffer

Signal transducer and activator of transcription 3

Thyroid hormone

Tris boric acid EDTA

Tris buffer saline

1,4-Bis[2-(3,5-dichloropyridyloxy)]benzene

Transforming growth factor alpha

Transforming growth factor beta

Tagged image file format

tumour necrosis factor alpha

Polyoxyethylene sorbitane monolaureate

Pirinixic Acid/ 4-chloro-6-[(2,3-dimethylphenyl)amino]-2-pyrimidinyl]thio]-acetic acid 


\section{Chapter 1 Introduction}

\section{Section 1.1 The Liver}

\section{Section 1.1.1 Histology and physiology of the liver}

The liver is the largest organ in the body. Found on the right side of the abdomen under the lungs covered partially by the lower ribs, it consists of two main lobes, the right lobe and the left lobe with the right being the largest (Mader, 2004). The liver has a central role in metabolic homeostasis of the body, as it is responsible for the metabolism, synthesis, storage and redistribution of nutrients, carbohydrates, fats and vitamins. One of the main functions of the liver is detoxification, which removes waste and xenobiotics by metabolic conversion and biliary excretion (Kurt, 1991).

The hepatic parenchyma is organized into units called liver lobules (Michalopoulos and DeFrances, 1997), as illustrated for the pig liver in Figure 1.1. The classic liver lobules are divided with connective tissue and appear in a hexagonal shape with a central vein in the middle and portal spaces (triads) at the corners. 


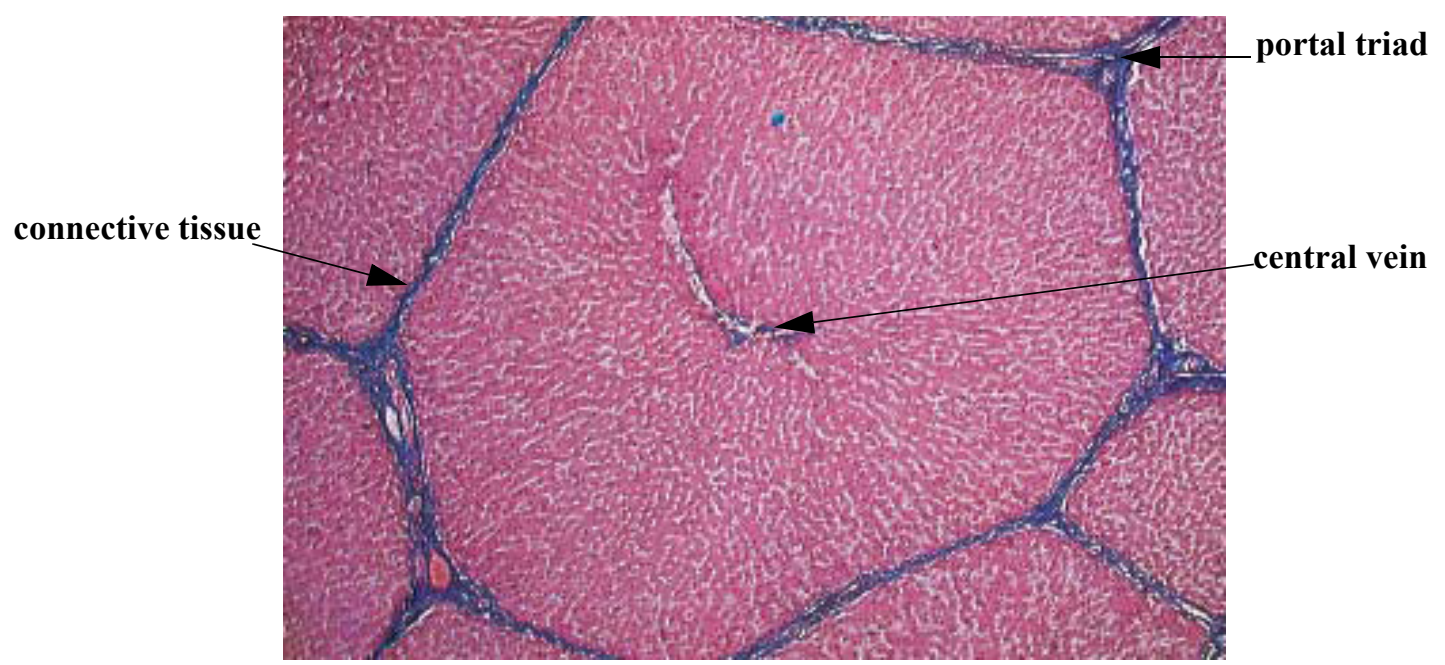

Figure 1.1 Histological view of the classic liver lobules. Histological view of a pig liver tissue, with a light microscope. Staining was with azan stain. The central vein is in the middle of the slide and the portal space (triad) are shown at the sides. The liver lobules are clearly identified with connective tissue defining each lobule (blue in colour). Magnification X40. Figure from (Kühnel, 2003).

A different structure of the liver is the portal lobule where the structure appears as a triangle with a central vein at each of the corners and a portal space in the middle. A third structure is called the liver acinus which appears as a diamond shape connecting a central vein to a portal space then a central vein and a portal space then back to the same central vein. It was reported that the liver acinus is the functional unit of the liver and is divided into three zones: Z1 periportal, Z2 intermediate and Z3 perivenous (Ross, 2003) indicated as 1, 2 and 3 in Figure 1.2. 


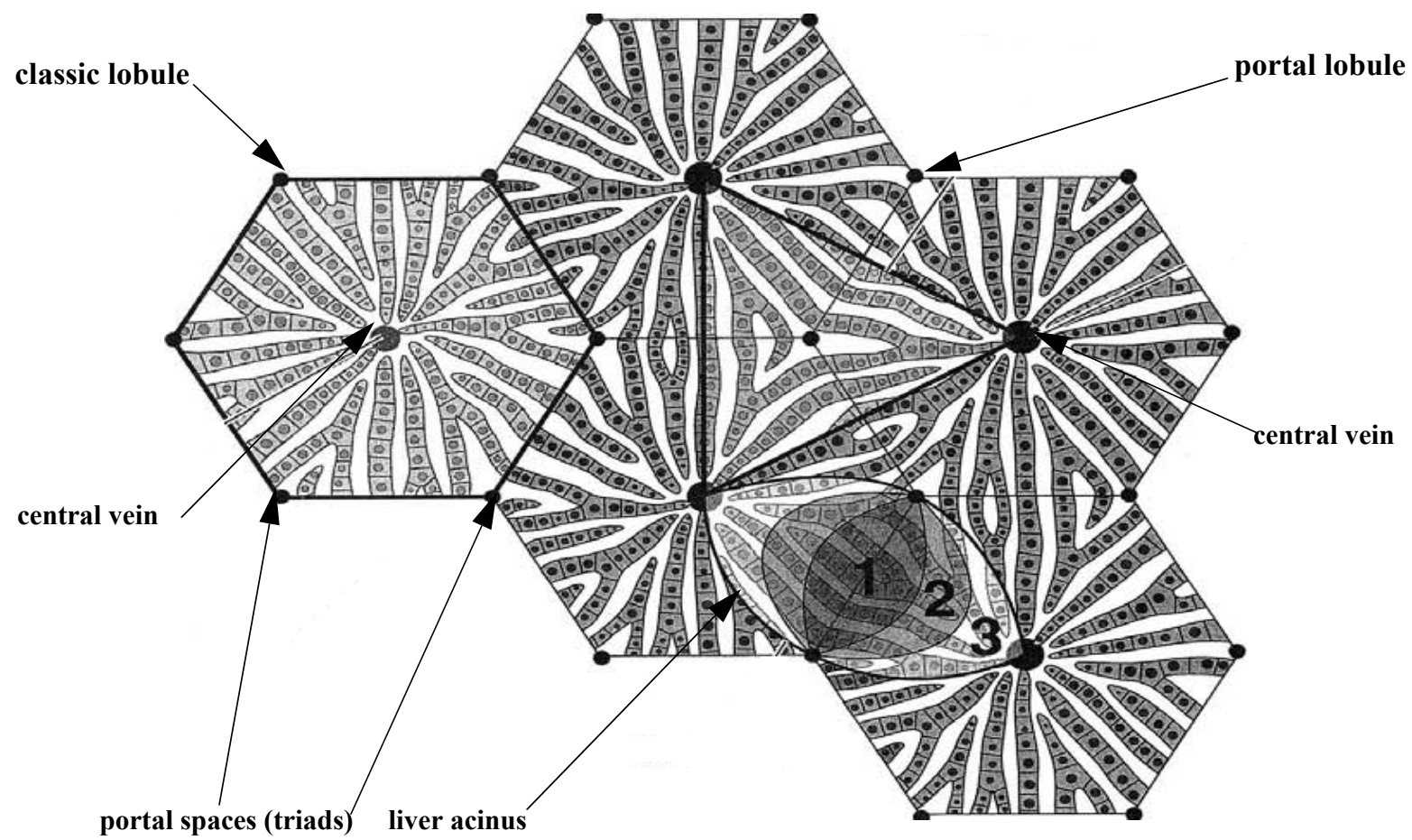

Figure 1.2 Diagram of the liver structure. Shown is the classic liver lobule were a central vein is in the middle and six portal triads are at the periphery. The portal lobule appears as a triangle with a central vein at each of the corners and a portal triad in the middle. The liver acinus appears as a diamond shape connected between a portal triad, central vein, portal triad and central vein this is the functional unit of the liver and is divided into three zones (the area around the central vein is zone $1(\mathrm{Z1})$, the area near the terminal portal vein is zone $3(\mathrm{Z3})$ and the area in between is zone $2(\mathrm{Z2})$ ). Figure from (Henrikson et al., 1997).

Liver cells closest to the terminal portal vein (periportal) receive blood richer in oxygen and nutrients than those located near the central vein (perivenous). The cells in these different zones perform different biochemical functions and respond differently to injuries, with regard to the cell organelle number and size, ploidy, pattern of enzymes activity, autonomous innervations, number of non parenchymatous cells, concentration of hormones, substrates and their metabolites, and the partial $\mathrm{O}_{2}$ pressure (Taub, 2004). Figure 1.3 depicts the structure of a liver lobule, with hepatocytes branching from the central vein to the portal vein (traid) in rows 1-2 cells thick called plates. The portal space includes the hepatic portal vein, the hepatic artery and the bile duct. 


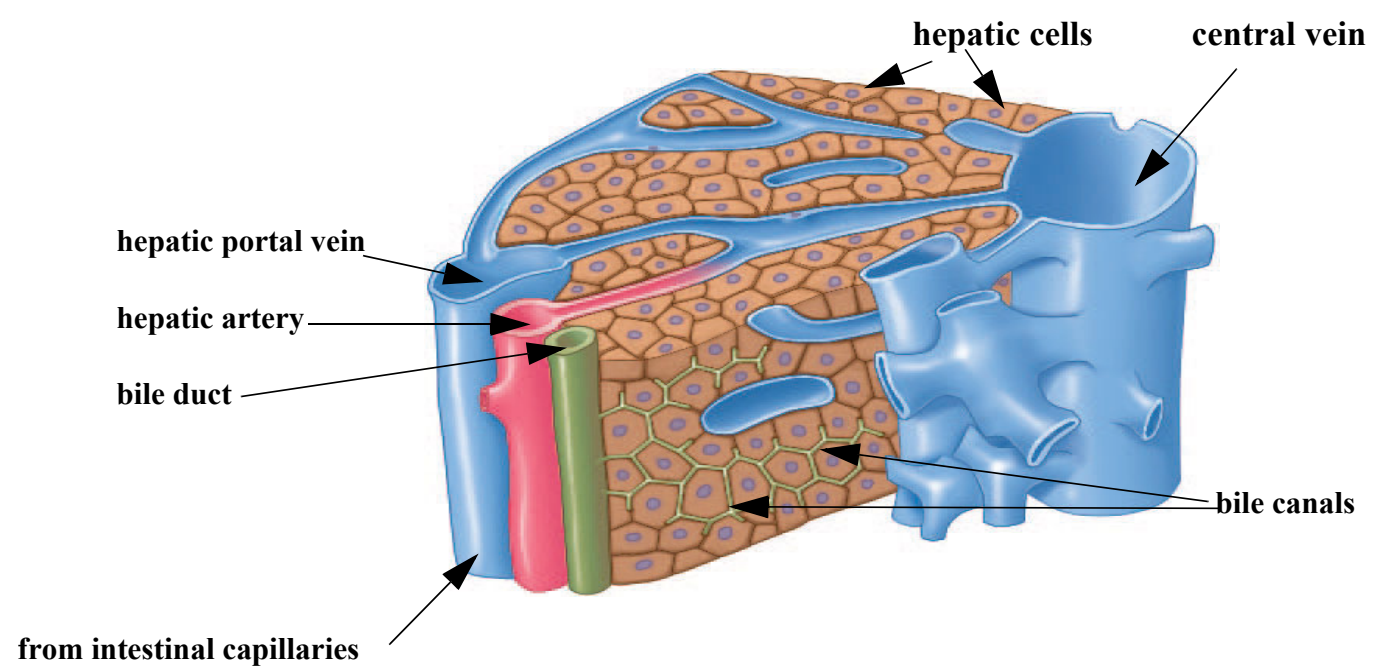

Figure 1.3 Diagrammatic structure of a liver lobule. the hepatocytes form rows of one or two cells thick and are called plates, the plates start at the central vein, also known as the inter lobular vein, and branch out in a star shaped way to the portal space. Between the cell plates are the sinusoids which contain the Kupffer cells and the epithelium cells (not shown), between each two hepatocytes starts the Bile canals which get larger and larger to make the bile ducts. A bile duct along with a portal vein and a hepatic artery get arranged in a group making the portal space. Figure from (Mader, 2004).

The main cell type found in the liver is parenchymal cells also known as the hepatocytes, which makes up most of the hepatic cells. Other cell types are the endothelial cells, Kupffer cells, lymphocytes, stellate cells and lipocytes (Dudek, 2000)(Taub, 2004) (Figure 1.4).

Endothelial cells line the sinusoids of the liver, and provide a large surface area for nutrient absorption, and Kupffer cells are situated in the sinusoids and have a phagocyte function. Also, it is thought that Kupffer cells produce cytokines (Taub, 2004).

Lymphocytes are considered part of the innate immune system that resides within the liver to help resist infection. Hepatic cells have various functions, including the storage of vitamin A and the production of the extracellular matrix and most of the factors that lead to hepatic fibrosis. All of these cell types are activated by hepatic injury (Taub, 2004). 


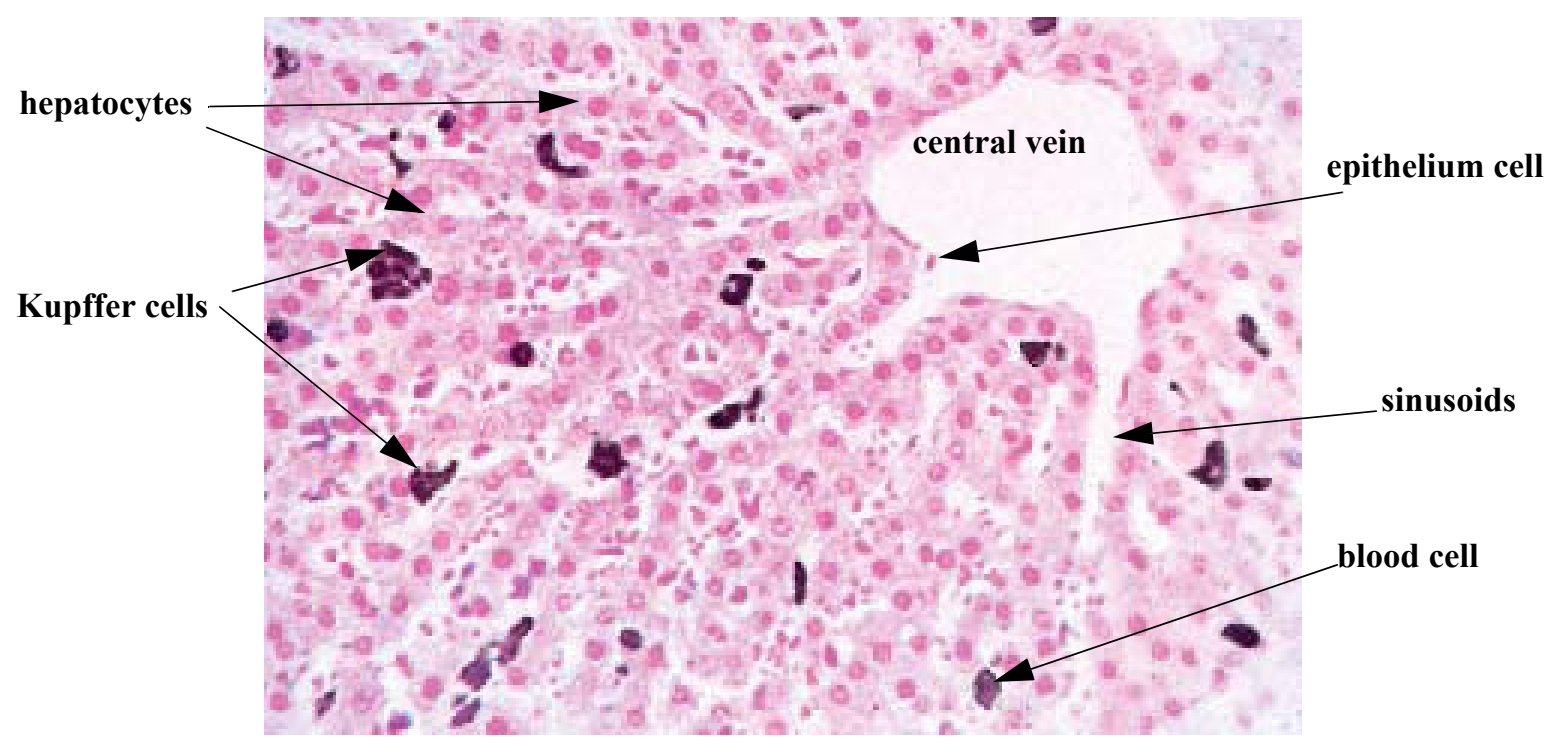

Figure 1.4 Histological section of liver cells. Histological section of liver tissue showing the hepatocytes in rows making the plates. Between the plates are the sinusoids, the endothelium cells are covering the sinusoids and some blood cells are shown in between the cells. The Kupffer cells are shown as dark stained cells. The stain is Giroud-Leblond; nuclear staining with carmine red; magnification: X300, from (Kühnel, 2003).

\section{Section 1.1.2 Liver regeneration (growth)}

Normally, mature hepatocytes live long and do not divide; they only proliferate in response to toxic injury and infection. Loss of liver function results in proliferation and restoration of functional liver tissue (Mangnall et al., 2003).

The fascinating two thirds partial hepatectomy $(\mathrm{PH})$ model in rodents was first pioneered by (Higgins, 1933) as a model for regrowth. In this model, two thirds of the liver was surgically removed, and the remaining liver enlarged until the original liver mass was restored, approximately 1 week after surgery, after which the regenerative process stopped. In this experimental system, liver regeneration does not require the recruitment of liver stem cells or progenitor cells, but involves replication of the mature functioning liver cells. The regenerative process is compensatory because the size of the resulted liver is determined by the demands of the organism, and, once the original mass of the liver has been re-established, proliferation stops (Michalo- 
poulos and DeFrances, 1997).

\section{Section 1.1.3 Basic characteristics of liver regeneration}

Because hepatocytes are mostly found in the G0 phase of the cell cycle, hepatic cell division is rarely found in the normal adult liver (Michalopoulos and DeFrances, 1997). It was reported that after partial hepatectomy the liver cells start dividing, and by day three the liver mass begins to increase, while the whole mass restoration is complete in just 5-7 days (Grisham, 1962).

Thus, after partial hepatectomy in rats nearly $95 \%$ of hepatocytes rapidly re-enter the cell cycle, and hepatic DNA synthesis (cells in the S phase) increases after 12 hours and peaks around 24 hours (Mangnall et al., 2003). However, the induction of non-parenchymal DNA synthesis occurs later (36-48 hours for kupffer cells).

Subsequent to the partial hepatectomy, the levels of hepatic DNA synthesis are lower, as the liver mass requires an average of 1.6 cycles of replication in all cells to be completely restored, taking around 7 days. The expression of the gene encoding $\beta$-actin (a growth related gene) after 2 hours is high until about 36 hours, while the insulin-like-growth-factor-binding protein-1 (IGFBP1) (encoded by a cell-cycle-regulated gene) peaks after 2-3 hours. Genes encoding the $\alpha$ isoform of CCAAT enhancer binding protein $(\mathrm{C} / \mathrm{EBP} \alpha)$, are down- regulated within the period of maximal growth and are expressed again after the growth phase has occurred. This is clarified in Figure 1.5 (Taub, 2004). 


\section{a}

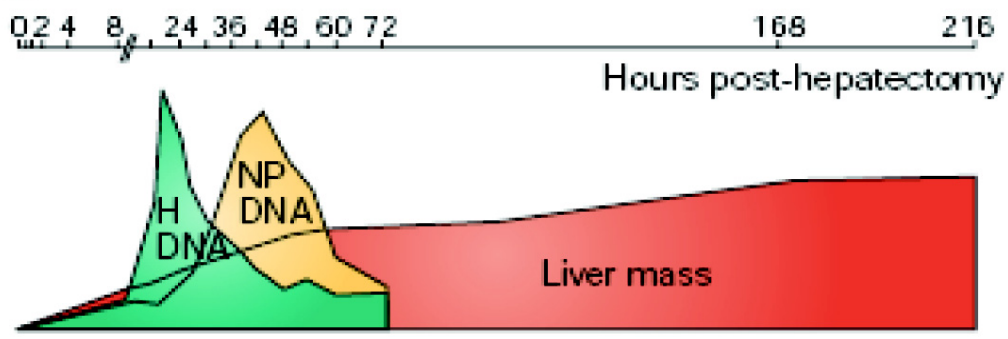

\section{b Growth-regulated genes}

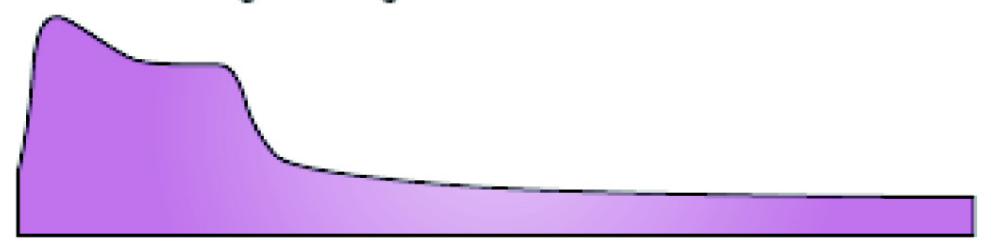

c Cell-cycle-regulated genes

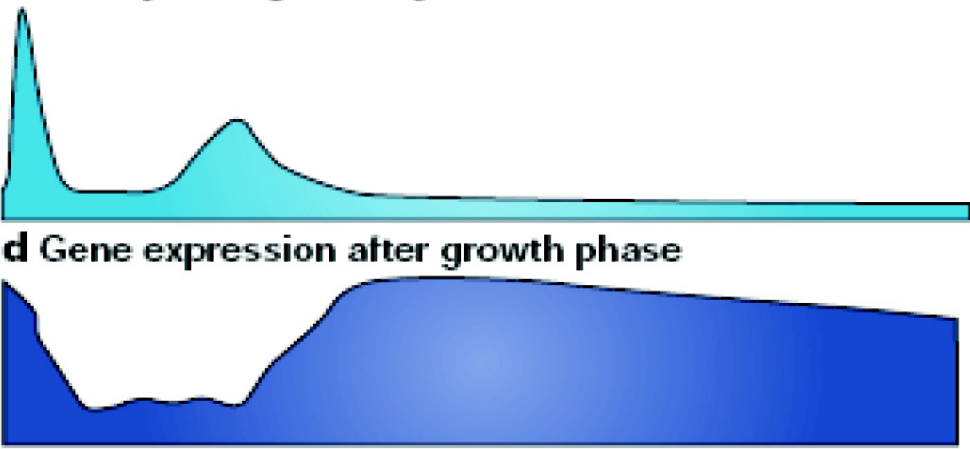

Figure 1.5 Diagrammatic illustration showing patterns of DNA synthesis and induction of gene expression during rat liver regeneration. a) 24 hours after partial hepatectomy, (H; green) DNA synthesis in hepatocytes peaks, but in the non-parenchymal cells DNA synthesis (NP; yellow) reaches its highest at 36-48 hours. Re accumulation of liver mass in red is finished in around a week. b) The pattern of induction of the genes expression for growth regulated genes, $(\beta$-actin). c) While the induction pattern of insulin like growth factor binding protein-1 $(I G F B P 1)$ representing the gene expression for cell-cycle-regulated genes. $d$ ) The genes encoding the $\alpha$ isoform of CCAAT enhancer binding protein $(C / E B P \alpha)$, are down- regulated within the period of maximal growth and are expressed again after the growth phase has occurred.(Taub, 2004).

By comparison, in mice after partial hepatectomy the DNA synthesis peak occurs later (36- 40 hours after partial hepatectomy) and varies between strains (Sigal et al., 1999).

Early studies in vitro with isolated hepatocytes, identified a number of potential hepatocyte growth factors such as HGF, TGF $\alpha$ and TGF $\beta$. It was difficult to confirm that any of these fac- 
tors had an vital role in liver regeneration, but it was noted that growth-factor-and cytokine-regulated pathways are activated during liver regeneration (Taub, 2004).

Transcription factors have been acknowledged to play a major role in making hepatocytes proliferate (Fausto, 2000), apparently through the induction of the hepatic expression of numerous immediate early genes linked to the cell cycle (Scearce et al., 1996). Knockout mouse studies were used to identify specific genes induced during the induction of DNA synthesis during hepatic regeneration. These studies established that cytokines might be responsible for regenerative response (Taub et al., 1999), and IL-6 could collaborate with additional factors to trigger the other up- regulated genes (Cressman et al., 1996). Other genes that are regulated during hepatic regeneration are the genes that encode the cyclin D1 (Schwabe et al., 2003)(Talarmin et al., 1999)(Diehl, et al., 1994), IGFBP1 91, STAT 3 and AP1 (Leu, et al., 2001)

One transcription factor, termed NF-kB, has been suggested to have a role in liver regeneration (Tewari et al., 1992). A potent inducer of $N F-k B$ is tumour necrosis factor $\alpha$ (TNF- $\alpha$ ) (Grilli et al., 1993)(Menegazzi et al., 1997).

The beginning of DNA synthesis is well synchronized in rat hepatocytes, starting in cells that surround the portal vein of the liver lobule and proceeding towards the central vein (Taub, 2004). Hepatic proliferation is also noted in the liver regeneration caused by apoptosis or necrosis that is induced by toxic chemicals e.g. $\mathrm{CCL}_{4}(\mathrm{Taub}, 2004)$ and peroxisome proliferators (Moody et al., 1991).

\section{Section 1.2 Peroxisome proliferation}

\section{Section 1.2.1 Peroxisomes}

Peroxisomes are single membrane-limited cytoplasmic organelles present in both animal and plant cells. They were first detected in 1954 and are known as "microbodies". They were re- 
ferred to as peroxisomes after it was found that they contain catalase and oxidase, which are involved in the degradation and production of hydrogen peroxide (Deduve, 1965). Other functions of the peroxisomes include $\beta$-oxidation of fatty acids and cholesterol metabolism (Holden and Tugwood, 1999).

Peroxisomes are mostly found in liver and kidney cells (Bernhard and Rouiller, 1956) (Rhodin, 1954). Leighton and his group found that peroxisomes account for nearly $2.5 \%$ of protein in rat liver (Leighton et al., 1968). The following year Weibel and his group found that the peroxisomes occupy about $1.5 \%$ of the parenchymal cell volume (Weibel et al., 1969).

Hepatocyte peroxisomes are affected in number and size by chemicals not related in structure, called the peroxisome proliferators (Reddy, 2004).

\section{Section 1.2.2 Peroxisome proliferators (PPs)}

Peroxisome proliferators are a group of structurally unrelated chemicals with different applications, such as hypolipidemic drugs, and industrial and agricultural chemicals (Moody et al., 1991).

It is reported that peroxisome proliferators induce peroxisome proliferation in livers of some rodents. Peroxisome proliferation involves changes in the ultra structure and metabolic capacity of the liver cell, such as the increase of peroxisome volume density, hepatomegaly, and an increase in $\beta$-oxidation of fatty acids and peroxisomal enzymes activities (Moody et al., 1991).

Interestingly, it has been reported that DNA synthesis is not affected by peroxisome proliferators in pure hepatocytes, rather they stimulate Kupffer cells to make mitogens which stimulate proliferation of parenchymal cells (Parzefall et al., 2001).

However, peroxisome proliferation involves several other changes that are not strictly 'peroxi- 
somal', and these changes involve metabolic functions in the cell, as well as shifts the rate of entry of hepatocytes into cell proliferation (mitosis) and cell death (apoptosis) (Cattley, 2003).

Although many chemicals have been evaluated for peroxisome proliferation, several have been commonly used in mechanistic studies. Among the hypolipidemic drugs studied, clofibrate (ester), clofibric acid, and ciprofibrate are in clinical use (Cattley, 2003). Other hypolipidemic drugs include WY-14,643, BR-931, methylclofenapate, and nafenopin, compounds that were discovered in the search for more potent drug candidates, but were not entered into clinical use.

Among the non drug compounds used in research is the phthalate ester plasticizer di-(2- ethylhexyl) phthalate (DEHP), which is often used because it is cheap, available with high purity, and easy to dose (Cattley, 2003). 


\section{Section 1.2.3 Ciprofibrate, cyproterone acetate and pregnenolone-16 $\alpha$-carbonitrile}

Ciprofibrate is a strong peroxisome proliferator activated receptor-alpha (PPAR $\alpha$ ) ligand (Mukherjee et al., 2002) from the fibrate hypolipidemic drug family, and a potent hepatocarcinogen (Meyer et al., 2003) (Yadetie et al., 2003).

The anti androgen cyproterone acetate (CPA) and pregnenolone-16 $\alpha$-carbonitrile $(\mathrm{PCN})$ are pregane $\mathrm{X}$ receptors (PXRs). Cyproterone acetate is reported to cause liver tumours and has a mutagenic effect in rats (Topinka et al., 2004a). It is also known to induce cell proliferation (Schulte-Hermann et al., 1980) and apoptosis (Kasper and Mueller, 1999) in rat liver in vitro and in vivo. Cyproterone acetate is used as a hormonal therapy to treat prostate cancer as it suppresses the action of testosterone and dihydrotestosterone on cells (Green et al., 2002). It is also reported to be used in some countries other that America and Japan as a hormone treatment for acne, with some contraceptive benefits (van Vloten et al., 2002).

Table 1.1 illustrates the chemical structure of ciprofibrate, CPA and PCN used in this study. 
Table 1.1 Chemical formula and structure of ciprofibrate, cyproterone acetate and pregnenolone-16 $\alpha$ carbonitrile. This table shows the systematic IUPAC (International Union Of Pure And Applied Chemistry) name, the chemical formula and 2 and 3 dimensional structure of the chemicals used to perform the induction of the hepatic DNA synthesis in this project. Chemical structures were drawn using CDS/ISIS DRAW Program.

\begin{tabular}{|c|c|c|c|}
\hline $\begin{array}{c}\text { Systematic IUPAC } \\
\text { Name }\end{array}$ & $\begin{array}{l}\text { Chemical } \\
\text { Formula }\end{array}$ & Structure & $\begin{array}{c}3 D \text { Structure } \\
\text { red }=\text { carbon } \\
\text { blue }=\text { oxygen } \\
\text { green }=\text { chlorene } \\
\text { yellow }=\text { nitrogen } \\
\text { pink }=\text { hydrogen }\end{array}$ \\
\hline $\begin{array}{l}\text { ciprofibrate } \\
\text { 2-[4-(2,2-dichlorocyclopro- } \\
\text { pyl) phenoxy] 2-methylpro- } \\
\text { panic acid }\end{array}$ & $\mathrm{C}_{13} \mathrm{H}_{14} \mathrm{Cl}_{2} \mathrm{O}_{3}$ & & \\
\hline $\begin{array}{l}\text { cyproterone acetate } \\
\text { (CPA) } \\
\text { chloro-6-hydroxy-17 alpha } \\
\text { methylene-1 alpha, } 2 \text { alpha } \\
\text { pregnadiene-4,6 dione-3, } 20 \\
\text { acetate }\end{array}$ & $\mathrm{C}_{24} \mathrm{H}_{29} \mathrm{ClO}_{4}$ & & \\
\hline $\begin{array}{l}\text { pregnenolone-16 } \alpha \text {-car- } \\
\text { bonitrile (PCN) } \\
\text { 3S,8S,9S,10R,13S,14S,16R,1 } \\
\text { 7S)-17-acetyl-3-hydroxy- } \\
\text { 10,13-dimethyl- } \\
\text { 2,3,4,7,8,9,11,12,14,15,16,17 } \\
\text {-dodecahydro-1H-cyclo- } \\
\text { penta[a]phenanthrene-16-car- } \\
\text { bonitrile }\end{array}$ & $\mathrm{C}_{22} \mathrm{H}_{31} \mathrm{NO}_{2}$ & & \\
\hline
\end{tabular}




\section{Section 1.2.4 Peroxisome proliferator activated receptor-alpha (PPAR- $\alpha)$}

A number of years ago PPAR $\alpha$ was the first of three structurally related peroxisome proliferator receptors (PPARs) to be identified of the soluble nuclear hormone receptor superfamily. Peroxisome proliferators are believed to act through this family of proteins (PPAR $\alpha$ ) (Issemann and Green, 1990). The other two receptors were later indicated and are now known as PPAR $\beta$ and PPAR $\gamma$ (Dreyer et al., 1992)(Kliewer et al., 1994), but they do not mediate peroxisome proliferation (Peraza et al., 2006).

PPAR along with constitutive active androstane receptor (CAR) and aryl hydrocarbon receptor (Ahr) are known to operate as sensors of xenobiotic entrance into the cell. Mice carrying knockouts in genes for the receptors cooperating with xenobiotic were revealed to be deficient for the promoting effects of these compounds (Yamamoto et al., 2004) (Peters et al., 1997a).

Also, PPARs are thought to be transcription factors that are activated by ligands and by interaction with elements situated $570 \mathrm{bp}$ upstream of the peroxisomal enzyme acyl CoA oxidase receptive genes (Tugwood et al., 1992). Studies have demonstrated that PPAR $\alpha$ is an obligatory factor in peroxisome proliferation in rodent hepatocytes in vivo and in vitro (Klaunig et al., 2003).

It has been suggested that Human PPAR $\alpha$ have many similar functional characteristics to the rodent receptors, suggesting that the former also may be activated by peroxisome proliferators and regulate specific gene expression (Ashby et al., 1994). However, PPAR $\alpha$ is less abundant in human liver than in rodent liver, which has led to the suggestion that species differences result from quantitative differences in gene expression. 


\section{Section 1.2.5 Toxicological changes induced by peroxisome proliferators}

Although there are no acknowledged toxicities linked with endogenous ligands of PPAR $\alpha$, there is a number of findings related to toxicity and the synthetic PPAR $\alpha$ ligands in animal models (Peraza et al., 2006).

For example it has been reported that administration of clofibrate (a fibrate peroxisome proliferator) can cause some signs of maternal toxicity if used prior to or during pregnancy in high doses (Cibelli et al., 1988)(Stefanini et al., 1989)(Wilson et al., 1991).

Other PPAR $\alpha$ agonists, like phthalates and trichloroethylene in rodents have been reported to cause altered ovulation (Davis et al., 1994), reduced fertility rates (Peters and Cook, 1973)(Singh et al., 1974), teratogenesis including cardiac, skeletal, and neural tube defects (Gao et al., 2003)(Ritter et al., 1985) impaired spermatogenesis and altered development of the male reproductive tract (Corton and Lapinskas, 2005).

It is also noted that exposure to perfluorooctanoic acid causes reduced fetal weights and cardiac and skeletal malformations (Lau et al., 2004). However, the toxic effects were not proven to be linked with PPAR $\alpha$ pathways as clarified by Peters et al. (1997b) who administered Di(2-ethylhexyl) phthalate (DEHP) during organogenesis, in wild-type and PPAR $\alpha$-null mice and this caused neural tube defects in both, indicating that PPAR $\alpha$ was not required to mediate the effect.

On the other hand, fibrate therapy is linked with cholelithiasis (gallstones), as it has been recorded in humans treated with fenofibrate, clofibrate or bezafibrate which were associated with an increased incidence of cholelithiasis (Caroli-Bosc et al., 2001)(Raedsch et al., 1995) and also myopathy and rarely rhabdomyolysis (Bridgman et al., 1972) (Alsheikh-Ali et al., 2004). 
But it is well-known that PPAR $\alpha$ ligands cause hepatocellular carcinomas in rodents, and they have also been connected to other malignancies, as they cause pancreatic acinar cell tumours and Leydig cell tumours (Reddy et al., 1980). Furthermore, pancreatic acinar cell tumours and Leydig cell tumours have been reported to occur only in rats, but not in mice (Klaunig et al., 2003). It was also reported that clofibrate and $\mathrm{Wy}-14,643$ treatments increase the growth of human breast cancer cell lines (Suchanek et al., 2002).

\section{Section 1.3 Mechanism of action of carcinogenesis}

Among the first stages of cancinogenesis provoked by chemicals are initiation and promotion, when both initiation and promotion occur this is known as "complete carcinogenesis" and the peroxisome proliferators would cause both initiation and promotion activities (Kobliakov, 2010). The initiation stage is provoked by genetic changes in the genome caused by genotoxic metabolites of carcinogens, whilst the promotion stage is initiated by a non genotoxic mechanism and does not effect the DNA structure (Gujaeva et al., 1998).

Promotion requires particular scenarios, including increased cell proliferation, decreased intercellular interactions, and inhibition of apoptosis (Kobliakov, 2010). This promotion stage, caused by non genotoxic compounds is not well studied and it is unknown if the pathways are similar to the initiation stage or not (Kobliakov, 2010).

Additionally, it is stated by $\mathrm{Wu}$ that the promoter induces the production of reactive oxygen species in the cells and this affects intercellular interactions, stimulates the cell migration, and inhibits apoptosis (Wu et al., 2006). However, the pathways responsible for these changes have yet to be resolved. 


\section{Section 1.3.1 Peroxisome proliferators induce liver cancer in rodents}

Peroxisome proliferators are known for their ability to cause hepatocellular carcinoma in laboratory rodents (Reddy et al., 1980). The effect of this is recorded by (Cattley et al., 1991) who showed that in rodents, after just one year of treatment with Wy-14,643 (a potent peroxisome proliferator) there was $100 \%$ incidence of multifocal liver cancer. Gonzalez and his group established that the PPAR $\alpha$ mediated pathways that control lipid metabolism and the cell proliferation pathways are independent of each other. This was achieved with PPAR $\alpha$ humanized transgenic mice, and this suggests that these mice would not be susceptible to peroxisome proliferator induced hepatocarcinogenesis (Cheung et al., 2004).

Other studies showed that just one week of exposure to Wy-14,643 causes hepatomegaly and hepatocytes entering S-phase. Also, this exposure resulted in hepatocellular neoplasms, including some carcinomas after 11 months exposure in wild type mice and not in PPAR $\alpha$ null mice. This makes it clear that PPAR $\alpha$ is essential for the increase in hepatic replicative DNA synthesis in response to peroxisome proliferators.

Although it is known that PPAR $\alpha$ cause cancer in long term exposures in rodents, there are significant differences in species response, and PPAR $\alpha$ is not recorded to induce peroxisome proliferation and hepatocarcinogenesis in humans (Yadetie et al., 2003).

\section{Section 1.3.2 Peroxisome proliferators are non-genotoxic carcinogens}

Chemical carcinogens are commonly classified on the basis of their mechanism of action; genotoxic (mutagenic) and non genotoxic (non mutagenic) (Weisburger and Williams, 2000). An important aspect of peroxisome proliferators is that they are non-genotoxic carcinogens (Ashby et al., 1994)(Peters et al., 1997a). 
It has been proposed that during carcinogenesis peroxisome proliferators promote liver tumours by increasing the production of $\mathrm{H}_{2} \mathrm{O}_{2}$ leading to the production of peroxisomal fatty acyl CoA oxidase (Yeldandi et al., 2000). Moreover, through carcinogenesis and tumour growth intercellular interactions are affected and this is important for the normal regulation of organs. The morphology of the cells are also changed, and the epithelial mesenchymal transition is detected (Radisky et al., 2005).

It is understood that peroxisome proliferators reduce the expression of glutathione peroxidase and increase the oxidative stress in hepatocytes caused by the large increase in the $\mathrm{H}_{2} \mathrm{O}_{2}$ levels and the gathering of lipofuscin in the liver cells (Yeldandi et al., 2000)(Kobliakov, 2010). It is also reported that peroxisome proliferators begin hepatocarcinogenesis in rodents by increasing cell proliferation (Reddy et al., 1980) (Becuwe and Dauca, 2005). However, the mechanism that PPAR $\alpha$ ligands cause cancer is still vague (Ashby et al., 1994)(Klaunig, 2003)(Peters et al., 2005).

Luci (Luci et al., 2007) argued that the hepatocarcinogenesis is a result of oxidative stress and an impaired balance between apoptosis and cell proliferation in the liver, while Shah and Morimura (Shah et al., 2007a) and (Morimura et al., 2006) found that PPAR $\alpha$ humanized mice appear to be resistant to the induction of peroxisome proliferators and less sensitive to the development of liver tumours. 


\section{Section 1.4 Induction of hepatic DNA synthesis by peroxisome prolifera- tors}

It is clear that DNA synthesis plays a significant role in carcinogenesis and that peroxisome proliferators provoke hepatic DNA synthesis that is associated with carcinogenesis (Marsman et al., 1988). It is therefore desirable to understand the mechanism of the induction of DNA synthesis by PPAR $\alpha$ ligands, particularly since these ligands increase the normal liver size, in contrast to the regenerative growth pathways induced by partial hepatectomy (Mangnall et al., 2003).

\section{Section 1.4.1 Acute and chronic effects of peroxisome proliferators on hepatic DNA synthesis}

Menegazzi's group showed that rats treated with a peroxisome proliferator known as nafenopin or with CPA (a PXR) would cause hepatic DNA synthesis that starts 18 to 24 hours after treatment. They also reported that the levels of hepatic TNF- mRNA, NF-B and AP-1 were not changed indicating a difference from the results obtained after partial hepatectomy, although the hepatic cells entered the S phase of the cell cycle at similar times (Menegazzi et al., 1997).

In a recent study, Al-kholaifi showed that the effect of ciprofibrate on hepatic DNA synthesis in male F-344/NHsd rats peaked between 24 and 48 hours after treatment, while 129S4/SvJae and 129S4/SvJae PPAR $\alpha$-null mice treated with ciprofibrate showed hepatic cells entering the S phase only after 3-4 days (Al Kholaifi, 2008)(Al Kholaifi et al., 2008).

It is known from former studies that the replicating hepatic nuclei are not distributed randomly within the rat liver, but are found predominantly in the periportal region (Barrass et al., 1993). Barrass's results were achieved in male Sprague-Dawley rats treated with methylcyclopentane (MCP) and clofibric acid for 1-26 weeks. This was confirmed by Al kholaifi with Fisher rats, while most mouse species' livers didn't show any preference in the zonation of hepatic DNA 
synthesis (Al Kholaifi et al., 2008). Other zonation studies on mouse liver using a different approach/method on young non treated $\mathrm{B} 6 \mathrm{C} 3 \mathrm{~F} 1$ and $\mathrm{C} 57 \mathrm{BL}$ mice showed that the distribution is mostly in the mid-zone Z2 (Amacher et al., 1998).

The difference in the kinetics of induction of hepatic DNA synthesis between mouse and rat after exposure to PPAR $\alpha$ ligands suggests that there might be a difference in the mechanism of hepatic DNA synthesis of the two species, and how each of the species' livers respond to PPA$\mathrm{R} \alpha$.

Frick and Blaauboer showed in separate studies that humans do not display the same range of hepatocarcinogen peroxisome proliferator-induced responses seen in rats and mice (Frick et al., 1987)(Blaauboer et al., 1990). Also it has been demonstrated that non-human primates and guinea pigs are unaffected by peroxisome proliferators (Bell et al., 1998). So, establishing an explanation for, and understanding the risks to man of exposure to these chemicals has been a major focus for research (Lake et al., 2000).

\section{Section 1.5 Gene expression in response to peroxisome proliferators}

PPAR $\alpha$ forms a heterodimer with the retinoid $\mathrm{x}$ receptor $\alpha$ (RXR) -after being provoked by the peroxisome proliferators- which then binds to precise regions on the DNA (called peroxisome proliferator hormone response elements; PPREs) of the targeted genes (Tugwood et al., 1992) as shown in Figure 1.6.

The PPAR $\alpha-R X R \alpha$ heterodimers attach to DNA sequences with repeats of the sequence AGGTCA (AGGTCA X AGGTCA) separated by one nucleotide (Jpenberg et al., 1997). This heterodimer would be able to stimulate transcription of a large number of genes, including those involved in lipid metabolism such as cytochrome P450 4A and acyl CoA oxidase. 


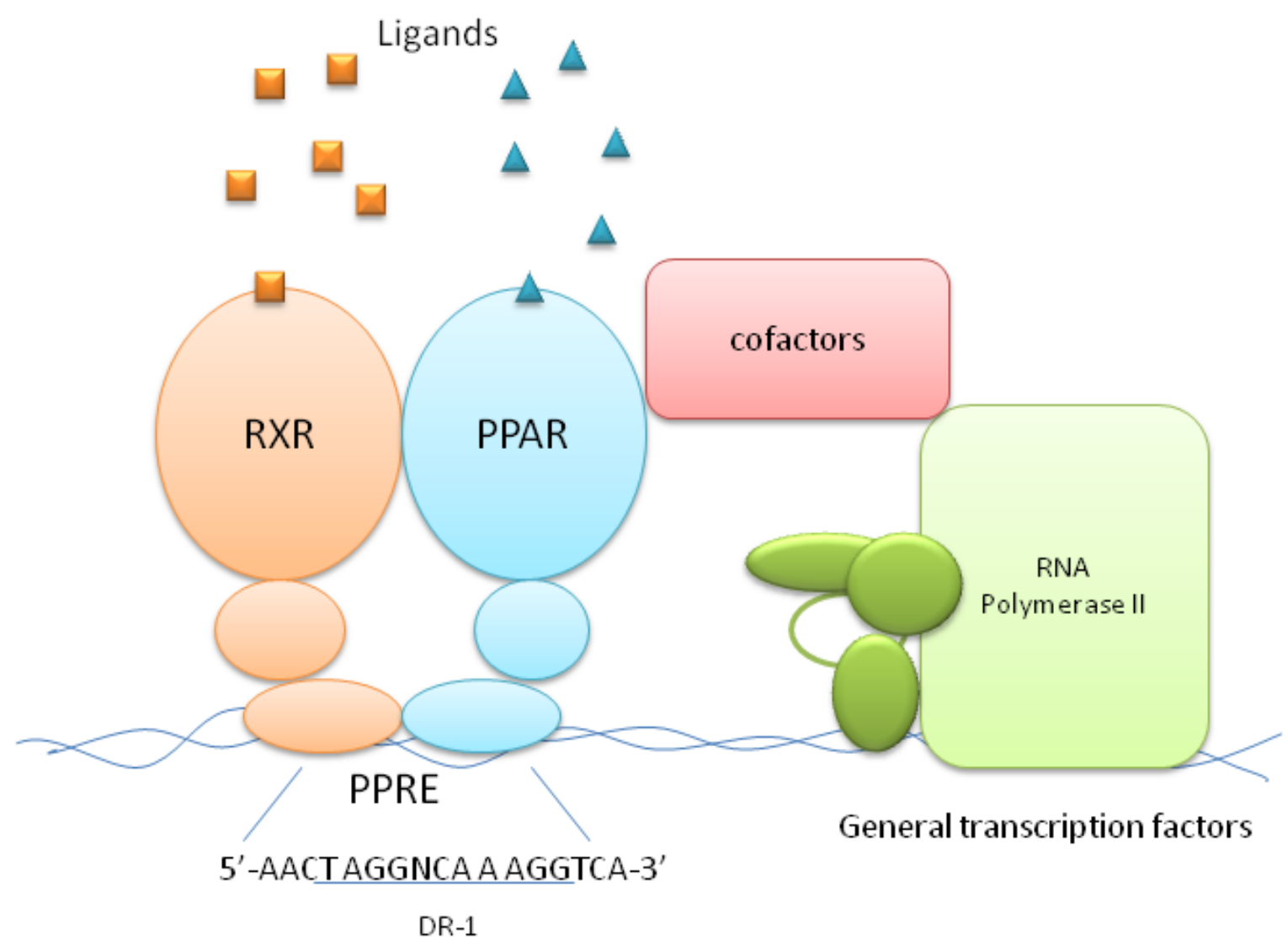

Figure 1.6 Schematic diagram of the PPAR mechanism of action. The blue triangles are peroxisome proliferator that bind to the PPAR, leading to heterodimer with retinoid $\mathrm{x}$ receptor (RXR) which has been activated by its ligands (orange squares). The PPAR/RXR heterodimer binds within the DNA binding C domain to peroxisome proliferator hormone response elements (PPRE) through a DNA sequence with repeats of the sequence AGGTCA (AGGTCA X AGGTCA) separated by one nucleotide (this would be located at the promoter of the target gene). The diagram is a modified version from (Keller et al., 2000).

Several studies showed that peroxisome proliferators are involved in the regulation of several genes that are involved in hepatic proliferation, metabolism, immune modulation, mitochondrial and peroxisomal fatty acid $\beta$-oxidation (Desvergne and Wahli, 1999) (Latruffe and Vamecq, 1997). Other studies reported that ciprofibrate is involved in modulating the expression of genes implicated in cell proliferation such as cyclins (Rininger et al., 1996)(Peters et al., 1998).

Yadetie examined the effects of $50 \mathrm{mg} \mathrm{kg}^{-1}$ body weight of ciprofibrate per day for 60 days on gene expression in the liver of rats by using a cDNA microarray analysis. From this it was found 
that a number of up- regulated genes were involved in lipid and sugar metabolism while other genes were implicated in growth and stress responses (Yadetie et al., 2003).

Peroxisome proliferators are reported to induce the transcription of the CYP4A1 gene (Hardwick et al., 1987), and the induction of $C Y P 4 A 1$ is linked with the transcription of genes encording the 3 oxoacyl CoA thiolase and the bifunctional enzyme acyl-CoA $(A C O)$ (Furuta et al., 1982)(Reddy et al., 1986).

Bell also characterized the induction of CYP4Al and acyl-CoA in vitro and found them highly induced after dosing rat hepatocytes with clofibric acid for 4 days, or with methylclofenapate, nafenopin, clofibric acid or mono (ethylhexyl) phthalate for $1 \mathrm{~h}$ and $8 \mathrm{~h}$. This suggested that the different time course of induction of $C Y P 4 A 1$ and acyl-CoA oxidase is not related to the type of peroxisome proliferator but to the process of peroxisome proliferation (Bell and Elcombe, 1991a).

In vivo studies in rats dosed intraperitoneally with methylclofenapate also showed significant induction of CYP4Al after $6 \mathrm{~h}, 8 \mathrm{~h}, 24 \mathrm{~h}$ and $30 \mathrm{~h}$, while the acyl-CoA showed no increase at 8 h but increased significantly after $24 \mathrm{~h}$ (Bell et al., 1991). As the induction of the CYP4Al gene is the first sign of the peroxisomal reaction, it is possibly the most significant enzymic indicator/ marker of peroxisome proliferation (Orton and Parker, 1982)(Hardwick et al., 1987).

In other reports the effects of peroxisome proliferators on immediate early gene expression have been related to the extracellular signal-regulated kinases and phosphorylation of the upstream regulator MAPK/ERK kinase signal transduction pathway (Rokos and Ledwith, 1997).

As PPARs can induce the regulation of a number of genes, PPARs can also down- regulate gene expression as they are necessary for the suppression of apolipoprotein CIII mRNA expression, 
but the mechanism is not clearly understood (Peters et al., 1997a). CYP2C11 expression is clearly down- regulated by peroxisome proliferators as reported in (Corton et al., 1998).

Gonzalez and his group demonstrated that hepatic microRNA expression was largely activated by PPAR $\alpha$. They studied a microRNA involved in cell growth, let-7C, and found it was suppressed following 4-h treatment, 2-week or 11-month constant treatment with the potent PPA$\mathrm{R} \alpha$ agonist $\mathrm{Wy}-14,643$ in wild-type mice. let-7C was shown to target $c$-myc. The induction of $c-m y c$ through let-7C consequently amplified expression of the oncogenic mir-17-92 cluster; this did not arise in PPAR $\alpha$ null mice (Shah et al., 2007a).

(Suzuki et al., 2010) examined the effect of Wy-14,643 on DNA damage in rat livers treated orally for 14 days and found that a number of DNA repair genes were induced such as Gadd45, Apex 1, Xrcc5 and M1h1. These results implied that hepatic DNA was damaged by Wy-14,643 but might be repaired via the activation of these DNA-repair genes.

The development of microarray tools has significantly changed gene expression analysis research. However, the reliability and reproducibility of RNA microarray data can be challenged. Therefore, confirmation of results with quantitative real- time PCR or a similar technique is essential (Baker et al., 2004). Baker found using cDNA microarray analysis and confirmation with real- time PCR that in clofibrate treated rats, hepatic expression of acyl CoA, topoisomerase II$\alpha$ and CYP4A1 were highly induced. Another tool used recently to study global gene expression is the RNAseq analysis technique. Also known as illumina sequencing, this technology is still very expensive and needs experience in bioinformatics, but it is fast and the illumina sequencing data is highly reproducible, with reasonably low technical variation in enabling identification of differentially expressed genes (Marioni et al., 2008). 


\section{Section 1.6 The aim of the Thesis}

The overall aim of this thesis is to shed some light on the mechanism of action of hepatic growth induced by peroxisome proliferators activating receptor ligand (PPAR $\alpha$ ), specifically ciprofibrate. This work is based on the assumption that increased DNA synthesis is causally related to the development of liver cancer.

To investigate how peroxisome proliferators induce hepatocyte proliferation and which genes they induce to cause cancer, the specific aims were;

1- To indicate when the induction of hepatic DNA synthesis provoked by ciprofibrate happens in mice and rats, by immunohistochemical technique.

2- To investigate where in the liver tissue the induction of hepatic DNA synthesis occurs in mice and rats dosed with ciprofibrate.

3- To characterize the genes responsible for triggering the induction of hepatic DNA synthesis caused by ciprofibrate in comparision with cyproterone acetate (CPA) by studying the immediate early induced genes. This was done with cDNA microarray, Transcriptome sequencing analysis and Quantitative Real Time PCR. 


\section{Chapter 2 Materials and Methods}

\section{Section 2.1 Materials}

\section{Section 2.1.1 Animals}

Male F-344/NHsd (Fisher) rats (14-15 weeks, 260 $\pm 20 \mathrm{~g}$ ) were bought from Harlan Laboratories, Inc. UK. DBA/2JCrl $(22 \pm 2 \mathrm{~g})$ and C57BL/6Crl $(20 \pm 2 \mathrm{~g})$ mice were used at age 9-10 weeks, and were purchased from Charles River Laboratories, Inc. UK.

Animals were matched for sex, strain, supplier and age, and were randomized on arrival on the basis of body weight in to the appropriate number of groups.

Animals were maintained under specific pathogen-free conditions, in plastic cages and were kept at $24 \pm 4^{\circ} \mathrm{C}$. The humidity was $70 \pm 5 \%$, with a $12 \mathrm{~h}$ day/night light cycle, with food and water available ad labium throughout the experimental period.

The animals were humanely killed with a single overdose of Dolethal (pentobarbital $200 \mathrm{mg} \mathrm{ml}^{-}$

1, purchased from Vetoquinol Company). The animals' experiments were performed in accordance with the Home Office guidance (Scientific Procedures) Act 1986.

\section{Section 2.1.2 Chemicals}

The peroxisome proliferator used was ciprofibrate as a powder and was a generous gift from Dr. T. J. B Gray, Sanofi- Aventis (Alnwick, UK).

The pregnane X receptor agonists used were cyproterone acetate CPA and pregnenolone-16 $\alpha$ carbonitrile PCN, and were bought from Sigma-Aldrich ${ }^{\circledR}$ as powders. 


\section{Section 2.1.3 Immunohistochemistry materials}

All chemicals used were of the highest quality available. 5-bromo-2'-deoxyuridine (BrdU), 3,3' diaminobenzidine tetrahydrochloride (DAB), bovine serum albumin (BSA), polyoxyethylene sorbitane monolaureate (Tween-20) and 10\% (w/v) formalin were purchased from Sigma-Al$\operatorname{drich}{ }^{\circledR}$.

A primary anti-BrdU mouse monoclonal antibody was purchased from GE healthcare (UK), and a secondary antibody (blotting grade affinity-purified goat anti-mouse $\operatorname{IgG}(\mathrm{H}+\mathrm{L})$ horseradish peroxidase conjugate) was purchased from Bio-Rad.

Ultrapure tris base was obtained from Melford Laboratories Ltd. DPX (Distyrene, plasticiser and xylene), hydrochloric acid and 30\% (w/v) hydrogen peroxide were obtained from Fisher Scientific, ammonium hydroxide from Aldrich, and cobalt chloride from AnalaR. Amersham cell proliferation kits were purchased from GE healthcare (UK).

Poly-L-lysine-coated slides (Polysine ${ }^{\mathrm{TM}}$ ) were obtained from Fisher, pure paraffin wax (melting point $56^{\circ} \mathrm{C}$ ) from RA lamb, Peel-A-Way ${ }^{\circledR}$ disposable histology molds from Polysciences Inc, and TAAB embedding stubs $(25 \mathrm{~mm})$ from TAAB laboratory and microscopy.

Glacial acetic acid, xylene, ethanol, methanol, sodium phosphate and haematoxylin stain were purchased from Sigma-Aldrich ${ }^{\circledR}$. Pure water was produced in this laboratory at a quality of $<$ $0.2 \mu \mathrm{S}$. 


\section{Section 2.1.4 Microarray materials}

\section{Section 2.1.4.1 RNA isolation materials}

TRI reagent ${ }^{\circledR}$ solution (a mixture of guanidine thiocyanate and phenol in a mono-phase solution) and 1-bromo-3-chloro-propane, Isopropanol and ethanol were bought from Sigma-Aldrich ${ }^{\circledR}$. SDS Sodium lauryl (dodecyl) sulfate $\left(\mathrm{C}_{12} \mathrm{H}_{25} \mathrm{SO}_{4} \mathrm{Na}\right)$ and ethidium bromide were bought from Fisher Scientific.

\section{Section 2.1.4.2 Synthesis and labelling of cDNA}

cDNA synthesis and labelling was with an amino allyl cDNA labelling kit from Ambion the RNA Company. Reagents used and included in the kit for cDNA labelling reactions are, 10X RT buffer, Oligo(dT) Primers [Oligo(dT)18, $50 \mathrm{mM}$ ] random decamers (50 mM), RNase inhibitor (10 units/ml), dNTP Mix (no dTTP) (10 mM each: dATP, dCTP, dGTP, dTTP)+ AA dUTP Mix, 3 mM dTTP, 3 mM 5-(3 aminoallyl)-2'-dUTP.

Also M-MLV reverse transcriptase (200 units $/ \mathrm{ml}), 3 \mathrm{M}$ sodium acetate ( $\mathrm{pH} 5.5)$, glycogen (5 $\mathrm{mg} \mathrm{ml}^{-1}$ ), $1 \mathrm{M}$ sodium hydroxide, DMSO (100\% dimethyl sulfoxide), coupling buffer, $1 \mathrm{M}$ HEPES (pH 7), 4 M hydroxylamine, water for 75\% ethanol, $100 \%$ ethanol and nuclease-free Water.

The fluorescent dyes used for the labelling were Alexa Fluor ${ }^{\circledR} 555$ and Alexa Fluor ${ }^{\circledR} 647$ reactive dyes from Invitrogen.

\section{Section 2.1.4.3 Microarray slides and hybridization materials}

Whole genome mouse Mouse Exonic Evidence Based Oligonucleotide (MEEBO) array slides were used. The arrays were printed over 2 slides $(\mathrm{A}+\mathrm{B})$, and were accompanied with a specific 
GenePix Array List (GAL) file.

The array slides were Gentix Aldehyde Plus arraying slides and were a kind gift from Dr T. Gant's lab, Systems Toxicology Group, Leicester University.

For the microarray hybridization of the cDNA, the tRNA used was from Invitrogen and 2X-enhanced cDNA hybridization buffer from Genisphere.

\section{Section 2.1.4.4 Microarray scanner}

An Axon 4200 scanner and GenePixPro(6) program was used to scan and analyse the slides. Both were situated at Dr T. Gant's laboratory, Systems Toxicology Group, Leicester University.

\section{Section 2.1.5 Transcriptome sequencing materials}

RNA sequencing was done with the $\mathrm{AB}$ SOLiD 3 platform, using short reads, at Dr Aziz Aboobaker's lab, Next Generation Sequencing Facility, Queens Medical Centre (QMC), University of Nottingham. Associated equipment for the transcriptome analysis was a COVARIS S2 sonicator, a DIGILAB hydroshear nanodrop 2000 and 3000 and a Qubit nucleic acid quantification agilent bioanalyser. 


\section{Section 2.1.6 Quantitative real- time PCR materials}

\section{Section 2.1.6.1 Synthesis of cDNA}

Total hepatic RNA was reverse transcribed to first strand cDNA using a High Capacity RNAto cDNA kit, and TaqMan ${ }^{\circledR}$ Gene Expression Master Mix which were from Applied Biosystems.

\section{Section 2.1.6.2 Primers and probes}

Real- time RT-PCR primers and probes for rat genes were designed using PRIMER 3 (Skaletsky, 2000) at http://frodo.wi.mit.edu/primer3/.

The primers and probes were checked for hairpins and dimers with AutoDimer v1 software and the primers were checked for specificity by Blast searching against the rat genome using the standard rodent database, at http://www.ebi.ac.uk/Tools/blastall/nucleotide.html.

The probes and primers were synthesized by Eurofins, MWG Operon. The sequence of the primers and probes and the dyes and quenchers that they are attached to are listed in Table 2.1. 
Table 2.1 RT-PCR oligonucleotides primers and probes for rat genes. Primers and probes are designated by letters indicating the forward primer F, the reverse primer R or the probe P. Sequences are given from 5'-->3'. The reporter dye is at the 5' end of the oligonucleotide. At $0647 \mathrm{~N}$ was used as an alternative to Cy5 where indicated.

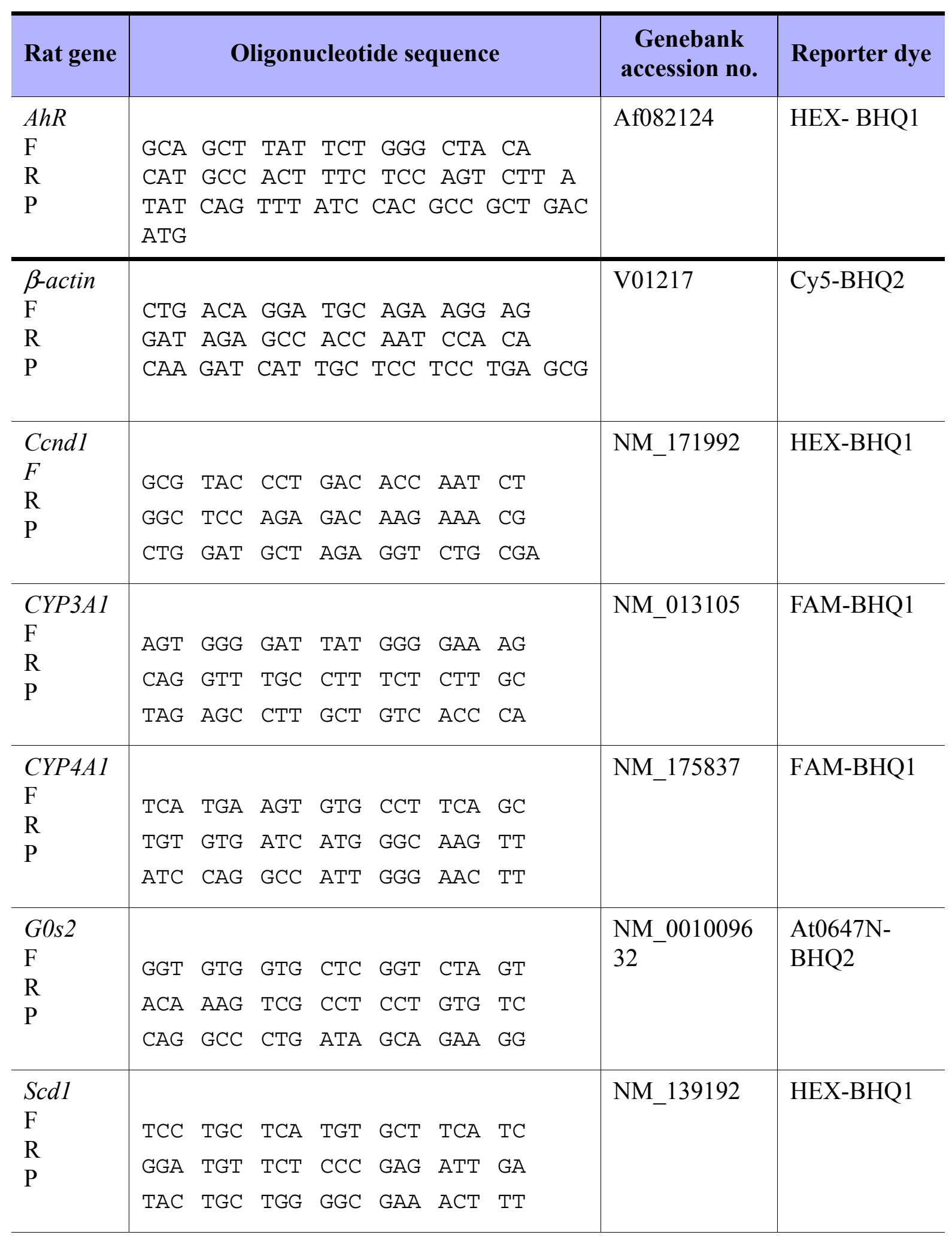




\section{Section 2.1.7 Software used in data analysis}

The NORT.T normalizing program was obtained from the Systems Toxicology Group, Leicester University (Dr Shu-Dong Zhang and Dr Timothy W. Gant) and was used for the initial normalizing of the scanning results and the microarray comparison experiments. The program can be downloaded from http://143.210.176.81/SystemsToxicology/Microarray_Softwares/

\section{Softwares_NorTT.aspx}

The microarray experimental information [(in accordance with Minimum Information About a Microarray Experiment (MIAME)] was stored in ArrayTrack, a software system for managing and interpreting microarray gene expression data developed by the Center for Toxicoinformatics at the National Centre for Toxicological Research (NCTR) of the U.S. Food and Drug Administration (FDA). The database generated from this thesis is accessible under the Univerity of Nottingham, file ABEER, from http://edkb.fda.gov/webstart/extdb_arraytrack/3.4/. R software version 2.9.0 ( $\mathrm{R}$ foundation for statistical computing) was used to analyse the final results for the microarrays.

The data from the RNA sequencing facilities (University of Nottingham Next Generation Sequencing Facility) were analysed with CLC Genomics Workbench 3.7 software. The original data can be found at http://spldeepseq.nottingham.ac.uk/ aziz/wtp rat/.

The rat genome used was from Ensembl at http://www.ensembl.org/Rattus_norvegicus/Info/In$\underline{\text { dex }}$, and the translation to gene names was done with rat genome database RGD tools at http:// rgd.mcw.edu/rgdweb/search/genes.html?100. Microarray heatmaps were established with High-Throughput GoMiner (Zeeberg, 2005). This software uses just + or - so it dose not show the differences in between but it gives the main pathways. 


\section{Section 2.2 Methods}

\section{Section 2.2.1 Dosing of animals}

The chemicals were administrated to the animals in different dosing schedules depending on the study, ensuring that the least suffering and stress was applied to the animals at all times.

The dosing schedules were:

1- Acute dosing schedule.

2- Chronic dosing schedule.

3- Gavage dosing schedule.

\section{Section 2.2.1.1 Acute dosing schedule}

In the acute study $100 \mathrm{mg} \mathrm{kg}^{-1}$ 5-bromo-2'-deoxyuridine (BrdU) was given to the animals by intra peritoneal (IP) injection, in a volume of $5 \mathrm{ml} \mathrm{kg}^{-1}$, two hours prior to killing the animals.

The BrdU was dissolved in phosphate buffer saline (PBS; $15 \mathrm{mM} \mathrm{NaH}_{2} \mathrm{PO}_{4}, 150 \mathrm{mM} \mathrm{NaCl}, \mathrm{pH}$ adjusted to 7.4 with $\mathrm{NaOH}$ ) then sterilized with a micro-filter (pore size of $0.2 \mu \mathrm{m}$ ).

All the animals were humanely killed with a single intraperitoneally overdose of Dolethal and death was confirmed by cervical dislocation of the neck. Figure 2.1 represents a cartoon of the experimental schedule of the acute dosing protocol. 


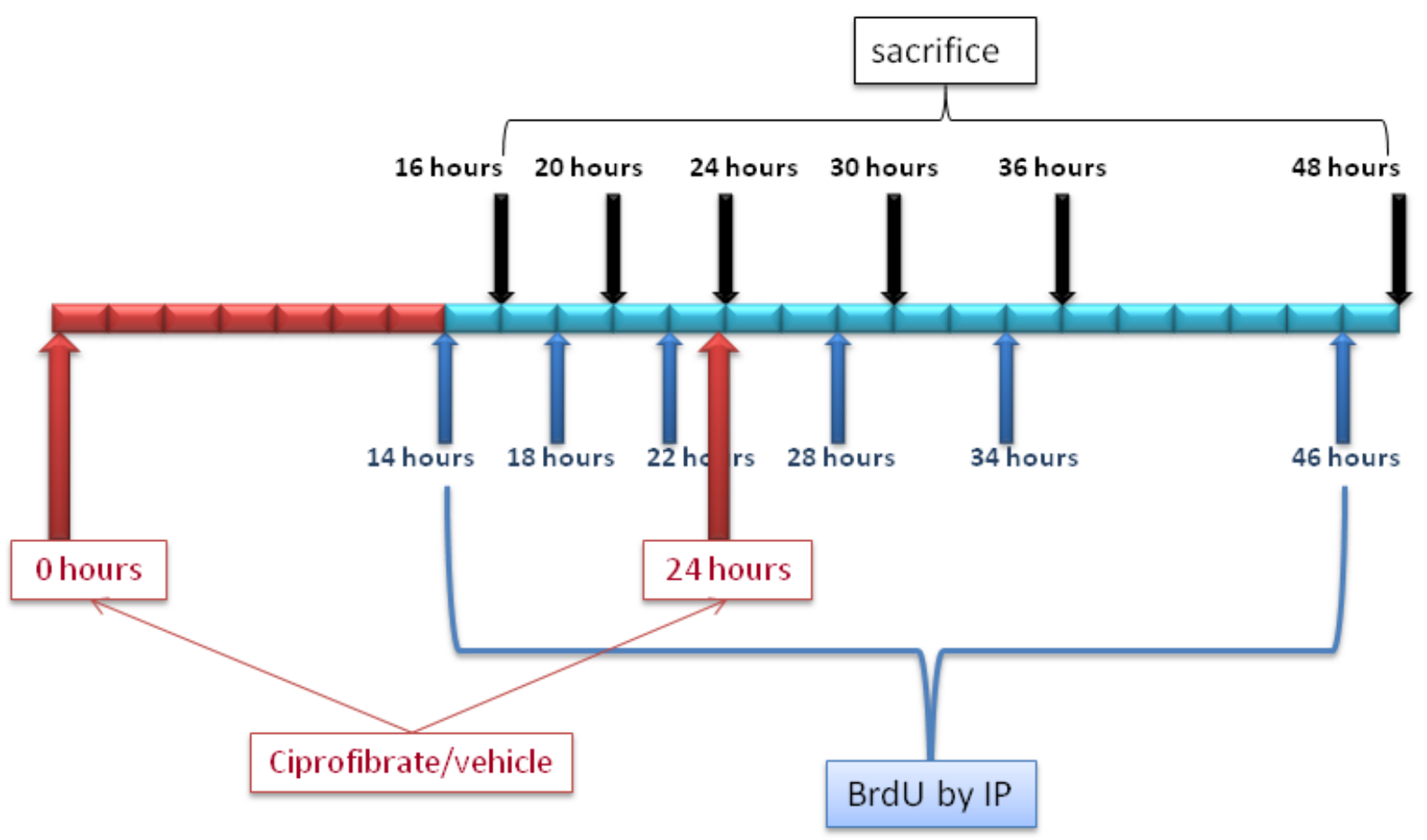

Figure 2.1 Schematic representation of acute and gavage dosing protocols. Cartoon describes the acute dosing schedule for studying the time course of induction of hepatic DNA synthesis. The blue arrows represent the number of hours when the acute IP dosing of the BrdU (100mg kg-1 body weight) accrued. The black arrows show the time of scarifying the animals 2 hours after the BrdU. The red arrows indicate the time of gavage dosing of the drug or vehicle at 0 or 24 hours. Each sequence of the time course line specifies a 2 hour time limit, the red is the time before the BrdU started.

\section{Section 2.2.1.2 Chronic dosing schedule}

The dosing of the BrdU to the animals in the chronic experiments was carried out by acclimatizing them to $10 \%(\mathrm{v} / \mathrm{v})$ Sainsbury's orange juice as their sole source of fluid for 7 days then on orange juice supplemented with $0.08 \%(w / v)$ BrdU. All drinking bottles containing BrdU were covered with aluminum foil to protect them from light, and were changed on a daily basis.

All the animals were humanely killed with a single intraperitoneally overdose of Dolethal and death was confirmed by cervical dislocation of the neck. In Figure 2.2 and Figure 2.3 a cartoon is illustrated showing the experimental schedule of the chronic dosing protocol for the testing of the effects of BrdU (Figure 2.2) and for the experimental design of the chronic dosing scheduale. 


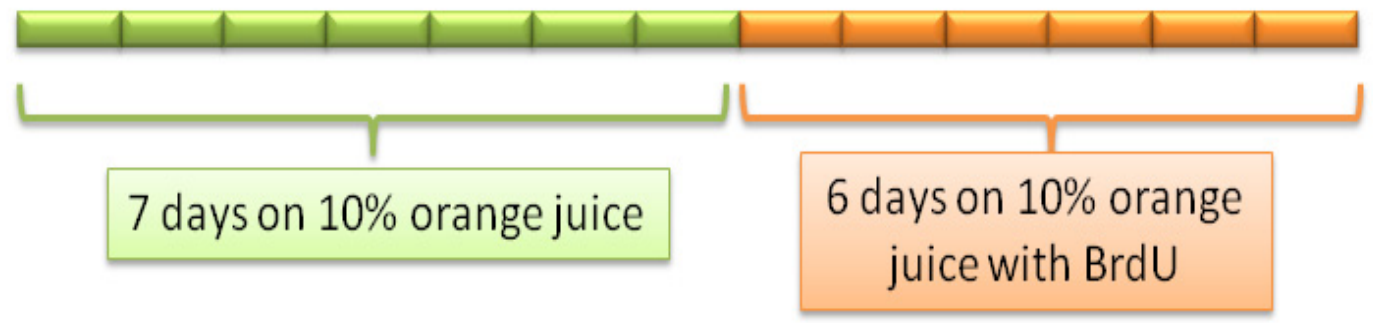

Figure 2.2 Schematic representation of chronic dosing protocol alone. Cartoon describes the chronic dosing schedule for studying the BrdU effects in mice. The green sequences show the number of days the animals were given $10 \%$ orange juice as sole source of drinking fluid. The orange sequences represent the number of days the animals had BrdU with the orange juice as their sole source of drinking fluid. Each sequence of the time course line specifies a 1 day time limit.

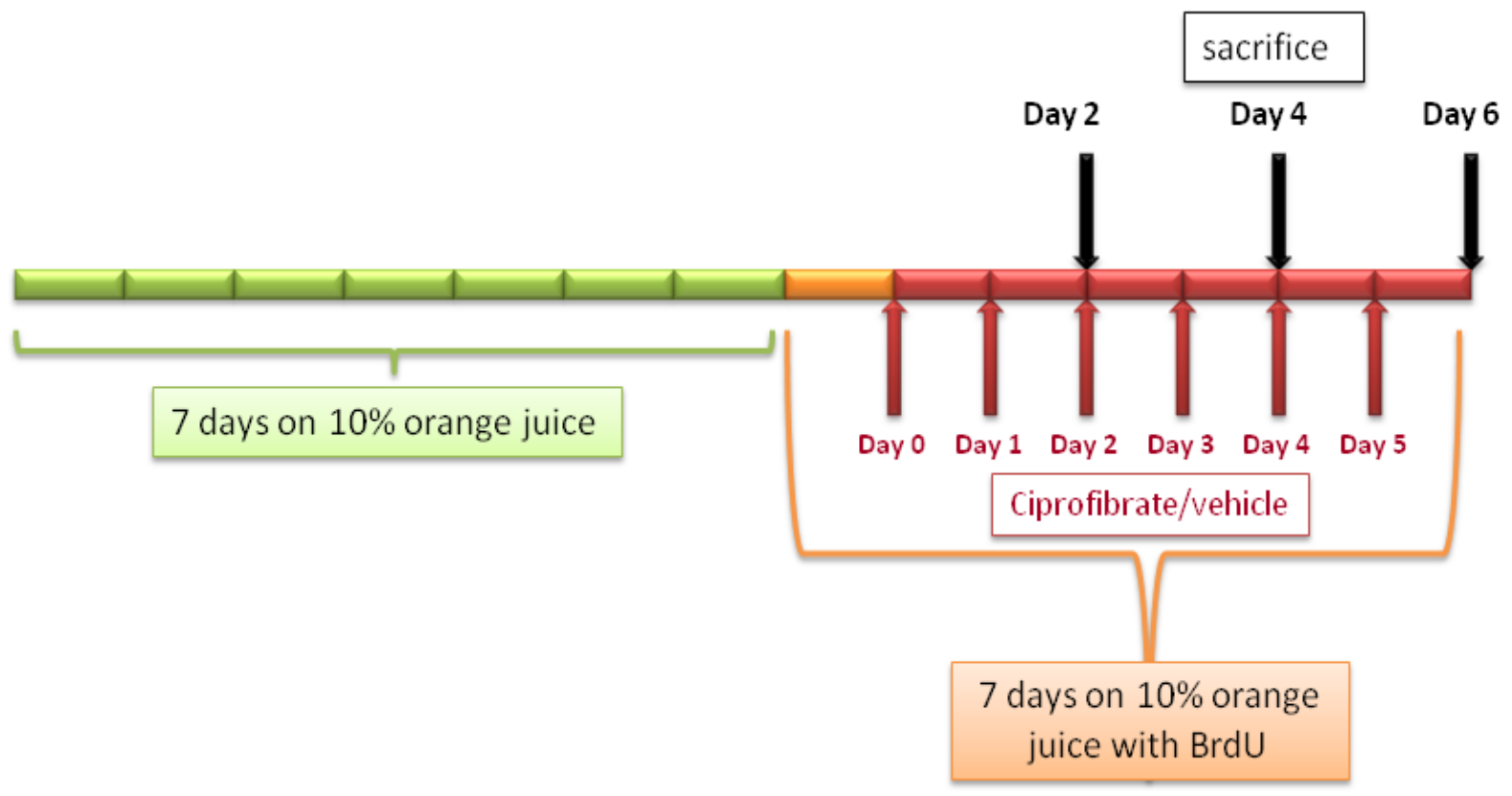

Figure 2.3 Schematic representation of chronic and gavage dosing protocols. Cartoon describes the chronic dosing schedule for studying the time course of induction of hepatic DNA synthesis. The green sequences show the number of days the animals were given $10 \%$ orange juice as their sole source of drinking fluid. The orange sequence represent the number of days the animals had BrdU with the orange juice as their sole source of drinking fluid. The red sequences show the number of days the animals had started the ciprofibrate with the BrdU in the orange juice as their sole source of drinking fluids. The red arrows indicate the time of gavage dosing of the drug or vehicle and the black arrows show the time of scarifying the animals. Each sequence of the time course line specifies a 1 day time limit. 


\section{Section 2.2.1.3 Gavage dosing schedule}

The ciprofibrate, cyproterone acetate (CPA), pregnenolone-16 $\alpha$-carbonitrile $(\mathrm{PCN})$ in the time course was $50 \mathrm{mg} \mathrm{kg}^{-1}$ ciprofibrate for $1,3,5,16,20,24,30$, and 48 hours in the rat study and $100 \mathrm{mg} \mathrm{kg}^{-1}$ for 2,4 and 6 days in the mouse study. For the CPA and PCN the dose was $100 \mathrm{mg}$ $\mathrm{kg}^{-1}$ for 24 hours. The doses for the dose response was 50, 100, 200, and $300 \mathrm{mg} \mathrm{kg}^{-1}$ after 24 hours.

These were administrated to the animals in corn oil as a vehicle by a gavage injection that enables the drug to be administrated straight to the stomach.

\section{Section 2.2.2 Animal observations and tissue collection}

The animals were observed 2-3 times daily for signs of distress or discomfort. Daily measurements of body weight were recorded at the same time (10-11am) each day, to monitor the wellbeing and health of the animals.

Immediately after killing the animals, blood samples were collected in plain tubes by cardiac puncture. After the blood had clotted (2-4 hours) it was centrifuged at $14000 \mathrm{Xg}$ and the serum frozen for the clinical chemistry procedures.

The liver weights of the animals were recorded and the percentage of the body weight to liver weight calculated. Aliquots of fresh liver and a part of the intestine (as positive control) were fixed for immunohistochemical analysis (formalin fixation), or snap frozen in liquid nitrogen for storage at $-80^{\circ} \mathrm{C}$ prior to biochemical analysis. 


\section{Section 2.2.3 Immunohistochemistry technique for BrdU paraffin sections}

This method was used to determine the percentage of BrdU-labelled cells during induction of DNA synthesis in the animals' liver as a result of the ciprofibrate's or cyproterone acetate's action. The two-step indirect method was originally optimized by (Al Kholaifi, 2008).

In this method the thymidine analog BrdU was dosed to the animals orally or injected.

\section{Section 2.2.3.1 Tissue processing}

Tissues were freshly collected from the animals. The livers and a section of the intestine were stored in a fixative $10 \%(\mathrm{v} / \mathrm{v})$ formalin until used. The tissues were left in the fixative not more than 3 days. Fixed tissues were dehydrated and infiltrated with paraffin wax by processing in a Shandon Citadel 2000 Automated Tissue Processor (protocol shown in Table 2.2). 
Table 2.2 Protocol for tissue processing.

\begin{tabular}{l|l}
\hline Solution & Time \\
\hline $70 \%$ ethanol & 6.5 hours \\
\hline $80 \%$ ethanol & 1 hour \\
\hline $90 \%$ ethanol & 1 hour \\
\hline $95 \%$ ethanol & 1 hour \\
\hline $100 \%$ ethanol & 1 hour \\
\hline $100 \%$ ethanol & 1 hour \\
\hline $100 \%$ ethanol & 1 hour \\
\hline xylene & 1 hour \\
\hline xylene & 1 hour \\
\hline xylene & 1 hour \\
\hline paraffin wax & 1 hour \\
\hline
\end{tabular}

After the tissue processing, the tissues were manually embedded in paraffin wax, and left on ice for at least 48 hours before sectioning with a microtome set to $4.5 \mu \mathrm{m}$.

The sections were floated on a preheated water bath to $37^{\circ} \mathrm{C}$ before mounting on Polylysine $\mathrm{TM}^{\mathrm{TM}}$ adhesive coated glass slides. The slides were then left overnight on a hot plate at $37^{\circ} \mathrm{C}$ to dry. 


\section{Section 2.2.3.2 BrdU immunohistochemical staining}

Immunohistochemical staining was performed by heating the sections for 2-3 minutes or until the wax was melted, then placing them in xylene for $5 \mathrm{~min}$. The sections were rehydrated in a decreasing series of ethanol concentrations $(100 \%, 70 \%, 50 \%)$ and then washed in water. The slides were then treated with fresh $3 \%(\mathrm{v} / \mathrm{v})$ hydrogen peroxide in methanol to quench the endogenous peroxidase, and then washed twice with PBS.

To retrieve the BrdU antigen a heat induced epitope retrieval technique was used, where the slides were plunged in boiling $10 \mathrm{mM}$ citric acid followed by $10 \mathrm{~min}$. at $60^{\circ} \mathrm{C}$, using a $700 \mathrm{Watt}-$ microwave (heating induces epitope retrieval by breaking the DNA, and unmasking the BrdU). Slides were then washed with PBS.

The slides were incubated horizontally, and in a warm, moist chamber with a $0.5 \%(\mathrm{w} / \mathrm{v})$ bovine serum albumin (BSA) blocking solution to block non-specific binding of cytosolic BrdU. Then the slides were incubated for 45 min with Amersham mouse monoclonal anti-BrdU antibody [1:1000 dilution in tris buffer saline (TBS)], then washed with distilled water.

The secondary antibody, blotting grade goat anti-rabbit IgG horseradish peroxidase conjugate, was added for $30 \mathrm{~min}$. The slides were then rinsed in PBS.

The slides were returned to a vertical orientation for incubation in the staining solution DAB reagent, before being washed with water.

The slides were then subjected to a standard histological staining procedure as shown in Table 2.3, where the slides were dipped in haematoxylin solution, washed, dipped in acid alcohol, then rinsed in running tap water, then in ammonia in water, and washed again in tap water. Then for the final dehydration of the slides, they were placed in an increasing series of ethanol $(50 \%$, 
$70 \%, 95 \%, 100 \%)$.

Finally the slides were treated with $100 \%$ xylene, and then mounted with DPX and covered with a cover slip each to protect the tissue from shrinking.

The slides were ready to be examined, preferably after 12-24 hours so the slides were completely dried. 
Table 2.3 Protocol for BrdU immunohistochemical staining.

\begin{tabular}{|c|c|c|}
\hline Application & Preparation of Application & Time \\
\hline Heat & heat the slides until the wax melts & 2-3 minutes \\
\hline Xylene & Xylene & 5 minutes \\
\hline Ethanol & $100 \%-70 \%-50 \%$ & $\begin{array}{l}8-4-3 \text { minutes } \\
\text { respectively }\end{array}$ \\
\hline $\mathrm{H}_{2} \mathrm{O}$ & $\mathrm{H}_{2} \mathrm{O}$ & 2 minutes \\
\hline $\mathrm{H}_{2} \mathrm{O}_{2}$ & $\begin{array}{l}3 \% \mathrm{H}_{2} \mathrm{O}_{2}(180 \mathrm{ml} \text { methanol }+20 \mathrm{ml} \text { hydrogen } \\
\text { peroxide })\end{array}$ & 15 minutes \\
\hline $\begin{array}{l}\text { Phosphate } \\
\text { buffer saline } \\
\text { PBS }\end{array}$ & $\begin{array}{l}0.1 \mathrm{M} \text { is } 11.5 \mathrm{~g} \mathrm{Na}_{2} \mathrm{HPO}_{4} \text { di-sodium hydrogen } \\
\text { orthophosphate } 2.96 \mathrm{~g} \mathrm{NaH}_{2} \mathrm{PO}_{4} \cdot 2 \mathrm{H}_{2} \mathrm{O} \text { sodium } \\
\text { phosphate and } 5.84 \mathrm{~g} \text { sodium chloride } \mathrm{NaCl} \text { in } \\
\text { 1 litre distilled water }\end{array}$ & 5 minutes twice $(\mathrm{X} 2)$ \\
\hline Citric acid & $\begin{array}{l}10 \mathrm{mM} 2.1 \mathrm{~g} \text { citric acid in } 1 \mathrm{~L} \mathrm{dH}_{2} \mathrm{O} \text {, adjust } \mathrm{pH} \text { at } \\
6.0 \text { using } 1 \mathrm{~N} \text { sodium hydroxide } \mathrm{NaOH} \text {. }\end{array}$ & $\begin{array}{l}\text { Boiled citric acid } 10 \\
\text { minutes at } 40^{\circ} \mathrm{C}\end{array}$ \\
\hline PBS & Phosphate buffer saline (as before) & 5 minutes \\
\hline $\begin{array}{l}\text { Bovine serum } \\
\text { albumin }\end{array}$ & $\begin{array}{l}\text { BSA } 5 \% \text { (blocking solution) is } 5 \mathrm{~g} \text { Bovine serum } \\
\text { albumin, } 0.5 \mathrm{ml} \text { Tween- } 20 \text { in } 100 \mathrm{ml} \text { PBS. }\end{array}$ & 15 minutes \\
\hline $\begin{array}{l}\text { Primary } \\
\text { antibodies }\end{array}$ & 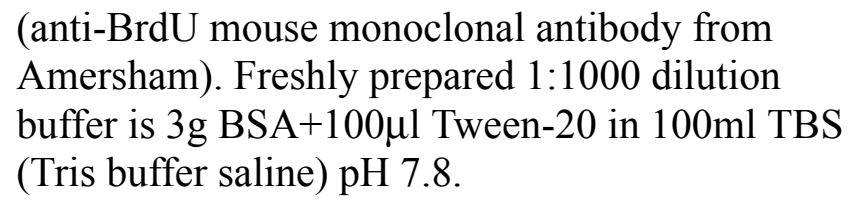 & 45 minutes \\
\hline $\mathrm{H}_{2} \mathrm{O}$ & $\mathrm{H}_{2} \mathrm{O}$ & 5 minutes \\
\hline
\end{tabular}


Table 2.3 Protocol for BrdU immunohistochemical staining.

\begin{tabular}{|c|c|c|}
\hline $\begin{array}{l}\text { Secondary } \\
\text { antibodies }\end{array}$ & $\begin{array}{l}\text { (peroxidase anti-mouse IgG from Bio-rad) freshly } \\
\text { prepare } 1: 100 / \text { slide. Dilution buffer is } 0.087 \mathrm{~g} \\
\text { monosodium phosphate monohydrate } \\
\mathrm{NaH}_{2} \mathrm{PO}_{4} \cdot \mathrm{H}_{2} \mathrm{O}, 0.194 \mathrm{~g} \text { disodium phosphate } \\
\text { (anhydrous) } \mathrm{Na}_{2} \mathrm{HPO}_{4}, 1.75 \mathrm{~g} \text { sodium chloride } \\
\mathrm{NaCl} \text { and } 2 \mathrm{~g} \mathrm{BSA} \text { in } 200 \mathrm{ml} \text { distilled } \mathrm{H}_{2} \mathrm{O}\end{array}$ & 30 minutes \\
\hline PBS & Phosphate buffer saline (as before) & 9 minutes \\
\hline $\begin{array}{l}\text { Staining solu- } \\
\text { tion DAB }\end{array}$ & $\begin{array}{l}\text { (development reagent is } 200 \mu l \text { hydrogen perox- } \\
\text { ide }+\mathrm{A}+4 \mathrm{ml} \text { of } \mathrm{B}) \mathrm{A} \text { development reagent is } \\
176 \mathrm{ml} \text { TBS } 10 \mathrm{mM} \mathrm{Ph} 7.6(1.21 \mathrm{~g} \text { tris base }+5.64 \mathrm{~g} \\
\mathrm{NaCl} \text {, adjust } \mathrm{PH} \text { to } 7.8 \text { using } \mathrm{HCl} \text { in } 1 \text { liter distal } \\
\text { water) with } 20 \mathrm{ml} \text { intensifier } 0.25 \% \text { cobaltous chlo- } \\
\text { ride. B is the DAB } 25 \mathrm{mg} / \mathrm{ml} \text { stock solution, and is } \\
0.5 \mathrm{~g} \text { DAB powder in } 20 \mathrm{ml} \text { phosphate buffer. }\end{array}$ & 8 minutes \\
\hline $\mathrm{H}_{2} \mathrm{O}$ & Distal $\mathrm{H}_{2} \mathrm{O}$ & 3 minutes \\
\hline $\begin{array}{l}\text { Haematoxy- } \\
\text { lin solution. }\end{array}$ & $\begin{array}{l}\text { (Harris) Haematoxylin } 100 \mathrm{ml}+\text { glacial acetic acid } \\
4 \mathrm{ml} \text {, filter before use. }\end{array}$ & 30 seconds \\
\hline $\mathrm{H}_{2} \mathrm{O}$ & Running tap water & 3 minutes \\
\hline Acid alcohol & $\begin{array}{l}\text { (for differentiation) } 700 \mathrm{ml} \text { commercial grade eth- } \\
\text { anol with } 300 \mathrm{ml} \text { distilled water and } 10 \mathrm{ml} \text { concen- } \\
\text { trated hydrochloric acid. }\end{array}$ & 5 seconds \\
\hline $\mathrm{H}_{2} \mathrm{O}$ & Rinse in running tap water & 1 minute \\
\hline Ammonia & $0.2 \%$ Ammonia in water & 1 second \\
\hline $\mathrm{H}_{2} \mathrm{O}$ & Tap water & 3 minutes \\
\hline Ethanol & Ethanol 50\%-70\%- 95\%-100\% & 1 minute each \\
\hline Xylene & Xylene (X2) & 1 minute each \\
\hline DPX & $\begin{array}{l}\text { Mount with DPX (Distyrene, plasterine, and } \\
\text { xylene) and cover with cover slide. }\end{array}$ & $\sim 1$ minute each slide \\
\hline
\end{tabular}




\section{Section 2.2.4 Examination of the slides}

The immunohistochemically stained slides were examined in one of two ways, depending on the study: 1- Labelling index studies

\section{2- Zonal distribution studies}

\section{Section 2.2.4.1 Labelling index studies}

To determine the hepatic DNA labelling index, one slide (with a slice of liver and gut) from each animal was used and 2000 nuclei were examined from random fields of view of each slide (the mean was calculated as the number of animals). Nuclei labelled with BrdU give a dark black/ brown colour (Figure 2.4) indicating that the cell has undergone DNA division. These cells were also counted as well as non-labelled nuclei. The percentage of the labelled nuclei was then calculated. A CX21 Olympus microscope was used with a graticule eye piece. The magnification used was X400.

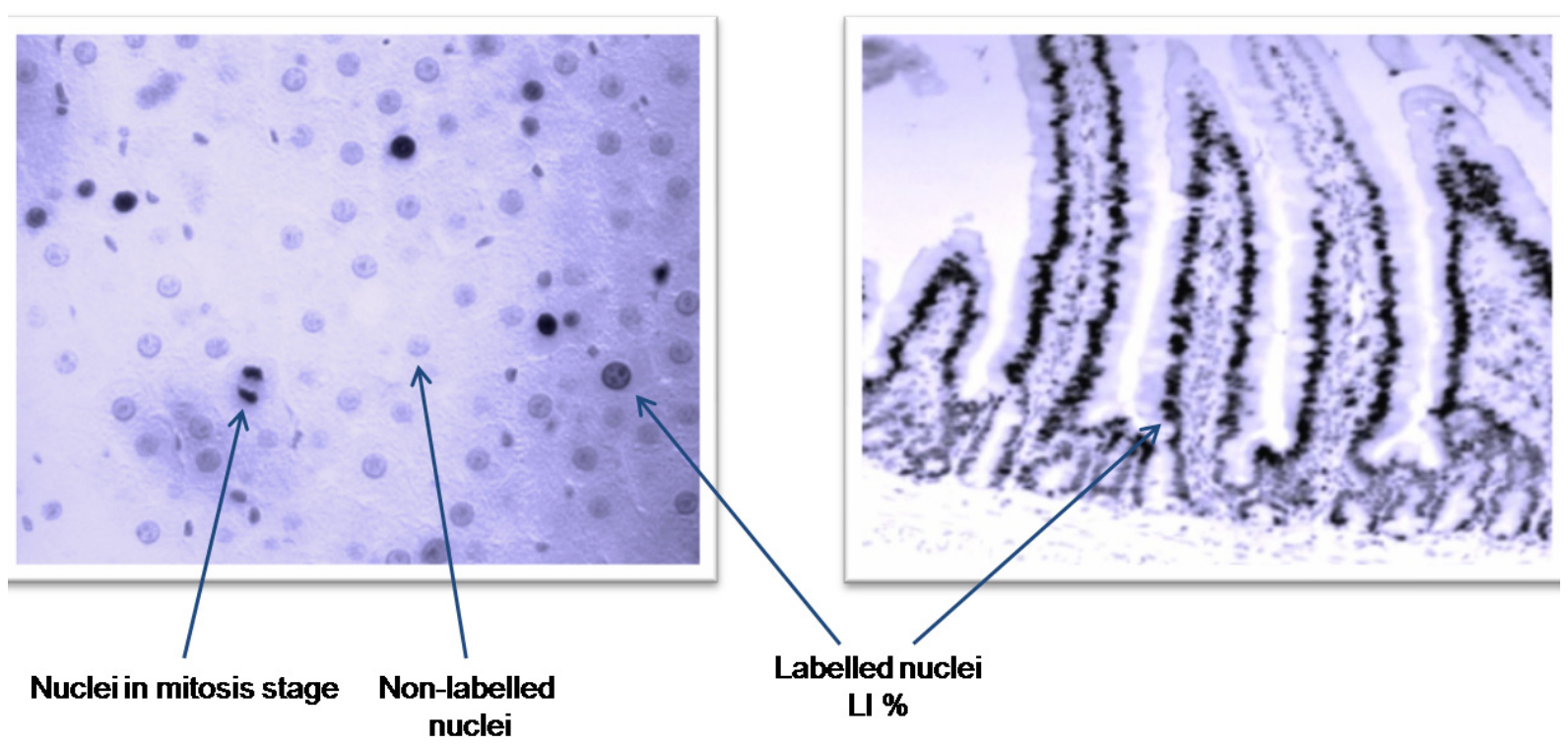

Figure 2.4 BrdU labelled hepatocytes. On the left a section of the liver with non-labelled and labelled hepatocytes. On the right a section of the intestine used as a control and shows the labelled epithelium cells in a dark colour and the non-labelled cells are pale at the top. The magnification of the liver is X400, and of the intestine is X100 


\section{Section 2.2.4.2 Zonal distribution studies}

To determine the zonal distribution of the BrdU-labelled hepatocytes; the number of labelled and non-labelled nuclei per field was counted.

A field is defined from (Barrass et al., 1993) as a radius of five to seven cells around either the portal space, which is the periportal region, or the central vein which is the perivenous region (Figure 2.5).

Ten random areas of both periportal and perivenous regions were counted (five each). Small central veins or portal spaces of similar sizes were selected for the analysis of the perivenous or periportal. One slide per animal was used. The total number of labelled nuclei in five fields was recorded for each of the periportal and perivenous zones.

An Olympus CX21 reflected light upright microscope was used at X400, with a graticule eye piece.

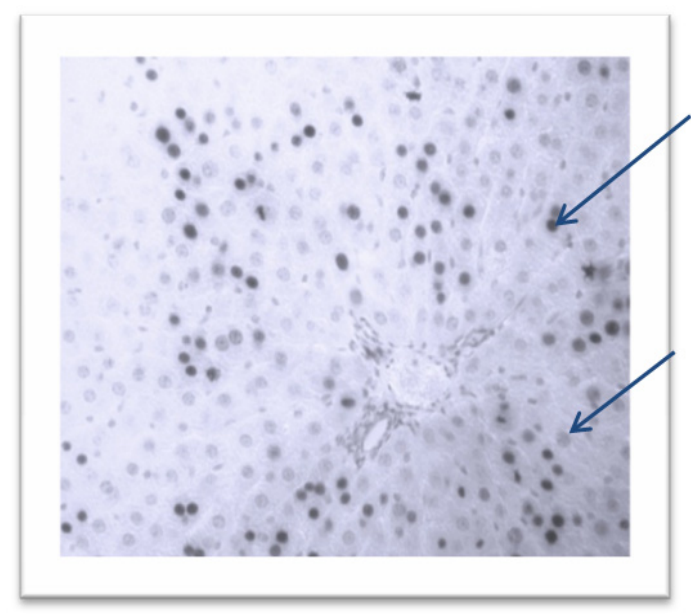

Portal space

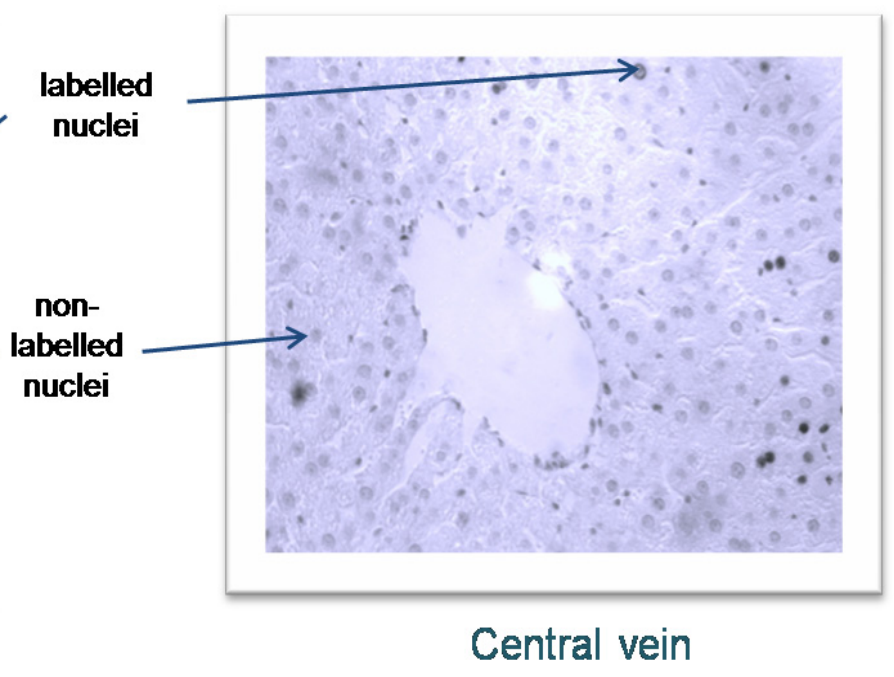

Figure 2.5 The periportal and perivenous zones. On the left is a portal space containing the portal vein, the hepatic artery and the bile duct and the surrounding hepatocytes which are the periportal zone. On the right is the central vein with the surrounding hepatocytes which count as the perivenous zone. The magnification is X100. 


\section{Section 2.2.5 Microarray analysis}

\section{Section 2.2.5.1 RNA isolations}

Total RNA was isolated using TRI reagent ${ }^{\circledR}$ solution from frozen liver cells with the following procedure:

TRI reagent ${ }^{\circledR}$ solution $(1 \mathrm{ml})$ was added to $80-90 \mathrm{mg}$ of frozen liver tissue pieces in a $1.5 \mathrm{ml}$ Ependorff tube, and homogenized with a mini homogenizer for 2-3 min. The mixture was left to sit at room temperature for $5 \mathrm{~min}$, before $200 \mu \mathrm{l}$ 1-bromo-3-chloro-propane (Sigma) was added and the mixture shaken vigorously for 15 seconds.

Then the samples were vortexed on full speed for 5-10 seconds, and incubated for 2-3 min at room temperature. The samples were centrifuged at $14000 \mathrm{Xg}$ for $14 \mathrm{~min}$, at $4^{\circ} \mathrm{C}$.

The upper layer was carefully transferred to a new RNAse-free $1.5 \mathrm{ml}$ Ependorff tube and $600 \mu 1$ isopropanol was added. After mixing, the tube was incubated at room temperature for $10 \mathrm{~min}$.

The samples were centrifuged at $14000 \mathrm{Xg}$ for $10 \mathrm{~min}$ to pellet the RNA. All subsequent procedures were performed at $4{ }^{\circ} \mathrm{C}$ (on ice). The supernatant was removed carefully, then the pellet was washed twice with $0.5 \mathrm{ml}$ ice cold $75 \%$ ethanol, centrifuging between each wash step.

The pellet was resuspended in $\sim 50-100 \mu$ diethyl pyro carbonate (DECP) water and stored at $80^{\circ} \mathrm{C}$ until use.

Note; DECP water was made by mixing $1 \mathrm{ml}$ DECP (diethyl pyro carbonate) and $9 \mathrm{ml}$ pure ethanol (absolute) in 1 litre distilled water, and then autoclaved.

Filter pipette tips and clean gloves were used for all the procedures. The gloves were changed on a regular basis. 


\section{Section 2.2.5.2 Synthesis and labelling of cDNA from RNA}

This was done with a modified technique, using an Amino allyl cDNA labelling Kit Ambion ${ }^{\circledR}$ the RNA company.

To reverse transcribe the RNA, $1 \mu 1 \mathrm{RT}$ primer was added to around $20 \mu \mathrm{g}$ total RNA and denatured at $75^{\circ} \mathrm{C}$ for $9 \mathrm{~min}$. Added to this was $2 \mu 110 \mathrm{X}$ RT buffer, $1 \mu 1 \mathrm{RNase}$ inhibitor, $1 \mu 1 \mathrm{dNTP}$ mix (dATP, dCTP, dGTP), $1 \mu \mathrm{l}$ dTP+AA dUTP mix and $2 \mu 1$ M-MLV reverse transcriptase.

The mixture was incubated at $42^{\circ} \mathrm{C}$ for $1 \mathrm{~h}$ and $45 \mathrm{~min}$, then $4 \mu \mathrm{l} 1 \mathrm{M} \mathrm{NaOH}$ was added before incubation at $65^{\circ} \mathrm{C}$ for $15 \mathrm{~min}$ to remove the template RNA by alkaline hydrolysis. The reaction was then neutralized with $10 \mu 11 \mathrm{M}$ HEPES buffer.

The cDNA was recovered by ethanol precipitation, by incubating with $3.4 \mu 13 \mathrm{M}$ sodium acetate and $100 \mu 1100 \%$ ethanol at $-80^{\circ} \mathrm{C}$ for $1-2 \mathrm{~h}$.

The cDNA was pelleted by centrifugation at $14000 \mathrm{Xg}$ at $4^{\circ} \mathrm{C}$ for $15 \mathrm{~min}$, the supernatant was carefully aspirated and discarded, and then the cDNA pellet was washed by adding $\sim 0.5 \mathrm{ml}$ of $75 \%(\mathrm{v} / \mathrm{v})$ ice cold ethanol and vortexed briefly, before centrifuged for $\sim 5 \mathrm{~min}$ at $14000 \mathrm{Xg}$ at $4^{\circ} \mathrm{C}$, and carefully removed and the supernatant discarded.

To remove the last traces of ethanol the tube was re-centrifuged for $\sim 5 \mathrm{~min}$ at $14000 \mathrm{Xg}$ at $4^{\circ} \mathrm{C}$, and a small sized pipet was used to remove the residual fluid.

The cDNA was then resuspended in $4.5 \mu 1$ coupling buffer and $2.5 \mu 1$ nuclease-free water, mixed thoroughly and gently vortexed, and then the tube was centrifuged briefly.

To couple dye to the amino modified cDNA, $3 \mu$ l fluorescent dyes Alexa Fluor ${ }^{\circledR} 555$ or Alexa Fluor ${ }^{\circledR} 647$ were dissolved in $3 \mu 1100 \%$ DMSO, then the dyes were added to the cDNA and 
incubated in the dark at room temperature for 1 hour.

$6 \mu \mathrm{l}$ of $4 \mathrm{M}$ hydroxylamine was added to the mixture, before incubation for $15 \mathrm{~min}$ at room temperature in the dark to terminate the coupling reaction.

The labelled cDNA was purified using rehydrated NucAway spin columns after hydrating the columns with $650 \mu 1$ nuclease free water for $1-2 \mathrm{~h}$ just before use. The cDNA was transferred on to the matrix of the NucAway spin columns and centrifuged at $750 \mathrm{Xg}$ for $2 \mathrm{~min}$ (according to the manufacturer's instructions).

The dyed -labelled cDNA was run through the column to a $1.5 \mathrm{ml}$ Ependorff tube positioned beneath the column and the free dye was retained in the spin column matrix.

The dye-labelled cDNA was prepared for concentration by ethanol precipitation by adding $9 \mu 1$ $2 \mathrm{M}$ sodium acetate and $250 \mu 1100 \%$ ethanol and storage at $-80^{\circ} \mathrm{C}$ overnight.

The next day the labelled cDNA was centrifuged for $15 \mathrm{~min}$ at $14000 \mathrm{Xg}$ at $4^{\circ} \mathrm{C}$ then the supernatant was carefully removed, and the dye-labelled cDNA pellet was washed by adding $\sim 0.5 \mathrm{ml}$ of $75 \%(v / v)$ ice cold ethanol and vortexed briefly.

The tube was then centrifuged for $\sim 5 \mathrm{~min}$ at $14000 \mathrm{Xg}$ at $4^{\circ} \mathrm{C}$, and carefully removed and the supernatant discarded. To remove the last traces of ethanol the tube was re-centrifuged for $\sim 5$ min at $14000 \mathrm{Xg}$ at $4^{\circ} \mathrm{C}$, and then with a small sized pipet the residual fluid was removed.

The cDNA was a small pellet, 1-2 mm in diameter, which was visibly red for the Alexa Fluor ${ }^{\circledR}$ 555 or blue for the Alexa Fluor ${ }^{\circledR} 647$.

The dye-labelled cDNA was suspended in 25-40 $\mu 1$ RNA-free water and the success of the labelling was assessed with a nanodrop machine to measure the optical density (OD) of the cDNA 
and the labelled dyes.

Note that all the labelled fluorescent steps were done in the dark.

\section{Section 2.2.5.3 Hybridization of the cDNA}

The dye-labelled cDNA was mixed with $2 \mu 1 \mathrm{tRNA}\left(4 \mathrm{ml} \mathrm{ml}^{-1}\right)$ and $40-80 \mu 1$ hybridization buffer and centrifuged briefly to collect the mix, then denatured for $5 \mathrm{~min}$ at $100^{\circ} \mathrm{C}$ and incubated for $1 \mathrm{~h}$ at $42^{\circ} \mathrm{C}$.

The MEEBO array slides and the cover slips were prepared for use by washing the oligo arrays twice in $0.2 \%(\mathrm{w} / \mathrm{v})$ sodium dodecyl sulfate (SDS) for $2 \mathrm{~min}$, then twice in $\mathrm{ddH}_{2} \mathrm{O}$ for $2 \mathrm{~min}$ each, and then dried by centrifugation at $250 \mathrm{Xg}$ for $4 \mathrm{~min}$.

The cover slips were washed in 1\% (w/v) SDS for 30 min and then underwent 5 X 5 min washes with $\mathrm{dH}_{2} \mathrm{O}$, before being spun dry/wiped dry and stored in a dust free environment.

The cDNA was spread on the MEEBO array slides by placing the slide over a template slide (to indicate where the array is located on the slide) and placing the coverslip over the array before carefully and slowly pipetting the labelled-cDNA between the slide and the coverslip at either end. The sample draws itself underneath the coverslip by capillary movement covering the entire array area. This was done in the dark.

The slides were then kept in the dark and placed on a slow moving shaker for a couple of minutes to assist an even spread of the cDNA on the array slide.

Nucleic acid hybridization was then performed by incubating the slides overnight at $42^{\circ} \mathrm{C}$ in a Gentix hybridization chamber. To ensure that the slides were kept humid, $5 \mathrm{ml}$ water was added in the chamber. 
The slides were washed after hybridization, for 5 min with 1 X SSC buffer and $0.03 \%(\mathrm{w} / \mathrm{v})$ SDS after removing the coverslips, and then were washed in $0.2 \mathrm{X} \mathrm{SSC}$ for $3 \mathrm{~min}$, and in $0.05 \mathrm{X} \mathrm{SSC}$ for $3 \mathrm{~min}$.

The slides were then dried by centrifuging them at $250 \mathrm{Xg}$ for $4 \mathrm{~min}$.

\section{Section 2.2.5.4 Scanning of the array slides}

The slides were scanned with a GenePix 4200A Axon scanner and a Genepix professional (6) and a Genepix professional (6) software program, with hardware settings of 635 (standard red) and 532 (standard green) for the wavelengths and laser power of $70 \%$ and filters of Cy5 and Cy3 for the high and low wavelengths respectively.

The slides were scanned at two wavelengths ( $532 \mathrm{~nm}$ for the Alexa Fluor ${ }^{\circledR} 555$ dye and $635 \mathrm{~nm}$ for the Alexa Fluor ${ }^{\circledR} 647$ dye).

The ratio was always on 635/532 with the GenePix array list (GAL) file. The images were saved as 3 multi-images, Tagged Image File Format TIFF (compressed).

\section{Section 2.2.5.5 Fitting features of the scanned array slides}

The images were opened for analysis with the GenePix Pro (6) program at a ratio formulation of 635/532. The blocks from the GenePix Array List (GAL) files were subsequently aligned on the images from the scanner. The relevant GAL file (A or B) was superimposed on the slide and each of the blocks and features aligned automatically. The features were then checked manually for empty or irrelevant features.

After fitting all the blocks and the features for each of the A and B slides, and the results from the analysis were saved as a GenePix results (GPR) file which could be opened in Excel. 


\section{Section 2.2.5.6 Normalization of the GPR files}

The files were normalised with NORTT, which is a normalise program and Student's t- test gene expression data program 1.1.0, from the MRC Toxicology Unit.

The normalization was an intensity-dependent normalization with settings to treat the background fluorescence as zero and to pre-condense data by gene identity. The labelling method was chosen as Cy3 for the control (555) and Cy5 for the treated (674). Data that is flagged by GenePix as having failed to record a florescence in both channels was ignored. A normalised data file *.NOR was generated and saved. Data which had a single channel only, failed the threshold test, or failed to pass the circularity test in GenePix 5.0 was written to a *.NEG file.

\section{Section 2.2.5.7 Analysis of the microarray data}

For the comparision and the quality control of the microarray data, microarray stastical analysis was done with Microsoft Excel 2007, where the power of the normalised $\log 2$ ratio of median was used.

To compare between the microarray data with linear regression, a VLOOKUP (VLOOKUP searches for a value in the first column of a table array and returns a value in the same row from another column in the table array) was used to identify the value of one array data corresponding to the value in the second array of data. The linear regression line was fitted with Graphpad prism 5. The microarray experimental data was stored and normalised in the Array Track and then the R software was used to analyse and identify the genes of interest.

High-Throughput GoMiner program (Zeeberg, 2005) was used to interpret the the microarray data. 


\section{Section 2.2.6 Transcriptome sequencing}

\section{Section 2.2.6.1 Sequencing}

RNA sequencing was performed on RNA liver samples from F344 rats treated with ciprofibrate/corn oil for 3 hours. The University of Nottingham Next Generation AB SOLID 3 platform Sequencer was used, where it was broken up to $\sim 20 \mathrm{Kbp}$ with a sonicator, then each sequence was ligated with a labeled sequence of nucleotides, this generate a monoclonal sequencing unit (which is the sequence attached to beans on a 1:1 basis).

The monoclonal sequence units were then placed on slides, and then the sequencer read the information from the slides as short reads (which are readings of short parts of the whole DNA). These short reads were assembled with Ensembl software.

\section{Section 2.2.6.2 Expression analysis}

After generating the data it was analysed with CLC Genomics Workbench 3.7 software. To analyse differential expression, it was of importance to tell the workbench program how the samples were related. This was done by setting up an experiment to define the relationship between the samples, which was defined as a two group experiment (control and treated) $n=4$. The samples were specified as unpaired multi-group comparison with the number of groups as 2 groups.

Normalization with CLC Genomics Workbench program was essential in order to ensure that the samples were comparable and assumptions on the data for analysis were met, and to remove the bias effects of the sample preparation and array processing. This was done with a quantile normalization method before the statistical analysis was carried out.

Quality control was performed on the normalised data with CLC Genomics Workbench pro- 
gram to enable visual inspection of the distribution and variability of the data, and to allow indecation of any unwanted systematic differences between the samples.

The tools used were box plots/analyzing distributions, Hierarchical Clustering of samples and Principal Component Analysis. After the above steps the samples were ready for statistical analysis. Following statistical analysis the retrieval of the genomic information was processed using rat genome data RGD base tools, by entering the Ensembl number of the genes manually to recover the gene name and description.

\section{Section 2.2.7 Quantitative real-time reverse transcriptase polymerase chain reaction (qRT-PCR)}

\section{Section 2.2.7.1 High Capacity RNA-to-cDNA}

cDNAs were made from each of the 4 biological replicates obtained for each of the 3 treatments at the 4 timepoints. This was done using the high capacity RNA-to-cDNA kit (Applied Biosystems) according to manufacturers' instructions. As negative controls, the reaction was set up without a RT enzyme mix (-RT) to ensure no contamination from the buffer, and the whole mix without the RNA (-RNA) was used to control for genomic DNA contamination. The samples were prepared by using up to $2 \mu \mathrm{g}$ of total RNA per $20 \mu \mathrm{l}$ reaction as in Table 2.4 . 
Table 2.4 Preparation of the RT reaction mix.

\begin{tabular}{l|l|l}
\hline \multicolumn{1}{c|}{ Component } & \multicolumn{1}{|c}{ Volume/reaction $(\mu \mathrm{l})$} & \multicolumn{1}{c}{ Volume/reaction $(\mu \mathrm{l})$} \\
\hline & $+\mathrm{RT}$ & -RT \\
\hline 2X RT buffer & 10.0 & 10.0 \\
\hline 20X RT enzyme mix & 1.0 & - \\
\hline nuclease-free water & quantity sufficient to $20 \mu \mathrm{l}$ & quantity sufficient to $20 \mu \mathrm{l}$ \\
\hline RNA sample & & up to $2 \mu 1$ \\
\hline total per reaction & up to $2 \mu 1$ & 20 \\
\hline & & \\
\hline
\end{tabular}

The tubes were mixed well and briefly centrifuged to spin down the contents and to eliminate air bubbles. Everything was on ice until used.

The samples were run with the program shown in Table 2.5 to initiate the reverse transcription reaction.

Table 2.5 Optimal conditions for use with high capacity RNA-to-cDNA kit.

\begin{tabular}{l|c|c}
\cline { 2 - 3 } & Temperature $^{\mathbf{0}} \mathbf{C}$ & Time (min) \\
\hline Step 1 & 37 & 60 \\
\hline Step 2 & 95 & 5 \\
\hline Step 3 & 4 & infinity \\
\hline
\end{tabular}

The cDNA was stored at $-20^{\circ} \mathrm{C}$ until used. 


\section{Section 2.2.7.2 Standard curves for qRT-PCR products}

Standard curves for each of the genes used (CYP4A1, CYP3A1 G0s2, Ccnd1, AhR, $\beta$-actin and Scd1) were created by using 5-fold serial dilutions of a control cDNA to demonstrate the qRTPCR efficiency. This was done in triplicate.

The standard curves for each of the genes were generated with MX4000 software using a least mean squares curve fitting logarithm. The regression value $r^{2}$ was generated for each gene as $(\mathrm{Y}=\mathrm{m} \log \mathrm{X}+\mathrm{b})$ where $\mathrm{m}$ is the slope of the line.

The average amplification efficiency was determined as it is directly related to the slope of the curve throughout the cycling reaction. The amplification efficiency is 10 (-1/slope). This corresponds to the number of template molecules that are duplicated every cycle.

\section{Section 2.2.7.3 Quantitative real-time PCR using TaqMan® gene expression}

This was done with TaqMan ${ }^{\circledR}$ gene expression master mix real-time PCR, which supplies a fluorescence reading of messenger RNA mRNA expression throughout each cycle of the PCR procedure, which in turn uses a quantitative study of mRNA expression based on PCR cycling threshold (Ct) values using MX4000 software. The primers and probes were amplified, with one or more endogenous control gene in the same reaction. The endogenous control was chosen on the fact that the gene induction was not changed in the control and samples treated with ciprofibrate or CPA.

The qRT-PCR was used to study the changes in gene expression of CYP4A1, CYP3A1 G0s2, $C c n d 1$, and $S c d 1$ by using $A h R$ and $\beta$-actin as normalization genes. CYP4A1 and CYP3A1 were used as positive controls for the ciprofibrate and CPA respectively. No template control (NTC), -RT and -RNA were run in parallel as negative controls, and each sample was done in two rep- 
licates.

The best annealing temperature, the amounts of Forward, Reverse, primers and cDNA were all optimized with stepwise procedures (data not shown). The real-time PCR reaction was determined as in (Table 2.6) and amplified as in (Table 2.7) with a TaqMan thermal cycler MX400. 
Table 2.6 Real-time PCR reaction. The amount of master mix is $18 \mu 1$ and then DECP water was added to the final amount of $45 \mu$ l. This was ready to be spread in two $20 \mu 1$ well on a 96 well plate. The concentrations of the primers were $10 \mathrm{pmol} / \mu \mathrm{l}$ for the primers and $5 \mathrm{pmol} / \mu 1$ for the probes.

\begin{tabular}{l|l|l|l}
\hline \multicolumn{1}{c|}{ Gene } & $\begin{array}{c}\text { Forward } \\
\text { primer }(\mu \mathrm{l})\end{array}$ & $\begin{array}{c}\text { Reverse } \\
\text { primer }(\mu \mathrm{l})\end{array}$ & Probe $(\mu \mathrm{l})$ \\
\hline AhR & 1.5 & 1.5 & 1.5 \\
\hline$\beta$-actin & 1.5 & 1.5 & 1.5 \\
\hline Ccnd1 & 1.5 & 2.25 & 2.25 \\
\hline CYP3A1 & 2.25 & 2.25 & 2.25 \\
\hline CYP4A1 & 2.25 & 2.25 & 2.25 \\
\hline G0s2 & 2.25 & 2.25 & 2.25 \\
\hline Scd1 & 2.25 & 2.25 & 2.25 \\
\hline
\end{tabular}

Table 2.7 Real-time PCR cycle program. The conditions of the real-time PCR reaction, the whole reaction was $90 \mathrm{~min}$.

\begin{tabular}{l|l|l}
\hline Number Of Cycles & Temperature $\left({ }^{\mathbf{0}} \mathrm{C}\right)$ & Time \\
\hline 1 & 95 & $10 \mathrm{~min}$ \\
\hline 40 & 95 & $20 \mathrm{sec}$ \\
\hline 40 & 60 & $1 \mathrm{~min}$ \\
\hline
\end{tabular}




\section{Section 2.2.7.4 Statistical analysis of qRT-PCR}

Biogazelle qBasePluse software was used to normalise and analyse the gene expression with the relative quantity method. The magnitudes of RNA number of the genes targeted were determined from the experiments $\mathrm{Ct}$ values. The copy number of the samples was normalised to that of the endogenous controls $A h R$ and $\beta$-actin.

\section{Section 2.2.8 Quantity and quality measurement of RNA and cDNA}

To quantitate the RNA, absorbance at 260nm was determined with a CECIL CE9500 Spectrophotometer, while a Nanodrop machine was used to measure the quantity of the cDNA and the amount of fluorescent labelling of the 555 and 647 dyes.

The concentrations of nucleic acid in the samples were determined according to 1 OD (optimal density) at $260 \mathrm{~nm}=20-33 \mathrm{ng} / \mu 1$ of single stranded DNA (for cDNA), and 1 OD at $260 \mathrm{~nm}=40$ $\mathrm{ng} / \mu \mathrm{l}$ of RNA.

Agarose gels $[2 \%(1.0 \mathrm{~g} / 50 \mathrm{ml})]$ were used to check the quality of the RNA. They were prepared by adding $1 \mathrm{~g}$ agarose powder to $50 \mathrm{ml} 1 \mathrm{X}$ tris boric acid EDTA (TBE) (10X TBE was prepared by adding $108 \mathrm{~g}$ Tris base, $55 \mathrm{~g}$ Boric acid, $9.3 \mathrm{~g} \mathrm{Na}{ }_{2}$ EDTA to 1 litre diluted water) with $0.5 \mathrm{ml}$ 10 X SDS. Gels were post-stained with ethidium bromide.

\section{Section 2.2.9 Measurement of serum Alanine Aminotransferase ALT}

Measurement of serum Alanine Aminotransferase (ALT) activity was carried out using Vitros ALT slides (Ortho-Clinical Diagnostics). The serum ALT test was performed as a service, in the Clinical Chemistry Section, Pathology Department in the Queens Medical Centre (QMC), Nottingham. 


\section{Section 2.2.10 Statistical analysis}

All data is represented as mean \pm standard deviation. Statistical significance was tested by Unpaired Student's t- test to compare between two data sets with two tailed distributions and a two sample equal variance. Dunnett's Multiple Comparison Test with a one way analysis of variance (ANOVA) was used for multiple comparisons. This was done with GraphPad prism 5.0 software (Inc, SanDiego, CA).

Statistical analysis for the RNA sequencing data was done with Student's t- test. Also the false discovery rate FDR was controlled (the false discovery rate is the proportion of false positives among the declared positive). The method used in CLC Genomics Workbench for controlling the FDR is that of Benjamini (Benjamini and Hochberg, 1995).

The inspection of the result of the statistical analysis was done with CLC Genomics Workbench software. 


\section{Chapter 3 Results}

\section{Section 3.1 Induction of hepatic DNA synthesis}

Mouse liver was initially chosen, as it might provide a better model than rat liver, because of the availability of knockout mice. However, previous studies on strains of mice dosed with peroxisome proliferators (Styles et al., 1990) showed that the induction of hepatic DNA synthesis in mice starts at 24 hours, while others (Al Kholaifi, 2008) and (Al Kholaifi et al., 2008) found that it did not start until after 3-4 days after dosing. It was therefore necessary to investigate when exactly the hepatic induction happens in different strains of mice.

\section{Section 3.1.1 Studies in mice}

\section{Section 3.1.1.1 Optimization of immunohistochemical technique}

The aim was to optimize the protocol for immunohistochemistry, specifically the secondary antibody concentrations and the dewaxing time for the histological process.

A set of liver sections were stained by immunohistochemical protocol as described in Section 2.2.3.2 using the Amersham mouse anti-BrdU labelling system to detect BrdU incorporation into DNA. Two antibodies were used, the primary antibody was anti-BrdU mouse monoclonal antibody (1:1000) and different concentrations of secondary antibody (blotting grade goat antirabbit LgG horseradish peroxidase conjugate) from Bio-rad company. The concentrations were 1:50, 1:100 and 1:500. Preliminary experiments revealed that the Bio-rad antibody gave a stronger signal than Sigma and Amersham antibodies (data not shown).

As shown in Figure 3.1 the immunoreactivity observed in slide A (1:50) is very strong but the noise is also very high. The other hand slide $\mathrm{C}(1: 500)$ has very low noise but BrdU is not de- 
tected in the hepatocytes. Slide B (1:100) shows a good signal-to-noise ratio, and this concentration of secondary was used for immunohistochemical staining for the rest of the experiments.

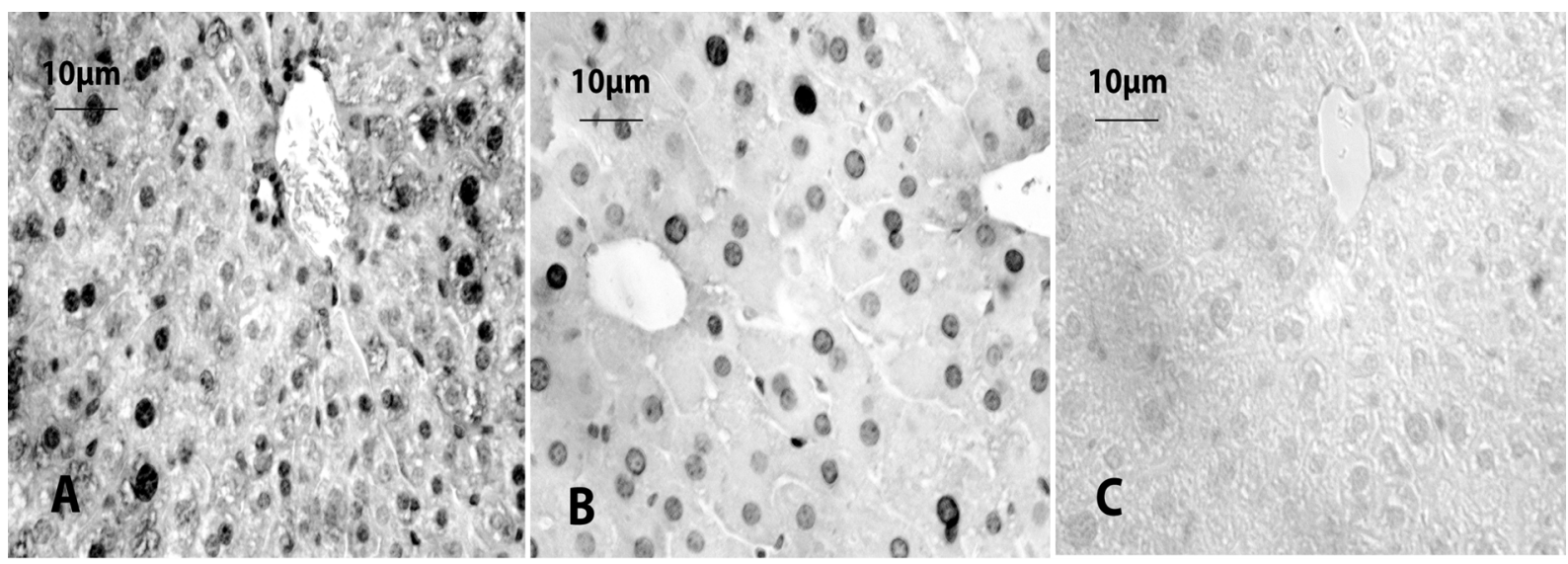

Figure 3.1 Optimization of secondary antibody concentration for immunohistochemistry. The figure shows slides stained with different concentrations of secondary antibody on $4.5 \mu \mathrm{m}$ thick liver sections from male $129 \mathrm{~S} 4 / \mathrm{SvJae}$ mice 9-10 weeks old. The animals were treated with $0.05 \mathrm{mg} / \mathrm{kg}$ BrdU with orange juice as their sole source of fluid, then gavaged with $100 \mathrm{mg} / \mathrm{kg}$ ciprofibrate for 4 days. The livers were then processed as in Section 2.2.3.1. The slides were stained according to immunohistochemical protocol using Amersham cell proliferation kit with different concentrations of secondary antibody from Bio-Rad. In slide A the concentration of the secondary antibody: buffer is 1:50, in slide B its 1:100 and in slide C 1:500. The slides are Harris haematoxylin counterstained. The photos were taken with a gray scale camera. The sections were examined under a light microscope at $400 \mathrm{x}$. The scale bar=10 $\mu \mathrm{m}$.

The next part was to optimize the dewaxing time. The existing protocol required leaving the slides in xylene pots for 2 X15 minutes.

After preparing the slides (Section 2.2.3.1) they were left at $40^{\circ} \mathrm{C}$ for 2 minutes (or until the wax started to melt) then in xylene for 5 minutes. Liver and gut sections stained with this protocol had a high signal-to-noise ratio when compared with the 30 minute dewaxing time (Figure 3.2). Gut sections were used for all the experiments as a positive control (Figure 3.2 E and F). The intestinal epithelium consistently undergoes cell renewal, so it will show if the BrdU is taken up by the animal or not, and the labelled nuclei have a high signal to noise ratio especially in the intestinal crypts where the proliferation and differentiation occurs (Wille et al., 2004). 
Similar optimization was undertaken to reduce the time needed for dehydration, hydration, and the time for primary antibody immunodetection of the incorporated BrdU (data not shown).

The overall time required for the immunohistochemical staining protocol was reduced from $\sim 6$ hours to $\sim 3.5$ hours. Thus, these data show that reducing the time for the immunohistochemical staining protocol does not necessarily decrease the quality of the slides. This revised procedure was used for the immunohistochemical staining for the rest of the experiments. 

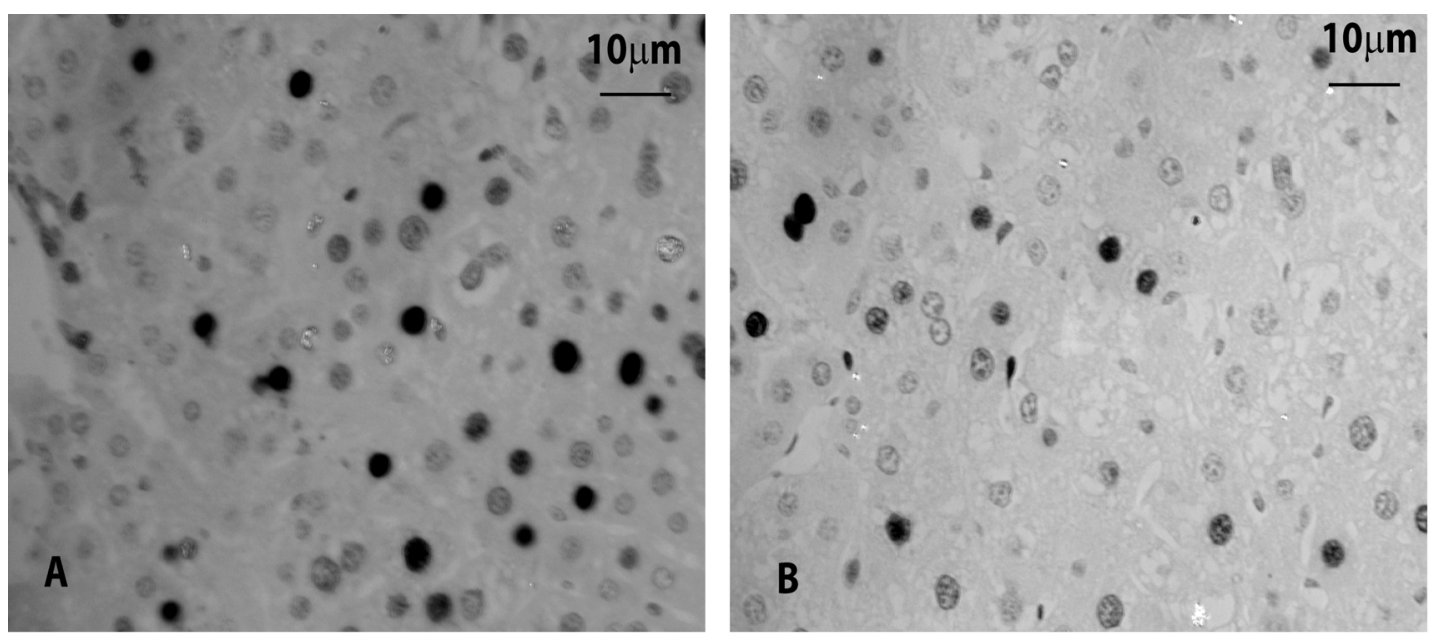

X400

liver
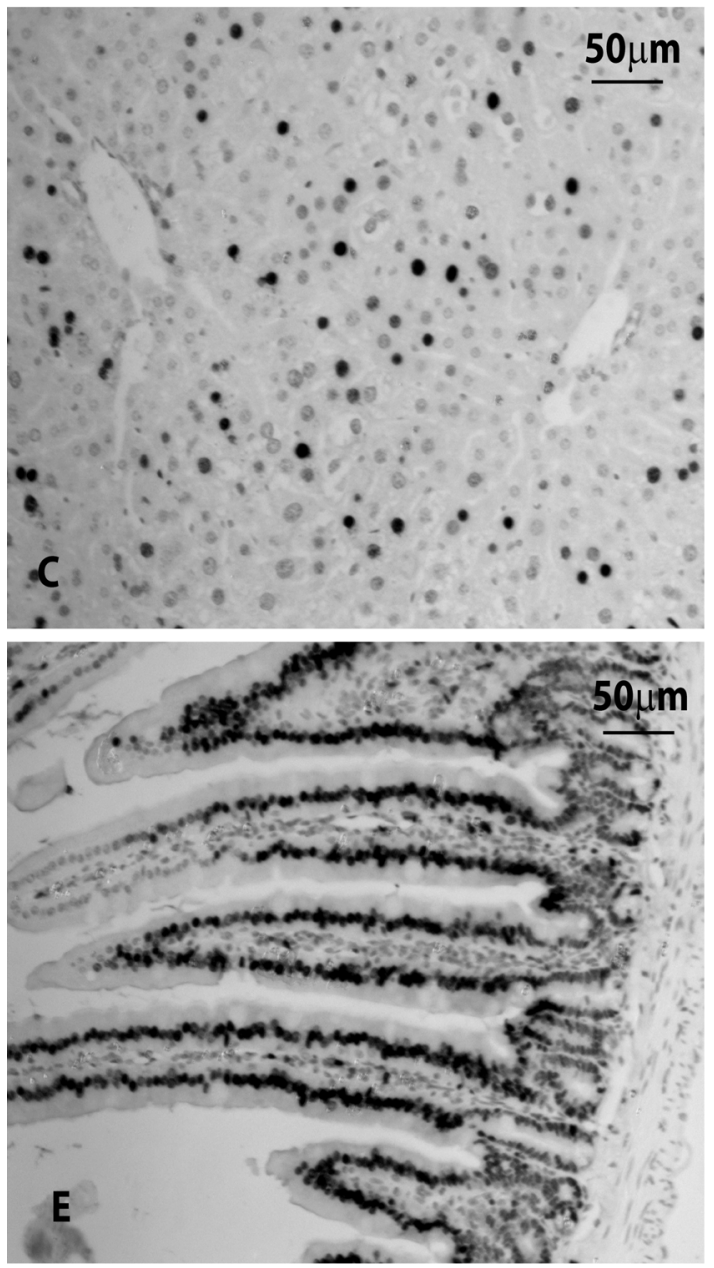

Dewax with heat
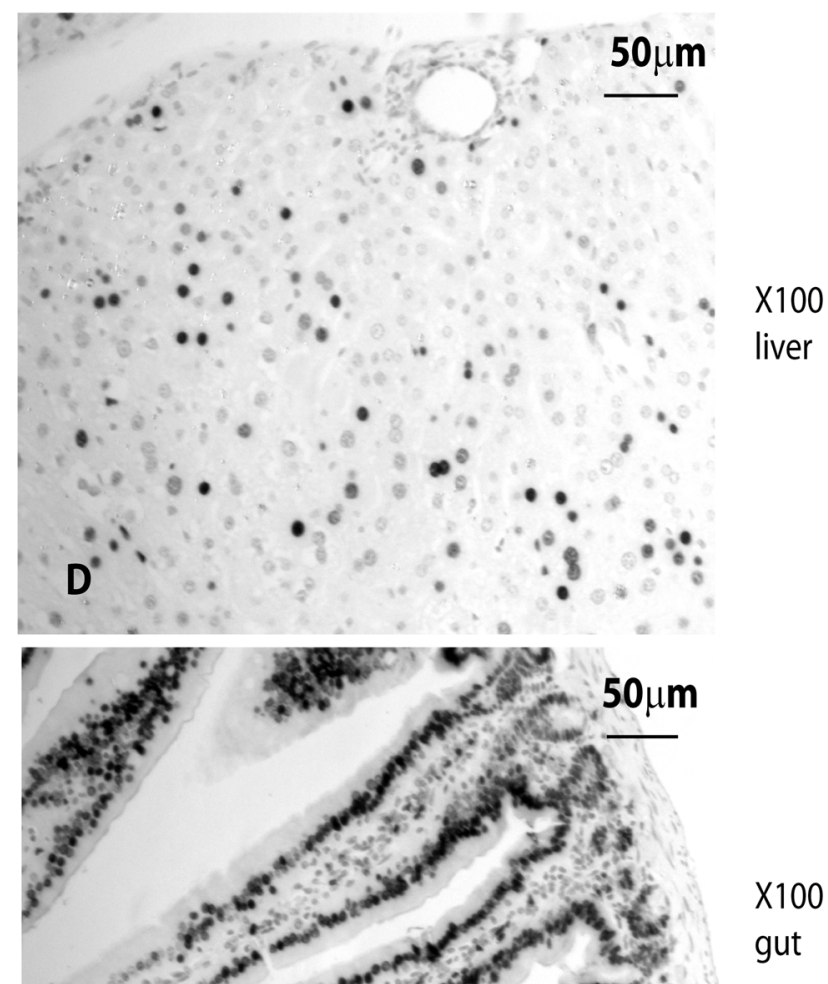

Figure 3.2 Optimizing of the dewaxing procedure. Liver and gut sections from male 129S4/SvJae mice. The animals were treated with BrdU for 5 days and gavaged with ciprofibrate for 4 days as shown in Figure 3.1. The slides were then stained with immunohistochemical protocol (Section 2.2.3.2). A,C (liver sections) and E (gut section) were dewaxed by putting the slides at $40^{\circ} \mathrm{C}$ for 2 minutes, then (while still hot) left in xylene for 5 minutes. B,D (liver sections) and F (gut section) were dewaxed by leaving in xylene for $2 \times 15$ minutes. Slides were counterstained with Harris haematoxylin. Sections were examined under a light microscope at $400 \mathrm{X}$. Photos were taken with a gray scale camera. For A and B the scale bar $=10 \mu \mathrm{m}$ for $\mathrm{C}, \mathrm{D}, \mathrm{E}$ and $\mathrm{F}$ the scale bar $=50 \mu \mathrm{m}$. 


\section{Section 3.1.1.2 Effect of ciprofibrate on hepatic DNA synthesis in mice}

Previous work (Al Kholaifi, 2008) in 129S4/SvJae mice showed that induction of hepatic DNA synthesis starts 3-4 days after dosing with peroxisome proliferators (methylclofenapate MCP), and this differs from work done by (Styles et al., 1990) on C57BL/6J mice who found that DNA synthesis starts as early as 24 hours after dosing with MCP.

This experiment was designed to study the time course of hepatic response to ciprofibrate in different strains of mice, to see whether the time course is distinct in different strains. Two inbred strains of mice were chosen $\mathrm{C} 57 \mathrm{BL} / 6 \mathrm{JCrl}$ which are resistant to liver carcinogenesis and DBA/ 2JCrl which are relatively susceptible to liver carcinogenesis (Diwan et al., 1986).

\section{Section 3.1.1.2.1 Effect of BrdU in DBA/2JCrl mice}

Before studying the effects of ciprofibrate on liver growth in DBA/2JCrl it was of importance to exclude any toxic effect from the BrdU -which is used as a DNA label- by studying the effect of BrdU on body weight (the effect on body weight acts as an indication for toxicity).

Male DBA/2JCrl mice were acclimatised for 7 days with $10 \%$ orange juice as their sole source of fluid, then dosed with $0.05 \%$ or $0.08 \%$ 5-Bromo-2'-deoxyuridine (BrdU) in $10 \%$ orange juice for 6 more days. The animals body weight was measured daily. The results established that, there was no significant difference between the weight of animals when beginning the experiment and at time of death (Student's un-paired t- test) (Figure 3.3).

From this result we can draw a conclusion that there was no gross toxic effect from the BrdU. 


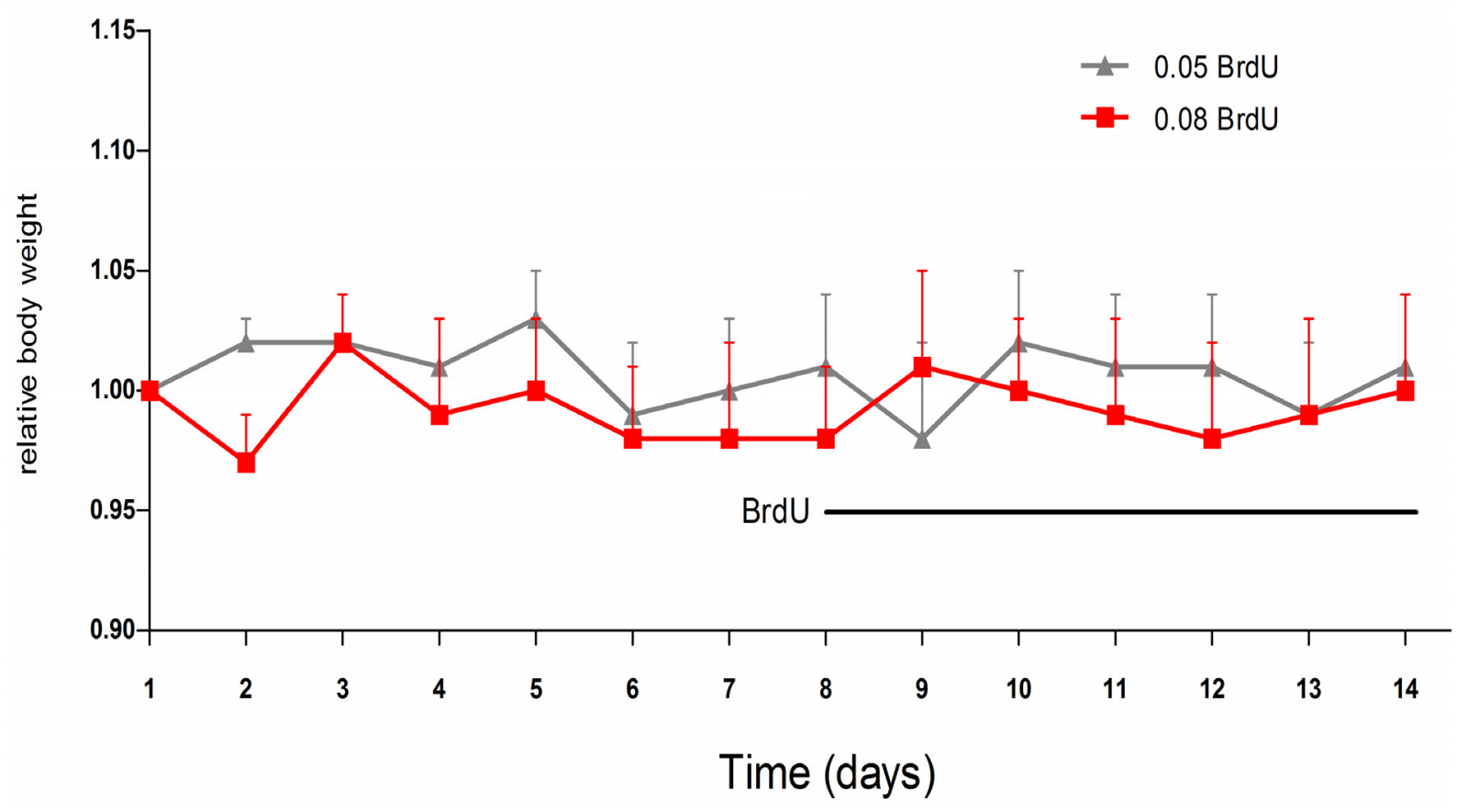

Figure 3.3 Effects of BrdU on body weight in DBA/2JCrl mice. Groups of (matching weight) male DBA/2JCrl mice aged 9-10 weeks old were acclimatised to $10 \%$ orange juice as their sole source of fluid, then were dosed with $0.08 \%$ (indicated by red squares) or $0.05 \%$ (indicated by gray triangles) BrdU in the orange juice for six more days (the beginning of the BrdU dosing is indicated by the horizontal black line). Mice body weights were measured on a daily basis for each individual mouse and relative body weight was calculated relative to the body weight for each individual mouse on day 0 . BrdU administration started on day 8, see Section 2.2.1.2. Data are the mean $\pm \mathrm{SD}$ of 6 animals. With un-paired Student's t- test there was no significant difference between the weight of animals when starting BrdU and at the time of death. $\mathrm{P}<0.05$. 


\section{Section 3.1.1.2.2 Effect of ciprofibrate in DBA/2JCrl mice}

The aim of this experiment was to test the effect of ciprofibrate on the induction of hepatic DNA synthesis in DBA/2JCrl mice.

Male DBA/2JCrl mice were acclimatized to $10 \%$ orange juice for 7 days then on day 8 they were given $0.08 \%$ BrdU with orange juice as their sole source of fluid. After one day of expo-

sure to BrdU, $100 \mathrm{mg} \mathrm{kg}^{-1} \mathrm{day}^{-1}$ ciprofibrate or corn oil (which is used as a vehicle) was administrated to the animals by gavage daily (see Section 2.2.1). Figure 3.4 shows the body weight relative to the body weight of each individual mouse on day 0 .

By day 3 it became apparent that one of the mice -in a control group- was preventing the rest of the group from eating by aggressive behavior, so the average body weight of the group came down on that day. The mouse was isolated, and the body weight of the group rose.

The results showed that the animals' body weight was significantly larger at the end of the experiment compared with the beginning of the experiment, (un-paired Student's t- test, $\mathrm{P}<0.05$ ).

This shows that the BrdU and the ciprofibrate have no toxic effect on the body weight of the DBA/2JCrl mice, and the growth of the animals was normal in comparison with the controls. 


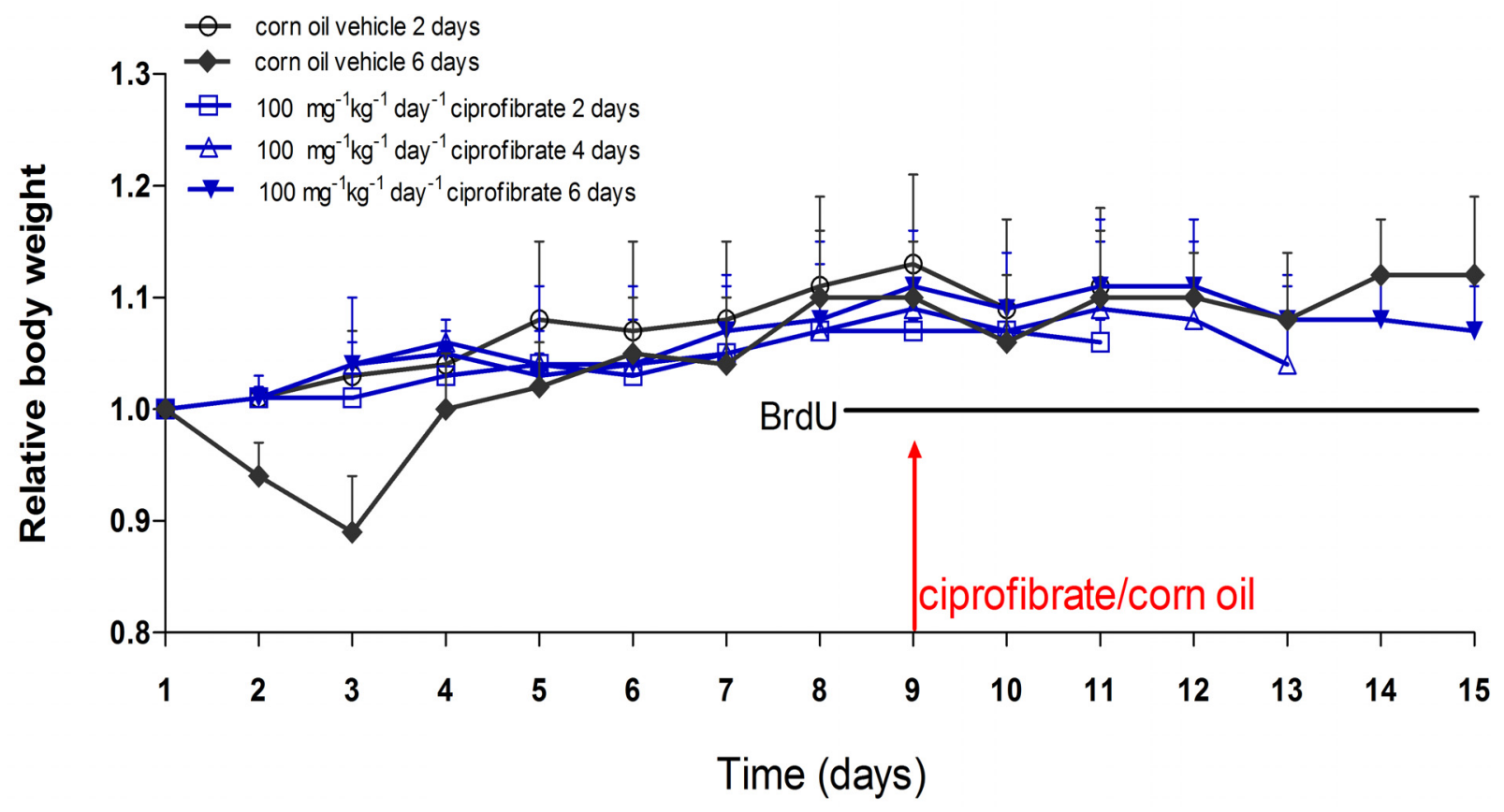

Figure 3.4 Effect of ciprofibrate on body weight in DBA/2JCrl mice. Groups of (matching weight) male DBA/JCrl mice aged 9-10 weeks old were acclimatised to $10 \%$ orange juice then given $0.08 \%$ BrdU with orange juice as their sole source of fluid. After one day of exposure to BrdU the animals were gavaged with corn oil (vehicle) or 100mg kg-1 day-1 ciprofibrate (Section 2.2.1), and then killed after 2, 4 and 6 days of exposure to the ciprofibrate/corn oil. Mice body weights were measured on a daily basis and body weight was calculated relative to the body weight for each individual mouse on day 0 . The BrdU administration started on day 8 and the red arrow indicates the beginning of administration of ciprofibrate/corn oil. Data are the mean $\pm \mathrm{SD}$ of 6 animals. Significant difference between the weight of animals when starting the experiment and at the time of death was done with unpaired t- test $(\mathrm{P}<0.05)$.

The effect of ciprofibrate on liver growth of $\mathrm{DBA} / 2 \mathrm{JCrl}$ mice is presented as relative liver weight and hepatic DNA synthesis (Figure 3.5).

Relative liver weight was significantly increased from $5.4 \pm 0.6 \%$ in the pooled control to $7.8 \pm 0.3 \%$ and $9.2 \pm 0.4 \%$ in the 4 and 6 days treated groups respectively, but there was no significant difference between the pooled control and the treated group for 2 days $(6.2 \pm 0.4 \%)$ with Dunnett's multiple comparison test $(\mathrm{P}<0.05)$ (Figure 3.5A).

The induction of hepatic DNA synthesis (the percentage of the BrdU-labelled hepatocytes to the total number of hepatocytes) was assessed as described in Section 2.2.4.1. The mice treated with 
ciprofibrate for 2 days had no significant difference from the pooled control with Dunnett's multiple comparison test. On the other hand, animals dosed for 4 and 6 days with ciprofibrate had a significantly larger hepatic labelling index indicating more hepatic DNA synthesis occurs than the pooled control, as shown in Figure 3.5B.

These data show that ciprofibrate increases liver weight and hepatic DNA labelling index after 4 days of dosing with ciprofibrate, but does not significantly affect the liver weight or hepatic DNA synthesis after two days' dosing. This result is substantively the same as previous findings in 129S4/SvJae mice (Al Kholaifi et al., 2008). In conclusion the ciprofibrate has no effect on body weight in $\mathrm{DBA} / 2 \mathrm{JCrl}$ mice treated with ciprofibrate up to 6 days. In liver growth studies, ciprofibrate did not show any significant increase on liver weight or on the induction of hepatic DNA synthesis after 2 days exposure to ciprofibrate but the statistically significant effect started after 4 days exposure. 

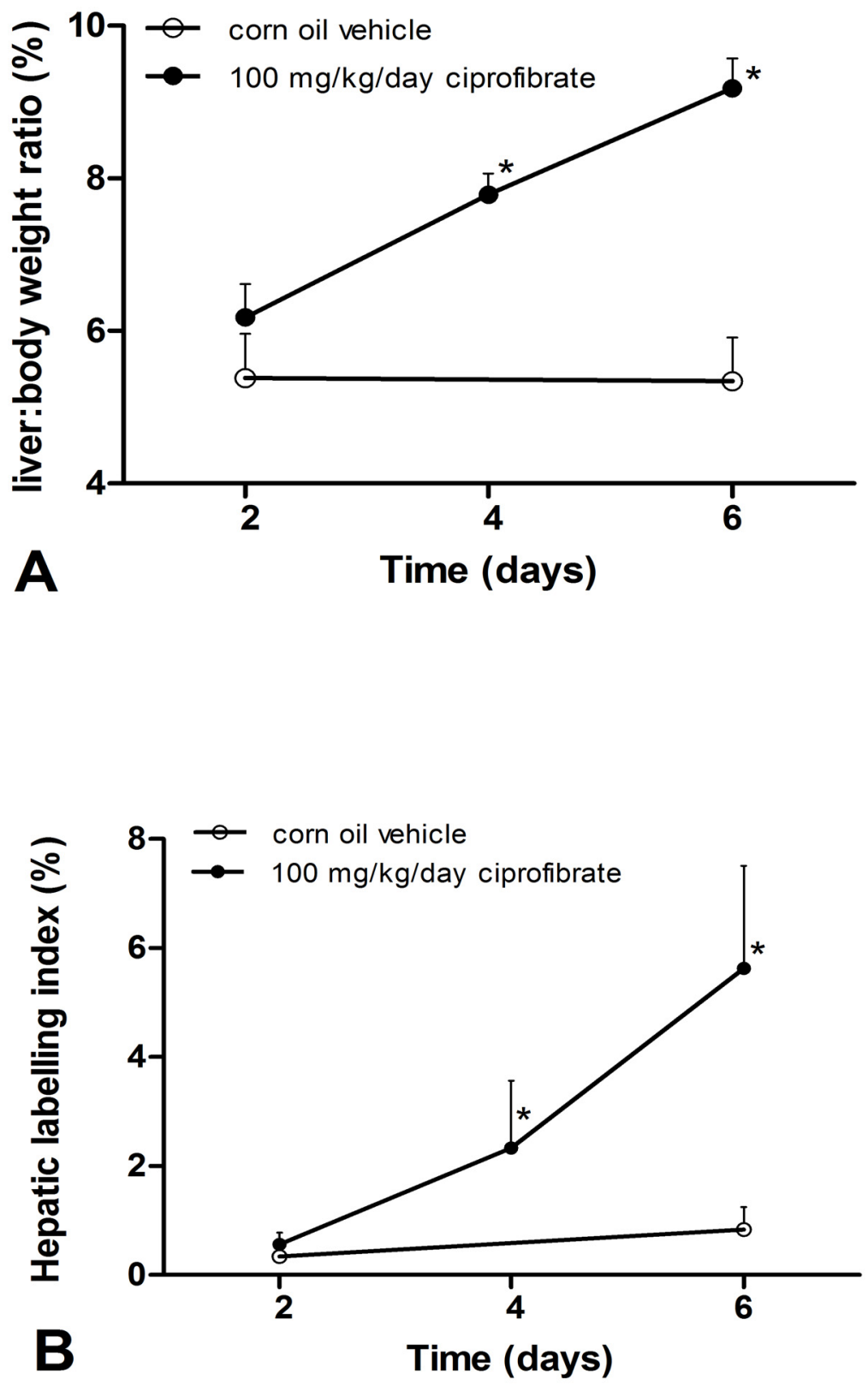

Figure 3.5 Effects of ciprofibrate on liver growth in DBA/2JCrl mice. Groups of six DBA/2JCrl male mice aged 9-10 weeks were dosed with $100 \mathrm{mg} \mathrm{kg}^{-1}$ day $^{-1}$ ciprofibrate or corn oil vehicle as described in Figure 3.4, and killed on days 2, 4 and 6. The left panel A shows liver to body weight ratio, the right panel $\mathbf{B}$ shows hepatic labelling index (the percentage of the labelled hepatocytes to the total number of hepatocytes). Comparision with Dunnett's multiple comparison test is against the pooled control group and statistically significant difference is indicated by an asterisk $(\mathrm{p}<0.05)$. 


\section{Section 3.1.1.3 Effect of ciprofibrate in C57BL/6JCrl mice}

Styles (Styles et al., 1990) has previously shown that methylclofenapate induced DNA synthesis at 24 hours after administration in the $\mathrm{C} 57 \mathrm{BL} / \mathrm{J}$ mouse strain. This experiment was designed to test the effect of ciprofibrate on the induction of hepatic DNA synthesis in C57BL/6JCrl mice by using immunohistochemical detection of BrdU.

Male $\mathrm{C} 57 \mathrm{BL} / 6 \mathrm{JCrl}$ mice were acclimatised to $10 \%$ orange juice for 7 days as their sole source of fluid, and then on day 8 they were given $0.08 \% \mathrm{BrdU}$ with orange juice. After one day of exposure to BrdU the mice were gavaged daily with ciprofibrate or corn oil/vehicle (as a control) (Section 2.2.1). Figure 3.6 shows the time course effects of $0.08 \%$ BrdU and $100 \mathrm{mg} \mathrm{kg}^{-1}$ day $^{-1}$ ciprofibrate in male $\mathrm{C} 57 \mathrm{BL} / 6 \mathrm{JCrl}$ mice on body weight relative to body weight of each individual mouse on day 0 . There was no significant difference between the animals body weight when starting the experiment and at time of death for all treated and control groups. Statistics was done with un-paired Student's t- test $(\mathrm{P}<0.05)$.

From these results it can be indicated that there was no toxic effect from BrdU or the ciprofibrate on $\mathrm{C} 57 \mathrm{BL} / 6 \mathrm{JCrl}$ male mice as measured by body weight loss. 


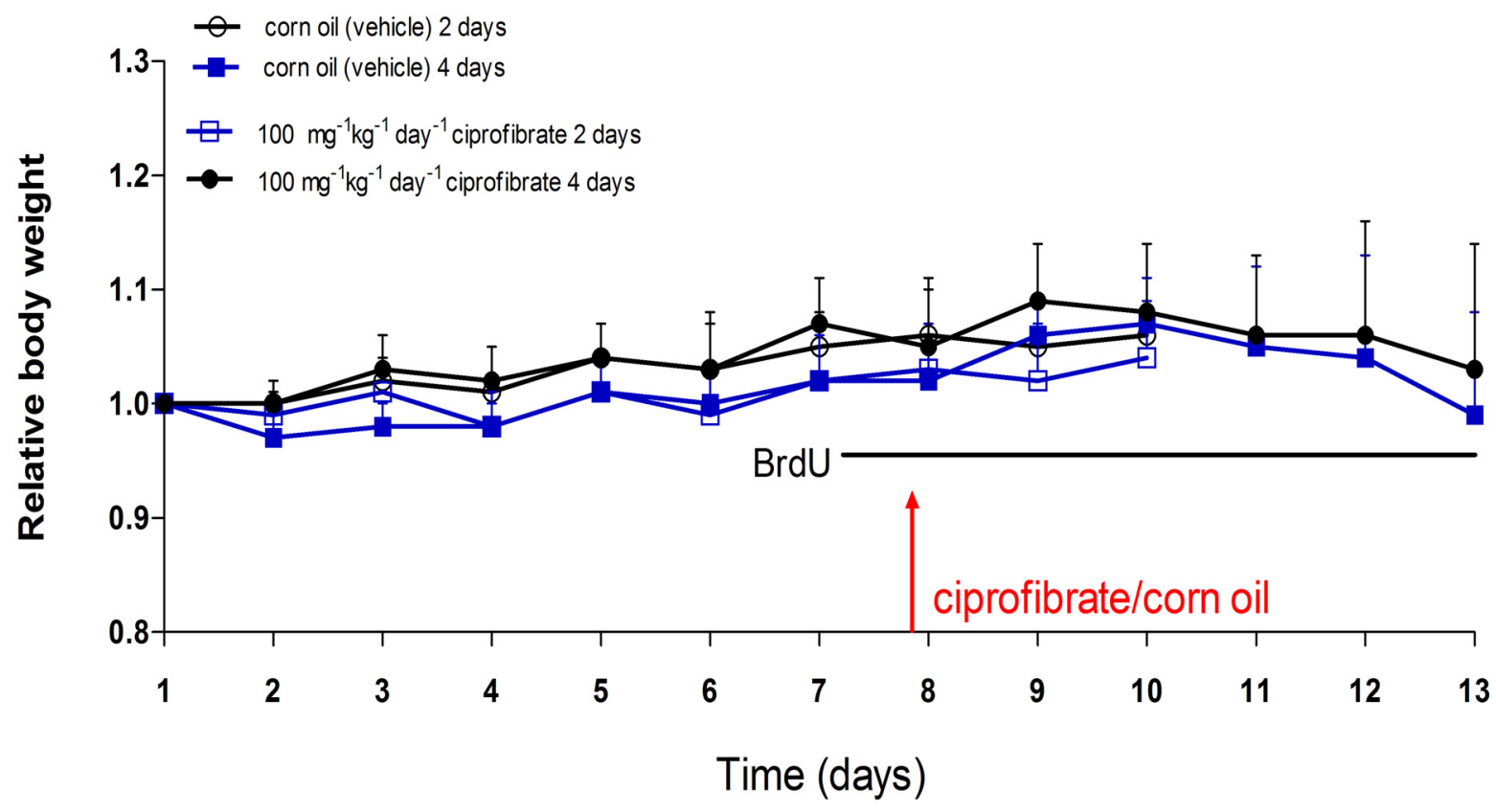

Figure 3.6 Effects of ciprofibrate on body weight in C57BL/6JCrl mice. Male C57BL/6JCrl mice aged 9-10 weeks were dosed with BrdU in the drinking orange juice and gavaged with corn oil (vehicle) or $100 \mathrm{mg} / \mathrm{kg} / \mathrm{day}$ ciprofibrate, then killed after 2 and 4 days (Section 2.2.1). Mice body weights were measured on a daily basis and relative body weight was calculated relative to the body weight for each individual mouse on day 0. The BrdU administration started on day 7 and the red arrow indicates the beginning of ciprofibrate/corn oil administration. Data are the mean $\pm \mathrm{SD}$ from 6 animals. There was no significant difference between the weight of the animals at the beginning of the experiment and at the time of death with students t- test $(\mathrm{P}<0.05)$.

There was significant increases in the relative liver weights, from $4.8 \pm 0.7 \%$ in the pooled control to $6.1 \pm 1.2 \%$ and $8.3 \pm 0.4 \%$ for the groups treated for 2 and 4 days respectively (Figure 3.7A). There was no significant difference in the hepatic labelling index between the pooled control and the group treated for 2 days with ciprofibrate, while the labelling index was significantly higher after 4 days of dosing with ciprofibrate, as shown in Figure 3.7B (statistics were done with Dunnett's multiple comparison test, $\mathrm{P}<0.05)$.

From this we can establish that ciprofibrate has no toxic effect on body weight of C57BL/6JCrl male mice, while it increases liver weight significantly over control after 2 days' treatment. The hepatic labelling index did not show any difference after 2 days' exposure to ciprofibrate but was significantly different after 4 days' exposure. 

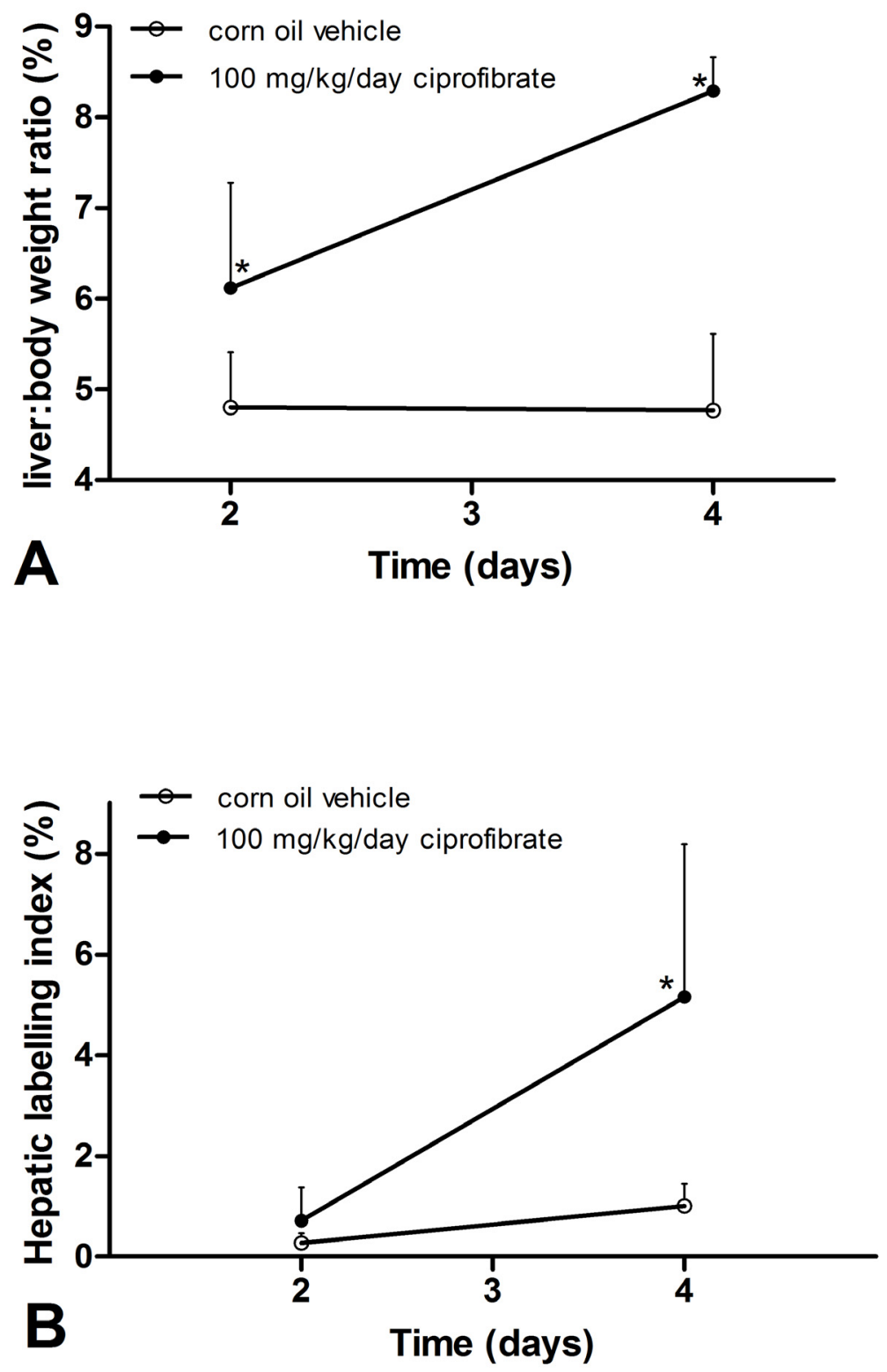

Figure 3.7 Effects of ciprofibrate on liver growth in C57BL/6Jcrl mice. Male C57BL/6JCrl mice aged 9-10 weeks were dosed as described earlier in Figure 3.6 with $100 \mathrm{mg} / \mathrm{kg} /$ day ciprofibrate or corn oil, then killed on days 2 and 4. In A Liver to body weight ratio was determined as described in Section 2.2.2. B shows hepatic labelling index (the percentage of the labelled hepatocytes to the total number of hepatocytes). Data shown are mean $\pm \operatorname{SD}(n=6)$. Statistically significant difference from the control group is indicated by an asterisk, with Dunnett's multiple comparison test. $(\mathrm{P}<0.05)$. 


\section{Section 3.1.2 Studies in F-344/NHsd rats}

The demonstration that the induction of hepatic DNA synthesis with ciprofibrate in mice starts after 3-4 days makes it quite hard to determine when the induction is triggered (there is a window of $\sim 2-3$ days where the signal could have happened). Therefore, rat liver was used to determine if species difference would affect the timing of hepatic DNA synthesis.

\section{Section 3.1.2.1 Effect of ciprofibrate on hepatic DNA synthesis in F-344/NHsd rats}

\section{Section 3.1.2.1.1 Time course of ciprofibrate effect in F-344/NHsd rats}

To identify the genes responsible for the hepatic DNA synthesis, it was necessary to identify when the induction of hepatic DNA synthesis peaks in F-344/NHsd rats dosed with ciprofibrate.

Groups of male F-344/NHsd rats were dosed with $50 \mathrm{mg} \mathrm{kg}^{-1}$ day ${ }^{-1}$ ciprofibrate or corn oil (vehicle) as a control, then killed after 16, 20, 24, 30, 36 and 48 hours. Two hours before killing they were dosed intraperitoneally (IP) with $100 \mathrm{mg} \mathrm{kg}^{-1}$ BrdU. This experiment was done on two different occasions. On the first the time points were 24, 30, 36 and 48 hours, and on the second the time points were 16, 20, 24 and 30 hours. both with controls at the latest and earliest time points. The animals were from the same source, and were the same strain and age (Section

\subsection{1).}

Liver weight to body weight ratio is shown in Figure 3.8. Analysis with Dunnett's multiple comparison test showed a significant difference between the liver weight to body weight ratio for the pooled control $3.6 \pm 0.4 \%$ and treated groups at the time points 24 hours $(4.0 \pm 0.2 \%), 30$ hours $(4.2 \pm 0.3 \%), 36$ hours $(4.1 \pm 0.3 \%)$, and 48 hours $(4.8 \pm 0.2 \%)$ while for the groups killed at the time points 16 and 20 hours there was no significant difference $(\mathrm{P}<0.05)$.

As a further test of whether the statistical significance found at the time points $24,30,36$ and 
48 hours is spurious the treated and control groups were compared against each other at each time point. It was found that the groups killed at the time points 24 and 30 hours had no significant difference when compared with the control groups at the same time point ( 24 hours treated against 24 hours control, 30 hours treated against 30 hours control). The group treated for 36 hours (there was no control at that time point) was compared against the control groups killed after 30 and 48 hours and there was no significant difference.

This indicates that the difference at the time points 24,30 and 36 hours are not biologically significant and the significance that appeared when comparing the treated with the pooled control was spurious. On the other hand, the group killed after 48 hours had a significant difference from the control at the same time point (Student's t- test, $\mathrm{P}<0.05$ ).

From this result it is established that the liver weight to body weight ratio of F-344NH/sd rats treated with $50 \mathrm{mg} \mathrm{kg}^{-1}$ ciprofibrate is biologically and significantly high at 48 hours, while there is no biological difference for the other time points. 


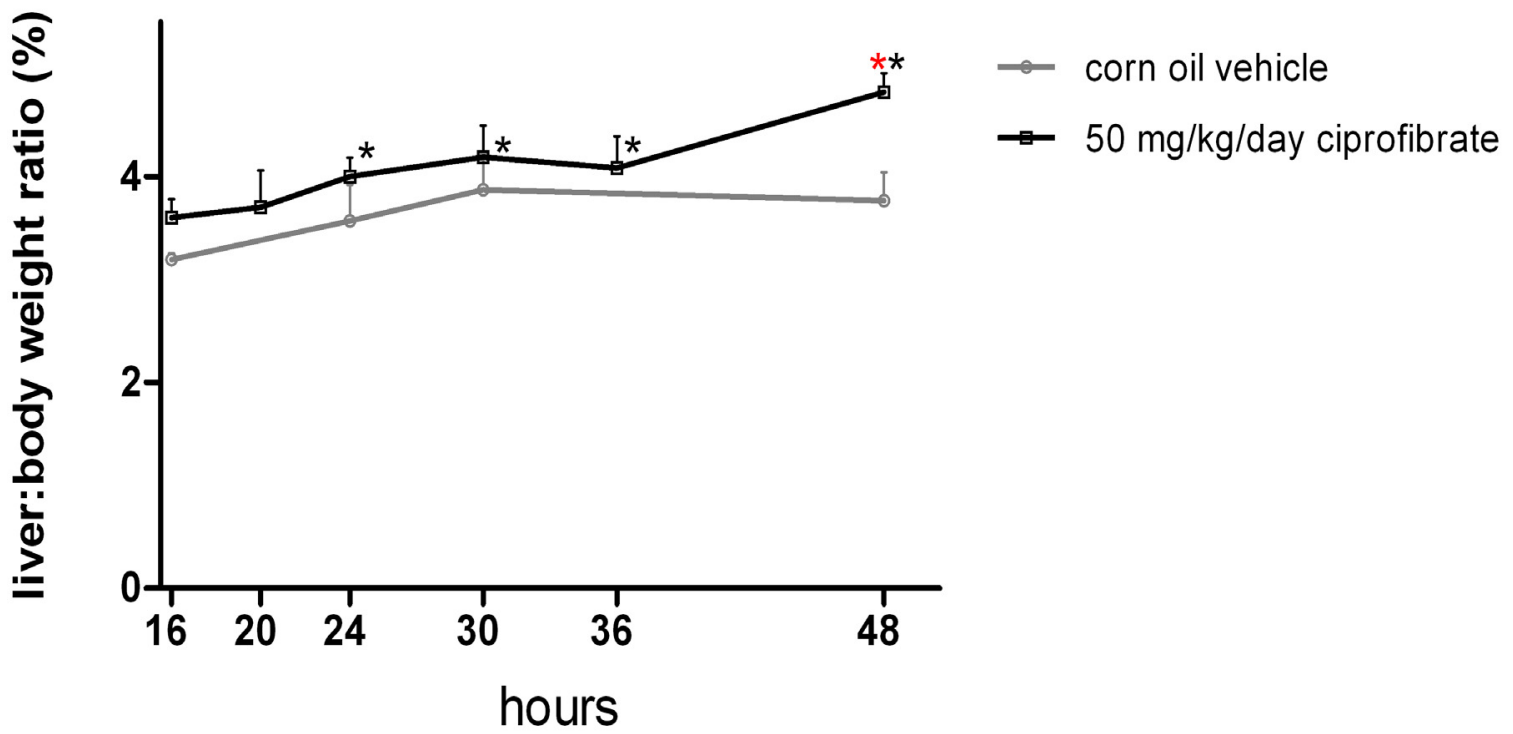

Figure 3.8 Time course of effects of ciprofibrate on liver weight in F-344/NHsd rats. Groups of male F-344/NHsd rats aged 14-15 weeks were dosed with $50 \mathrm{mg} / \mathrm{kg} /$ day ciprofibrate or corn oil (vehicle), then killed at the time points indicated, BrdU labelling was intraperitoneally (IP) two hours before killing (Section 2.2). Each point represents the mean $\pm \mathrm{SD}$ of 6 animals, and is representative of results obtained from two experiments. Statistically significant difference from the pooled control groups is indicated by a black asterisk with Dunett's multiple comparison test $(\mathrm{P}<0.05)$. Statistically significant difference from individual controls is indicated by a red asterisk with Student's t- test $(\mathrm{P}<0.05)$.

Figure 3.9 shows the time course of the hepatic labelling index in male F-344/NHsd rats. The results showed a significant difference in the hepatic DNA synthesis between the pooled control groups $(0.3 \pm 0.4 \%)$ and the group dosed with ciprofibrate at time 0 hour and killed after 24 hours $(3.8 \pm 1.8 \%), 30$ hours $(2.1 \pm 1.1 \%)$ and 48 hours $(4.3 \pm 1.4 \%)$, while the groups dosed for 16 hours $(0.2 \pm 0.1 \%), 20$ hours $(0.3 \pm 0.2 \%)$ and the 30 hours $(2.1 \pm 1.1 \%)$ had no significant difference from the pooled control group and fell to background levels. This gave two peaks; the first at 24 hours and the second at 48 hours.

From these results it can be established that for F-344NHsd rats treated with $50 \mathrm{mg} \mathrm{kg}^{-1} \mathrm{day}^{-1}$ ciprofibrate the labelling index starts low then goes up at 24 hours and comes back down to background level, then up again at 48 hours. This could be as a response to the second dose that 
is given after the first 24 hours and this would suggest the pattern that a peak develops after 24

hours from dosing. However, this needs to be investigated further.

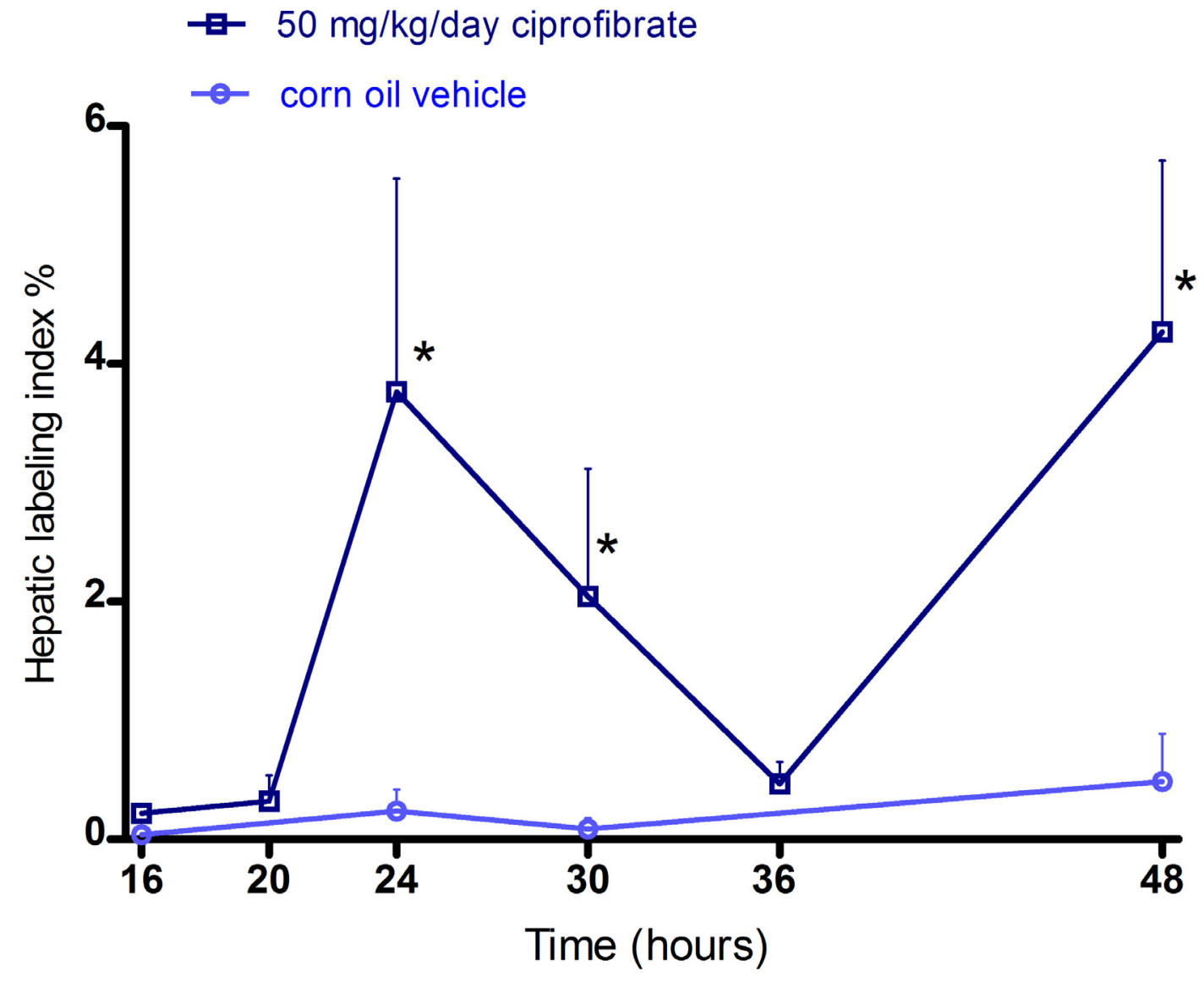

Figure 3.9 Time course of effects of ciprofibrate on hepatic DNA synthesis in F-344/NHsd rats. Groups of male rats were dosed with $50 \mathrm{mg} \mathrm{kg}^{-1} \mathrm{day}^{-1}$ ciprofibrate or corn oil (vehicle) as described in Figure 3.8. Immunohistochemical protocol and counting as in Section 2.2.3.2 and Section 2.2.4.1. All data are expressed as mean $\pm \mathrm{SD}$ of 6 animals, and are representative of results obtained from two independent experiments (in one experiment the time points were at 24,30,36 and 48 hour and in the other experiment the time points were 16, 20, 24 and 30 hours). Statistically significant difference from the pooled control group is indicated by an asterisk ( $\mathrm{P}$ $<0.05)$ (Statistic done with Dunett's multiple comparison test). 


\section{Section 3.1.2.1.2 Dose response for ciprofibrate in rats}

The objective of this experiment was to determine the optimal dose of ciprofibrate in F-344/ NHsd rats that give the highest hepatic replicative DNA synthesis.

Al Kholaifi (Al Kholaifi, 2008) demonstrated that the induction of DNA synthesis in hepatocytes in F-344NHsd rats starts after 1 day of dosing with ciprofibrate, using a chronic BrdU labelling system where the hepatic DNA synthesis was acclimated in the liver. Also, Section 3.1.2.1.1 showed that the hepatic replicative DNA synthesis in F-344/NHsd rats is at the highest after 24 hours. Therefore the hepatic labelling index was determined after 24 hours.

Groups of six animals were gavaged with different concentrations of ciprofibrate dissolved in corn oil [0, 50, 100, 200, $300 \mathrm{mg} \mathrm{kg}^{-1}$ body weight] and killed after 24 hours. Two hours before killing, the animals were given $100 \mathrm{mg} \mathrm{kg}^{-1} \mathrm{BrdU}$ intraperitoneally (IP) (Section 2.2). The liver weight ratios increased significantly at the doses 100 and $200 \mathrm{mg} \mathrm{kg}^{-1}$ ciprofibrate to $4.1 \pm 0.3 \%$ and $4.6 \pm 0.5 \%$ in comparison with the control group $3.5 \pm 0.2 \%$. The liver weight was not increased at the dose $300 \mathrm{mg} \mathrm{kg}^{-1}$ to $(3.9 \pm 0.08 \%)$ as illustrated in Figure 3.10A.

A similar pattern was found in the labelling index data. At 24 hours after dosing the labelling index for rats dosed with 50,100 and $200 \mathrm{mg} / \mathrm{kg}$ body weight ciprofibrate were $6.3 \pm 2.6 \%$, $6.0 \pm 3.0 \%$ and $5.9 \pm 1.0 \%$ respectively, in comparison to the control (vehicle) that was $0.2 \pm 0.2 \%$ and all three doses were significantly higher than the control with Dunnett's multiple comparison test. As for the group dosed with $300 \mathrm{mg} \mathrm{kg}^{-1}$ ciprofibrate the induction went down to $0.76 \pm 0.64 \%$ (Figure $3.10 \mathrm{~B}$ ). This reduced response of the $300 \mathrm{mg} \mathrm{kg}^{-1}$ implies that it is a result of a toxic reaction and is suppressing the liver growth.

These results establish that the doses 50,100 and $200 \mathrm{mg} \mathrm{kg}^{-1}$ body weight give a similar label- 
ling index. The concentration $50 \mathrm{mg} \mathrm{kg}^{-1}$ was selected for the assay as a optimal dose of ciprofibrate for F-344NHsd rats, because it was the smallest amount of compound and it gave a reasonably good labelling index.
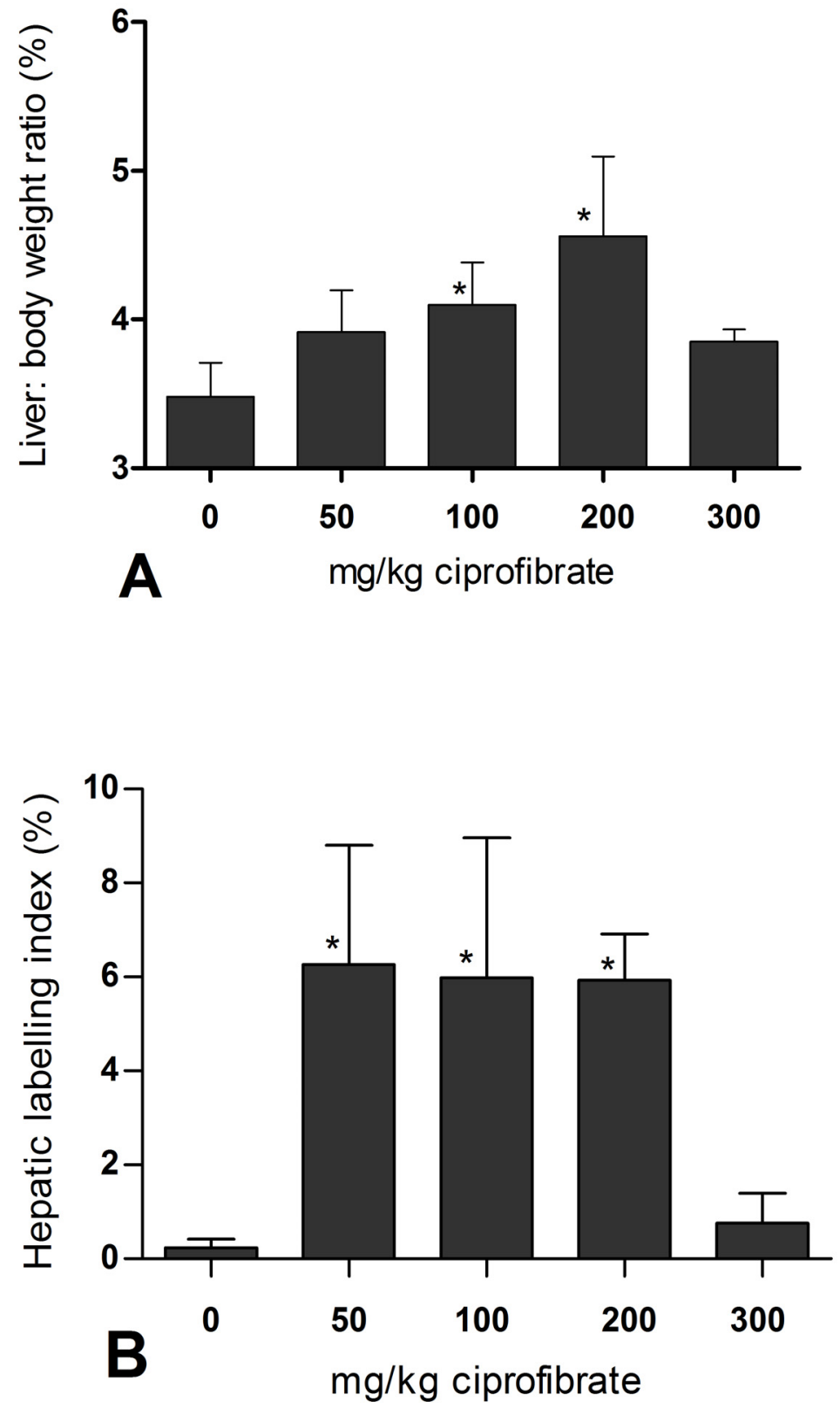

Figure 3.10 Dose response of ciprofibrate on liver growth in F-344/NHsd rats. Groups of (matching weight) male F344/NHsd rats aged 14-15 weeks were dosed at time 0 hour, with the indicated dose of vehicle or ciprofibrate, then at 22 hours they were dosed intraperitoneally with BrdU and killed at 24 hours (Section 2.2.1). A shows liver-to-body weight ratios. B shows labelling index (determined by immunocytochemical localization of BrdU see Section 2.2.4.1). All data are expressed as mean $\pm \mathrm{SD}$ of 6 animals, Statistically significant difference from the control group is indicated by an asterisk with Dunett's multiple comparison test $(\mathrm{P}<0.05)$. 
Serum from the F-344HN/sd rats was assayed for alanine aminotransferase (ALT), as a test for hepatic damage (see Section 2.2.5.1). ALT level in the F-344HN/sd rat groups treated with ciprofibrate appeared higher at 100 and $200 \mathrm{mg} \mathrm{kg}^{-1}$ than in the control group, but this was not a significant difference with Dunnett's multiple comparison test $(\mathrm{P}<0.05)$ (Figure 3.11).

In conclusion the doses 50,100, 200 and $300 \mathrm{mg} \mathrm{kg}^{-1}$ ciprofibrate have no significant toxic effect on the liver tissue.

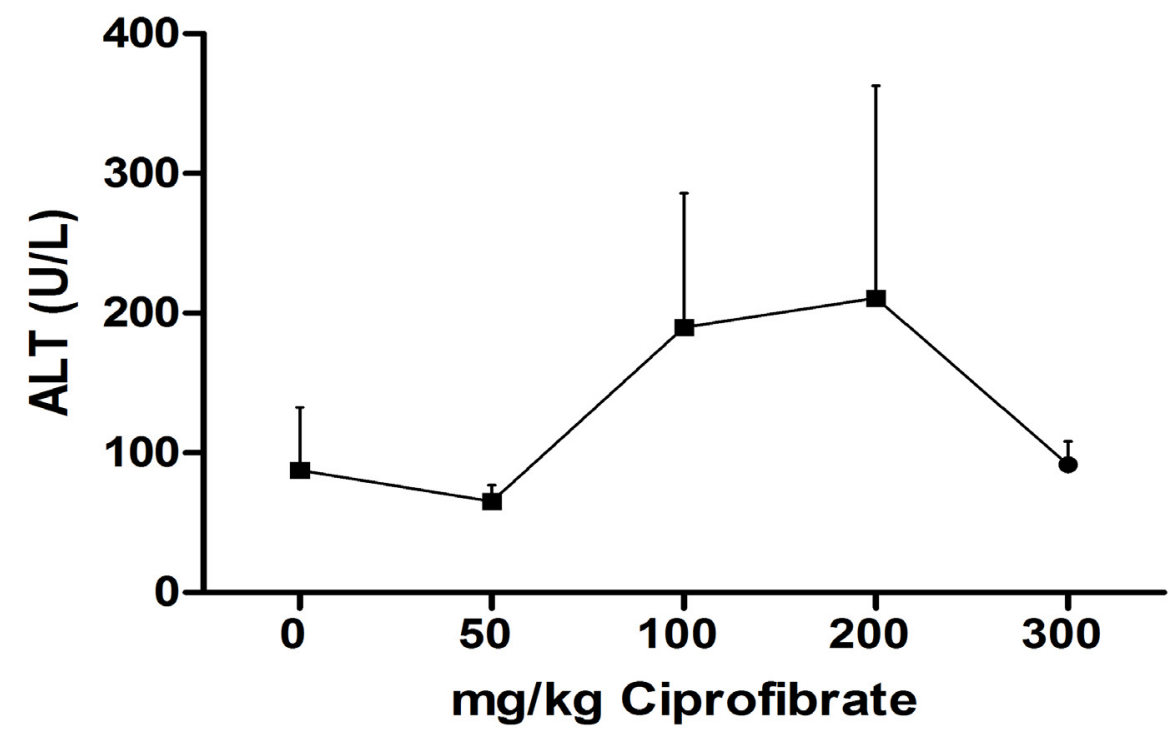

Figure 3.11 Effect of ciprofibrate on serum aminotransferase (ALT). Groups of (matching weight) male F-344NHsd rats aged 14-15 weeks were dosed with the indicated dose of vehicle or ciprofibrate, and killed after 24 hours as described earlier in Figure 3.10. Serum aminotransferase (ALT) activity was determined using Vitros ALT slides (Ortho-Clinical Diagnostics). The procedure was performed in the clinical chemistry department, Queens Medical Center (QMC) at Nottingham (see Section 2.2.5.1). Data are the mean \pm SD of 6 animals. Statistics done with Dunnett's multiple comparison test $(\mathrm{P}<0.05)$. 


\section{Section 3.1.2.2 Effect of pregnane $X$ receptor (PXR) ligands on hepatic DNA synthesis in F-344NHsd rats}

It is known from the literature that the pregnane $\mathrm{X}$ receptor (PXR) ligands strongly enhance hepatic DNA synthesis of male and female Wistar rats (Schulte-Hermann et al., 1980). This experiment was designed to test the effects of the pregnane $\mathrm{X}$ receptor (PXR) ligands on liver growth and hepatic DNA synthesis of F-344/NHsd rats. The PXR ligands are used as a positive control, with a different mechanism for induction of hepatic DNA synthesis.

\section{Section 3.1.2.2.1 PXR ligands in male and female rats: Pilot study}

The aim of this experiment was to choose between cyproterone acetate CPA, and pregnenolone16 $\alpha$-carbonitrile PCN, based on their effects on hepatic DNA synthesis in male or female rats.

Two male and female F-344/NHsd rats were dosed with $100 \mathrm{mg} \mathrm{kg}^{-1}$ (the doses were chosen from the literature (Topinka et al., 2004b) and (Guzelian et al., 2006)) CPA or PCN or corn oil (vehicle), then killed after 24 hours. Two hours before killing they were dosed intraperitoneally with $100 \mathrm{mg} \mathrm{kg}^{-1} \mathrm{BrdU}$. Liver weight to body weight ratio is shown in Figure 3.12A.

There was an increase in liver to body weight ratio for the male group treated with CPA $4.8 \%$ and $4.5 \%$ in comparison with the control at $3.9 \%$ and $3.7 \%$, the liver weight ratio in male rats treated with PCN is $3.9 \%$ and $4.0 \%$ and for the females treated with CPA it was $3.9 \%$ and $3.6 \%$. The labelling index for the male group treated with CPA was $6.7 \%$ and $7.6 \%$ and for the group treated with PCN was $6.6 \%$ and $6.3 \%$ in comparison with the control group $0.5 \%$ and $0.3 \%$ but the female group was extremely high at $49.2 \%$ and $53.3 \%$ (Figure $3.12 \mathrm{~B}$ ).

From these results it was decided to use CPA on males as the CPA gave the highest liver to body weight ratio and a high labelling index for the males (in comparison with male F-344/NHsd rats 
treated with ciprofibrate the value was $3.8 \pm 1.8 \%$ as shown in Figure 3.9$)$, and the CPA was easier to dissolve in the corn oil than the PCN, which could only be used as a suspension. Although the female group gave a very high labelling index it was not a properly controlled experiment since there was no female control group, and so there were two variables (dose and sex) when compared with male controls. It would be interesting to investigate the effects of CPA on liver growth in female rats.
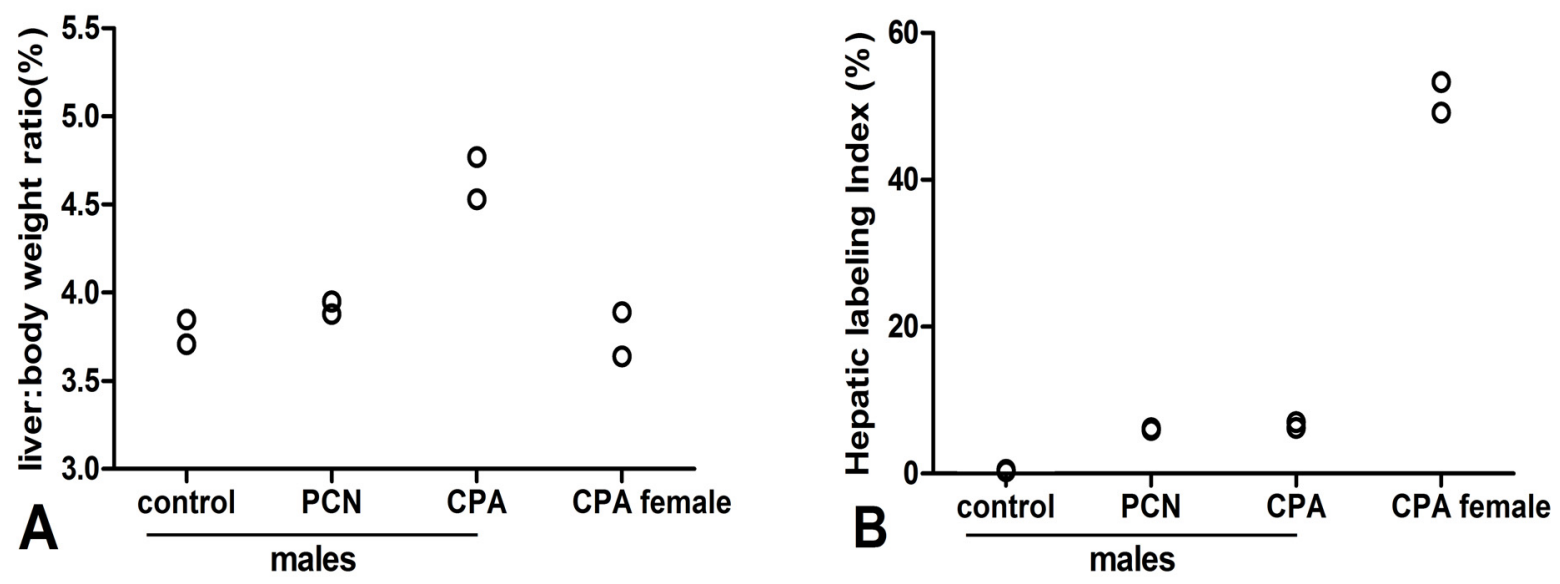

Figure 3.12 Effects of PXR ligands in male and female rats: pilot study . Three groups of male F-344/ NHsd rats aged 14-15 weeks were treated with 100mg kg-1 PCN, CPA or corn oil and a group of females were treated with $100 \mathrm{mg} \mathrm{kg}^{-1} \mathrm{CPA}$. They were then killed after 24 hours. Two hours before killing they were dosed intraperitoneally with BrdU (Section 2.2). A shows liver weight to body weight ratio. B shows the hepatic DNA synthesis (as determined by immunocytochemical localization of $\operatorname{BrdU})(n=2)$. 


\section{Section 3.1.2.2.2 Effects of CPA in male F-344/NHsd rats}

The aim of this experiment was to investigate more rigorously the effects of CPA on liver growth and DNA synthesis in male F-344NHsd rats.

Rats were dosed with $100 \mathrm{mg} \mathrm{kg}^{-1} \mathrm{CPA}$ or corn oil (vehicle), then killed after 24 hours. Two hours before killing, they were dosed intraperitoneally with BrdU. The liver was then processed and stained by immunohistochemical protocol (Section 2.2.3). Liver weight to body weight ratio is shown in Figure 3.13A.

Analysis with Student's t- test showed no significant difference between liver weight to body weight ratio for the control $(3.8 \pm 0.5 \%)$ and treated group $(4.2 \pm 0.3 \%)$. There was a significant difference in the labelling index between the control group $(0.1 \pm 0.1 \%)$ and the group dosed with CPA $(7.8 \pm 2.9 \%)$ Figure 3.13B.

This result revealed that CPA in male F-344NHsd rats had no significant effect on liver weight to body weight ratio after 24 hours, but has a significant effect on the labelling index. 


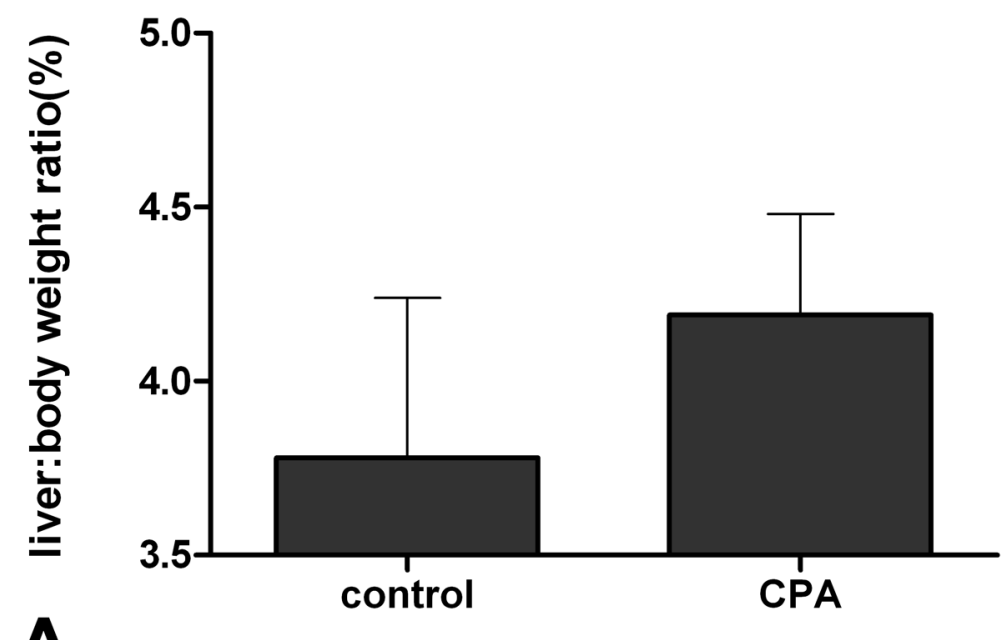

A

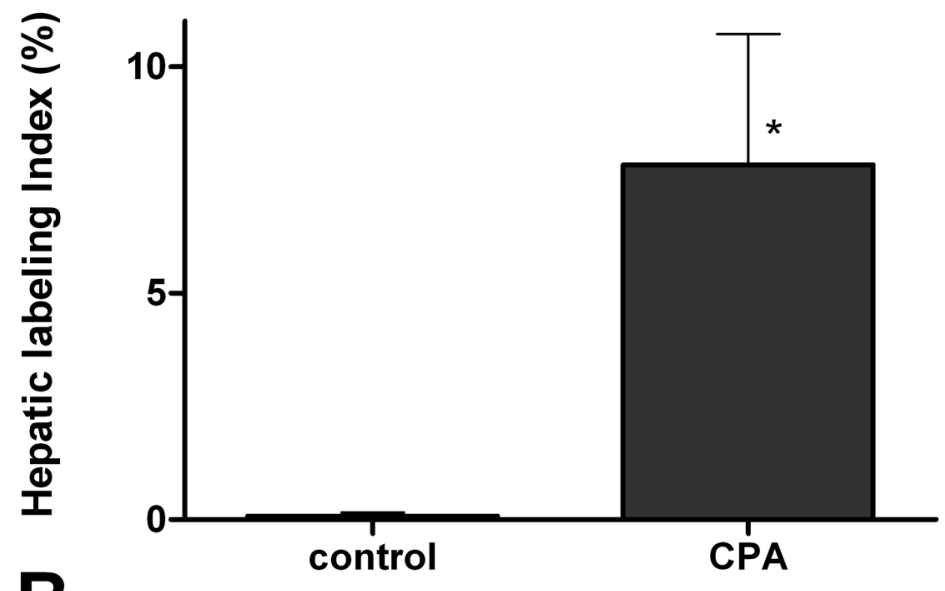

Figure 3.13 Effects of CPA on liver growth in F-344NHsd rats. Male F-344NHsd rats aged 14-15 weeks, were dosed with $100 \mathrm{mg} \mathrm{kg}^{-1} \mathrm{CPA}$ or corn oil (vehicle), and killed after 24 hours (Section 2.2.1). A shows liver weight to body weight ratio. B shows the immunocytochemical localization of BrdU (as in Section 2.2.4.1) for the control and $\mathrm{CPA}$ treated group. All data are expressed as mean $\pm \mathrm{SD}$ of 6 animals, Statistically significant difference from the control group is indicated by an asterisk, Statistics done was with Student's t- test $(\mathrm{P}<0.05)$. 


\section{Section 3.2 Zonal distribution of DNA synthesis in liver}

The experiments below were designed to establish if the replicating hepatocytes are found mostly in the periportal or centrilobular regions for F-344NHsd rats and different strains of mice dosed with different treatments. Table 3.1 shows the strains of mouse or rat, which had been studied dosed with different treatments. It should be noted that some of the slides used were taken from (Al Kholaifi, 2008). Al Kholaifi dosed the animals and stained the slides with immunohistochemical technique. I then read the slides and determined the zonation of the BrdUlabelled hepatic nuclei in the periportal and perivenous zones as described in Section 2.2.4.2:

Table 3.1 Zonal distribution study.

\begin{tabular}{l|l|l|l|l}
\hline No & Receptor & \multicolumn{1}{|c|}{ Treatment } & \multicolumn{1}{|c}{ Species/strain } & \multicolumn{1}{|c}{ Reference } \\
\hline $\mathbf{1}$ & PPAR $\alpha$ & ciprofibrate & F-344NHsd rats & Section 3.1.2.1 \\
\hline $\mathbf{2}$ & PXR & CPA & F-344NHsd rats & Section 3.1.2.2.2 \\
\hline $\mathbf{3}$ & CAR & TCPOBOP & 129S4/SvJae mice & (Al Kholaifi, 2008) \\
\hline $\mathbf{4}$ & PPAR $\alpha$ & ciprofibrate & 129S4/SvJae mice & (Al Kholaifi, 2008) \\
\hline $\mathbf{5}$ & PPAR $\alpha$ & ciprofibrate & 129S4/SvJae PPAR $\alpha$-null mice & (Al Kholaifi, 2008) \\
\hline $\mathbf{6}$ & PPAR $\alpha$ & ciprofibrate & C57BL/6JCrl mice & Section 3.1.1.3 \\
\hline $\mathbf{7}$ & PPAR $\alpha$ & ciprofibrate & DBA/2JCrl mice & Section 3.1.1.2.2 \\
\hline $\mathbf{8}$ & PPAR $\alpha$ & MCP & 129S4/SvJae mice & (Al Kholaifi, 2008) \\
\hline $\mathbf{9}$ & PPAR $\alpha$ & MCP & AP mice & (Al Kholaifi, 2008) \\
\hline
\end{tabular}




\section{Section 3.2.1 Zonation studies in F-344/NHsd rats \\ Section 3.2.1.1 Induction of hepatic DNA synthesis by PPAR $\alpha$ ligands (ciprofibrate)}

This experiment was designed to determine the lobular distribution of hepatocellular proliferation in liver of F-344/NHsd rats treated with ciprofibrate. Figure 3.14 shows immunohistochemical localization of hepatic DNA synthesis in F-344/NHsd rats treated with $50 \mathrm{mg} \mathrm{kg}^{-1}$ ciprofibrate for 4 days (Section 2.2.4.1).

Figure 3.14A and B show central veins (CV) on the right hand side. Hepatocytes closest to the (CV) are not BrdU-stained. In Figure 3.14C a portal space (PS) is on the right hand side and the stained hepatic nuclei are mostly gathered around the (PS). Closer examination of immunohistochemical-stained slides on higher power (X400) show a clear distribution of labelled nuclei Figure 3.15. The hepatocytes around the central vein show little labelling as shown in Figure 3.15A and B. While several labelled cells gather around the portal space (Figure 3.15C and D) upon visual inspection.

From this it established that the zonal distribution of hepatic replication in male F-344/NHsd rats dosed with ciprofibrate is not randomly distributed and was more situated at the periportal zone than at the central veins, and this is consistent with the results established from (Barrass et al., 1993) on Sprague-Dawley rats treated with MCP and clofibric acid. 

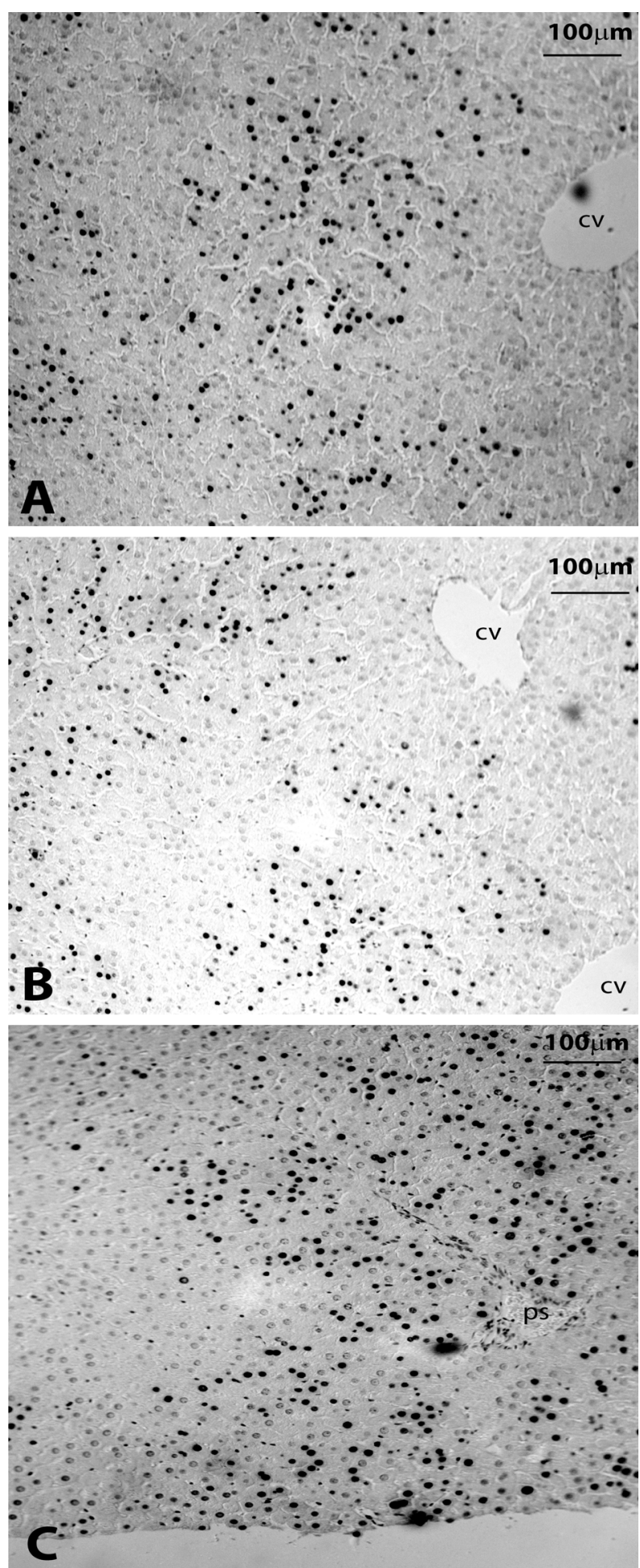

Figure 3.14 Zonal distribution of hepatic replication in F-344/NHsd rats. Immunohistochemical sections of livers from male Fisher 344/NHsd rats aged 14-15 weeks and treated with BrdU in orange juice as described in Section 2.2.1.2. Then gavaged with $50 \mathrm{mg} \mathrm{kg}^{-1} \mathrm{day}^{-1}$ ciprofibrate for 4 days. A and B show central veins (CV); hepatocytes in the area closest to the $\mathrm{CV}$ are not BrdU stained. $\mathrm{C}$ shows a portal space (PS) on the right hand side, and the hepatocytes are mostly stained in the area around the PS. Sections were examined under a light microscope at X40. Photos were taken with a gray scale camera. The scale bar $=100 \mu \mathrm{m}$. Slides were from (Al Kholaifi, 2008) (personal communication). 

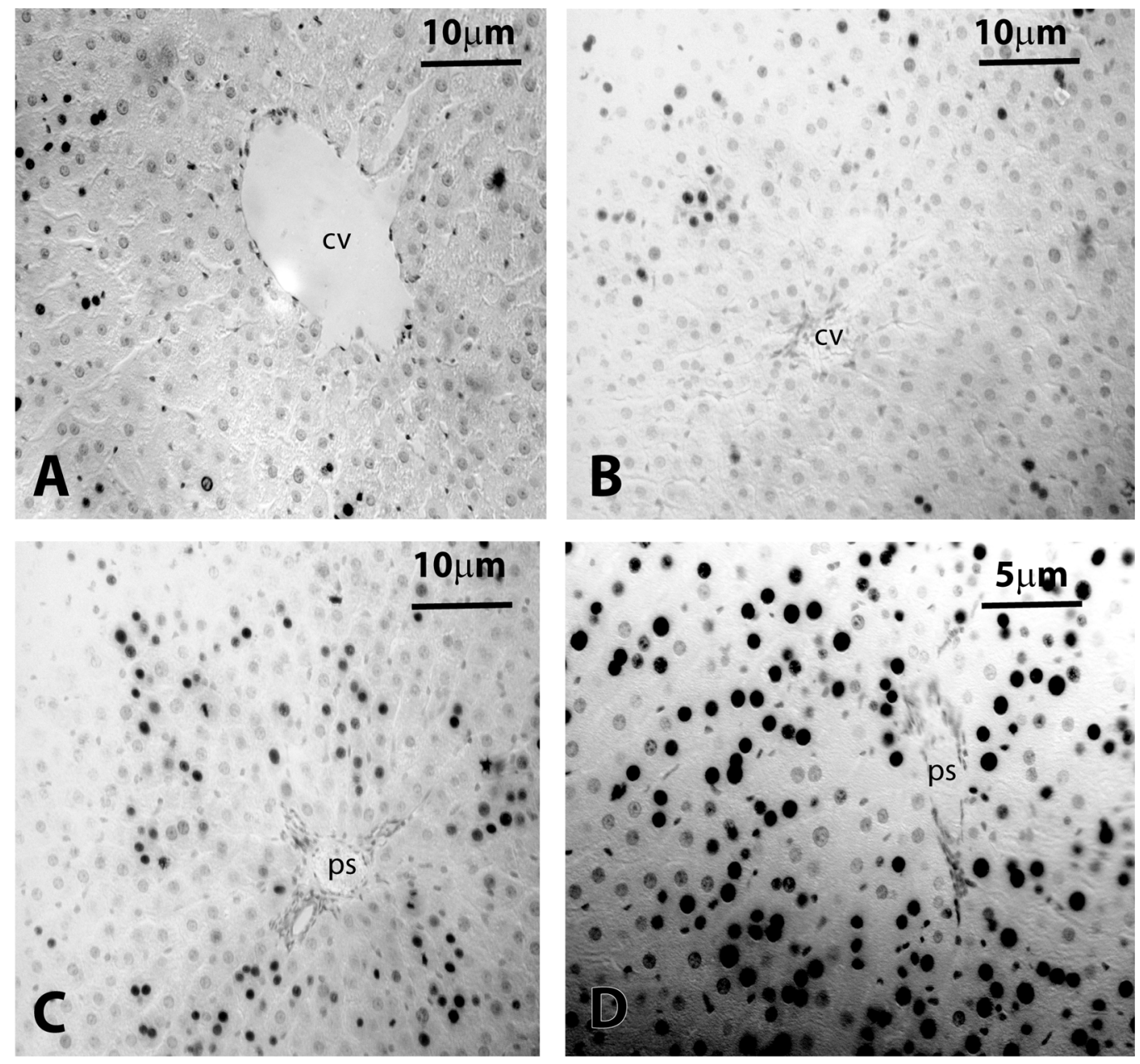

Figure 3.15 Central vein and portal space of liver sections in F-344/NHsd rats. Liver sections in male Fisher 344/NHSd rats aged 14-15 weeks and treated with BrdU. Then gavaged with $50 \mathrm{mg}$ kg-1 day-1 ciprofibrate for 4 days Section 2.2.1. A and B panels show central veins CV and the area around it. C and D show portal spaces PS and the area around it. Sections were examined under a light microscope at X400. Photos were taken with a gray scale camera. In $\mathrm{A}, \mathrm{B}$ and $\mathrm{C}$ the scale bar $=10 \mu \mathrm{m}$. In $\mathrm{D}$ the scale bar $=5 \mu \mathrm{m}$. Slides were a kind gift from (Al Kholaifi et al., 2008) (personal communication).

The distribution of labelled hepatocytes was determined in periportal and centrilobular zones, as described in Section 2.2.4.2. There was a significant difference between the incidence of labelled hepatocytes between centrilobular and periportal regions in the control (Figure 3.16A) and treated animals according to Student's t- test $(\mathrm{p}<0.05)$ (Figure 3.16B), with the number of labelled cells being larger in the periportal region by 4,12 and 20 fold in the rats treated with ciprofibrate for 1, 2 and 4 days. 
These results show the hepatic zonal distribution of F-344/NHsd rats liver is periportal rather

than centilobular, and that treatment with ciprofibrate emphasises this result.
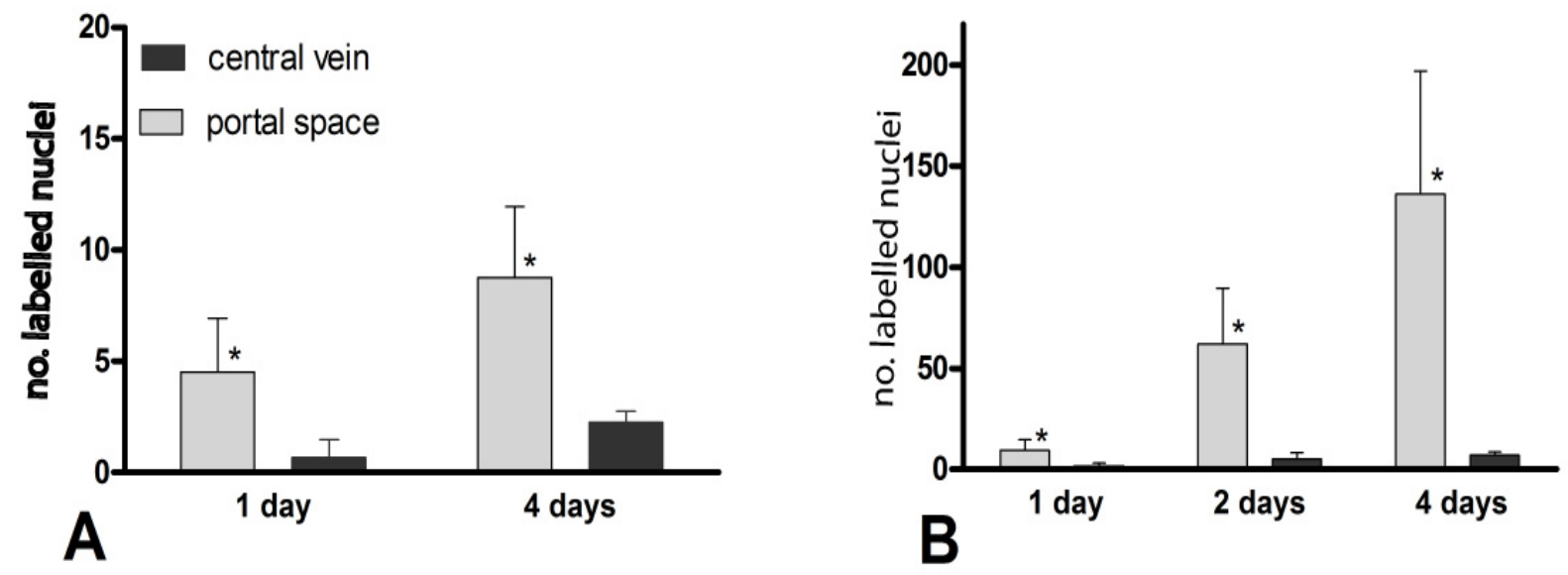

Figure 3.16 Hepatic zonal distribution of cell proliferation in rats treated with ciprofibrate. Male F-344/NHsd rats aged 14-15 weeks and treated with BrdU (Section 2.2.1). Visualization of BrdU-stained hepatocyte nuclei was undertaken using the method of (Barrass et al., 1993) described in Section 2.2.4.2. The number of cells labelled in periportal (PS- gray bars) or centrilobular (CV-black bars) is shown in $\mathbf{A}$ for vehicle control rats orally treated with corn oil for 1 and 4 days (the number of animals is $6 \& 4$ respectively) and in $\mathbf{B}$ animals treated orally with $50 \mathrm{mg} \mathrm{kg}^{-1}$ day $^{-1}$ ciprofibrate for 1,2 and 4 days (the number of animals is 6,5 and 5 respectively). The bars show the mean value, and the error bars depict one standard deviation. Statistically significant difference from the control group is indicated by an asterisk. Statistics done was with Student's t- test $(\mathrm{P}<0.05)$. 


\section{Section 3.2.1.2 Induction of DNA synthesis by the PXR ligand cyproterone acetate (CPA)}

The aim of this experiment was to determine lobular distribution of hepatocellular proliferation in liver of F-344/NHsd rats treated with cyproterone acetate (CPA).

Male F-344/NHsd rats were treated with $100 \mathrm{mg} \mathrm{kg}^{-1} \mathrm{CPA}$ as described in Section 3.1.2.2.2. Immunohistochemical staining was applied on the liver tissue and the distribution of labelled hepatocytes was determined in periportal and centrilobular zones, as described in Section 2.2.4.2.

There was a significant difference in the number of labelled hepatocytes between centrilobular and periportal regions as in Figure 3.17 with the number of labelled cells being larger in the periportal region, comparable to the results that were achieved from the previous experiments on F344/NHsd rats treated with corn oil or ciprofibrate (the statistic used was Student's t- test, $\mathrm{P}<0.05$, the number of animals is 6).

From these results we can establish that the hepatic zonal distribution of F-344/NHsd rats liver has a periportal distribution when treated with CPA, and this is consistent with the result found by (Barrass et al., 1993) and the results found earlier for ciprofibrate (Section 3.2.1.1). 


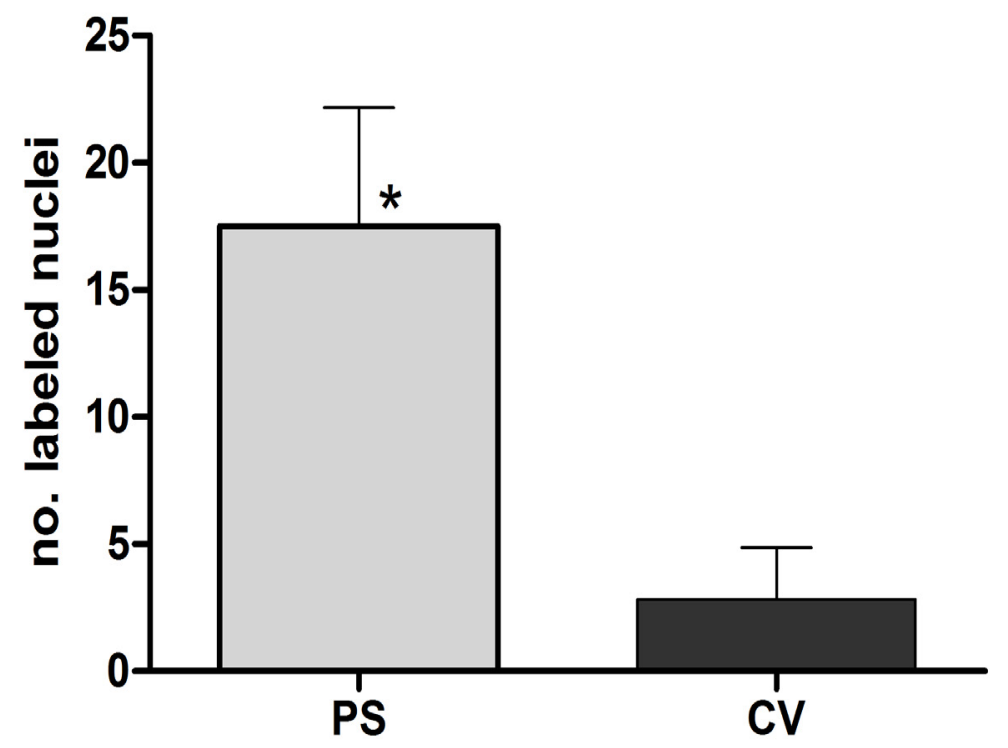

Figure 3.17 Hepatic zonal distribution of cell proliferation in rats treated with CPA. Male F$344 \mathrm{NHsd}$ rats aged 14-15 weeks old were dosed with $100 \mathrm{mg} \mathrm{kg}^{-1} \mathrm{CPA}$ and killed after 24 hours. Two hours before killing they were dosed intraperitoneally with BrdU. Immunohistochemical protocol and visualization of BrdUstained hepatocyte nuclei was undertaken as described in Section 2.2.4.2. The figure shows the number of cells labelled in the periportal region (PS- gray bar) or in the centrilobular region (CV- black bar) (the number of amimals is 6). Statistically significant difference is indicated by an asterisk with Student's t- test between the PS and the CV(P $<0.05)$. 


\section{Section 3.2.2 Zonation studies in mouse}

These experiments were designed to establish if the replicating hepatocytes are found mostly in the periportal or centrilobular regions for different strains of mice dosed with different hapatic inducing chemicals.

\section{Section 3.2.2.1 Induction of hepatic DNA synthesis by the constitutive androstane receptor (CAR) agonist TCPOBOP in 129S4/SvJae mice}

This experiment was designed to determine the lobular distribution of hepatocellular proliferation in male and female 129S4/SvJae wild type mice, treated with a CAR agonist TCPOBOP, as a hepatocyte mitogen, to determine if this caused differential lobular zonation of hepatocyte labelling. 129S4/SvJae mice were dosed with BrdU added to the orange juice as their sole source of fluid. After at least one day on BrdU, the animals were dosed by gavage with $3 \mathrm{mg}$ $\mathrm{kg}^{-1}$ TCPOBOP and killed after 2 days. Immunohistochemical staining was done on the liver tissue as in Section 2.2.3.2. Visualization of BrdU-stained hepatocyte nuclei was undertaken, essentially as described in Section 2.2.4.1.

Figure 3.18 shows immunohistochemical localization of hepatic DNA synthesis in liver sections. Figure 3.18A and B show central veins on the right hand side and portal spaces on the left. Figure 3.18C shows a CV in the middle top of the liver section. All the slides when examined on low power did not show any zonation for the BrdU-stained hepatocytes and the labelled hepatocytes were evenly distributed in the liver lobule. Examination of mice slides on higher power (X400) corroborated a homogeneous distribution of labelled nuclei. The BrdU-stained hepatocytes around the central veins and the portal spaces do not show any preferential lobular distribution as shown in Figure 3.19A, B, C and D. From this it established that the zonal distribution of hepatic replication in male 129S4/SvJae mice has no discernible difference between the periportal and the perivenous zones. 

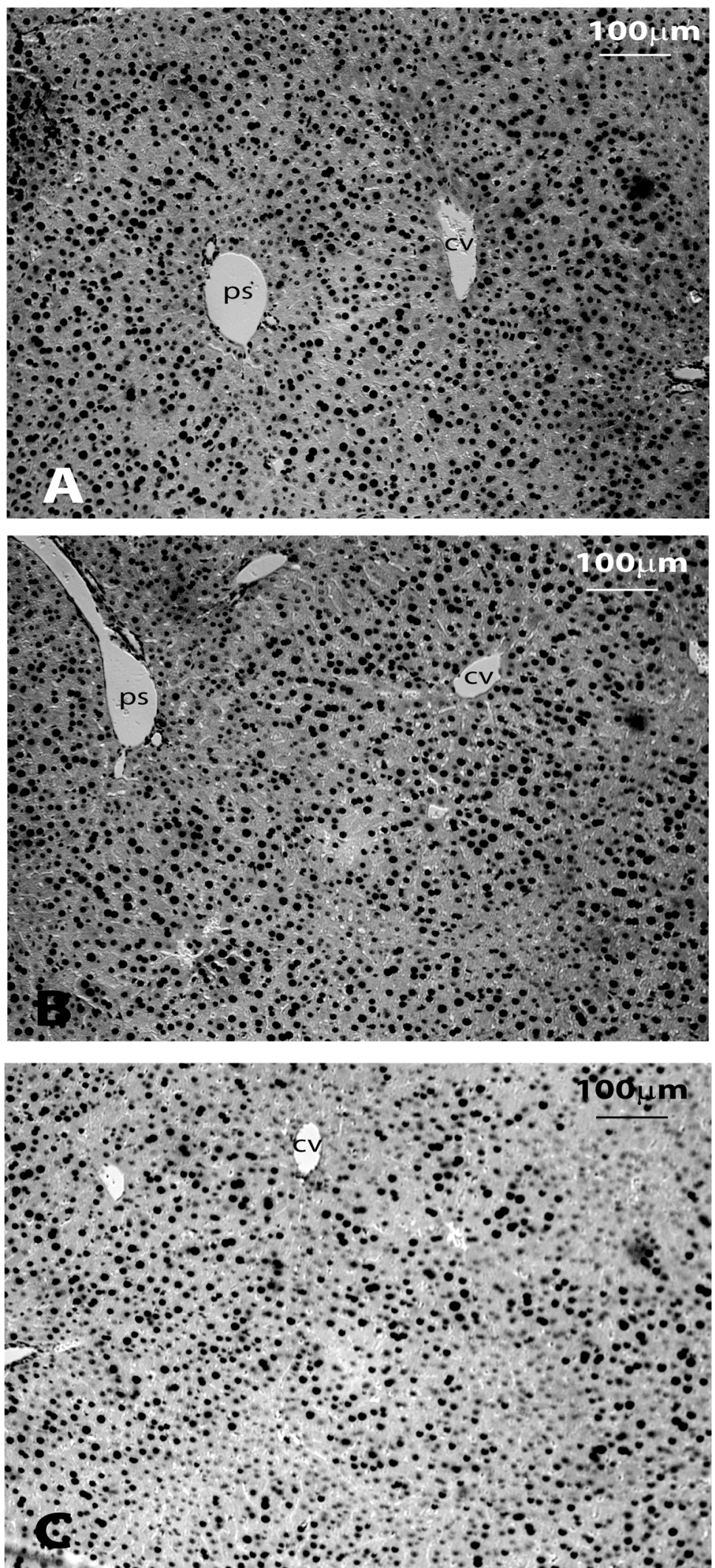

Figure 3.18 Zonal distribution of hepatic replication in 129S4/SvJae mice. Male 129S4/SvJae mice aged 9-10 weeks were dosed with BrdU then gavaged with $3 \mathrm{mg} \mathrm{kg}^{-1}$ TCPOBOP and killed after 2 days. Immunohistochemical protocol and visualization of BrdU-stained hepatocyte nuclei was undertaken on liver sections as described in Section 2.2.3.2 and Section 2.2.4.2. A- C sections were examined under a light microscope at 40X. Photos were taken with a gray scale camera. The scale bar $=100 \mu \mathrm{m}$. Slides were a gift from (Al Kholaifi et al., 2008). 

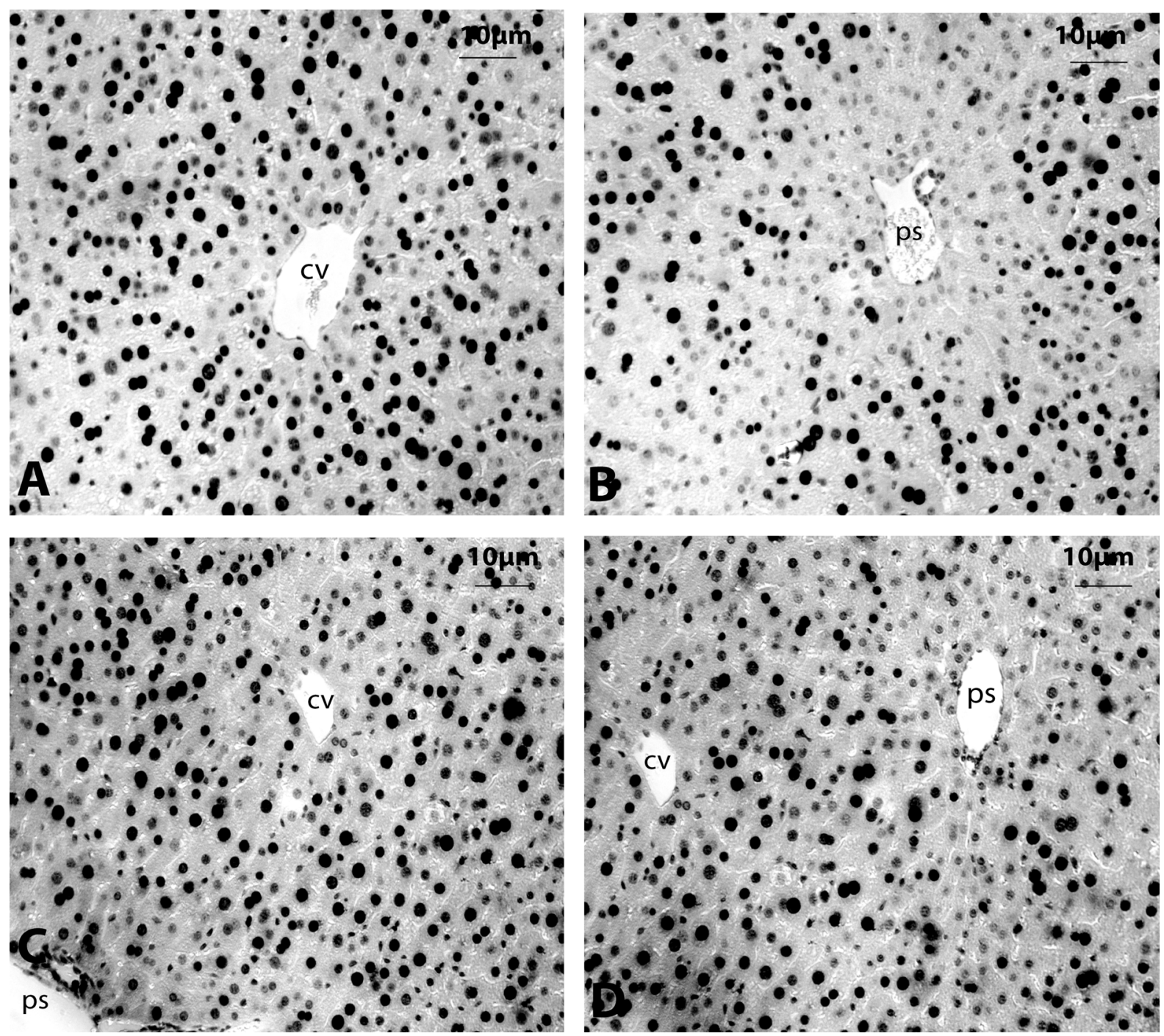

Figure 3.19 Central veins and portal spaces of liver sections in 129S4/Svae mouse. Immunohistochemical staining of liver from 129S4/SvJae male mice, the animals were dosed with BrdU and TCPOBOP as in Figure 3.18, slides were a kind gift from (Al Kholaifi et al., 2008). Visualization of BrdU-stained hepatocyte nuclei was undertaken as in Section 2.2.4.2. The scale bar represents $10 \mu \mathrm{m}$. Sections A-D were examined under a light microscope at $400 \mathrm{X}$. Photos were taken with a gray scale camera.

There was no significant difference in the hepatic zonation between the periportal and the perivenous regions according to Student's t- test $(\mathrm{P}>0.05)$ for male groups (control and treated) and the control female group, as shown in Figure 3.20. However, for the female group treated with TCPOBOP there was a significant zonation $(\mathrm{P}=0.005)$. 
In this case, the labelled cells were preferentially perivenous (CV), although the magnitude of the effect was relatively small, with the number of labelled cells in the perivenous region being less than two times greater than those in the periportal region. The total labelling index was strongly increased by TCPOBOP.

From these results it was found there was no significant difference in the number of labelled hepatocytes between the periportal and the perivenous zones in male and female 129S4/SvJae control mice and the male mice treated with TCPOBOP, but there was a significant effect for treated female mice where the labelled cells were preferentially perivenous.

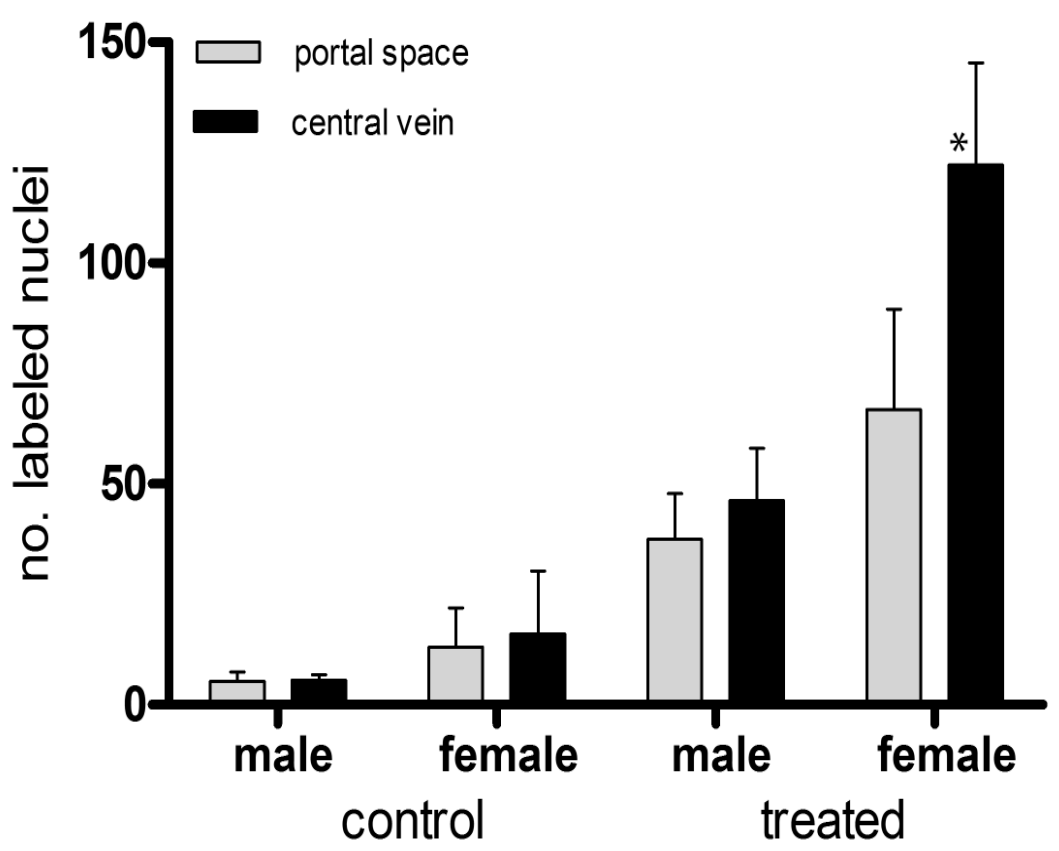

Figure 3.20 Zonal distribution of hepatic DNA synthesis in 129S4/SvJae mice treated with TCPOBOP. Male and female 129S4/SvJae mice were treated with BrdU then gavaged with a single dose of 3 $\mathrm{mg} \mathrm{kg}^{-1}$ TCPOBOP and killed after 2 days. Livers were subjected to the immunohistochemical protocol as described in (Section 2.2.3.2). The number of cells labelled in periportal (PS- gray bars) or centrilobular (CV-black bars) is shown for the control $(\mathrm{n}=4)$ and treated $(\mathrm{n}=5)$ group for males and females. The bars show the mean value, and the error bars depict one standard deviation. Statistically significant difference between the CV and the PS is indicated by an asterisk. Statistic was done with Student's t- test $(\mathrm{P}<0.05)$. 


\section{Section 3.2.2.2 Induction of hepatic DNA synthesis by PPAR $\alpha$ ligands (ciprofibrate)}

\section{Section 3.2.2.2.1 Zonation in 129S4/SvJae mice treated with ciprofibrate.}

This experiment was designed to determine the lobular distribution of hepatocellular proliferation in the liver of $129 \mathrm{~S} 4 / \mathrm{SvJ}$ ae mice treated with ciprofibrate.

129S4/SvJae male mice were stained for BrdU labelling and treated with $100 \mathrm{mg} \mathrm{kg}^{-1} \mathrm{day}^{-1} \mathrm{cip}-$ rofibrate or corn oil as shown in Section 2.2.1.2 and Section 2.2.1.3. The number of labelled cells in the periportal or centrilobular areas was determined as described earlier in Section 2.2.4.2. Dosing with corn oil was for two days and ciprofibrate was 3,4 and 6 days Figure 3.21A. There was no significant difference in the number of labelled hepatocytes between the portal space zone and the central vein zone for all the groups. There was also no significant difference in a separate experiment, where mice were administered $300 \mathrm{mg} \mathrm{kg}^{-1}$ ciprofibrate for 5 days Figure 3.21B.

In different experiments of animals treated with corn oil for 4 and 6 days there was no significant difference between the periportal region and the centrilobular. When all the control data (2, 4,5 , and 6 days) were pooled together there still was no significant difference in lobular distribution of labelled hepatocytes (data not shown). Statistics done with Student's t- test $(\mathrm{P}<0.05)$.

These results show that hepatic zonal distribution of DNA synthesis in 129S4/SvJae mice treated with corn oil (vehicle)/ ciprofibrate is consistent throughout the liver zones and does not accumulate in any of the periportal or perivenous zones, and there is no effect of time $(2,4,5$ and 6 days) or different doses of ciprofibrate $100,300 \mathrm{mg} \mathrm{kg}^{-1}$ day $^{-1}$ on the distribution. 

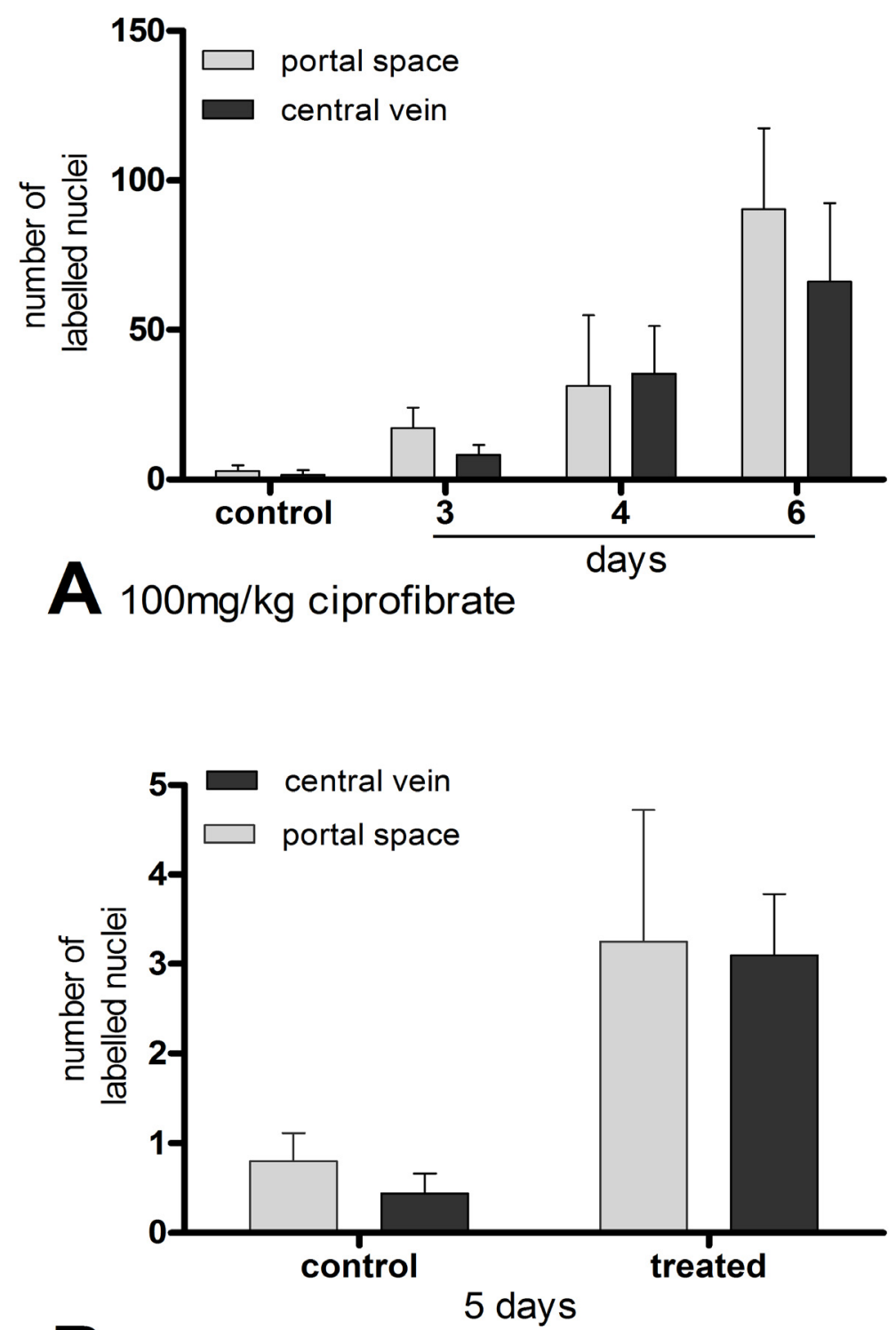

B $300 \mathrm{mg} / \mathrm{kg}$ ciprofibrate

Figure 3.21 Lobular distribution of hepatic DNA synthesis in ciprofibrate-treated 129S4/SvJae mice. Male 129S4/SvJae mice aged 9-10 weeks were treated with BrdU and the liver processed and visualization of BrdU-stained hepatocyte nuclei was undertaken as in Section 2.2.4.2. The number of cells labelled in periportal (PSgray bars) or centrilobular (CV-black bars) is shown, in $\mathbf{A}$ for animals treated orally with corn oil for the control group and with $100 \mathrm{mg} \mathrm{kg}^{-1}$ Ciprofibrate for 3, 4 and 6 days (the mean is for 5 animals). B shows animals treated orally with corn oil (control) or $300 \mathrm{mg} \mathrm{kg}^{-1}$ Ciprofibrate for 5 days (the mean is for 4 animals). There was no significant difference between the number of labelled hepatocytes in portal space and central vein areas for all groups. The bars show the mean value, and the error bars depict one standard deviation. Statistics done was with Student's t- test $(\mathrm{P}<0.05)$. 


\section{Section 3.2.2.2.2 Zonation in 129S4/SvJae PPAR $\alpha$-null (129S4/SvJae-Ppara ${ }^{\text {tm1Gonz/ }}$ tm1Gonz) mice treated with ciprofibrate.}

This experiment was designed to determine the lobular distribution of hepatocellular proliferation in liver of male 129S4/SvJae nullizygous for PPAR (the tm1Gonz allele) mice which were treated with $100 \mathrm{mg} \mathrm{kg}^{-1}$ day $^{-1}$ ciprofibrate.

Male 129S4/SvJae PPARa-null mice were stained for BrdU labelling and orally dosed with 100 $\mathrm{mg} \mathrm{kg}^{-1}$ day $^{-1}$ ciprofibrate or corn oil (vehicle) for two and four days, as shown in Section 2.2.1.2 and Section 2.2.1.3. The number of labelled cells in the periportal or centrilobular areas were determined as described in Section 2.2.4.2. Figure 3.22 shows that there was no significant difference in the number of labelled hepatocytes between portal space and central vein zones for all the control and treated groups, although the mean value is higher in the PS for the treated groups and the control for 4 days. Statistics were done with Student's t- test $\mathrm{P}<0.05$.

These results indicate that the hepatic zonal distribution of male 129S4/SvJae PPARa-null mice treated with corn oil (vehicle) or $100 \mathrm{mg} \mathrm{kg}^{-1} \mathrm{day}^{-1}$ ciprofibrate is consistent through out the liver lobule zones and does not significantly accumulate in any of the periportal or perivenous regions. 


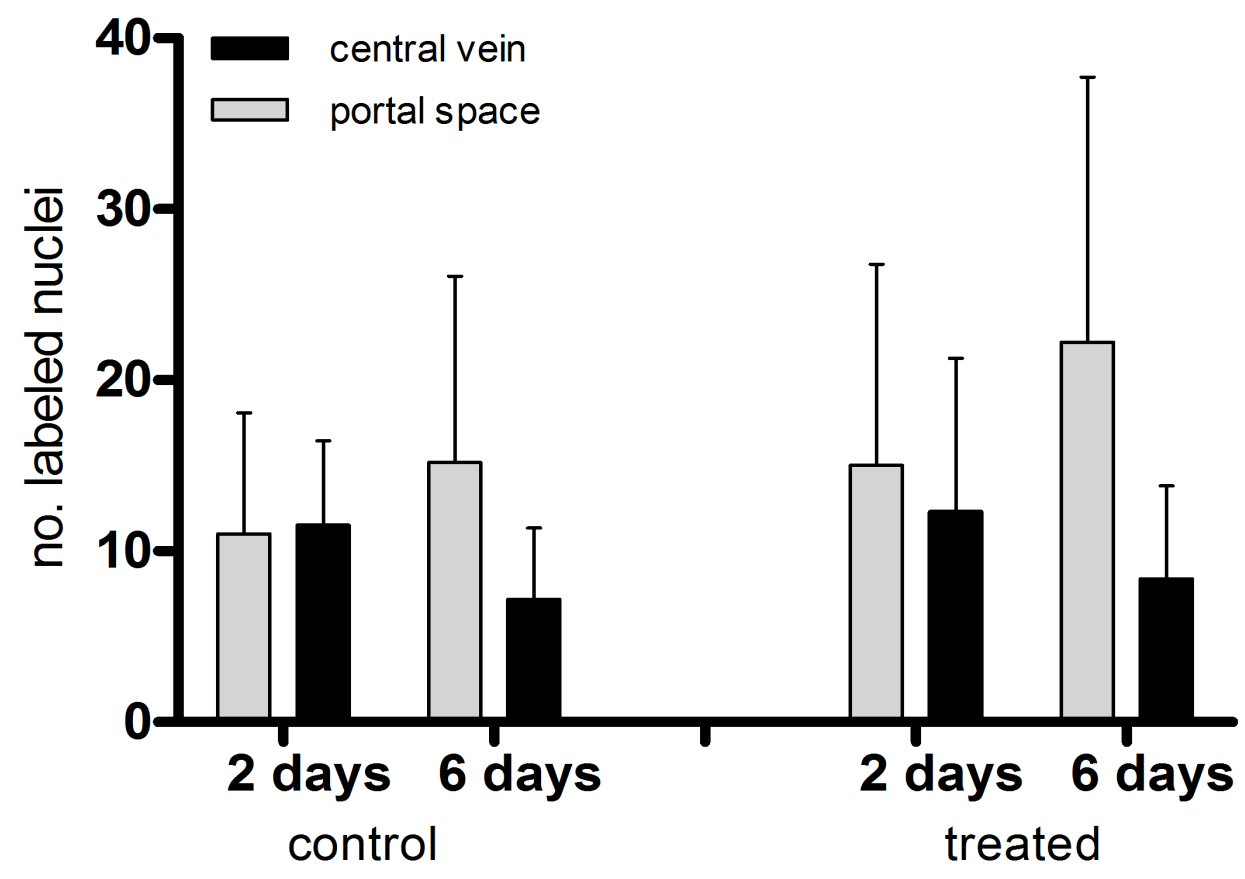

Figure 3.22 Lobular localization of DNA labelling in 129S4/SvJae (Ppara ${ }^{\text {tm1Gonz/tm1Gonz }}$ male mice. Male 129S4/SvJae (Ppara ${ }^{\mathrm{tm} 1 \mathrm{Gonz} / \mathrm{tm} 1 \mathrm{Gonz}}$ ) mice aged 9-10 weeks were treated with BrdU (Section 2.2.1.2). The number of cells labelled in periportal (PS- gray bars) or centrilobular (CV-black bars) is shown for control or animals treated orally with $100 \mathrm{mg} \mathrm{kg}^{-1}$ ciprofibrate for 2 and 6 days (for the control the mean is for 2 and 5 animals), for the treated the number of animals is 3 and 5 for days 2 and 6 respectively). The bars show the mean value, and the error bars depict one standard deviation. There was no difference between portal space and central vein for all the groups with Student's t- test $(\mathrm{P}<0.05)$.

\section{Section 3.2.2.2.3 Zonation in C57BL/6JCrl mice treated with ciprofibrate.}

The above results did not show a significant preferential periportal distribution of hepatocyte labelling in 129S4/SvJae mice. However, it is possible that there could be zonal distribution of labelling in a different mouse strain, so this experiment was designed to determine the lobular distribution of hepatocellular proliferation in the liver of male $\mathrm{C} 57 \mathrm{BL} / 6 \mathrm{JCrl}$ mice treated with ciprofibrate. Male C57BL/6JCrl mice were stained for BrdU labelling as shown in Section

\subsubsection{3.}

The number of labelled cells in the periportal or centrilobular areas were determined as described in Section 2.2.4.2. The mice were dosed orally with $100 \mathrm{mg} \mathrm{kg}^{-1} \mathrm{day}^{-1}$ ciprofibrate or 
corn oil for two and four days Figure 3.23. There was no significant difference in the number of labelled hepatocytes found around the portal space and central vein zones for all the groups, although the mean value is higher in the PS for all the groups. Statistics were done with Student's t- test, $\mathrm{P}<0.05$. $(\mathrm{n}=6)$.

These results show that the hepatic zonal distribution of DNA synthesis in C57BL/6JCrl male mice treated with corn oil/ ciprofibrate for 2 and 4 days is consistent throughout the liver zones and does not significantly accumulate in any of the periportal or perivenous zones.

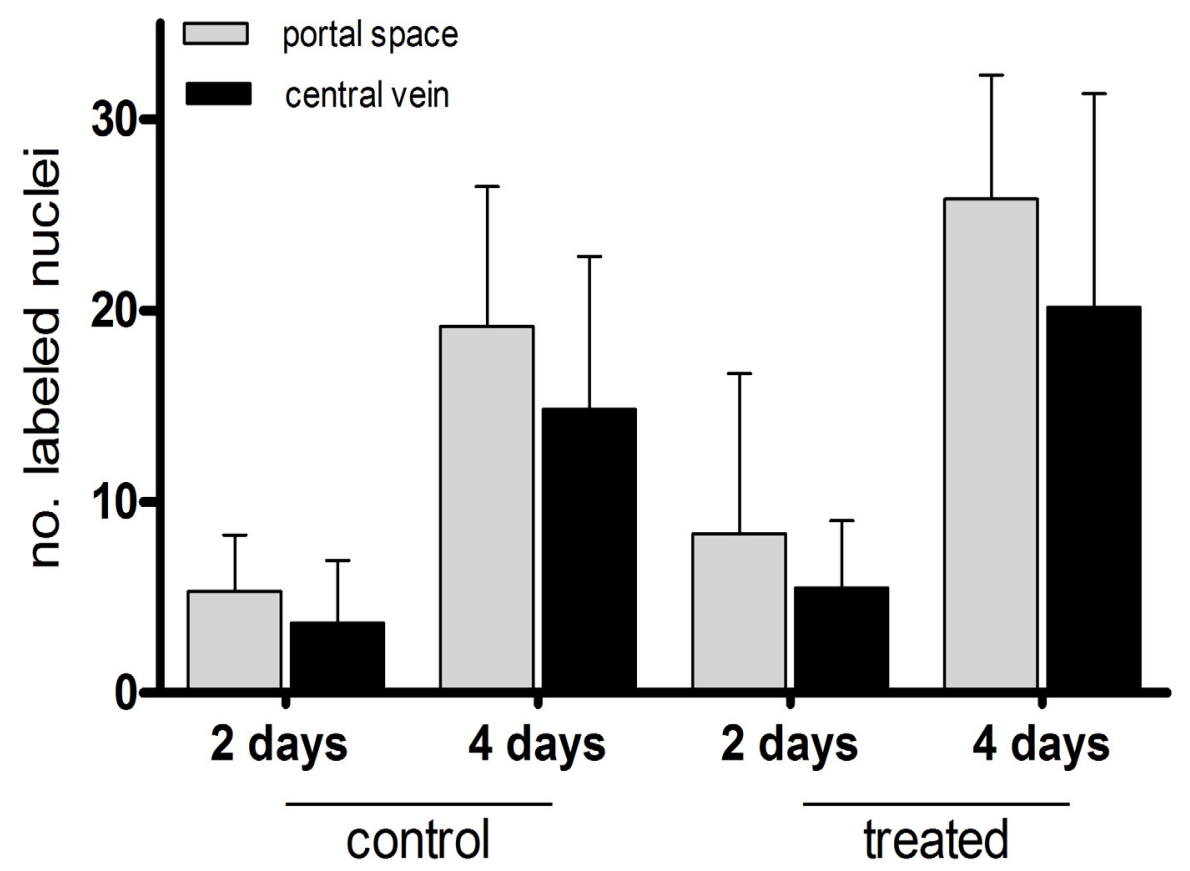

Figure 3.23 Lobular localization of hepatic DNA labelling in C57BL/6JCrl mice treated with ciprofibrate. Male C57BL/6JCrl mice aged 9-10 weeks were treated with BrdU as in Section 2.2.1.2. The number of cells labelled in periportal (PS- gray bars) or centrilobular (CV- black bars) is shown for animals treated orally with control (corn oil) or $100 \mathrm{mg} \mathrm{kg}^{-1}$ day $^{-1}$ ciprofibrate for 2 or 4 days. The bars show the mean value, and the error bars depict one standard deviation is for 6 animals. There was no difference between portal space and central vein for all the groups with Student's t- test $(\mathrm{P}<0.05)$. 


\section{Section 3.2.2.2.4 Zonation in DBA/2JCrl mice treated with ciprofibrate.}

This experiment was designed to determine the lobular distribution of hepatocellular proliferation in the liver of male DBA/2JCrl mice treated with ciprofibrate.

Male DBA/2JCrl mice were stained for BrdU labelling as shown in Section 3.1.1.2.2. The number of labelled cells in the periportal or centrilobular areas were determined as described in Section 2.2.4.2. The mice were dosed orally with corn oil for two and six days or $100 \mathrm{mg} \mathrm{kg}^{-1} \mathrm{day}^{-}$

${ }^{1}$ ciprofibrate for two, four and six days Figure 3.24. There was no significant difference in the number of labelled hepatocytes found around the portal space and central vein zones for all the groups.

These results show the hepatic zonal distribution of DNA synthesis in DBA/2JCrl male mice treated with corn oil (vehicle)/ ciprofibrate for two, four and six days is consistent throughout the liver zones and does not accumulate significantly in any of the periportal or perivenous zones. 


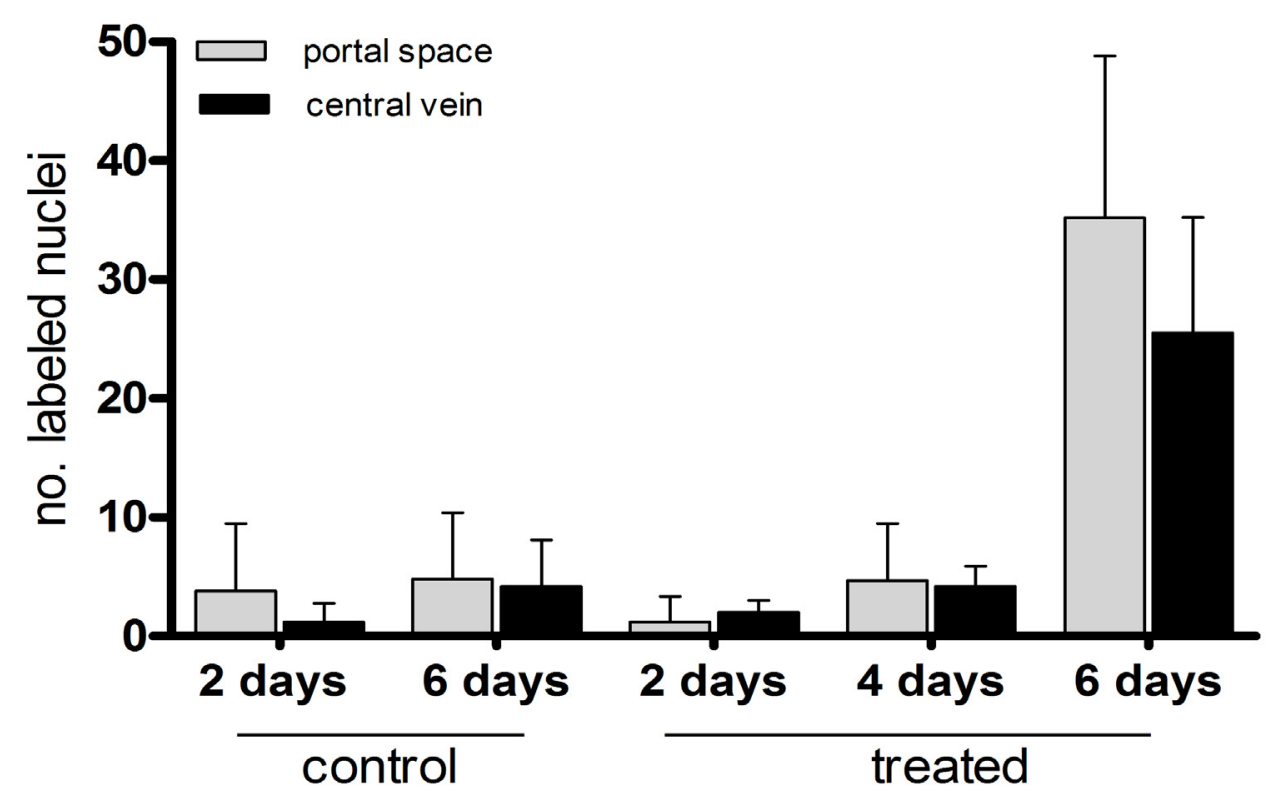

Figure 3.24 Lobular localization of hepatic DNA labelling in DBA/2JCrl mice treated with ciprofibrate. Male DBA/2JCrl mice aged 9-10 weeks were treated with BrdU as in Section 2.2.1.2. The number of cells labelled in periportal (PS- gray bars) or centrilobular (CV-black bars) is shown for animals treated orally with control (corn oil) for 2 and 6 days or $100 \mathrm{mg} \mathrm{kg}^{-1} \mathrm{day}^{-1}$ ciprofibrate for 2, 4 or 6 days. The bars show the mean value, and the error bars depict one standard deviation for 6 animals. No difference between portal space and central vein for all the groups with Student's t- test $(\mathrm{P}<0.05)$.

\section{Section 3.2.2.3 Induction of hepatic DNA synthesis by the PPAR $\alpha$ methylclofenapate.}

From the results before, it was possible that the failure to observe lobular localization of hepatocyte DNA synthesis was due to an idiosyncratic response to ciprofibrate. Therefore, the peroxisome proliferator methylclofenapate (MCP) was used, as an agent that has previously been shown to lead to zonated DNA synthesis induction in rats (Barrass et al., 1993).

\section{Section 3.2.2.3.1 Zonation in 129S4/SvJae mice treated with MCP}

This experiment was designed to determine the lobular distribution of hepatocellular proliferation in the liver of male 129S4/SvJae mice treated with $25 \mathrm{mg} \mathrm{kg}^{-1} \mathrm{day}^{-1} \mathrm{MCP}$ for 3 and 4 days. Male 129S4/SvJae mice aged 9-10 weeks were stained for BrdU labelling as shown in Section 
2.2.1.2. The number of labelled cells in the periportal or centrilobular areas were determined (as described in Section 2.2.4.2).

The mice were dosed orally with corn oil for four days or $25 \mathrm{mg} \mathrm{kg}^{-1} \mathrm{day}^{-1} \mathrm{MCP}$ for 3 and 4 days Figure 3.25. There was no significant difference in the number of labelled hepatocytes found around the portal space and the central vein zones for all the 129S4/SvJae male mice groups when treated with $25 \mathrm{mg} \mathrm{kg}^{-1} \mathrm{day}^{-1} \mathrm{MCP}$ for 3 and 4 days.

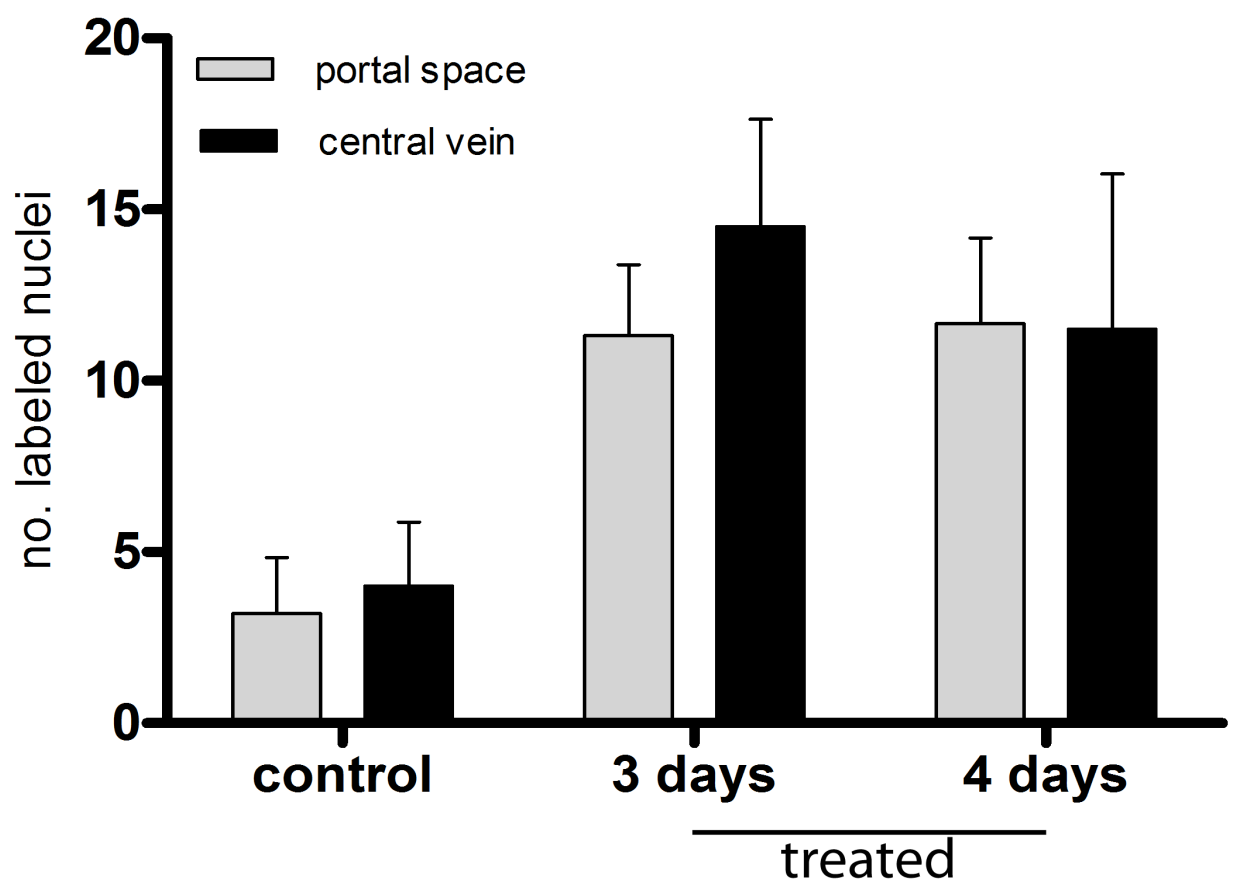

Figure 3.25 Zonal distribution of hepatic DNA synthesis in 129S4/SvJae mice treated with MCP. Male 129S4/SvJae mice aged 9-10 weeks were treated with BrdU as in Section 2.2.1.2 The number of cells labelled in periportal (PS- gray bars) or centrilobular (CV- black bars) is shown for control for 4 days (the number of animals is 5), or treated with $25 \mathrm{mg} \mathrm{kg}$-1 day-1 MCP methylclofenapate for 3 and 4 days (the number of animals is 6). Visualization of BrdU-stained hepatocyte nuclei was undertaken as mentioned in Section 2.2.4.2. The bars show the mean value, and the error bars depict one standard deviation. There was no significant difference between portal space and central vein for all the groups according to Student's t- test $(\mathrm{P}<0.05)$. 


\section{Section 3.2.2.3.2 Zonation in Alderley park (AP) mice treated with MCP.}

This experiment was designed to determine the lobular distribution of hepatocellular proliferation in liver of male Alderley park [AP] mice treated orally with $25 \mathrm{mg} \mathrm{kg}^{-1} \mathrm{day}^{-1} \mathrm{MCP}$ for 3 and 4 days.

Male Alderley park mice aged 9-10 weeks were stained for BrdU labelling as shown in Section 2.2.1.2. The number of labelled cells in the periportal or centrilobular areas were determined.

It was found in male AP mice treated with $25 \mathrm{mg} \mathrm{kg}^{-1} \mathrm{day}^{-1} \mathrm{MCP}$ that there was a significant difference in the number of labelled hepatocytes between the periportal and the perivenous zones (statistics used was with Student's t- test, $\mathrm{P}<0.005$ ) for the control and the treated group for 4 days with MCP. The results show a larger distribution of hepatic DNA synthesis at the periportal. As for the group treated for 3 days, there was no significant difference between the number of labelled cells situated around the PS and CV (Figure 3.26).

From this result it is established that the hepatic zonal distribution between the periportal and perivenous regions is not significantly different for male AP mice dosed with $25 \mathrm{mg} \mathrm{kg}^{-1} \mathrm{day}^{-1}$ MCP for 3 days. As for the AP mice dosed for 4 days with MCP and the control group, the distribution of hepatic DNA synthesis was primarily periportal. 


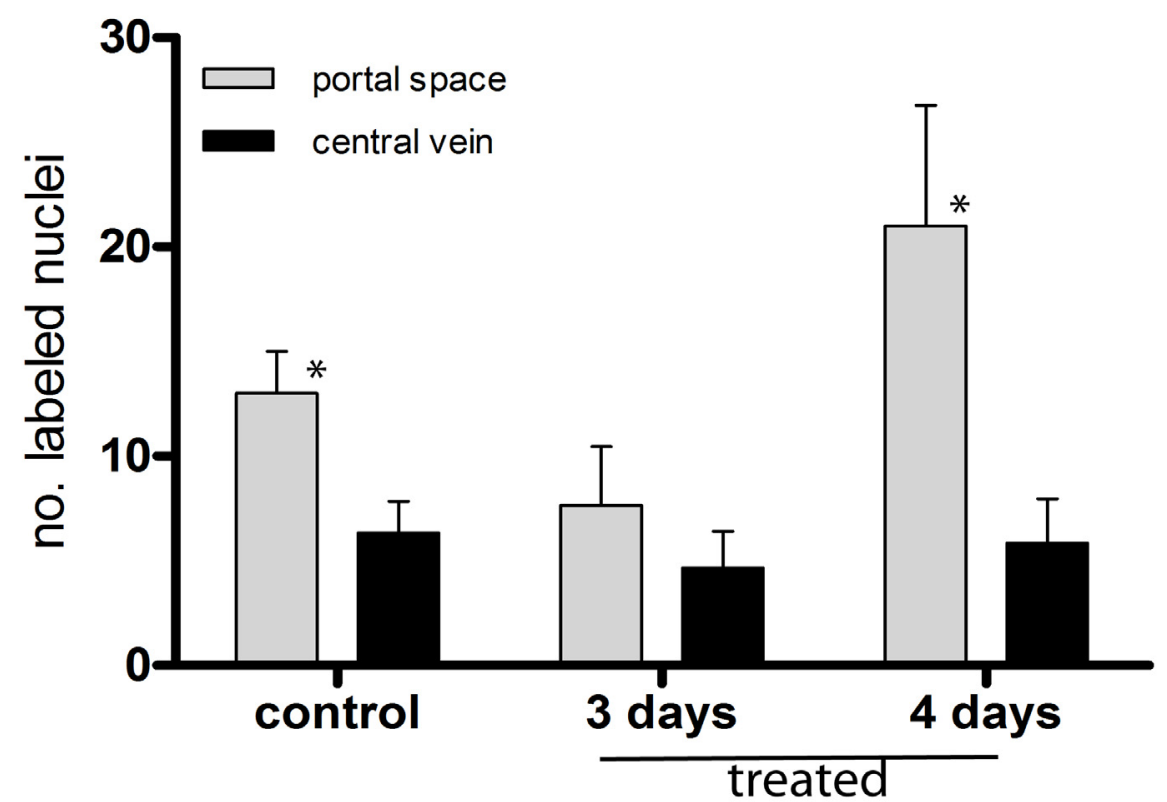

Figure 3.26 Zonal distribution of hepatic DNA synthesis in AP mice treated with MCP. Male AP mice aged 14-15 weeks old were treated with BrdU as described earlier in Figure 3.25. The number of cells labelled in periportal (PS- gray bars) or centrilobular (CV- black bars) is shown for control (4 days) or treated with $25 \mathrm{mg} \mathrm{kg}^{-1}$ day $^{-1}$ MCP methylclofenapate for 3 and 4 days (the number of animals is 6). Visualization of BrdU-stained hepatocyte nuclei was undertaken as mentioned in Section 2.2.4.2. The bars show the mean value, and the error bars depict one standard deviation. Statistically significant difference from the control group is indicated by an asterisk according to Student's t- test $(\mathrm{P}<0.05)$. 


\section{Section 3.3 Microarray analysis}

Knowledge from the previous results Section 3.1.2 that hepatic DNA synthesis occurs 24 hours after dosing, and the fact that cells need from 18-20 hours to undergo DNA synthesis, suggests that the transcriptional signal is sensed within the first five hours after dosing. From this, the 15 hour window was targeted in order to specify the early genes that may be induced, and which could be responsible for hepatic DNA synthesis at 24 hours.

The microarray analysis was applied as in Section 2.2.5 to measure the expression levels of genes induced by $50 \mathrm{mg} \mathrm{kg}^{-1}$ ciprofibrate in livers of F-344NHsd rats after 1, 3, 5 and 24 hours in comparision with the control.

A number of controls were used;

- Corn oil (vehicle) dosed rats were used as negative controls.

- Rats dosed with PXR ligands (cyproterone acetate CPA) were used as positive controls, to compare genes that are involved in hepatic DNA synthesis, but which might not be specific for the PPAR $\alpha$ ligands (ciprofibrate).

- 24 hour points were used to confirm the induction happens at 24 hours by the immunohistochemical protocol and to rule out genes that would be induced after 24 hours as these genes are not of our interest.

- A general or common reference/control which is the most commonly used design of microarray experiments. This also has the benefit of a competent comparison of samples (Cherkaoui-Malki et al., 2001).

In Figure 3.27 is a diagram that clarifies the experiment design. This experiment was done in parallel with the time course done in Section 3.1.2. 


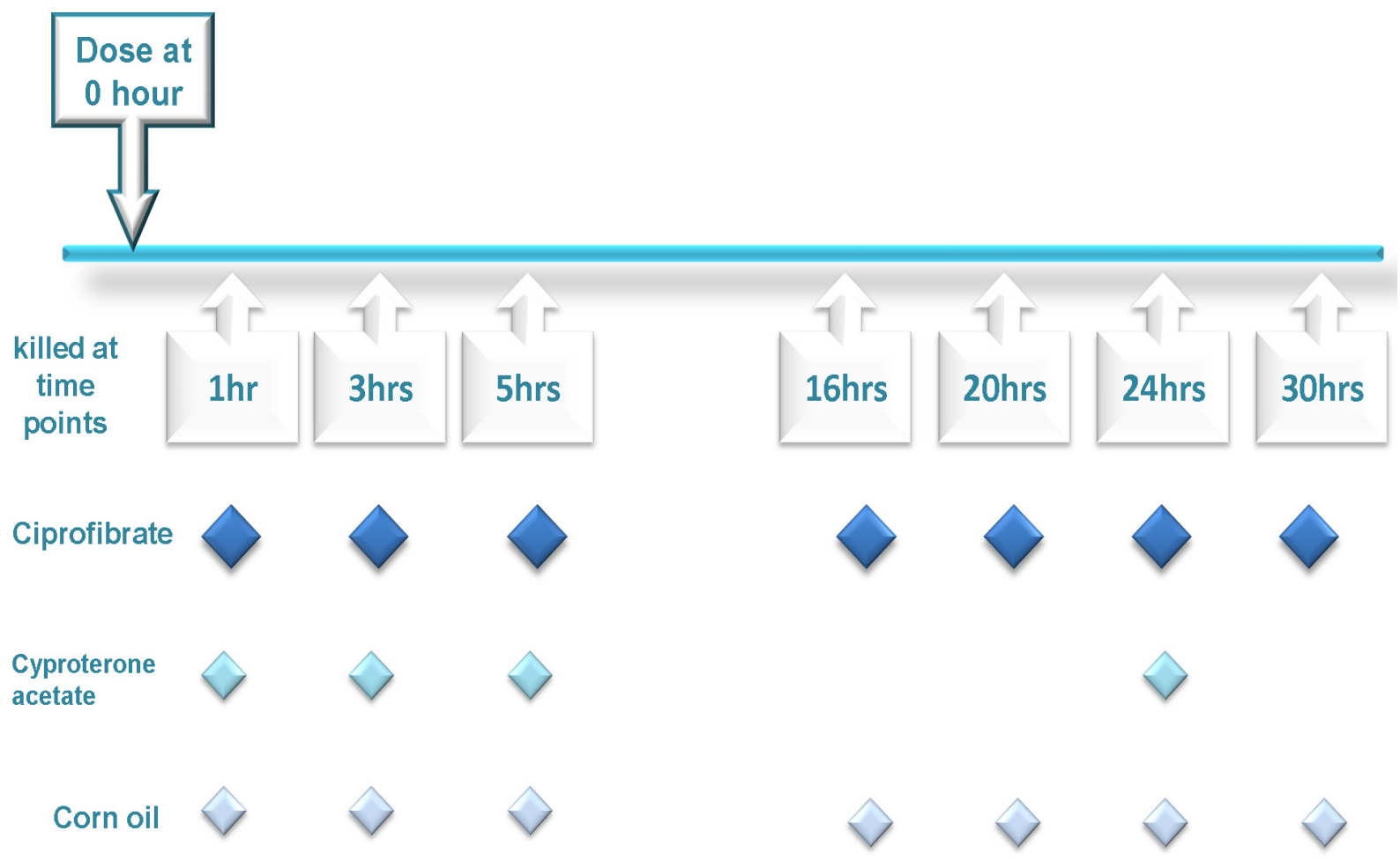

Figure 3.27 Time course of hepatic DNA synthesis in F-344NHsd rats. Groups of F-344NHsd rats were dosed by gavage with $50 \mathrm{mg} \mathrm{kg}^{-1}$ ciprofibrate or $100 \mathrm{mg} \mathrm{kg}^{-1}$ cyproterone acetate or corn oil, then killed after $1,3,5$ and 24 hours. The groups killed after 24 hours were dosed intraperitoneally two hours before killing with BrdU and immunohistochemical protocol was undertaken (Section 2.1.3). Each point represents the number of animals is 4 for the time points 1, 3 and 5 hours and the number of animals is 5 for the group treated with ciprofibrate after 24 hour. The number of animals used is 6 for the groups treated with CPA and corn oil killed after 24 hours. Microarray analysis was done on all the time points at 1, 3,5 and 24 hours in 4 biological replicates and 2 technical replicates.

Figure 3.28 shows that in this experiment there was a statistically significant induction of hepatic DNA synthesis after 24 hours for the group treated with ciprofibrate and even higher for the group treated with cyproterone acetate, according to the measurements of hepatic labelling index with immunohistochemistry.

Liver weight to body weight ratios were calculated for all the time points (Figure 3.29), and there was no significant difference between the control and treated (ciprofibrate/ CPA) groups for all the time points (1, 3, 5, and 24 hours). 


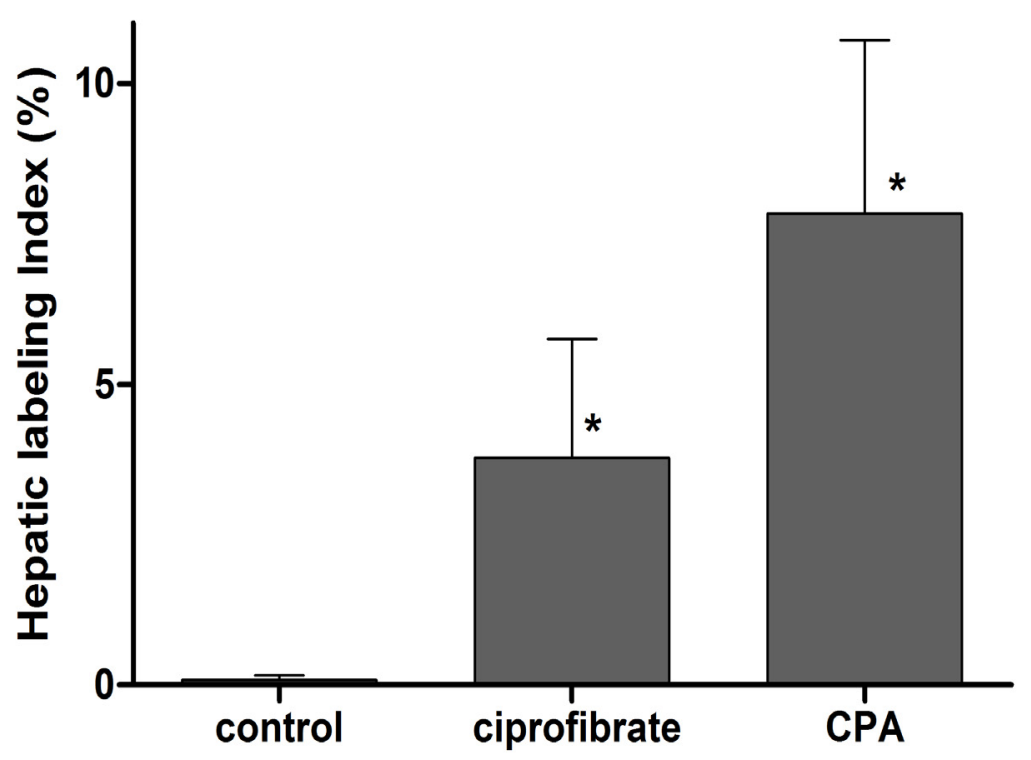

Figure 3.28 Effects of ciprofibrate and CPA on hepatic DNA synthesis in F-344NHsd rats after 24 hours of dosing. Male F-344NHsd rats aged 14-15 weeks were dosed with corn oil (vehicle), 50 $\mathrm{mg} \mathrm{kg}{ }^{-1}$ ciprofibrate or $100 \mathrm{mg} \mathrm{kg}^{-1}$ cyproterone acetate CPA, then killed and assayed after 24 hours (Section 2.1.1). All data are expressed as mean \pm SD for 6 animals. Statistically significant differences from the control group are indicated by an asterisk. Statistics were performed with Dunnett's multiple comparison test $(\mathrm{P}<0.05)$. exception for the number of animals in the ciprofibrate group was 5.

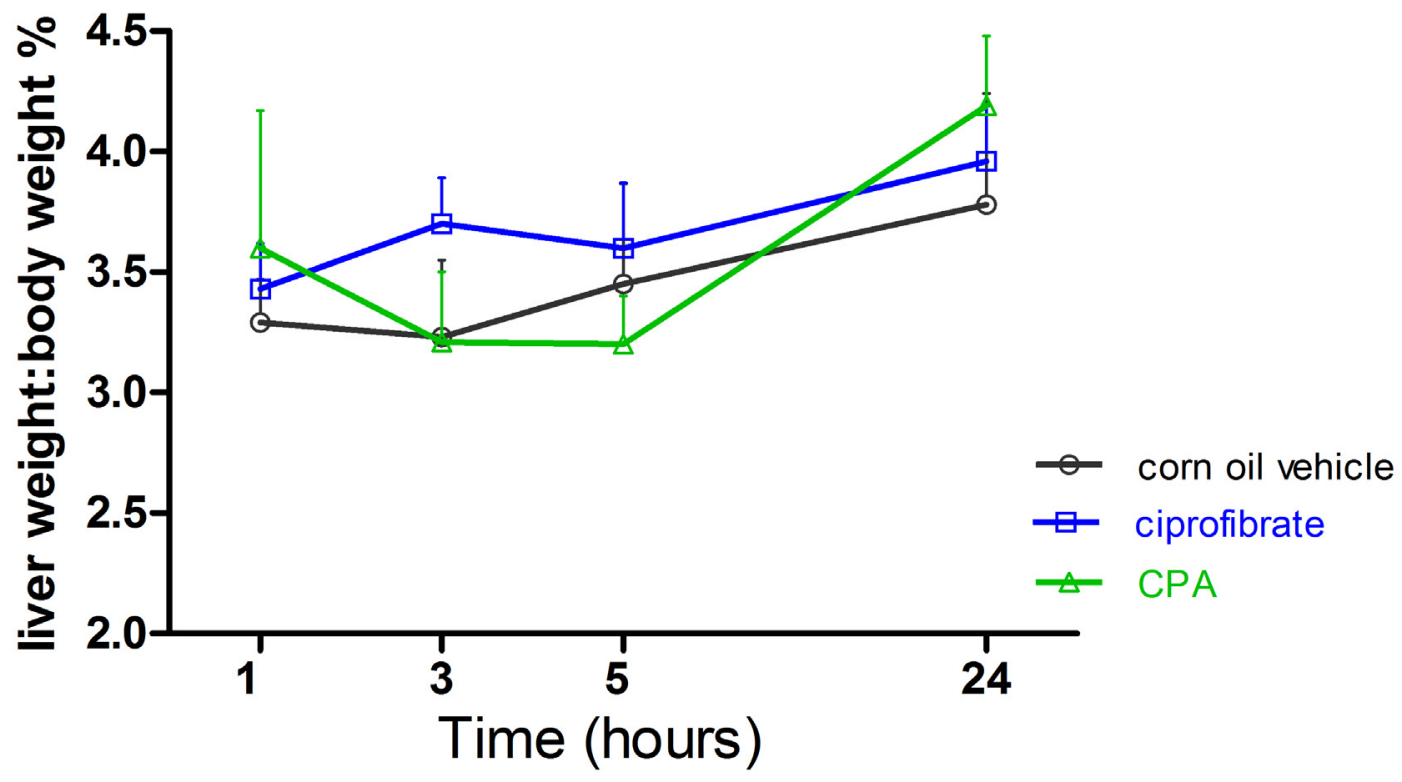

Figure 3.29 Effects of ciprofibrate and CPA on liver weight in F-344NHsd rats. Male F-344NHsd rats aged 14-15 weeks were dosed with corn oil (vehicle), $50 \mathrm{mg} \mathrm{kg}^{-1}$ ciprofibrate or $100 \mathrm{mg} \mathrm{kg}^{-1}$ cyproterone acetate (CPA), then killed after 1, 3, 5 and 24 hours. Liver weight to body weight ratio was determined as in Section 2.2.2. All data are expressed as mean $\pm \mathrm{SD}$. There was no significant difference between the treated and control groups with Dunnett's multiple comparison test $(\mathrm{P}<0.05) . \mathrm{n}=4$ for the time points 1,3 and 5 hours, $\mathrm{n}=6$ for time point 24 hours corn oil and CPA, $\mathrm{n}=5$ for the time point 24 hours treated with ciprofibrate ( $\mathrm{n}=$ number of animals). 


\section{Section 3.3.1 Assessment of RNA quality and quantity}

The liver tissue sampled at intervals after dosing was snap frozen in liquid nitrogen and stored in a $-80^{\circ} \mathrm{C}$ freezer until use. RNA isolation was processed with TRI reagent as in Section 2.2.5.1 for all the liver tissues. Preliminary experiments with a mini prep method and the TRI reagent method showed that the higher quality RNA preparations were established with the TRI reagent, as shown in Figure 3.30A where the $28 \mathrm{~S}$ and $18 \mathrm{~S}$ rRNA bands are sharper in lanes 3 and 4 while the RNA in lanes 6 and 7 (the mini prep) was more smeared. Also the TRI reagent method (when overloading the RNA on the agarose gel; Figure 3.30B) showed the 5S band indicating that the microRNA was intact.

The quality of the total RNA for all the samples was assessed by the relative intensities of the $28 \mathrm{~S}$ and $18 \mathrm{~S}$ rRNA bands visualized by electrophoresis on $2 \%$ agarose gels with a $1 \mathrm{~kb}$ Plus DNA ladder and stained with ethidium bromide. Figure 3.31 and Figure 3.32 show intact total RNA with sharp $28 \mathrm{~S}$ and $18 \mathrm{~S}$ ribosomal RNA bands. The $28 \mathrm{~S}$ rRNA band is approximately twice as intense as the $18 \mathrm{~S}$ rRNA band. The $5 \mathrm{~S}$ rRNA was determined by comparing with the literature and with the ladder and appears as a faint band (in most of the lanes that have been slightly overloaded) indicating the microRNAs.

The yield of the RNA was measured by a CECIL CE9500 spectophotometer, and the total yield of each of the RNAs from the liver tissues were in a range between $8.2 \pm 3.9 \mu \mathrm{g} \mathrm{mg}^{-1}$. A reference RNA control was made by mixing aliquots of all the RNAs to be used in the microarray hybridization -to remove any bias from the 555 and 647 Alexa dyes.

From the above analysis it was established that the TRI reagent method works well, yielding intact microRNAs. All the RNAs used were of good quality and had a yield sufficiently high for microarray analysis. 


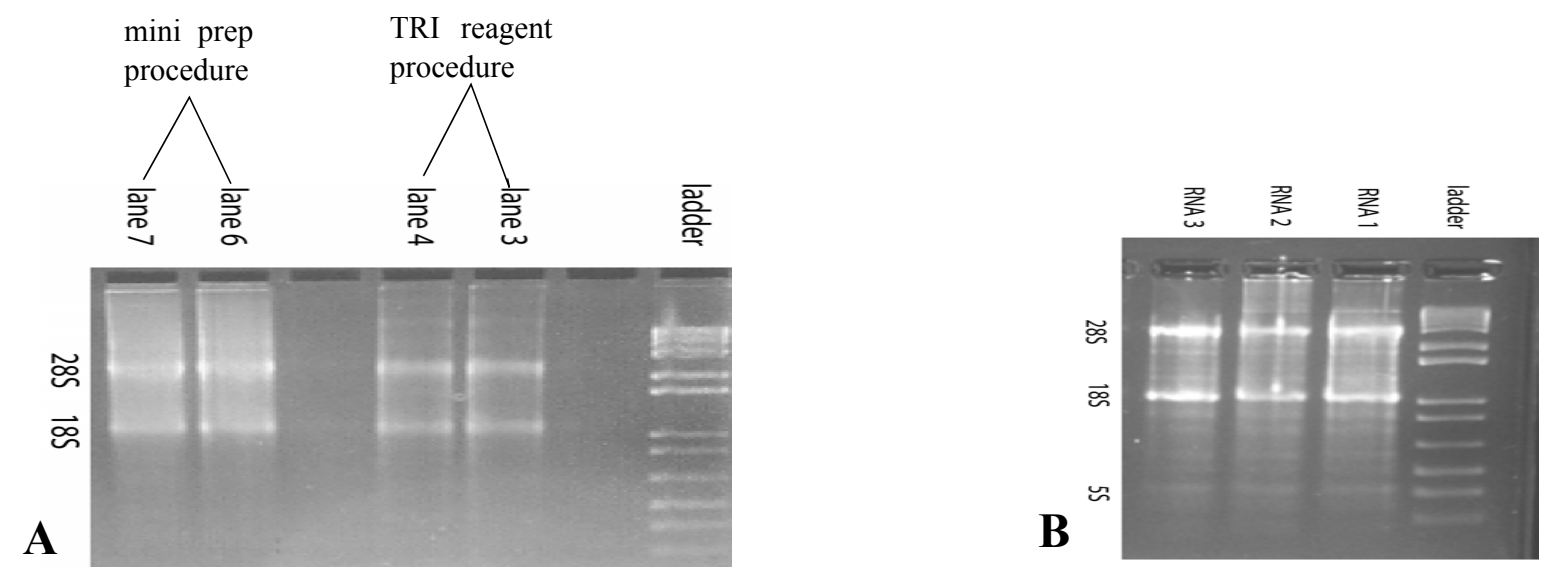

Figure 3.30 Optimizing RNA isolation from rat liver. Agarose gels (2\%) stained with ethidium bromide as shown in Section 2.2.8. In A, the ladder is a $1 \mathrm{~kb}$ Plus DNA ladder, lanes 3 and 4 have RNA made by the TRI reagent procedure; lanes 6 and 7 have RNA made with the mini prep procedure. In B, the ladder is a $1 \mathrm{~kb}$ Plus DNA ladder, RNAs in lanes 1, 2 and 3 were made with TRI reagent method. A larger amount of the RNA was loaded to show the microRNA band at $5 \mathrm{~S}$ as a faint band. The major RNA bands are shown at $28 \mathrm{~S}$ and $18 \mathrm{~S}$.

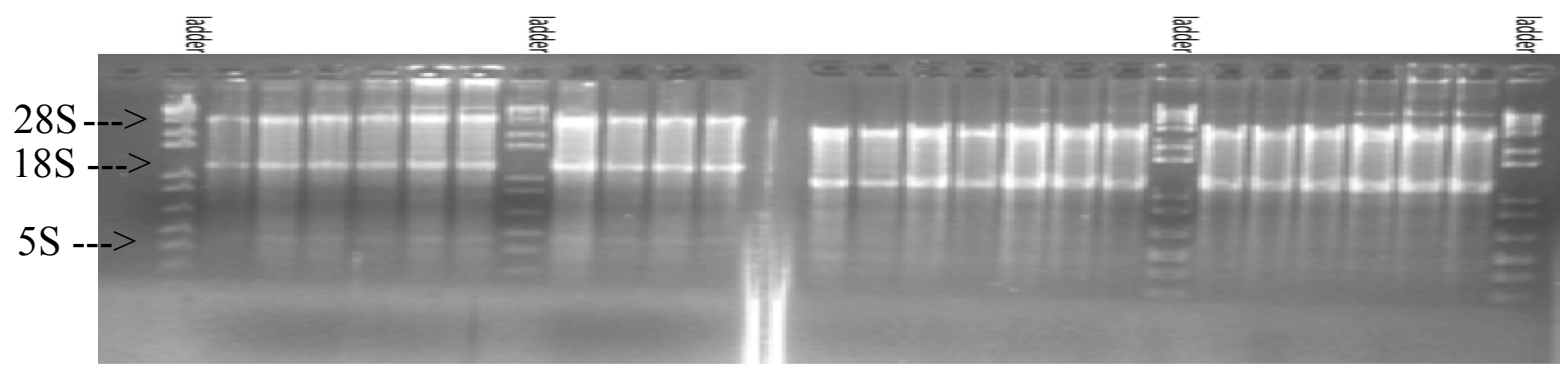

Figure 3.31 Agarose gel with RNA from F-344NHsd rat liver. Agarose gel electrophoresis (2\%) was performed as described in Section 2.2.8 with a $1 \mathrm{~kb}$ Plus DNA ladder to mark the nuclear weight of the RNA and dyed with ethidium bromide. The lanes were loaded with RNA samples from F-344NHsd rat liver treated with ciprofibrate for 24 hours.

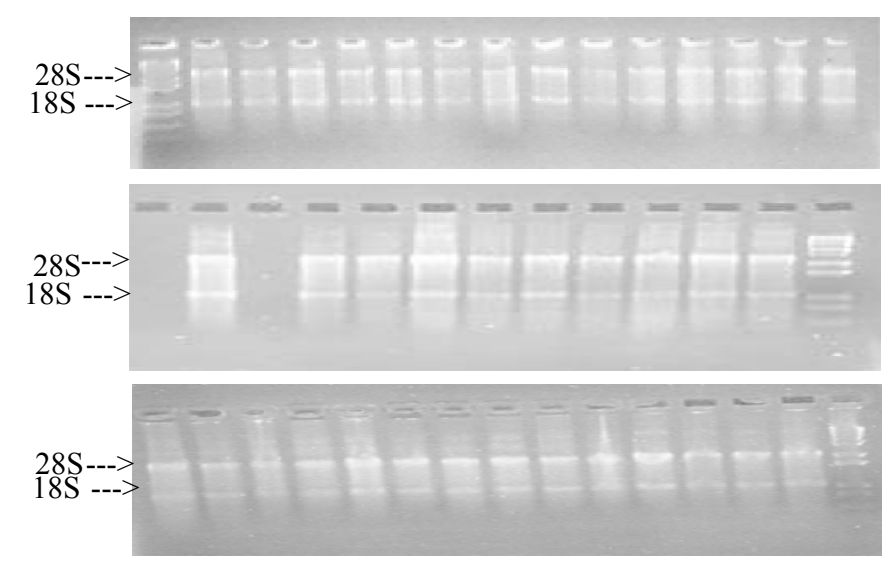

Figure 3.32 More examples of agarose gels loaded with RNAs from F-344NHsd rats. Agarose gel electrophoresis was made as described in Figure 3.30 with a $1 \mathrm{~kb}$ Plus DNA ladder to mark the nuclear weight of the RNA and dyed with ethidiome bromide. Intact total RNA with sharp 28S and 18S ribosomal RNA bands are shown. The lanes were loaded with RNA samples from F-344NHsd rat liver treated with CPA. 


\section{Section 3.3.2 Incorporation of Alexa dyes in the cDNA}

RNAs were made to cDNAs labelled with Alexa dyes 555 and 647. The Amino allyl cDNA labelling used a two step process, and all the steps were made with a negative control (sample with no RNA) and a positive control (RNA supplied in the kit). All the samples' incorporation of the Alexa dyes and the cDNA quantities were determined using a nanodrop machine, and the cDNA amounts were around $80 \pm 20 \mathrm{ng} \mu \mathrm{l}^{-1}$ (and might go up to $200 \mathrm{ng} \mu \mathrm{l}^{-1}$ ), and the incorporated dye was approximately $8 \pm 4 \mathrm{pmol} \mathrm{ul}^{-1}$ (and might go up to $20 \mathrm{pmol} \mathrm{ul}^{-1}$ ) for each of the Alexa dye 555 and 647 (Appendix I). The Amino allyl cDNA labelling kit -from Ambion- was used for the rest of the analysis, and optimizing was done to dilute the cDNA, and also to decrease the costs as will be described in Section 3.3.3.

\section{Section 3.3.3 Optimization of the microarray technique}

Figure 3.33 shows a typical outcome of the scanned "MEEBO" -Mouse genome set- microarray slide. The scanner functions using sequential scanning to create 3 images: the slide is scanned twice; first using the green $532 \mathrm{~nm}$ laser that scans the 555 Alexa dye (Figure 3.33A), and then the red $635 \mathrm{~nm}$ laser and this scans the 647 Alexa Dye (Figure 3.33B). The third slide with a ratio image where the second wavelength image is composed on the first as in Figure 3.33C, where a green spot indicates the treatment for this specific gene has less activity than the reference control; a red spot indicates the treatment would have more activity than the reference control; and a yellow spot means that there is no change in the level of activity between the two populations of test and reference control would be where the control and treated are the same. Notice for each of the red and the green scans there are white spots indicating saturating fluorescence. 


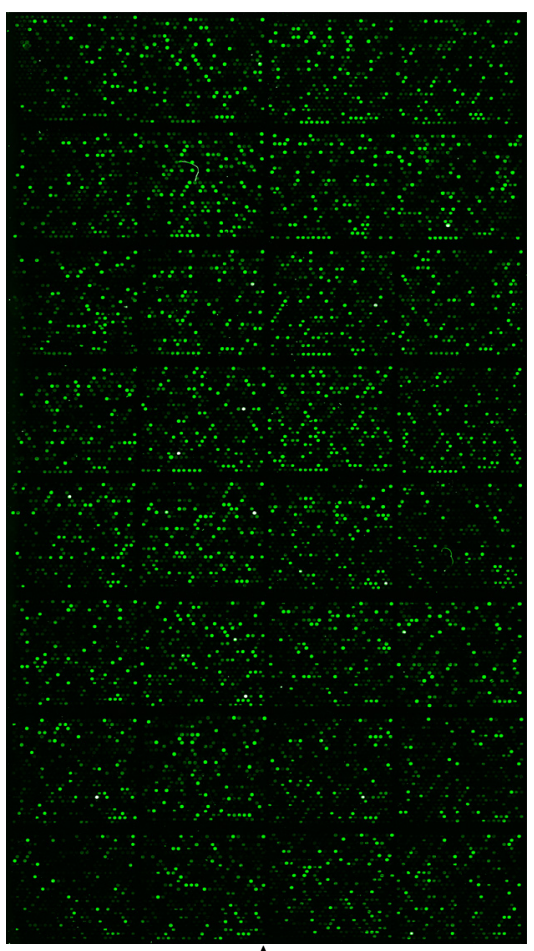

A
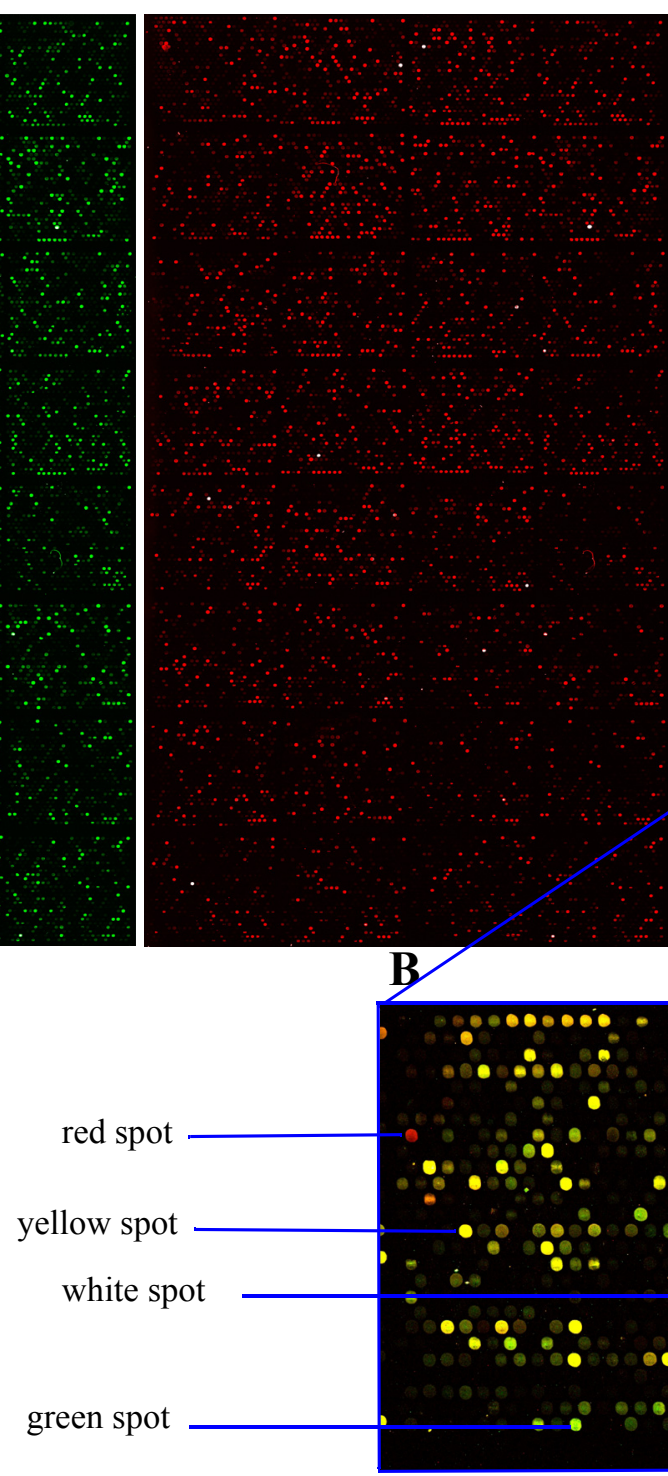

green spot
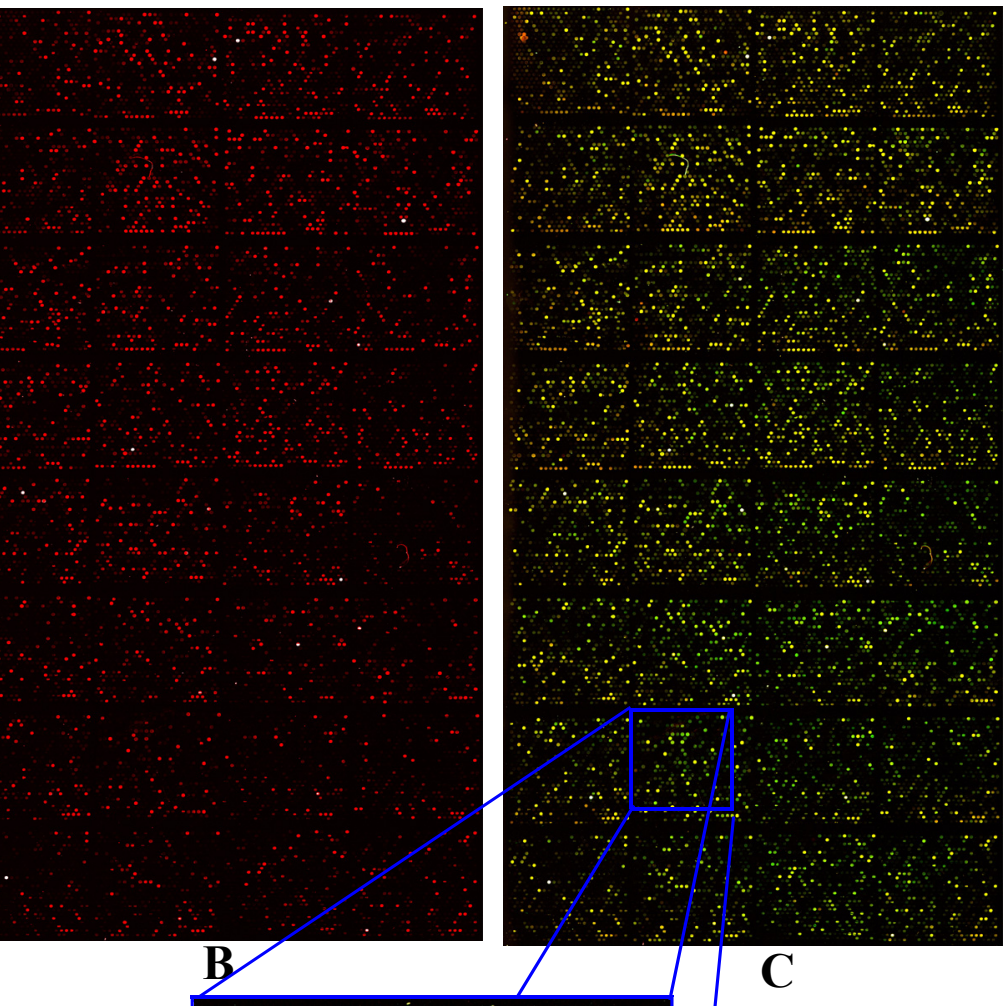

C

Figure 3.33 Images of the scanned microarray slide. Outcome of the Axon 4200 scanner, A shows the image with the green 555 fluorescent. B shows the image with the red 674 fluorescent. $\mathbf{C}+\mathbf{D}$ shows the combined colours, where a green spot indicates the treatment for this specific gene has less activity than the reference control; a red spot indicates the treatment would have more activity than the reference control; and a yellow spot means that there is no change in the level of activity between the two groups control and treated. Notice for each of the red and the green scans there are white spots indicating a large intensity of the fluorescent. 
It was of importance to validate the microarray technique to ensure the results are reliable and repeatable with the least expense possible. So, the following issues were addressed in an independent experiment: (1) Section 3.3.3.1- Reproducibility of the scanning. (2) Section 3.3.3.2Reproducibility of the hybridizating. (3) Section 3.3.3.3- Testing of the concentration of cDNA. For optimizing the microarray technique, RNA extracted from liver of F-344NHsd rats treated with ciprofibrate at 24 hours was used. Groups of the same cDNA were labelled and hybridized as described in Section 2.1.4.2. They were then all scanned. A random group was chosen to be scanned repeatedly. All groups then went through the analyzing process, then normalised using the NORTT program, and then compared against each other.

\section{Section 3.3.3.1 Reproducibility of scanning}

The aim of this experiment was to determine that the scanning section of the microarray technique is reliable and the results are repeatable. Slides were chosen at random and each slide was scanned twice. The data from the scanner was normalised and one set of scan results was compared against the other.

The results in Figure 3.34 shows the linear regression between the first and the second scan at a 1:1 ratio, which means that a specific gene that is high in one scan is also high in the other scan, and the ones that are low in one, would be low in the other scan. As the $r^{2}=$ from 0.9 to 0.6 , it can be said that the two scans of the same slide are $60-90 \%$ reproducible. 


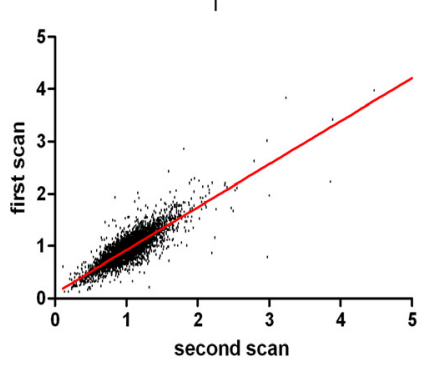

4

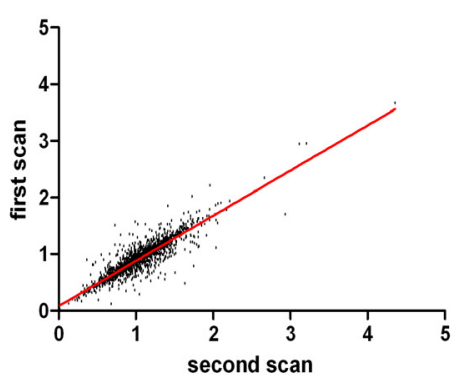

7

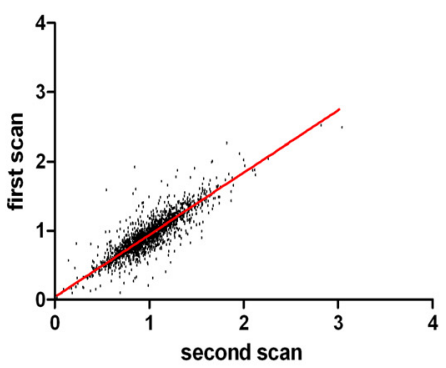

2

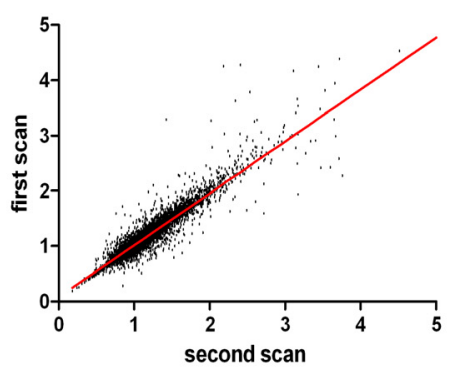

5

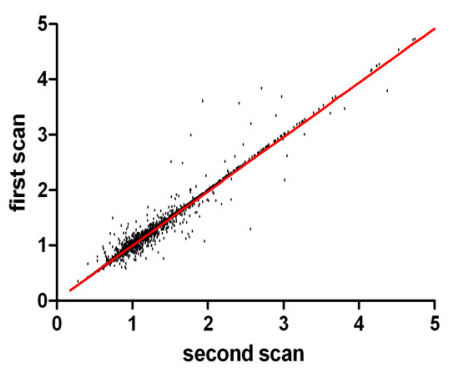

8

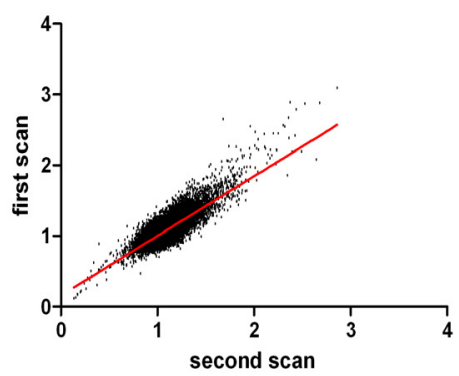

3

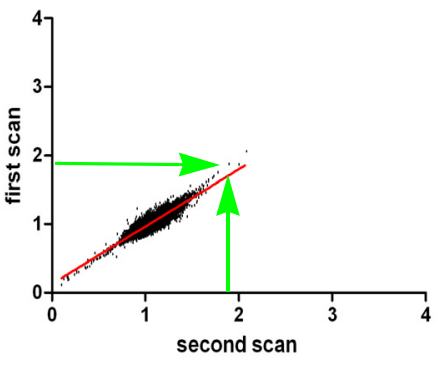

6

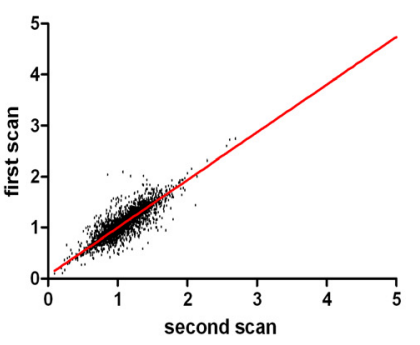

9

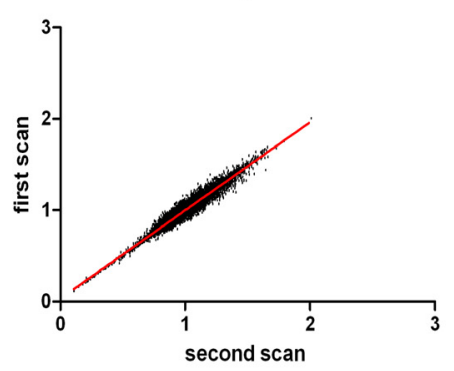

Figure 3.34 Reproducibility of scanning. Each plot shows a comparison between two set of genes of the same slide when scanned twice. On the $\mathrm{Y}$ axis is a set of the fold-inducion of the normalised $\log 2$ ratio of median for the first scan, and the $X$ axis is the same for the second scan, the linear regression line is at a angle at $\sim 45^{\circ}, r^{2}=0.8 \pm 0.1$. The 2 green arrows are pointing to the same spot (gene) indecating that this gene's fold induction is just under 2 in both of the scans, and this is the same for most of the genes. 


\section{Section 3.3.3.2 Reproducibility of hybridization}

It was necessary to ensure that the hybridization in this protocol was repeatable. In this section cDNAs were hybridized on three different sets of slides, then the slides were scanned, and the results from the scans were normalised as shown in Section 2.2.5. The results were then compared. Preliminary experiments showed that, when the same cDNA is hybridized on different slides, they did not give repeatable results as in Figure 3.35. The $r^{2}=0.2 \pm 0.1$ meaning; when comparing a gene from slide 1 against the same gene in slide 2 it gives a different fold induction. Thus the same cDNA when hybridized on different slides gives a $20-30 \%$ similarity. This was a problem, and results from this hybridizations were not reliable. 
cDNA 1

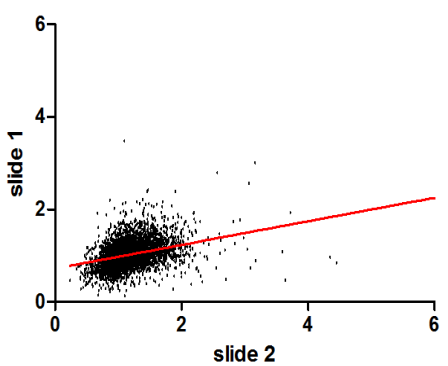

cDNA 4

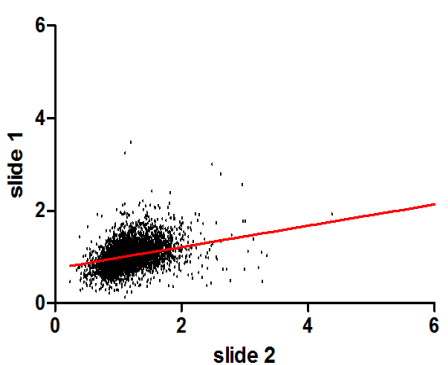

CDNA 7

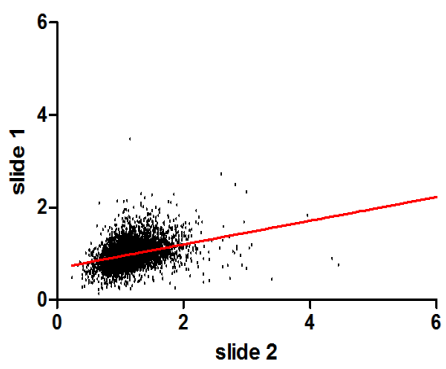

cDNA 2

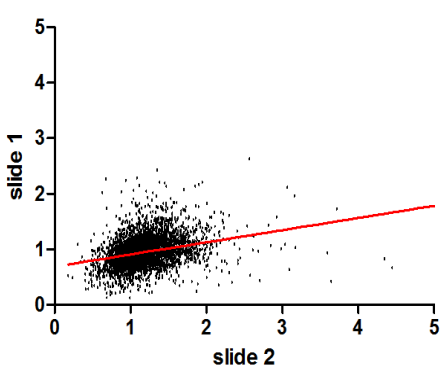

CDNA 5

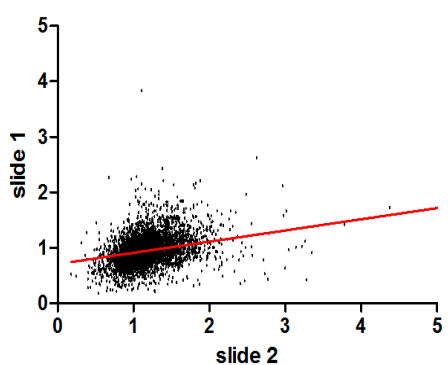

CDNA 8

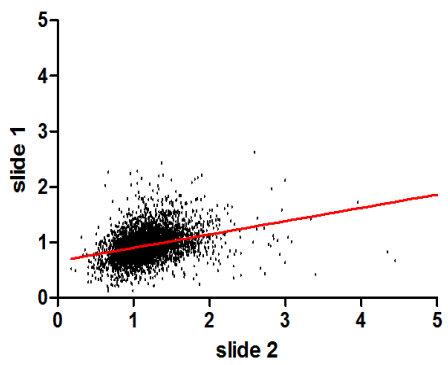

cDNA 3

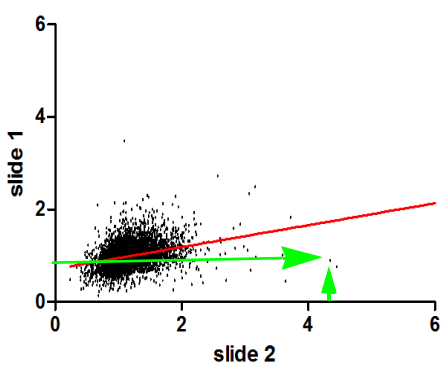

cDNA 6

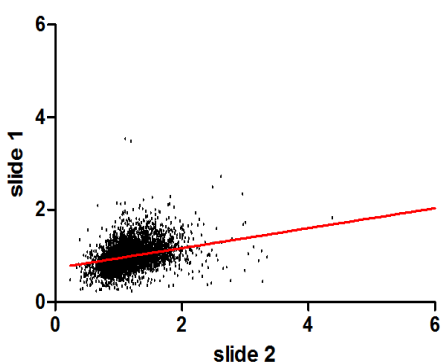

cDNA 9

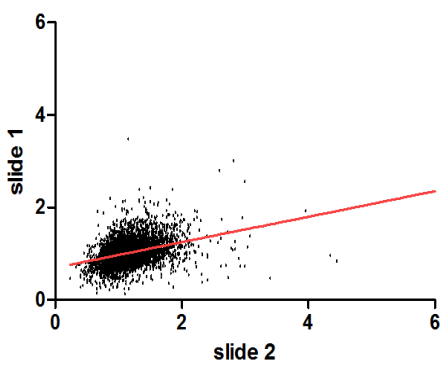

Figure 3.35 Reproducibility of hybridization. Each plot shows two sets of genes from the same cDNA hybridized on different microarray slides, processed as in Figure 3.34. The genes then plotted, the Y axis is a set of the fold-inducion of the normalised $\log 2$ ratio of median for the first slide, and the $\mathrm{X}$ axis is the same for the second slide. The line presents the linear regression line, the $r^{2}=0.2 \pm 0.1$. The green arrows are pointing to the same spot (gene) indecating that the genes fold induction is different in each of the slides (under 1 in the first slide and over 4 in the second slide). 
It was essential to address the issue of not being able to get the same results from the same cDNA hybridized on different slides before being able to consider using the microarray technique for further analysis. Therefore looking into the microarray procedure systematically by checking all the steps (hybridizing, scanning and fitting features) was a reliable technique and the results were comparable to each other and gave a higher $\mathrm{r}^{2}$ (Figure 3.36).

The main area where the error could be made was misplacing the gene names on the gene spots of the slides (human error) when featuring the scan to the GAL file. The improvement here is that when fitting the features greater care was taken and there were also some markers on the slides to indicate where exactly each gene is situated. From the above information it was decided that all the hybridizations have to have technical replicates that were at least $60 \%$ similar to be considered in the analysis. 
cDNA 1

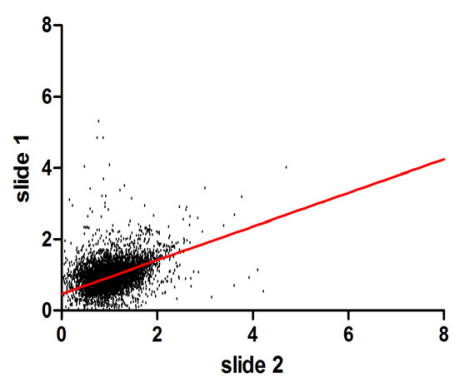

CDNA 4

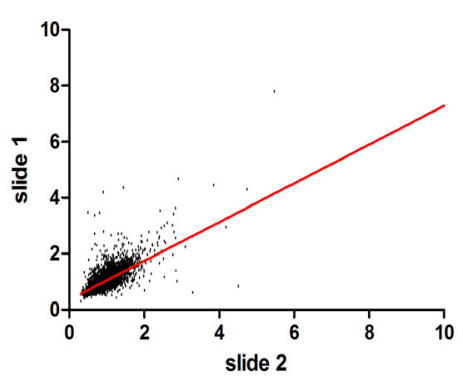

CDNA 7

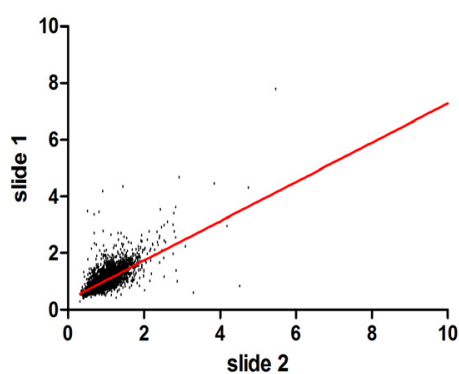

CDNA 2

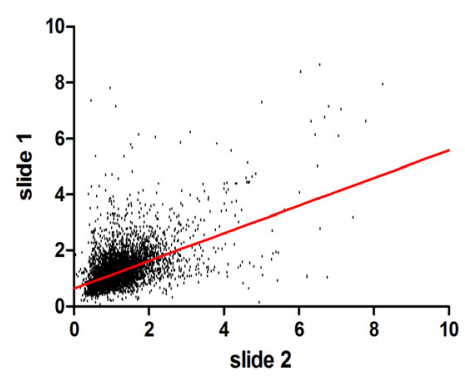

CDNA 5

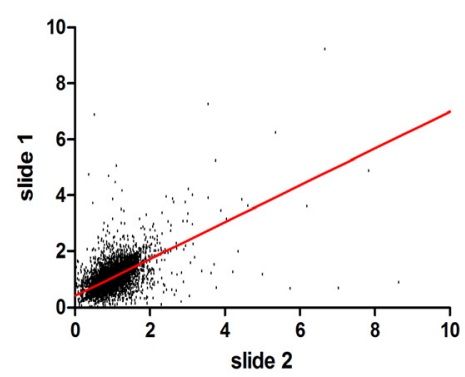

CDNA 8

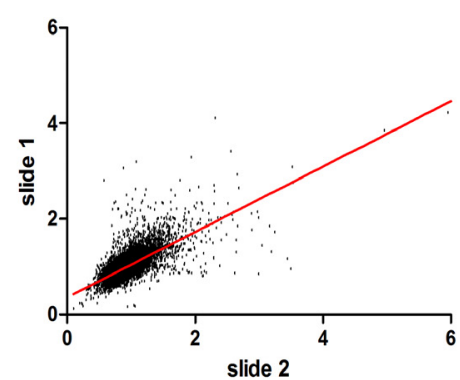

CDNA 3

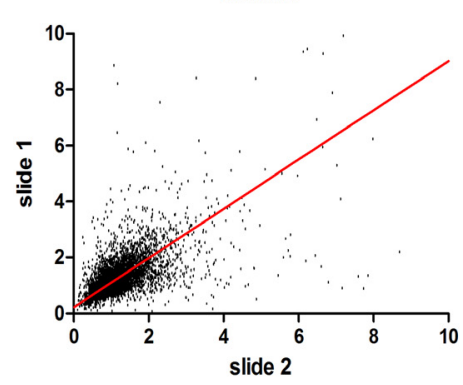

CDNA 6

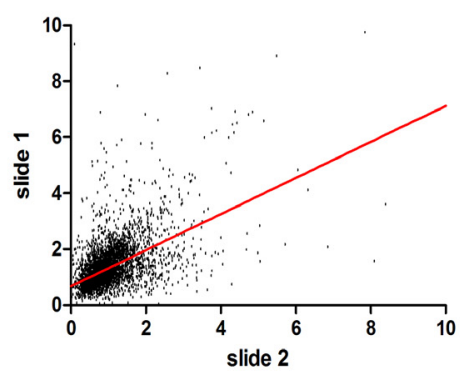

cDNA 9

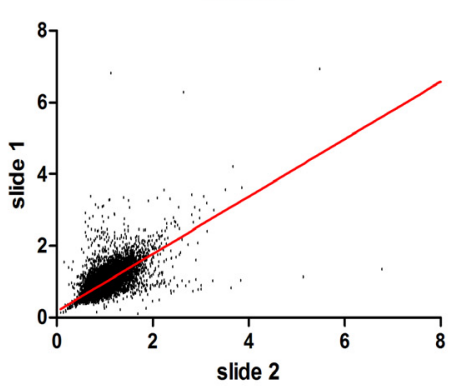

Figure 3.36 Reproducibility of hybridization (improved). Each of the figures show two sets of genes of the same cDNA hybridized on different slides, then processed as in Figure 3.34. The genes were then plotted; on the Y axis is a set of the fold-inducion of the normalised $\log 2$ ratio of median for the first slide, and on $\mathrm{X}$ the same for the second slide. The linear regression line is shown in red and had $\mathrm{ar}^{2}=0.6 \pm 0.1$. The improvement here is when fitting the features more care was taken and there were also some markers on the slides to indicate where exactly each gene is situated on the slide. 


\section{Section 3.3.3.3 Testing of the cDNA concentration}

Because of the expense of the cDNA labelling kit it was desirable to try to decrease these expenses to make it possible to continue with the rest of the planned experiments. So, it was decided to cut the costs in half by diluting the cDNA and spreading what is usually spread on one set of slides to be spread on two sets of slides (to be used as technical replicates). Figure 3.37 shows a comparison between the undiluted cDNA (concentrated 50:1:50 $\mu 1$ of 80ng $\mu \mathrm{l}^{-1}$ labelled-cDNA: tRNA: hybridization buffer) and the diluted cDNA (50:30:2:80 $\mu 1$ of $80 \mathrm{ng}^{\mu \mathrm{l}^{-1}}$ labelled-cDNA:DEPC $\mathrm{H}_{2} \mathrm{O}$ :tRNA: hybridization buffer).

An experiment was designed where 4 replicates of the same cDNA was labelled (the cDNA was from a sample of liver treated with ciprofibrate and killed after 24 hours). cDNA 1, 2 and 3 were hybridized as concentrated, cDNA 4 was diluted and hybridized on 2 sets of slides. The slides were then compared, the diluted against the undiluted.

When comparing the technical replicates, diluted vs. diluted, non-diluted vs. non-diluted and diluted vs. non-diluted, they all gave a similar results of $60 \%$ similarity (the mean and standard deviation of all the $\left.\mathrm{r}^{2}=0.6 \pm 0.1\right)$. This means that the dilution of the cDNA sample did not affect its quality. This dilution method was used for the rest of the experiments. 
CDNA 3

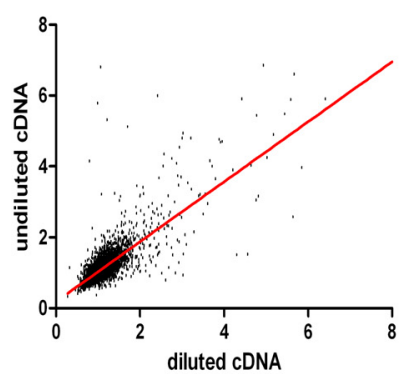

cDNA 4

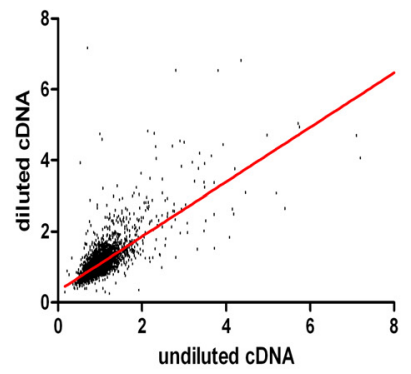

CDNA 7

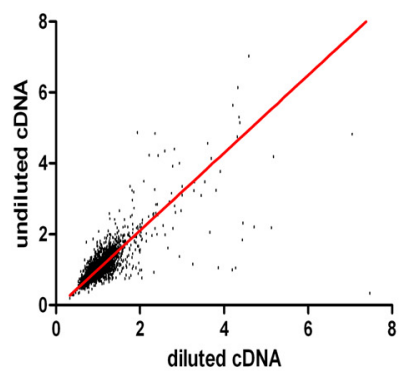

CDNA 1

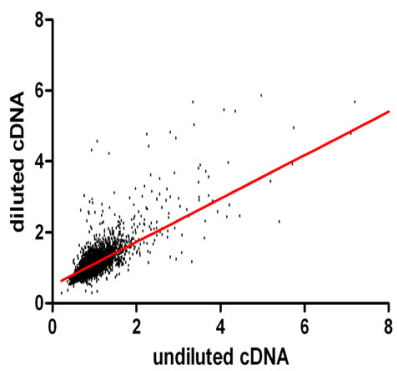

CDNA 5

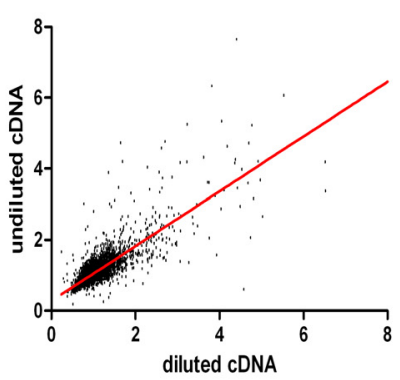

CDNA 8

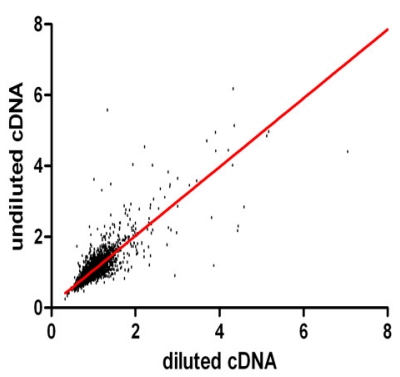

CDNA 2

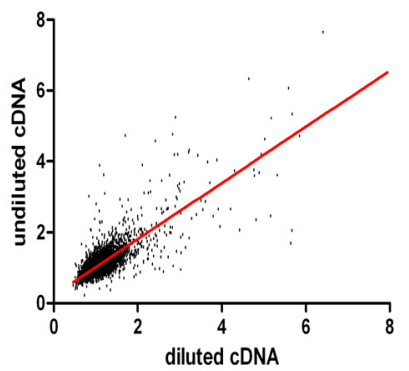

CDNA 9

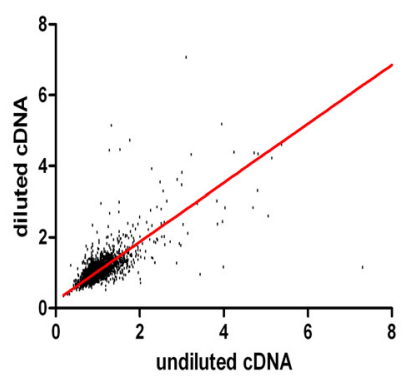

CDNA 6

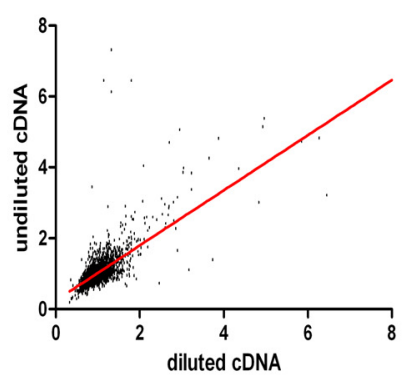

Figure 3.37 Testing of the cDNA concentration. Each of the figures shows a comparison between the diluted cDNA and undiluted cDNA. Hybridized on different slides, then processed as in Figure 3.34. The genes were then plotted as in Figure 3.36. The linear regression line is shown in red and the mean and standard deviation of all the samples is $r^{2}=0.6 \pm 0.1$. 
From these results, it was found that the optimal way to resolve inconsistently issues in microarray procedures was to:

1- Use more replicates, so 4 biological replicates and 2 technical replicates were used.

2- Compare the technical replicates against each other and accept only the results that the $\mathrm{r}^{2}$ is more that 0.6 .
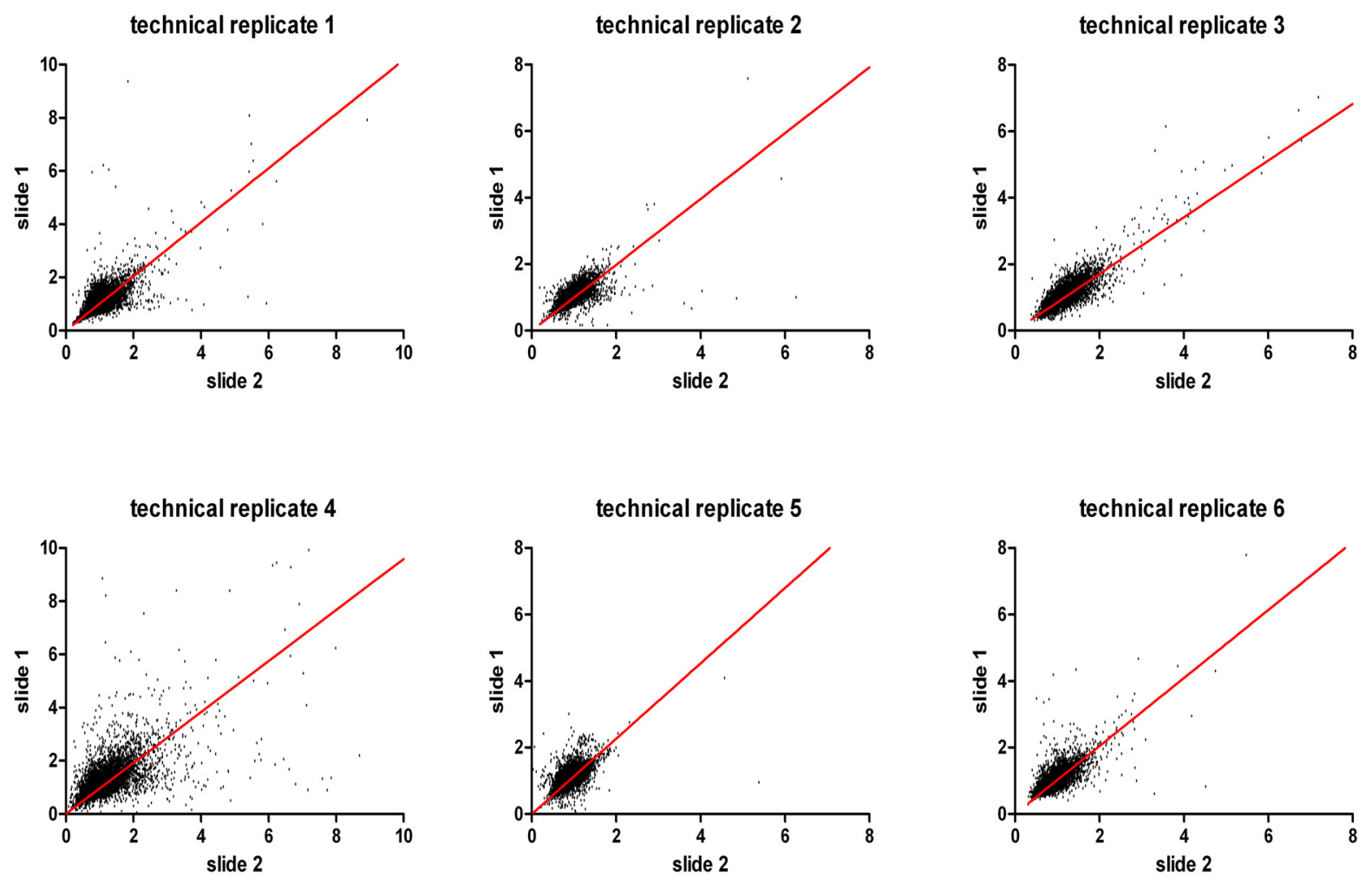

Figure 3.38 Examples of technical replicates . Each plot shows a comparison of technical replicates from the same diluted cDNA. The samples were hybridized on different slides, then processed as in Figure 3.34. The genes were then plotted as in Figure 3.36. The linear regression line is shown in red and the mean and standard deviation of the $\mathrm{r}^{2}=0.6 \pm 0.1$. 


\section{Section 3.3.4 Microarray analysis of dosed rats after 24 hours}

In order to measure the expression levels of early genes that may be up- regulated after dosing of ciprofibrate, and might be responsible for the induction of hepatic DNA synthesis, microarray analysis was applied as in Section 2.2 .5 on F-344 fisher rats dosed with $50 \mathrm{mg} \mathrm{kg}^{-1}$ ciprofibrate, or $100 \mathrm{mg} \mathrm{kg}^{-1} \mathrm{CPA}$, or corn oil and killed after 1, 3, 5 and 24 hours in comparison with the control.

Preliminary results were established from microarray analysis done on F-344 fisher rats treated with ciprofibrate, CPA and corn oil for 24 hours. This was to help ensure that the analysis and processing of the data is reliable, by checking for induction of specific genes (used as markers) that are known from the literature to be induced after 24 hours of dosing with ciprofibrate and CPA.

Analysis of the 24 hour groups with R software revealed 1597 genes whose expression was significantly changed (FDR p-value $<0.05$ ). The whole list is attached in a CD at the end of the Thesis. Table 3.2 shows a list of up- regulated genes for samples treated with ciprofibrate for 24 hours, that have a fold induction of $>1.2$ fold change. These include Cyp4A1 (CYP4A10), a gene that is a known marker for PPAR $\alpha$ agonists treatments. Also an up- regulation of GstYb4 (Gstm3) gene was detected for the F-344HNsd rats dosed with CPA as shown in Table 3.3. This gene is known to be induced by CPA (Krebs et al., 1998). Significantly down- regulated genes for the samples treated with ciprofibrate for 24 hours are listed in Table 3.4, and the samples treated with CPA for 24 hours are listed in Table 3.5. The cut-off for choosing the fold change depended on the number of genes in each group. From this we can say that the microarray method and the analysis used to achieve these results were all reliable and reproducible, and that we could proceed with the analysis of the early hour samples at 1,3 and 5 hours treated with ciprofibrate and CPA. 
Table 3.2 Known up- regulated genes at $\mathbf{2 4}$ hour in ciprofibrate dosed Fisher rats. The list of up- regulated genes for male F-344NHsd rats aged 14-15 weeks dosed with $50 \mathrm{mg} \mathrm{kg}^{-1}$ ciprofibrate then killed after 24 hours. Microarray analysis was carried out as in Section 2.2.5.

\begin{tabular}{|c|c|c|c|}
\hline Description & Name & $\begin{array}{l}\text { Mean fold } \\
\text { change }\end{array}$ & $\begin{array}{l}\text { FDR p- } \\
\text { value }\end{array}$ \\
\hline $\begin{array}{l}\text { Mus musculus 3-ketoacyl-CoA } \\
\text { thiolase B }\end{array}$ & MGC29978 & 3.51 & 0.000001 \\
\hline $\begin{array}{l}\text { Cytochrome P450, family } 4 \text {, } \\
\text { subfamily a, polypeptide } 1\end{array}$ & Cyp4A1 (CYP4A10) & 2.97 & 0.00001 \\
\hline Cytosolic thioesterase 1 & Cte 1 & 2.39 & 0.000001 \\
\hline Member RAS oncogene family & Rab19 & 2.26 & 0.00001 \\
\hline $\begin{array}{l}\text { Solute carrier family } 9 \text { (sodium/ } \\
\text { hydrogen exchanger), member } 2\end{array}$ & Slc9a2 & 1.78 & 0.00001 \\
\hline Tensin 1 & E030037J05Rik & 1.70 & 0.000001 \\
\hline $\begin{array}{l}\text { Mitochondrial ribosomal pro- } \\
\text { tein S18A }\end{array}$ & $18 \mathrm{~S}$ & 1.62 & 0.00001 \\
\hline Lactate dehydrogenase $\mathrm{C}$ & Ldh3 & 1.61 & 0.00001 \\
\hline NMDA receptor regulated 1 & Narg1 & 1.53 & 0.0001 \\
\hline $\begin{array}{l}\text { RIKEN cDNA 5430402E10 } \\
\text { gene }\end{array}$ & 5430402E10Rik & 1.46 & 0.00001 \\
\hline $\begin{array}{l}\text { Polymerase (RNA) II (DNA } \\
\text { directed) polypeptide A }\end{array}$ & Polr2a & 1.46 & 0.00001 \\
\hline \multirow{2}{*}{$\begin{array}{l}\text { Succinate-CoA ligase, alpha } \\
\text { subunit }\end{array}$} & Suclg1 & 1.41 & 0.0001 \\
\hline & LOC14433 & 1.39 & 0.00011 \\
\hline Talin & TIn & 1.37 & 0.0001 \\
\hline $\begin{array}{l}\text { RIKEN cDNA 2300009N04 } \\
\text { gene }\end{array}$ & 2300009N04Rik & 1.33 & 0.0001 \\
\hline $\begin{array}{l}\text { Heat shock protein } 90 \text {, alpha } \\
\text { (cytosolic), }\end{array}$ & Hspca & 1.28 & 0.000001 \\
\hline $\begin{array}{l}\text { UDP glucuronosyltransferase } 1 \\
\text { family, polypeptide A5 }\end{array}$ & Ugt1A5 & 1.27 & 0.000001 \\
\hline Adenosine A2B receptor & Adora2b & 1.26 & 0.000001 \\
\hline $\begin{array}{l}\text { Putative homeodomain tran- } \\
\text { scription factor } 1\end{array}$ & Phtfl & 1.21 & 0.00001 \\
\hline
\end{tabular}


Table 3.3 Known up- regulated genes at 24 hour in CPA dosed Fisher rats. The list of up-regulated genes for male F-344NHsd rats aged 14-15 weeks dosed with $100 \mathrm{mg} \mathrm{kg}^{-1} \mathrm{CPA}$ then killed after 24 hours. Microarray analysis was carried out as in Section 2.2.5

\begin{tabular}{l|l|l|l}
\hline \multicolumn{1}{c|}{ Description } & \multicolumn{1}{c|}{ Name } & $\begin{array}{c}\text { Mean fold } \\
\text { change }\end{array}$ & \multicolumn{1}{c}{$\begin{array}{c}\text { FDR p- } \\
\text { value }\end{array}$} \\
\hline $\begin{array}{l}\text { Glutathione S-transferase Alpha } \\
1\end{array}$ & Gsta1 & 2.01 & 0.0001 \\
\hline Heat Shock Protein A8 & Hspa8 & 1.88 & 0.0001 \\
\hline Glutathione S-transferase Mu 3 & GstYb4 (Gstm3) & 1.87 & 0.0001 \\
\hline $\begin{array}{l}\text { Udp Glucuronosyltransferase 1 } \\
\text { Family, Polypeptide A5 }\end{array}$ & Ugt1a5 & 1.67 & 0.0001 \\
\hline Major Urinary Protein 3 & Mup3 & 1.47 & 0.0001 \\
\hline $\begin{array}{l}\text { Eukaryotic Translation Elonga- } \\
\text { tion Factor 1 Alpha 1 }\end{array}$ & Eef1a1 & 1.42 & 0.0001 \\
\hline Ribosomal Protein S6 & Rps6 & 1.27 & 0.0001 \\
\hline Metallothionein 1a & Mt1 & 1.26 & 0.0001 \\
\hline Ubiquitin C & Ubc & 1.18 & 0.00001 \\
\hline Apolipoprotein A-i & Apoa1 & 1.16 & 0.0001 \\
\hline
\end{tabular}


Table 3.4 Known down- regulated genes at 24 hour in ciprofibrate dosed Fisher rats. The list of the downregulated genes for male F-344NHsd rats aged 14-15 weeks dosed with $50 \mathrm{mg} \mathrm{kg}^{-1}$ ciprofibrate, then killed after 24 hours. Microarray analysis was determined as in Section 2.2.5.

\begin{tabular}{l|l|l|l}
\hline \multicolumn{1}{c|}{ Description } & \multicolumn{1}{|c|}{ Name } & $\begin{array}{c}\text { Mean fold } \\
\text { change }\end{array}$ & \multicolumn{1}{|c}{$\begin{array}{c}\text { FDR p- } \\
\text { value }\end{array}$} \\
\hline Major urinary protein 2 & Mup2 & -2.47 & 0.0001 \\
\hline Zinc finger protein 598 & Zfp598 & -1.85 & 0.002 \\
\hline Fibrinogen gamma chain & Fgg & -1.77 & 0.0001 \\
\hline Murinoglobulin 2 & Mug2 & -1.54 & 0.0001 \\
\hline $\begin{array}{l}\text { Cytochrome P450, family 2, subfamily } \\
\text { c, polypeptide 29 }\end{array}$ & CYP2c29 & -1.44 & 0.0001 \\
\hline $\begin{array}{l}\text { Polymerase (RNA) II (DNA directed) } \\
\text { polypeptide A }\end{array}$ & Polr2a & -1.38 & 0.0001 \\
\hline Brain protein 44-like & Brp441 & -1.27 & 0.0001 \\
\hline Cysteine dioxygenase, type I & Cdo1 & -1.23 & 0.0001 \\
\hline Ornithine carbamoyltransferase & Otc & -1.21 & 0.0001 \\
\hline & Sepina3a & -1.21 & 0.0001 \\
\hline
\end{tabular}

Table 3.5 Known down- regulated genes at 24 hour in CPA dosed Fisher rats. The list of the down- regulated genes for male F-344NHsd rats aged 14-15 weeks dosed with $100 \mathrm{mg} \mathrm{kg}^{-1} \mathrm{CPA}$, then killed after 24 hours. Microarray analysis was determined as in Section 2.2.5.

\begin{tabular}{l|l|l|l}
\hline \multicolumn{1}{c|}{ Description } & \multicolumn{1}{|c|}{ Name } & \multicolumn{1}{|c}{$\begin{array}{c}\text { Mean fold } \\
\text { change }\end{array}$} & $\begin{array}{c}\text { FDR p- } \\
\text { value }\end{array}$ \\
\hline RIKEN cDNA 2300009N04 gene & 2300009N04Rik & -1.52 & 0.00001 \\
\hline Major urinary protein 2 & Mup2 & -1.29 & 0.00001 \\
\hline Ribonuclease, RNase A family 4 & Rnase4 & -1.27 & 0.00001 \\
\hline Transferrin & Trf & -1.19 & 0.00001 \\
\hline $\begin{array}{l}\text { Cytochrome P450, family 2, subfamily } \\
\text { d, polypeptide 26 }\end{array}$ & CYP2d26 & -1.14 & 0.00001 \\
\hline
\end{tabular}


Figure 3.39 shows a heatmap depicting the hepatic genes that were affected by the ciprofibrate after 24 hour treatment: red indicates highly-induced, and blue indicates down- regulation of the genes. These were established with High-Throughput GoMiner (Zeeberg, 2005)). Also the Figure shows the different pathways that are changed with the ciprofibrate dose after 24 hours. The main changed pathways are the fatty acid metabolic process where 5 genes from 14 total genes involved in this process were over expressed (35.7\%), and the monocarboxylic acid metabolic process with 5 out of 19 genes (26.3\%), also, fatty acid $\beta$ oxidation and acyl-CoA metabolic process had both 50\% up- regulation. 


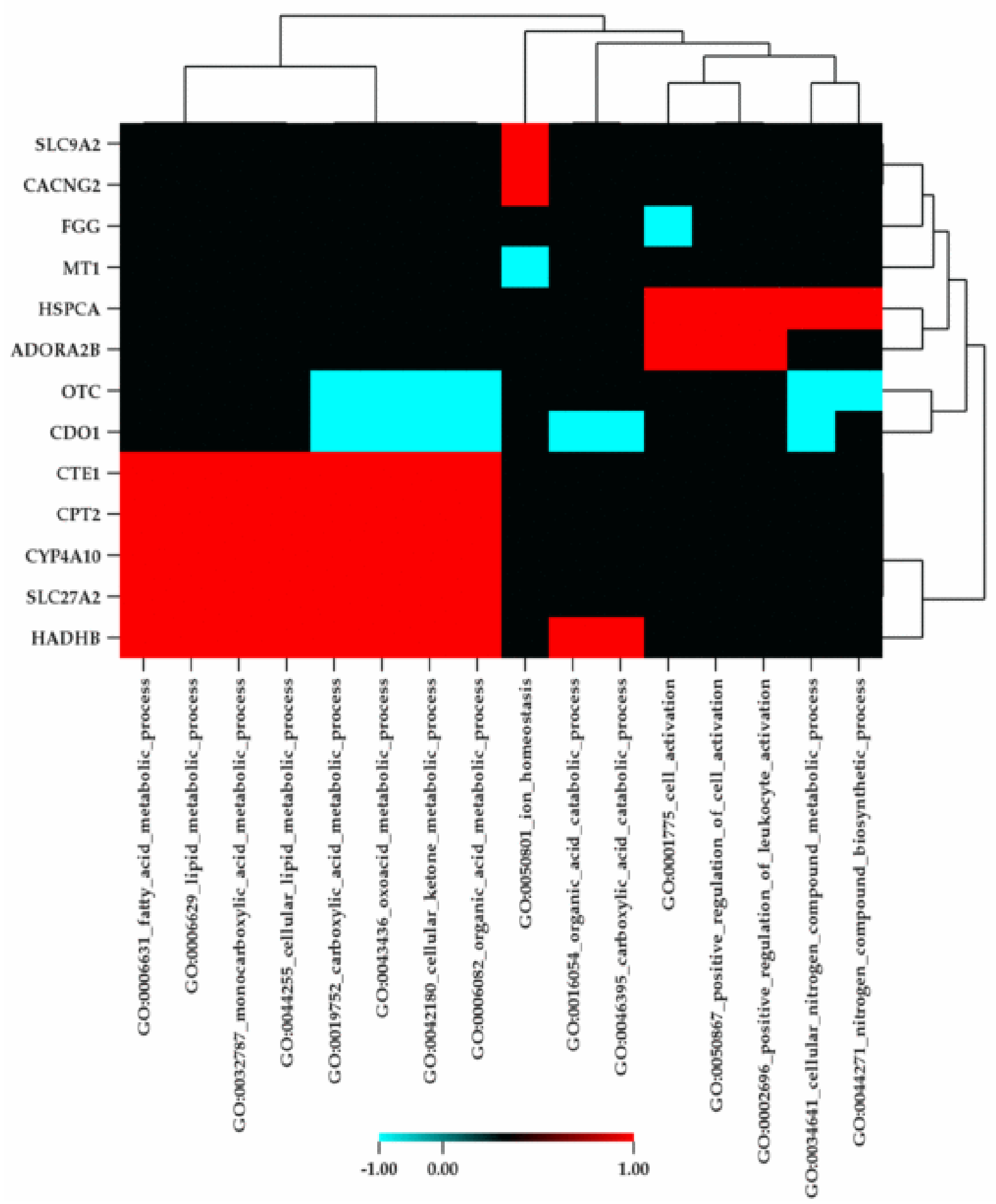

Figure 3.39 Effect of ciprofibrate on gene expression after 24 hour. Male F-344NHsd rats aged 14-15 weeks were dosed with $50 \mathrm{mg}$ kg-1 ciprofibrate, then killed after 24 hours. Microarray analysis was carried out as in Section 2.2.5, this heatmap was established with High-Throughput GoMiner (Zeeberg, 2005). Red demonstrates up- regulated, and blue demonstrates down- regulated ( -1 down- regulated, +1 up- regulated). 
In Figure 3.40 is a heatmap showing the affected hepatic genes up/down- regulated with the CPA after 24 hours: red describes highly induced, and blue demonstrates down- regulated induction of the genes. The Figure shows the different pathways that are changed with the CPA dose after 24 hours. Nevertheless, the highly changed processes are the glutathione transferase activity where 2 of 3 genes are over expressed (66.7\%), the other process is related to the interphase of mitotic cell cycle which is also 2 out of 3 over expressed genes $(66.7 \%)$. 


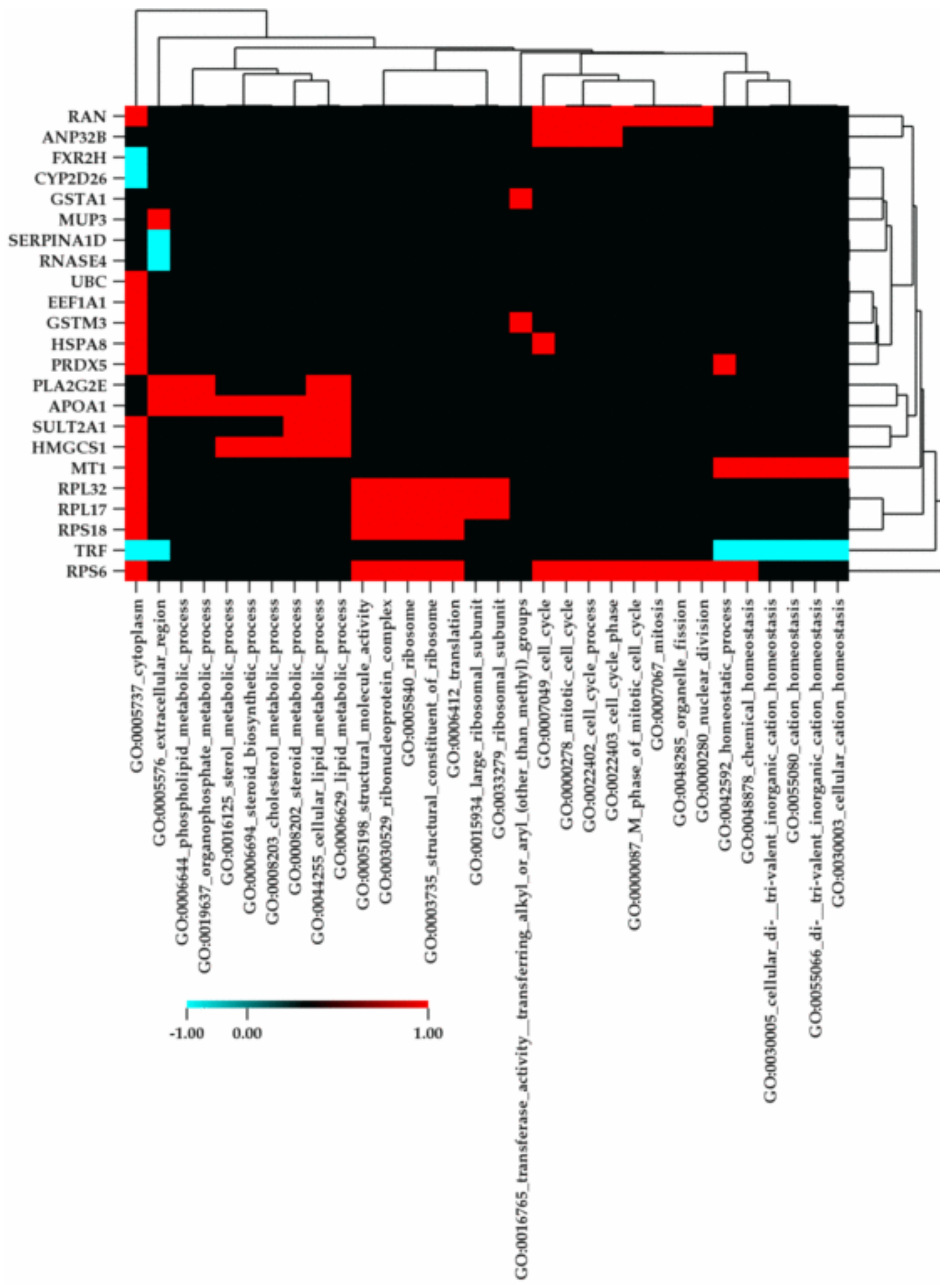

Figure 3.40 Effect of CPA after 24 hour on gene expression. Male F-344NHsd rats aged 14-15 weeks dosed with $100 \mathrm{mg}$ kg-1 CPA, then killed after 24 hours. Microarray analysis was carried out as in Section 2.2.5, this heatmap was established with High-Throughput GoMiner (Zeeberg, 2005). Red demonstrates up- regulated, and blue demonstrates down- regulated (-1 down- regulated, +1 up- regulated). 


\section{Section 3.3.5 Microarray analysis of ciprofibrate dosed rats after 1, 3, and 5 hours}

Having performed preliminary analysis at 24 hours (Section 3.3.4). The microarray analysis of the early hour samples was undertaken. This was done collectively at 1, 3 and 5 hours for the hepatic samples from F-344NHsd fisher rats dosed with $50 \mathrm{mg} \mathrm{kg}^{-1}$ ciprofibrate, $100 \mathrm{mg} \mathrm{kg}^{-1}$ CPA, or corn oil (Section 2.2.5).

The analysis of the 1, 3 and 5 hour groups with R software revealed 1377 significant genes for each of the groups (FDR p-value $<0.05$ ) out of 5826 genes, (the whole list is attached in a CD at the end of the Thesis). A list of the up- regulated genes for the samples treated with ciprofibrate for 1 hour with a fold induction of $>2.6$ fold change is presented in Table 3.6 which include Igf1, Sstr4, Abcc2, mup 1, mmu and Adamts, and the down- regulated genes after 1 hour is found in Table 3.7, while a list of up and down- regulated genes for 3 hour samples are shown in Table 3.8 (fold change $>1.7$ ) and Table 3.9 respectively which include, a number of the up- regulated for 3 hours are Seprinalb, mup4, Mug2, Gstal and Atp8b3. A list of the genes up and downregulated with ciprofibrate after 5 hours are listed in Table 3.10 (fold change $>2.0$ ) and Table 3.11 respectively, the up- regulated genes include Seprina1b, Mug1, Sema5a, My16, Mup4, and Mug4. The different cut-off for the fold changes depends on the number of genes in each of the groups. 
Table 3.6 Up- regulated genes at 1 hour in ciprofibrate dosed Fisher rats. The list of up- regulated genes for male F-344NHsd rats aged 14-15 weeks dosed with $50 \mathrm{mg} \mathrm{kg}^{-1}$ ciprofibrate then killed after 1 hours. Microarray analysis was carried out as in Section 2.2.5.

\begin{tabular}{|c|c|c|c|}
\hline Description & Name & $\begin{array}{l}\text { Mean fold } \\
\text { change }\end{array}$ & $\begin{array}{l}\text { FDR p- } \\
\text { value }\end{array}$ \\
\hline $\begin{array}{l}\text { FXYD domain-containing ion transport } \\
\text { regulator } 2\end{array}$ & Fxyd2 & 3.86 & 0.0001 \\
\hline Insulin-like growth factor 1 & Igf1 & 3.39 & 0.005 \\
\hline Olfactory receptor 976 & Olfr976 & 3.37 & 0.0001 \\
\hline Serine/threonine kinase 3 & Stk3 & 3.29 & 0.0001 \\
\hline N-myc downstream regulated gene 1 & Ndrg1 & 3.19 & 0.0001 \\
\hline Somatostatin receptor 4 & Sstr4 & 3.18 & 0.003 \\
\hline $\begin{array}{l}\text { Adaptor-related protein complex } 1 \text {, sigma } \\
1 \text { subunit }\end{array}$ & Ap1s1 & 3.13 & 0.0001 \\
\hline Thymidylate synthetase & Tyms & 3.09 & 0.0001 \\
\hline Carboxypeptidase A5 & Cpa5 & 3.08 & 0.001 \\
\hline Zinc finger protein 64 & Zfp64 & 3.07 & 0.006 \\
\hline Complement factor $\mathrm{H}$ & Cfh & 3.06 & 0.002 \\
\hline Zinc finger protein 180 & Zfp180 & 2.99 & 0.0001 \\
\hline PDZ domain containing 3 & Pdzk2 & 2.92 & 0.003 \\
\hline $\begin{array}{l}\text { DNA segment, Chr 11, Brigham \& } \\
\text { Women's Genetics } 0517 \text { expressed }\end{array}$ & D11Bwg0517e & 2.91 & 0.0001 \\
\hline CD68 antigen & Cd68 & 2.90 & 0.0001 \\
\hline $\begin{array}{l}\text { Sema domain, seven thrombospondin } \\
\text { repeats, transmembrane domain and short } \\
\text { cytoplasmic domain } 5 \mathrm{~A}\end{array}$ & Sema5a & 2.89 & 0.00011 \\
\hline Serum amyloid A 3 & Saa3 & 2.89 & 0.0001 \\
\hline Chloride intracellular channel 1 & Clic1 & 2.86 & 0.008 \\
\hline Dihydropyrimidinase-like 2 & Dpys12 & 2.86 & 0.008 \\
\hline Proteolipid protein 1 & Plp1 & 2.85 & 0.0001 \\
\hline Otoancorin & Otoa & 2.82 & 0.0001 \\
\hline Kinesin family member 9 & Kif9 & 2.82 & 0.0001 \\
\hline Deoxynucleotidyltransferase, terminal & Dntt & 2.79 & 0.0001 \\
\hline
\end{tabular}


Table 3.6 Up- regulated genes at 1 hour in ciprofibrate dosed Fisher rats. The list of up- regulated genes for male F-344NHsd rats aged 14-15 weeks dosed with $50 \mathrm{mg} \mathrm{kg}^{-1}$ ciprofibrate then killed after 1 hours. Microarray analysis was carried out as in Section 2.2.5.

\begin{tabular}{l|l|l|l}
\hline \multicolumn{1}{c|}{ Description } & \multicolumn{1}{|c|}{ Name } & \multicolumn{1}{c}{$\begin{array}{c}\text { Mean fold } \\
\text { change }\end{array}$} & \multicolumn{1}{c}{$\begin{array}{c}\text { FDR p- } \\
\text { value }\end{array}$} \\
\hline Transmembrane protein 140 & 1110007F12Rik & 2.77 & 0.0001 \\
\hline Telomeric repeat binding factor 2 & Terf2 & 2.77 & 0.003 \\
\hline PWWP domain containing 2A & mmu & 2.76 & 0.001 \\
\hline Chemokine-like receptor 1 & Cmklr1 & 2.74 & 0.008 \\
\hline Galactosyltransferase I & B4galt7 & 2.73 & 0.0001 \\
\hline $\begin{array}{l}\text { Phosphoinositide binding specific) mem- } \\
\text { ber 3 }\end{array}$ & Plekha3 & 2.73 & 0.0001 \\
\hline $\begin{array}{l}\text { Ganglioside-induced differentiation-asso- } \\
\text { ciated protein 1-like 1 }\end{array}$ & Gdap111 & 2.73 & 0.001 \\
\hline BTB (POZ) domain containing 9 & Btbd9 & 2.72 & 0.0001 \\
\hline $\begin{array}{l}\text { ATP-binding cassette, sub-family C } \\
\text { member 2 }\end{array}$ & Abcc2 & 2.72 & 0.0001 \\
\hline Major urinary protein 1 & Mup1 & 2.71 & 0.001 \\
\hline $\begin{array}{l}\text { ADAM metallopeptidase with thrombos- } \\
\text { pondin type 1 motif, 2 }\end{array}$ & Adamts2 & 2.71 & 0.0001 \\
\hline $\begin{array}{l}\text { Mucin 13, cell surface associated } \\
\text { Endoplasmic reticulum protein 44 }\end{array}$ & Ly64 & 2.70 & 0.003 \\
\hline
\end{tabular}


Table 3.7 Down-down- reg regulated genes at 1 hour in ciprofibrate dosed Fisher rats. The list of downregulated genes for male F-344NHsd rats aged 14-15 weeks dosed with $50 \mathrm{mg} \mathrm{kg}^{-1}$ ciprofibrate then killed after 1 hours. Microarray analysis was carried out as in Section 2.2.5.

\begin{tabular}{|c|c|c|c|}
\hline Description & Name & $\begin{array}{l}\text { Mean fold } \\
\text { change }\end{array}$ & $\begin{array}{l}\text { FDR p- } \\
\text { value }\end{array}$ \\
\hline Fibroblast growth factor 21 & Fgf21 & -6.62 & 0.0001 \\
\hline Regulator of G-protein signalling like 2 & Rgs12 & -5.89 & 0.0001 \\
\hline Ubiquitin specific peptidase 28 & Usp28 & -5.74 & 0.0001 \\
\hline Chloride channel 6 & Clcn6 & -5.48 & 0.0001 \\
\hline Aspartyl-tRNA synthetase & Dars & -5.28 & 0.0001 \\
\hline Zinc finger, DHHC-type containing 9 & Zdhhc9 & -5.20 & 0.0001 \\
\hline $\begin{array}{l}\text { ArfGAP with RhoGAP domain, ankyrin } \\
\text { repeat and PH domain } 1\end{array}$ & Centd2 & -4.99 & 0.0001 \\
\hline Origin recognition complex, subunit 6 like & Orc61 & -4.36 & 0.0001 \\
\hline Vanin 3 & Vnn3 & -4.03 & 0.0001 \\
\hline Zinc finger protein 212 & Zfp212 & -4.03 & 0.0001 \\
\hline Poliovirus receptor-related 4 & Pvrl4 & -3.98 & 0.0001 \\
\hline Frizzled homolog 7 & Fzd7 & -3.93 & 0.00011 \\
\hline Transforming growth factor, beta 1 & Tgfb1 & -3.90 & 0.0001 \\
\hline Proprotein convertase subtilisin/kexin type 4 & Pcsk4 & -3.85 & 0.022 \\
\hline $\begin{array}{l}\text { UDP glucuronosyltransferase } 1 \text { family, } \\
\text { polypeptide A6 }\end{array}$ & Ugtla6 & -3.84 & 0.0001 \\
\hline Rho GDP dissociation inhibitor (GDI) alpha & Arhgdia & -3.83 & 0.0001 \\
\hline $\begin{array}{l}\text { PRP4 pre-mRNA processing factor } 4 \\
\text { homolog }\end{array}$ & Prpf4 & -3.75 & 0.0001 \\
\hline $\begin{array}{l}\text { Immunoglobulin superfamily, DCC sub- } \\
\text { class, member } 3\end{array}$ & Punc & -3.65 & 0.0001 \\
\hline $\begin{array}{l}\text { MAP/microtubule affinity-regulating kinase } \\
2\end{array}$ & Mark2 & -3.65 & 0.012 \\
\hline $\begin{array}{l}\text { WD repeat and HMG-box DNA binding } \\
\text { protein } 1\end{array}$ & Wdhd 1 & -3.60 & 0.0001 \\
\hline Tubulin folding cofactor B & Ckap1 & -3.32 & 0.0001 \\
\hline Keratinocyte associated protein 2 & Krtcap2 & -3.29 & 0.0001 \\
\hline Homeobox A3 & Hoxa3 & -3.22 & 0.0001 \\
\hline
\end{tabular}


Table 3.7 Down-down- reg regulated genes at 1 hour in ciprofibrate dosed Fisher rats. The list of downregulated genes for male F-344NHsd rats aged 14-15 weeks dosed with $50 \mathrm{mg} \mathrm{kg}^{-1}$ ciprofibrate then killed after 1 hours. Microarray analysis was carried out as in Section 2.2.5.

\begin{tabular}{|c|c|c|c|}
\hline Description & Name & $\begin{array}{l}\text { Mean fold } \\
\text { change }\end{array}$ & $\begin{array}{l}\text { FDR p- } \\
\text { value }\end{array}$ \\
\hline Cystathionase (cystathionine gamma-lyase) & Cth & -3.09 & 0.0001 \\
\hline $\begin{array}{l}\text { ASF1 anti-silencing function } 1 \text { homolog B } \\
\text { (S. cerevisiae) }\end{array}$ & Asflb & -3.02 & 0.001 \\
\hline E2F transcription factor 2 & $\mathrm{E} 2 \mathrm{f} 2$ & -2.84 & 0.002 \\
\hline Rho-related BTB domain containing 2 & Rhobtb2 & -2.82 & 0.004 \\
\hline Uracil DNA glycosylase & Ung & -2.75 & 0.001 \\
\hline CD97 antigen & $\mathrm{Cd} 97$ & -2.74 & 0.0001 \\
\hline Pro-platelet basic protein & $\mathrm{Cxcl} 7$ & -2.72 & 0.0001 \\
\hline $\begin{array}{l}\text { Mannosyl (alpha-1,6-)-glycoprotein beta- } \\
\text { 1,2-N-acetylglucosaminyltransferase }\end{array}$ & GnT & -2.69 & 0.005 \\
\hline Glucosamine-6-phosphate deaminase 2 & Gnpda2 & -2.69 & 0.019 \\
\hline Jagged 2 & Jag2 & -2.64 & 0.016 \\
\hline Immunoglobulin kappa chain variable 28 & IGKV2 & -2.64 & 0.008 \\
\hline HIV-1 Rev binding protein 2 & Hrb2 & -2.55 & 0.003 \\
\hline $\begin{array}{l}\text { Antigen identified by monoclonal antibody } \\
\text { Ki-67 }\end{array}$ & Mki67 & -2.55 & 0.0001 \\
\hline Vomeronasal 1 receptor, $\mathrm{H} 3$ & V1rh3 & -2.47 & 0.001 \\
\hline Ubiquitin-like modifier activating enzyme 1 & Ube1x & -2.34 & 0.0001 \\
\hline Formiminotransferase cyclodeaminase & Ftcd & -2.30 & 0.0001 \\
\hline $\begin{array}{l}\text { Phenylalanyl-tRNA synthetase } 2 \text {, mitochon- } \\
\text { drial }\end{array}$ & Fars1 & -2.26 & 0.001 \\
\hline Zinc finger protein 364 & Zfp364 & -2.24 & 0.0001 \\
\hline RAR-related orphan receptor B & Rorb & -2.20 & 0.0001 \\
\hline TNFAIP3 interacting protein 1 & Tnip1 & -2.17 & 0.035 \\
\hline $\begin{array}{l}\text { Cas-Br-M (murine) ecotropic retroviral } \\
\text { transforming sequence } b\end{array}$ & Cblb & -2.16 & 0.001 \\
\hline Splicing factor, arginine/serine-rich 9 & Sfrs9 & -2.12 & 0.0001 \\
\hline Papillary renal cell carcinoma & Prcc & -2.04 & 0.007 \\
\hline $\begin{array}{l}\text { Receptor-interacting serine-threonine kinase } \\
2\end{array}$ & Ripk2 & -2.04 & 0.003 \\
\hline
\end{tabular}


Table 3.7 Down-down- reg regulated genes at 1 hour in ciprofibrate dosed Fisher rats. The list of downregulated genes for male F-344NHsd rats aged 14-15 weeks dosed with $50 \mathrm{mg} \mathrm{kg}^{-1}$ ciprofibrate then killed after 1 hours. Microarray analysis was carried out as in Section 2.2.5.

\begin{tabular}{l|l|l|l}
\hline \multicolumn{1}{c|}{ Description } & \multicolumn{1}{|c|}{ Name } & $\begin{array}{c}\text { Mean fold } \\
\text { change }\end{array}$ & \multicolumn{1}{|c}{$\begin{array}{c}\text { FDR p- } \\
\text { value }\end{array}$} \\
\hline $\begin{array}{l}\text { Phosphate regulating endopeptidase } \\
\text { homolog, X-linked }\end{array}$ & Phex & -2.02 & 0.021 \\
\hline Xylosyltransferase II & Xylt2 & -2.02 & 0.045 \\
\hline Pumilio homolog 1 & Pum1 & -2.01 & 0.001 \\
\hline $\begin{array}{l}\text { Phosphodiesterase 4D interacting protein } \\
\text { (myomegalin) }\end{array}$ & Usmg4 & -2.01 & 0.003 \\
\hline
\end{tabular}


Table 3.8 Up- regulated genes after 3 hours in ciprofibrate dosed Fisher rats. The list of up- regulated genes for male F-344NHsd rats aged 14-15 weeks dosed with $50 \mathrm{mg} \mathrm{kg}^{-1}$ ciprofibrate then killed after 3 hours. Microarray analysis was carried out as in Section 2.2.5.

\begin{tabular}{|c|c|c|c|}
\hline Description & Name & $\begin{array}{l}\text { Mean fold } \\
\text { change }\end{array}$ & $\begin{array}{l}\text { FDR p- } \\
\text { value }\end{array}$ \\
\hline $\begin{array}{l}\text { Proteasome (prosome, } \\
\text { macropain) subunit, beta type } 9\end{array}$ & Psmb9 & 3.65 & 0.0001 \\
\hline $\begin{array}{l}\text { Inositol polyphosphate phos- } \\
\text { phatase-like } 1\end{array}$ & Inppl1 & 3.07 & 0.001 \\
\hline Opioid growth factor receptor & Ogfr & 2.95 & 0.0001 \\
\hline Serum amyloid A 3 & Saa3 & 2.71 & 0.0001 \\
\hline Transmembrane protein 222 & D4Ertd196e & 2.47 & 0.0001 \\
\hline Otoancorin & Otoa & 2.43 & 0.0001 \\
\hline Histone cluster $1, \mathrm{H} 2 \mathrm{af}$ & Hist1h2af & 2.40 & 0.0001 \\
\hline Hemopexin & Hpxn & 2.24 & 0.005 \\
\hline Olfactory receptor 1395 & Olfr1395 & 2.23 & 0.000 \\
\hline Serine/threonine kinase 25 & Stk25 & 2.17 & 0.003 \\
\hline $\begin{array}{l}\text { UDP-GlcNAc:betaGal beta-1,3- } \\
\text { N-acetylglucosaminyltrans- } \\
\text { ferase } 7\end{array}$ & B3gnt7 & 2.17 & 0.0001 \\
\hline Iroquois homeobox 1 & Irx1 & 2.06 & 0.001 \\
\hline WW domain binding protein 1 & Wbp1 & 2.05 & 0.002 \\
\hline $\begin{array}{l}\text { Serine (or cysteine) preptidase } \\
\text { inhibitor, clade } A \text {, member } 1 \mathrm{~B}\end{array}$ & Serpinalb & 2.05 & 0.001 \\
\hline Major urinary protein 4 & Mup4 & 2.03 & 0.006 \\
\hline Insulin 1 & Ins1 & 2.02 & 0.000 \\
\hline Group specific component & $\mathrm{Gc}$ & 2.02 & 0.000 \\
\hline FLYWCH-type zinc finger 1 & E030034P13Rik & 2.01 & 0.000 \\
\hline $\begin{array}{l}\text { Extracellular matrix component; } \\
\text { may play a role in fibrosis and } \\
\text { tumour metastasis }\end{array}$ & Fn1 & 1.96 & 0.000 \\
\hline Testis expressed 264 & Tex264 & 1.92 & 0.005 \\
\hline Metallothionein 1 , pseudogene 1 & Mt1 & 1.90 & 0.001 \\
\hline DAZ associated protein 1 & Dazap1 & 1.89 & 0.000 \\
\hline
\end{tabular}


Table 3.8 Up- regulated genes after 3 hours in ciprofibrate dosed Fisher rats. The list of up- regulated genes for male F-344NHsd rats aged 14-15 weeks dosed with $50 \mathrm{mg} \mathrm{kg}^{-1}$ ciprofibrate then killed after 3 hours. Microarray analysis was carried out as in Section 2.2.5.

\begin{tabular}{|c|c|c|c|}
\hline Description & Name & $\begin{array}{l}\text { Mean fold } \\
\text { change }\end{array}$ & $\begin{array}{l}\text { FDR p- } \\
\text { value }\end{array}$ \\
\hline $\begin{array}{l}\text { DNA (cytosine-5-)-methyltrans- } \\
\text { ferase 3-like }\end{array}$ & Dnmt31 & 1.87 & 0.007 \\
\hline $\begin{array}{l}\text { Serpin peptidase inhibitor, clade } \\
\text { A } 1\end{array}$ & Serpinal & 1.87 & 0.001 \\
\hline Ventral anterior homeobox 2 & $\operatorname{Vax} 2$ & 1.87 & 0.0001 \\
\hline $\begin{array}{l}\text { Receptor (G protein-coupled) } \\
\text { activity modifying protein } 2\end{array}$ & Ramp2 & 1.83 & 0.0001 \\
\hline $\begin{array}{l}\text { Deiodinase, iodothyronine, type } \\
\text { III }\end{array}$ & Dio3 & 1.81 & 0.006 \\
\hline $\begin{array}{l}\text { Coiled-coil domain containing } \\
146\end{array}$ & 4930528G09Rik & 1.80 & 0.004 \\
\hline Ribosomal protein S17 & Rps17 & 1.78 & 0.001 \\
\hline Cathepsin Z & Ctsz & 1.76 & 0.0001 \\
\hline $\begin{array}{l}\text { Glutathione S-transferase alpha } \\
1\end{array}$ & Gsta1 & 1.75 & 0.0001 \\
\hline Murinoglobulin 2 & Mug2 & 1.75 & 0.0001 \\
\hline $\begin{array}{l}\text { ATPase, Class I, type } 8 B \text {, mem- } \\
\text { ber } 3\end{array}$ & Atp8b3 & 1.74 & 0.0001 \\
\hline $\begin{array}{l}\text { RIKEN cDNA 1700048F04 } \\
\text { gene }\end{array}$ & 1700048F04Rik & 1.74 & 0.002 \\
\hline $\begin{array}{l}\text { Interferon, alpha-inducible pro- } \\
\text { tein } 27 \text { like } 1\end{array}$ & D12Ertd647e & 1.74 & 0.004 \\
\hline $\begin{array}{l}\text { Coiled-coil domain containing } \\
89\end{array}$ & 1700019B01Rik & 1.72 & 0.001 \\
\hline Synaptogyrin 4 & Syngr4 & 1.70 & 0.0001 \\
\hline
\end{tabular}


Table 3.9 Down- regulated genes after 3 hours in ciprofibrate dosed Fisher rats. The list of down- regulated genes for male F-344NHsd rats aged 14-15 weeks dosed with $50 \mathrm{mg} \mathrm{kg}^{-1}$ ciprofibrate then killed after 3 hours. Microarray analysis was carried out as in Section 2.2.5.

\begin{tabular}{|c|c|c|c|}
\hline Discription & Name & $\begin{array}{l}\text { Mean fold } \\
\text { change }\end{array}$ & $\begin{array}{l}\text { FDR p- } \\
\text { value }\end{array}$ \\
\hline $\begin{array}{l}\text { 6-phosphofructo-2-kinase/fructose- } \\
\text { 2,6-biphosphatase } 2\end{array}$ & Pfkfb2 & -3.55 & 0.0001 \\
\hline Intraflagellar transport 122 homolog & Wdr10 & -2.97 & 0.0001 \\
\hline $\begin{array}{l}\text { Cystathionase (cystathionine gamma- } \\
\text { lyase) }\end{array}$ & Cth & -2.62 & 0.0001 \\
\hline $\begin{array}{l}\text { KH domain containing, RNA binding, } \\
\text { signal transduction associated } 2\end{array}$ & Khdrbs2 & -2.45 & 0.0001 \\
\hline $\begin{array}{l}\text { C-type lectin domain family } 4 \text {, mem- } \\
\text { ber e }\end{array}$ & Clecsf9 & -2.39 & 0.011 \\
\hline Casein kinase 2 , alpha 1 polypeptide & Csnk2a1 & -2.37 & 0.025 \\
\hline Transportin 1 & Tnpo1 & -2.04 & 0.002 \\
\hline $\begin{array}{l}\text { Potassium voltage-gated channel, } \\
\text { KQT-like subfamily, member } 2\end{array}$ & Kcnq2 & -2.02 & 0.008 \\
\hline
\end{tabular}


Table 3.10 Up- regulated genes after 5 hours in ciprofibrate dosed Fisher rats. The list of up- regulated genes for male F-344NHsd rats aged 14-15 weeks dosed with $50 \mathrm{mg} \mathrm{kg}^{-1}$ ciprofibrate then killed after 5 hours. Microarray analysis was carried out as in Section 2.2.5.

\begin{tabular}{|c|c|c|c|}
\hline Description & Name & $\begin{array}{l}\text { Mean fold } \\
\text { change }\end{array}$ & $\begin{array}{l}\text { FDR p- } \\
\text { value }\end{array}$ \\
\hline Group specific component & $\mathrm{Gc}$ & 3.64 & 0.0001 \\
\hline Apolipoprotein B & Apob & 2.92 & 0.0001 \\
\hline Dual specificity phosphatase 14 & Dusp14 & 2.88 & 0.0001 \\
\hline $\begin{array}{l}\text { Mucin 2, oligomeric mucus/gel-form- } \\
\text { ing }\end{array}$ & Muc2 & 2.88 & 0.0001 \\
\hline Glucosidase, alpha; neutral C & 5830445O15Rik & 2.86 & 0.004 \\
\hline $\begin{array}{l}\text { Serine (or cysteine) preptidase inhibi- } \\
\text { tor, clade A, member } 1 \mathrm{~B}\end{array}$ & Serpina $1 b$ & 2.81 & 0.001 \\
\hline Kininogen 1 & Kng1 & 2.79 & 0.0001 \\
\hline Murinoglobulin 1 & Mug1 & 2.76 & 0.0001 \\
\hline Hemopexin & Hpxn & 2.57 & 0.005 \\
\hline Metallothionein 1 & Mt1 & 2.55 & 0.001 \\
\hline $\begin{array}{l}\text { Microtubule-associated protein } 7 \\
\text { domain containing } 1\end{array}$ & ВC019977 & 2.54 & 0.0001 \\
\hline $\begin{array}{l}\text { Potassium voltage-gated channel, sub- } \\
\text { family } \mathrm{H} \text {, member } 1\end{array}$ & Kcnh1 & 2.48 & 0.001 \\
\hline $\begin{array}{l}\text { Hyaluronan and proteoglycan link pro- } \\
\text { tein } 4\end{array}$ & Hapln4 & 2.42 & 0.0001 \\
\hline Per-hexamer repeat gene 5 & Phxr5 & 2.41 & 0.003 \\
\hline $\begin{array}{l}\text { Peptidylprolyl isomerase A (cyclophi- } \\
\text { lin A) }\end{array}$ & Ppia & 2.41 & 0.0001 \\
\hline $\begin{array}{l}\text { Sortilin-related VPS10 domain con- } \\
\text { taining receptor } 2\end{array}$ & Sorcs2 & 2.40 & 0.002 \\
\hline $\begin{array}{l}\text { Serine (or cysteine) proteinase inhibi- } \\
\text { tor, clade } \mathrm{A}, \text { member } 3 \mathrm{M}\end{array}$ & Serpina3m & 2.39 & 0.001 \\
\hline Gulonolactone (L-) oxidase & Gulo & 2.39 & 0.0001 \\
\hline Transmembrane protein $41 \mathrm{a}$ & 5730578N08Rik & 2.37 & 0.001 \\
\hline RIKEN cDNA $1700001 \mathrm{G} 17$ gene & 1700001G17Rik & 2.32 & 0.0001 \\
\hline RIKEN cDNA 4930543D07 gene & 4930543D07Rik & 2.31 & 0.005 \\
\hline
\end{tabular}


Table 3.10 Up- regulated genes after 5 hours in ciprofibrate dosed Fisher rats. The list of up- regulated genes for male F-344NHsd rats aged 14-15 weeks dosed with $50 \mathrm{mg} \mathrm{kg}^{-1}$ ciprofibrate then killed after 5 hours. Microarray analysis was carried out as in Section 2.2.5.

\begin{tabular}{|c|c|c|c|}
\hline Description & Name & $\begin{array}{l}\text { Mean fold } \\
\text { change }\end{array}$ & $\begin{array}{l}\text { FDR p- } \\
\text { value }\end{array}$ \\
\hline $\begin{array}{l}\text { Sema domain, seven thrombospondin } \\
\text { repeats transmembrane domain } 5 \mathrm{~B}\end{array}$ & Sema5b & 2.31 & 0.004 \\
\hline $\begin{array}{l}\text { Sema domain, seven thrombospondin } \\
\text { repeats transmembrane domain } 5 \mathrm{~A}\end{array}$ & Sema5a & 2.29 & 0.0001 \\
\hline Fructose-1,6-bisphosphatase 1 & Fbp1 & 2.27 & 0.0001 \\
\hline Myosin, light chain 6 & Myl6 & 2.27 & 0.001 \\
\hline Collagen, type XI, alpha 2 & Coll1a2 & 2.26 & 0.005 \\
\hline Major urinary protein 4 & Mup4 & 2.26 & 0.006 \\
\hline $\begin{array}{l}\text { Human immunodeficiency virus type I } \\
\text { enhancer binding protein } 1\end{array}$ & Hivep1 & 2.26 & 0.0001 \\
\hline Serum amyloid P-component & Apcs & 2.24 & 0.0001 \\
\hline B9 protein domain 1 & Eppb9 & 2.22 & 0.0001 \\
\hline Ankyrin repeat domain 40 & Gcap 15 & 2.22 & 0.00011 \\
\hline $\begin{array}{l}\text { Propionyl-coenzyme A carboxylase, } \\
\text { alpha polypeptide }\end{array}$ & Pcca & 2.20 & 0.001 \\
\hline Murinoglobulin 2 & Mug2 & 2.17 & 0.0001 \\
\hline Metallothionein 4 & Mt4 & 2.17 & 0.009 \\
\hline $\begin{array}{l}\text { Ubiquitin A-52 residue ribosomal pro- } \\
\text { tein fusion product } 1\end{array}$ & Uba52 & 2.16 & 0.002 \\
\hline Ceruloplasmin & $\mathrm{Cp}$ & 2.16 & 0.0001 \\
\hline Prostaglandin E synthase 2 & Ptges2 & 2.16 & 0.0001 \\
\hline Fetuin B & Fetub & 2.16 & 0.001 \\
\hline Glutathione transferase zeta 1 & Gstz1 & 2.13 & 0.0001 \\
\hline RIKEN cDNA 4930444A02 gene & 4930444A02Rik & 2.13 & 0.0001 \\
\hline $\begin{array}{l}\text { Vitamin K epoxide reductase complex, } \\
\text { subunit } 1\end{array}$ & Vkorc1 & 2.12 & 0.006 \\
\hline RIKEN cDNA 2010107G23 gene & 2010107G23Rik & 2.11 & 0.007 \\
\hline Olfactory receptor 123 & Olfr 123 & 2.11 & 0.003 \\
\hline
\end{tabular}


Table 3.11 Down- regulated genes after 5 hours in ciprofibrate dosed Fisher rats. The list of downregulated genes for male F-344NHsd rats aged 14-15 weeks dosed with $50 \mathrm{mg} \mathrm{kg}^{-1}$ ciprofibrate then killed after 5 hours. Microarray analysis was carried out as in Section 2.2.5.

\begin{tabular}{|c|c|c|c|}
\hline Description & Name & $\begin{array}{l}\text { Mean fold } \\
\text { change }\end{array}$ & $\begin{array}{l}\text { FDR p- } \\
\text { value }\end{array}$ \\
\hline NmrA-like family domain containing 1 & 1110025F24Rik & -4.91 & 0.00001 \\
\hline $\begin{array}{l}\text { Neural precursor cell expressed, develop- } \\
\text { mentally down-regulated } 4\end{array}$ & Nedd4 & -4.49 & 0.00001 \\
\hline Zinc finger, MIZ-type containing 1 & $\mathrm{BC} 065120$ & -4.31 & 0.00001 \\
\hline $\begin{array}{l}\text { RAS (RAD and GEM)-like GTP-binding } \\
1\end{array}$ & Rem1 & -3.79 & 0.00001 \\
\hline Adenylate cyclase 8 (brain) & Adcy 8 & -3.57 & 0.00001 \\
\hline Taste receptor, type 2, member 116 & Tas2r116 & -3.50 & 0.026 \\
\hline Phosphofructokinase, platelet & Pfkp & -3.41 & 0.0001 \\
\hline Rab40c, member RAS oncogene family & Rab40c & -3.35 & 0.027 \\
\hline $\begin{array}{l}\text { Mucin 5AC, oligomeric mucus/gel-form- } \\
\text { ing }\end{array}$ & Muc5ac & -3.19 & 0.0001 \\
\hline Tubulin folding cofactor B & Ckap1 & -3.16 & 0.0001 \\
\hline $\begin{array}{l}\text { Cas-Br-M (murine) ecotropic retroviral } \\
\text { transforming sequence } b\end{array}$ & Cblb & -3.10 & 0.005 \\
\hline $\begin{array}{l}\text { Acyl-Coenzyme A dehydrogenase, short/ } \\
\text { branched chain }\end{array}$ & Acadsb & -2.93 & 0.0001 \\
\hline Cyclin B3 & Ccnb3 & -2.89 & 0.00001 \\
\hline RAN binding protein 1 & Ranbp1 & -2.89 & 0.004 \\
\hline RAB interacting factor & Rabif & -2.87 & 0.001 \\
\hline Usher syndrome $1 \mathrm{C}$ binding protein 1 & Ushbp1 & -2.81 & 0.0001 \\
\hline Zinc finger protein 212 & Zfp212 & -2.70 & 0.0001 \\
\hline Diazepam binding inhibitor-like 5 & Dbil5 & -2.70 & 0.030 \\
\hline Immunoglobulin lambda chain complex & Igl & -2.68 & 0.00011 \\
\hline $\begin{array}{l}\text { Minichromosome maintenance complex } \\
\text { component } 5\end{array}$ & Mcm5 & -2.55 & 0.0001 \\
\hline TPX2, microtubule-associated, homolog & Tpx2 & -2.50 & 0.004 \\
\hline Olfactory receptor 609 & Olfr609 & -2.46 & 0.026 \\
\hline Casein kinase 2 , alpha 1 polypeptide & Csnk2a1 & -2.43 & 0.025 \\
\hline
\end{tabular}


Table 3.11 Down- regulated genes after 5 hours in ciprofibrate dosed Fisher rats. The list of downregulated genes for male F-344NHsd rats aged 14-15 weeks dosed with $50 \mathrm{mg} \mathrm{kg}^{-1}$ ciprofibrate then killed after 5 hours. Microarray analysis was carried out as in Section 2.2.5.

\begin{tabular}{l|l|l|l}
\hline \multicolumn{1}{c|}{ Description } & \multicolumn{1}{|c|}{ Name } & $\begin{array}{c}\text { Mean fold } \\
\text { change }\end{array}$ & \multicolumn{1}{|c}{$\begin{array}{c}\text { FDR p- } \\
\text { value }\end{array}$} \\
\hline Sonic hedgehog & Shh & -2.38 & 0.005 \\
\hline Transglutaminase 5 & Tgm5 & -2.25 & 0.012 \\
\hline Nuclear transcription factor-Y alpha & Nfya & -2.15 & 0.00001 \\
\hline $\begin{array}{l}\text { Poly (ADP-ribose) polymerase family, } \\
\text { member 12 }\end{array}$ & Zc3hdc1 & -2.13 & 0.036 \\
\hline
\end{tabular}

Figure 3.41 shows a heatmap of the hepatic genes that were highly induced with ciprofibrate after 5 hours. Inaddition, the trees at the top and right show how these genes and pathways cluster together. Apparently there was not enough data to be able to generate figures for the other time points (as indicated by the software). Genes of the acute phase response were found to be up- regulated in both the 3 and 5 hour treated groups. For the 3 hour group there was 4 out of 23 genes responsible for the acute phase response (17.4\%) and in the 5 hour group there was 8 out of 23 genes $(34.8 \%)$.

This also was the case for the genes of the acute inflammatory response, where for the 3 hour group there was 4 out of 43 genes and for the 5 hours there was 9 out of 43 genes $(20.9 \%)$. As for the genes of the response to wounding in the 3 hour samples there was 7 out of $193(3.6 \%)$ and 19 out of 193 genes $(9.8 \%)$ for the 5 hour samples. 

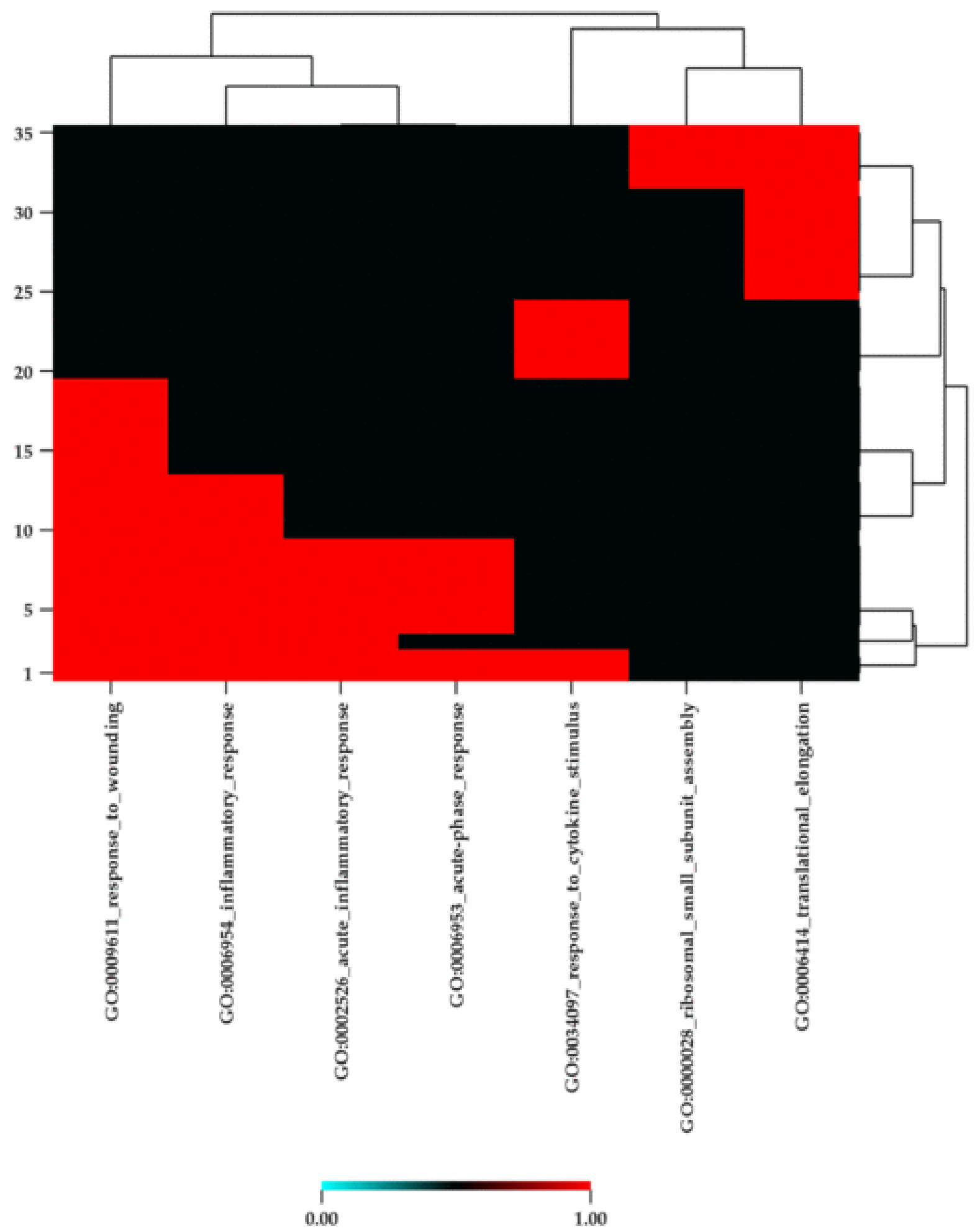

Figure 3.41 Heatmap for microarray analysis of ciprofibrate gene expression after 5 hours.

Male F-344/NHsd rats aged 14-15 weeks dosed with $50 \mathrm{mg}$ kg-1 ciprofibrate, then killed after 24 hours. The numbers at the left side refer to genes $1=$ SERPINA1A, 5= HP, 10= SERPINC1, 15=UCN2, 20= STATG, 25= TUBB4, $30=\mathrm{CDC} 20,35=\mathrm{RPS} 27$. Microarray analysis was carried out as in Section 2.2.5, this heatmap was established with High-Throughput GoMiner (Zeeberg, 2005). Red demonstrates up- regulated, and blue demonstrates down- regulated (-1 down- regulated, +1 up- regulated). 


\section{Section 3.3.6 Microarray analysis of CPA dosed rats after 1, 3, and 5 hours}

Microarray analysis was performed with hepatic samples from F-344NHsd fisher rats dosed with $100 \mathrm{mg} \mathrm{kg}^{-1} \mathrm{CPA}$ (Section 2.2.5). A list of the up- regulated genes for the samples treated with CPA for 1 hour with a fold induction of $>1.2$ fold change is presented in Table 3.12 including Cd97, Sstr4 and Rnf141. A list of down- regulated genes after 1 hour is presented in Table 3.13, while a list of up- regulated genes for 3 hour samples were found in Table 3.14 (fold change >1.0) including Hpxn, Cyp2c29, and Seprina3m and Table 3.15 lists the down- regulated genes after 3 hours CPA treatment. The genes up- regulated with ciprofibrate after 5 hours were listed in Table 3.16 (fold change >1.5) including Scd1, Mug2, Ppplcb and Hspd1, and the down- regulated genes were listed in Table 3.17. 
Table 3.12 Up- regulated genes at 1 hour in CPA dosed Fisher rats. A list of up- regulated genes for male F$344 \mathrm{NHsd}$ rats aged 14-15 weeks dosed with $100 \mathrm{mg} \mathrm{kg}^{-1} \mathrm{CPA}$ then killed after 1 hours. Microarray analysis was determined as in Section 2.2.5.

\begin{tabular}{l|l|l|l}
\hline \multicolumn{1}{c|}{ Description } & \multicolumn{1}{|c|}{ Name } & \multicolumn{1}{c}{$\begin{array}{c}\text { Mean fold } \\
\text { change }\end{array}$} & \multicolumn{1}{|c}{$\begin{array}{c}\text { FDR p- } \\
\text { value }\end{array}$} \\
\hline CD97 molecule & Cd97 & 2.50 & 0.0001 \\
\hline Lix1-like & D130027M04Rik & 1.47 & 0.005 \\
\hline Somatostatin receptor 4 & Sstr4 & 1.47 & 0.003 \\
\hline $\begin{array}{l}\text { Transient receptor potential cation } \\
\text { channel, subfamily C, member 4 asso- } \\
\text { ciated protein }\end{array}$ & Trpc4ap & 1.29 & 0.003 \\
\hline E2F transcription factor 3 & E2f3 & 1.86 & 0.039 \\
\hline $\begin{array}{l}\text { Sirtuin (silent mating type information } \\
\text { regulation 2 homolog) 2 }\end{array}$ & Sirt2 & 1.80 & 0.013 \\
\hline $\begin{array}{l}\text { MCF.2 cell line derived transforming } \\
\text { sequence-like }\end{array}$ & Mcf21 & 1.22 & 0.042 \\
\hline Kinesin family member 3B & Kif3b & 1.39 & 0.010 \\
\hline Dual specificity phosphatase 28 & $0710001 \mathrm{~B} 24 \mathrm{Rik}$ & 1.16 & 0.002 \\
\hline Neurexin 3 & Nrxn3 & 1.71 & 0.038 \\
\hline Ring finger protein 141 & Rnf141 & 1.22 & 0.0001 \\
\hline
\end{tabular}


Table 3.13 Down- regulated genes at 1 hour in CPA dosed Fisher rats. A list of down- regulated genes for male F-344NHsd rats aged 14-15 weeks dosed with $100 \mathrm{mg} \mathrm{kg}^{-1} \mathrm{CPA}$ then killed after 1 hours. Microarray analysis was determined as in Section 2.2.5.

\begin{tabular}{l|l|l|l}
\hline \multicolumn{1}{c|}{ Description } & \multicolumn{1}{|c|}{ Name } & \multicolumn{1}{c|}{$\begin{array}{c}\text { Mean fold } \\
\text { change }\end{array}$} & \multicolumn{1}{|c}{$\begin{array}{c}\text { FDR p- } \\
\text { value }\end{array}$} \\
\hline Phospholipase A2, group IIC & Pla2g2c & -3.09 & 0.006 \\
\hline RIKEN cDNA 4930507D10 gene & 4930507D10Rik & -3.03 & 0.021 \\
\hline $\begin{array}{l}\text { Caspase recruitment domain family, } \\
\text { member 10 }\end{array}$ & Card10 & -2.62 & 0.001 \\
\hline Kruppel-like factor 15 & Klf15 & -2.60 & 0.002 \\
\hline $\begin{array}{l}\text { Protein phosphatase 1, regulatory } \\
\text { (inhibitor) subunit 14A }\end{array}$ & Ppp1r14a & -2.58 & 0.021 \\
\hline Retinoic acid induced 1 & Rai1 & -2.38 & 0.006 \\
\hline RIKEN cDNA 4933433G15 gene & 4933433 G15Rik & -2.31 & 0.012 \\
\hline RIKEN cDNA 7030407O06 gene & 7030407 O06Rik & -2.30 & 0.015 \\
\hline Hepatocyte nuclear factor 4, alpha & Hnf4a & -2.25 & 0.021 \\
\hline GS homeobox 1 & Gsh1 & -2.23 & 0.0001 \\
\hline RIKEN cDNA 9530085L11 gene & 9530085L11Rik & -2.13 & 0.0001 \\
\hline RIKEN cDNA 1810046J19 gene & $1810046 J 19 R i k$ & -2.05 & 0.033 \\
\hline
\end{tabular}


Table 3.14 Up- regulated genes after 3 hours in CPA dosed Fisher rats. A list of up- regulated genes for male F-344NHsd rats aged 14-15 weeks dosed with $100 \mathrm{mg} \mathrm{kg}^{-1} \mathrm{CPA}$ then killed after 3 hours. Microarray analysis was determined as in Section 2.2.5.

\begin{tabular}{l|l|l|l}
\hline \multicolumn{1}{c|}{ Description } & \multicolumn{1}{|c|}{ Name } & \multicolumn{1}{c|}{$\begin{array}{c}\text { Mean fold } \\
\text { change }\end{array}$} & \multicolumn{1}{|c}{$\begin{array}{c}\text { FDR p- } \\
\text { value }\end{array}$} \\
\hline RIKEN cDNA E130101E03 gene & E130101E03Rik & 1.16 & 0.003 \\
\hline Hemopexin & Hpxn & 1.14 & 0.005 \\
\hline $\begin{array}{l}\text { COP9 constitutive photomorphogenic } \\
\text { homolog subunit 4 }\end{array}$ & Cops4 & 1.30 & 0.012 \\
\hline $\begin{array}{l}\text { Hairy/enhancer-of-split related with } \\
\text { YRPW motif 1 }\end{array}$ & Hey1 & 1.12 & 0.028 \\
\hline $\begin{array}{l}\text { Cytochrome P450, family 2, subfamily } \\
\text { c, polypeptide 29 }\end{array}$ & Cyp2c29 & 1.08 & 0.039 \\
\hline $\begin{array}{l}\text { Serine (or cysteine) proteinase inhibi- } \\
\text { tor, clade A, member 3M }\end{array}$ & Serpina3m & 1.12 & 0.001 \\
\hline
\end{tabular}

Table 3.15 Down- regulated genes after 3 hours in CPA dosed Fisher rats. A list of down- regulated genes for male F-344NHsd rats aged 14-15 weeks dosed with $100 \mathrm{mg} \mathrm{kg}^{-1} \mathrm{CPA}$ then killed after 3 hours. Microarray analysis was determined as in Section 2.2.5

\begin{tabular}{l|l|l|l}
\hline \multicolumn{1}{c|}{ Description } & \multicolumn{1}{|c|}{ Name } & \multicolumn{1}{c|}{$\begin{array}{c}\text { Mean fold } \\
\text { change }\end{array}$} & \multicolumn{1}{c}{$\begin{array}{c}\text { FDR p- } \\
\text { value }\end{array}$} \\
\hline Membrane-associated ring finger & Axot & -2.35 & 0.006 \\
\hline Aminolevulinate, delta-, synthase 1 & Alas1 & -1.84 & 0.0001 \\
\hline $\begin{array}{l}\text { Cytochrome P450, family 3, subfamily } \\
\text { a, polypeptide 44 }\end{array}$ & Cyp3a44 & -1.46 & 0.001 \\
\hline $\begin{array}{l}\text { UDP glycosyltransferase 1 family, } \\
\text { polypeptide A10 }\end{array}$ & Ugt1a13 & -1.13 & 0.002 \\
\hline $\begin{array}{l}\text { ER degradation enhancer, mannosi- } \\
\text { dase alpha-like 1 }\end{array}$ & Edem1 & -1.01 & 0.002 \\
\hline \begin{tabular}{l} 
Serum induced transcript 1 \\
\hline
\end{tabular} & Sif1 & -1.01 & 0.020 \\
\hline
\end{tabular}


Table 3.16 Up- regulated genes after 5 hours in CPA dosed Fisher rats. A list of up- regulated genes for male F-344NHsd rats aged 14-15 weeks dosed with $100 \mathrm{mg} \mathrm{kg}^{-1} \mathrm{CPA}$ then killed after 5 hours. Microarray analysis was determined as in Section 2.2.5

\begin{tabular}{|c|c|c|c|}
\hline Description & Name & $\begin{array}{l}\text { Mean fold } \\
\text { change }\end{array}$ & $\begin{array}{l}\text { FDR p- } \\
\text { value }\end{array}$ \\
\hline Cathepsin E & C920004C08Rik & 3.48 & 0.0001 \\
\hline Metallothionein & $\mathrm{mt}$ & 2.87 & 0.0001 \\
\hline Murinoglobulin 1 & Mug1 & 2.47 & 0.0001 \\
\hline Stearoyl-Coenzyme A desaturase 1 & Scd1 & 2.21 & 0.0001 \\
\hline $\begin{array}{l}\text { ADAM metallopeptidase with throm- } \\
\text { bospondin type } 1 \text { motif, } 1\end{array}$ & Adamts1 & 2.17 & 0.001 \\
\hline Group specific component & $\mathrm{Gc}$ & 2.18 & 0.0001 \\
\hline RIKEN cDNA 2810455D13 gene & 2810455D13Rik & 2.12 & 0.003 \\
\hline Frizzled homolog 7 & Fzd7 & 2.10 & 0.0001 \\
\hline Murinoglobulin 2 & Mug2 & 2.09 & 0.0001 \\
\hline Zinc finger protein 335 & 1810045J01Rik & 2.02 & 0.006 \\
\hline Beta-2 microglobulin & $\mathrm{B} 2 \mathrm{~m}$ & 2.01 & 0.004 \\
\hline cDNA sequence BC018242 & $\mathrm{BC} 018242$ & 1.95 & 0.006 \\
\hline RIKEN cDNA 2600006L11 gene & 2600006L11Rik & 1.91 & 0.0001 \\
\hline $\begin{array}{l}\text { Protein phosphatase } 1 \text {, catalytic sub- } \\
\text { unit, beta isoform }\end{array}$ & Ppp1cb & 1.91 & 0.002 \\
\hline Predicted gene & IGKV12 & 1.87 & 0.0001 \\
\hline $\begin{array}{l}\text { Transmembrane BAX inhibitor motif } \\
\text { containing } 6\end{array}$ & Tegt & 1.81 & 0.003 \\
\hline $\begin{array}{l}\text { C-type lectin domain family } 5 \text {, mem- } \\
\text { ber a }\end{array}$ & Clecsf5 & 1.80 & 0.0001 \\
\hline SET binding protein 1 & Setbp1 & 1.66 & 0.005 \\
\hline RIKEN cDNA 4930538K18 gene & 4930538K18Rik & 1.64 & 0.0001 \\
\hline Ribosomal protein L5 & Rpl5 & 1.63 & 0.006 \\
\hline Sulfotransferase family $2 \mathrm{~A}$,member 2 & Sult2a2 & 1.61 & 0.008 \\
\hline $\begin{array}{l}\text { Pregnancy upregulated non-ubiqui- } \\
\text { tously expressed CaM kinase }\end{array}$ & Pnck & 1.59 & 0.0001 \\
\hline Heat shock protein 1 & Hspd1 & 1.58 & 0.005 \\
\hline
\end{tabular}


Table 3.17 Down- regulated genes after 5 hours in CPA dosed Fisher rats. A list of down- regulated genes for male F-344NHsd rats aged 14-15 weeks dosed with $100 \mathrm{mg} \mathrm{kg}^{-1} \mathrm{CPA}$ then killed after 5 hours. Microarray analysis was determined as in Section 2.2.5

\begin{tabular}{l|l|l|l}
\hline \multicolumn{1}{c|}{ Description } & \multicolumn{1}{c|}{ Name } & \multicolumn{1}{c|}{$\begin{array}{c}\text { Mean fold } \\
\text { change }\end{array}$} & \multicolumn{1}{|c}{$\begin{array}{c}\text { FDR p- } \\
\text { value }\end{array}$} \\
\hline $\begin{array}{l}\text { Acyl-Coenzyme A dehydrogenase, } \\
\text { short/branched chain }\end{array}$ & Acadsb & -3.56 & 0.0001 \\
\hline Diazepam binding inhibitor-like 5 & Dbil5 & -2.76 & 0.030 \\
\hline Splicing factor, arginine/serine-rich 16 & Sfrs16 & -2.53 & 0.007 \\
\hline $\begin{array}{l}\text { Inositol polyphosphate phosphatase- } \\
\text { like 1 }\end{array}$ & Inppl1 & -2.50 & 0.001 \\
\hline ArfGAP with dual PH domains 1 & Centa1 & -2.43 & 0.027 \\
\hline RIKEN cDNA 1700034B16 gene & 1700034 B16Rik & -2.37 & 0.001 \\
\hline $\begin{array}{l}\text { Calcineurin-like phosphoesterase } \\
\text { domain containing 1 }\end{array}$ & C530044N13Rik & -2.23 & 0.033 \\
\hline RIKEN cDNA 1700126L10 gene & $1700126 L 10 R i k$ & -2.22 & 0.006 \\
\hline Mitochondrial ribosomal protein S18A & 18 S & -2.19 & 0.0001 \\
\hline RIKEN cDNA 2300009N04 gene & 2300009N04Rik & -2.16 & 0.0001 \\
\hline
\end{tabular}

Figure 3.42 shows a heatmap of the hepatic genes that were highly induced with CPA after 3 hours. In addition, the trees at the top and right show how these genes and pathways cluster together. There was not enough data to be able to generate figures for the other time points, or for the down- regulated genes, and there was not any related pathways that were repeated with the 1,3 and 5 hour time points. 


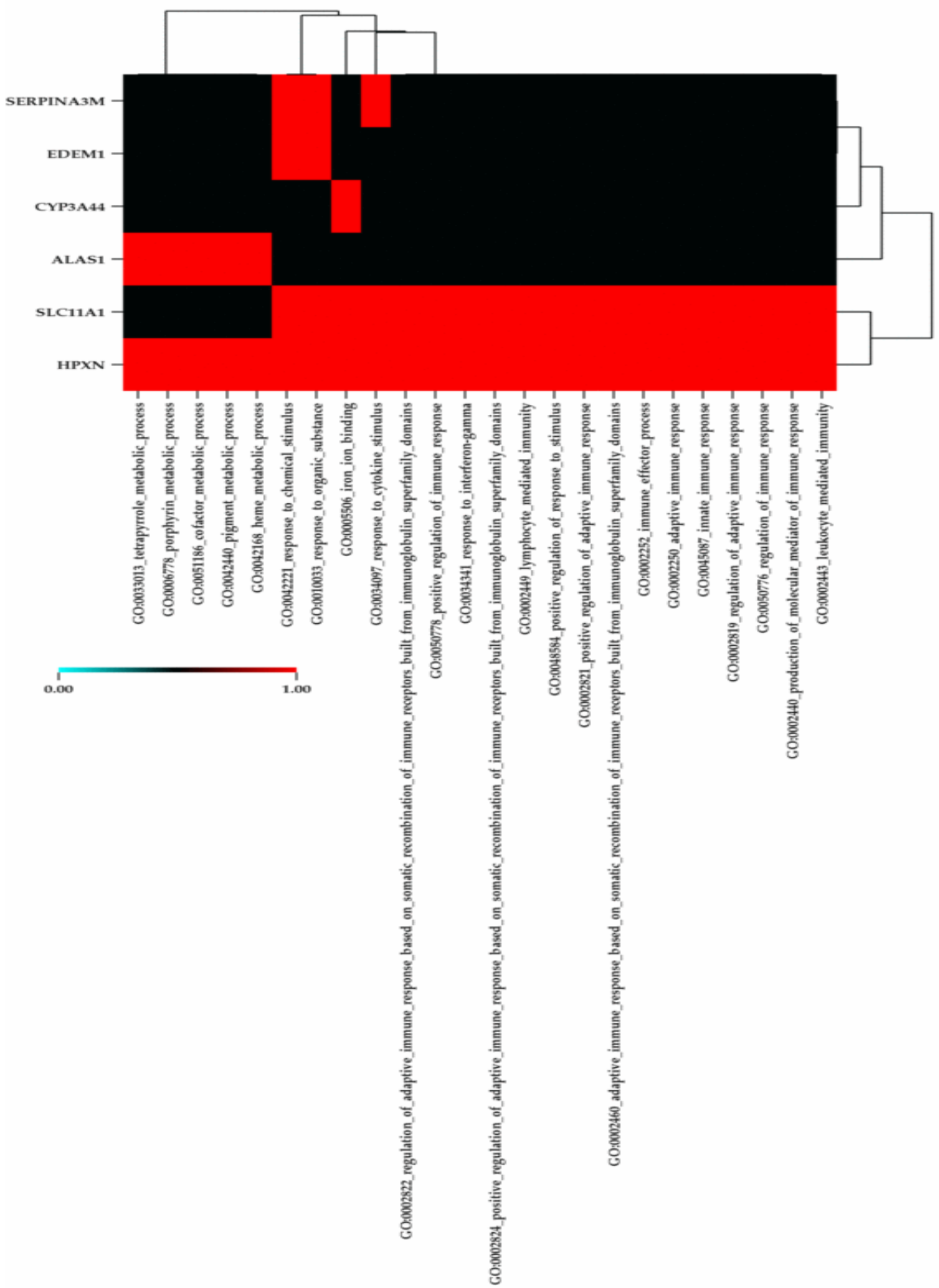

Figure 3.42 Heatmap for microarray analysis of CPA treated samples after 3 hours. Male F-344NHsd rats aged 14-15 weeks dosed with $100 \mathrm{mg}$ kg-1 CPA, then killed after 24 hours. Microarray analysis was determined as in Section 2.2.5, this heatmap was established with High-Throughput GoMiner (Zeeberg et al., 2005). Red demonstrates up- regulated, and blue demonstrates down- regulated (-1 down- regulated, +1 up- regulated). 


\section{Section 3.4 Transcriptome sequencing analysis}

To study the early genes whose expression may be linked to the induction of hepatic DNA synthesis, RNA sequencing (whole transcriptome sequencing) was applied to the mRNAs isolated from F-344 fisher rats dosed with $50 \mathrm{mg} \mathrm{kg}^{-1}$ ciprofibrate or corn oil and killed after 3 hours. This was done with the Next Generation sequencing facilities, at the Deep seq research facility at the University of Nottingham (The AB SOLID 3 platform) as described in Section 2.2.6. The number of genes that resulted from this analysis was 24962 genes, with 705 genes that have a FDR $p$-value correction of $<0.05$, and 4245 genes that have the $p$-value is $<0.05$. In this analysis reads per kilobase of exon model per million mapped reads (RPKM) was used, which normalises for the difference in number of mapped reads between the samples ( 4 treated and 4 control samples).

\section{Section 3.4.1 Comparing the data in a scatter plot}

To show the effect of the ciprofibrate against the control on the genes a scatter plot was applied, this represents the number and distribution of the genes after the analysis. Shown in Figure 3.43 the spread of the control normalised genes against the treated normalised genes is illustrated The original data can be found at http://spldeepseq.nottingham.ac.uk/ aziz/wtp_rat/.

The points closest to the linear regression plot (the $\mathrm{x}=\mathrm{y}$ line in the plot) are the genes which are least affected by the treatment. Genes of interest would be represented by the points that are most dispersed along an axis perpendicular to the linear regression plot. It is clarified in Figure 3.43 that the genes are behaving in a similar way because most of the genes are close to the $x=y$ line, but if they are affected by the ciprofibrate as there is a drift away from the main line, and these should be the differently induced genes that are of interest. 


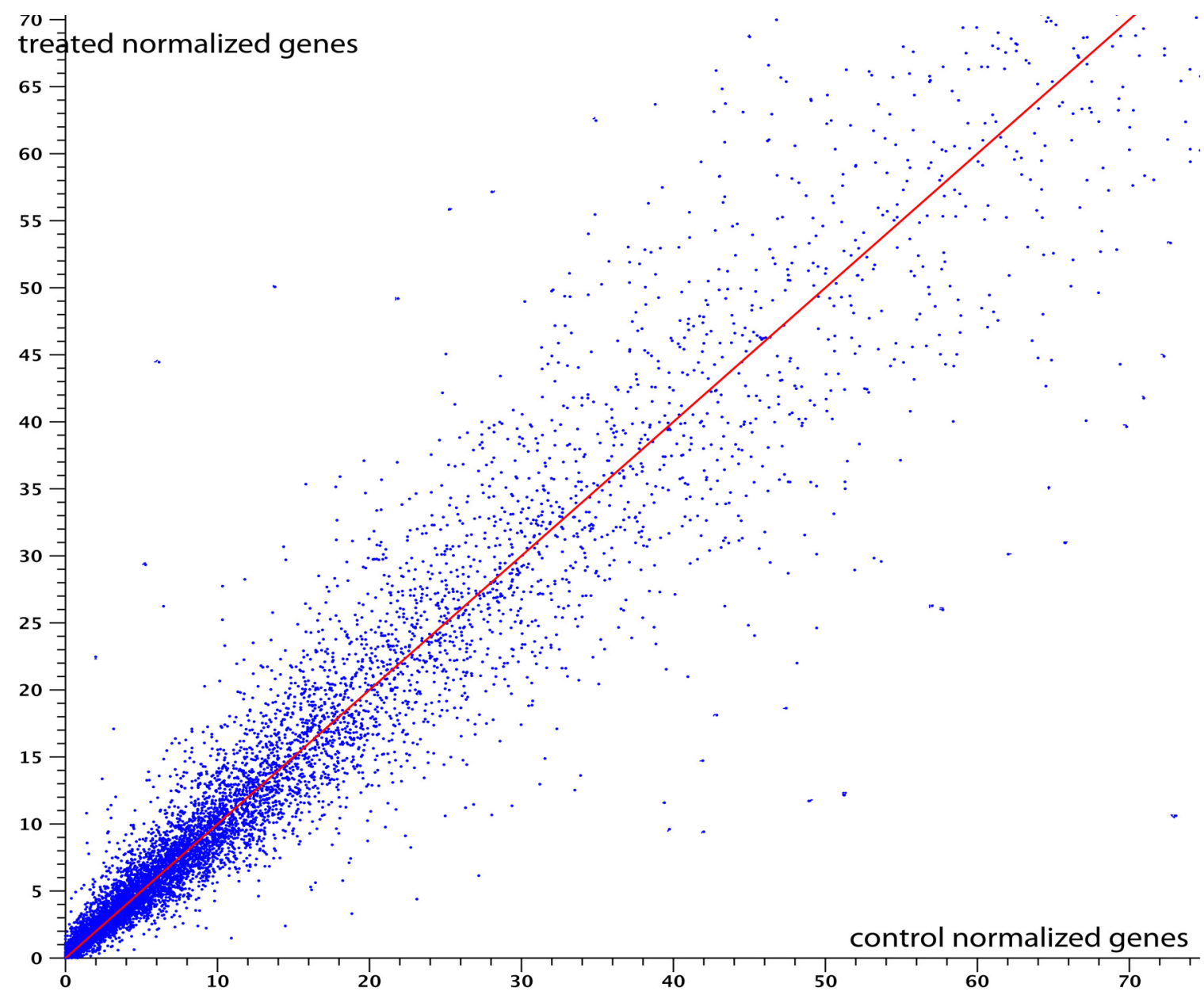

Figure 3.43 Scatter plot view of transcriptome data. A scatter plot view of the treated normalised mean data for each gene against the control normalised means, from the liver-RNA of F-344NHsd fisher rats dosed with $50 \mathrm{mg} \mathrm{kg}^{-1}$ ciprofibrate (or corn oil) for 3 hours. Shown in red is a linear regression plot of the points. Each point indicates the relationship between the control and treated samples. (Software used The CLC Genomics Workbench). 


\section{Section 3.4.2 Checking between and within the groups variability}

The objective here is to compare and examine the general distributions of the data within the same group. This is important to exclude any flaws in the preparation or other defects in the control and treated groups, so box plots were used.

The normalised expression values of the control data are shown in Figure 3.44 where the 4 samples are similar in spread (the upper and lower bars are aligned) and the median lines in all the boxes are aligned. Similar results were observed in the normalised treated data (Figure 3.45) and the data for the whole experiment (when comparing the treated against the control) (Figure $3.46)$.

From the spread of the samples in the figures it can be concluded that the samples are equally distributed within the control/ treated groups and in the whole experiment, and this indicates that the preparation and processing of the samples were correctly labelled and assigned in each of the groups. 


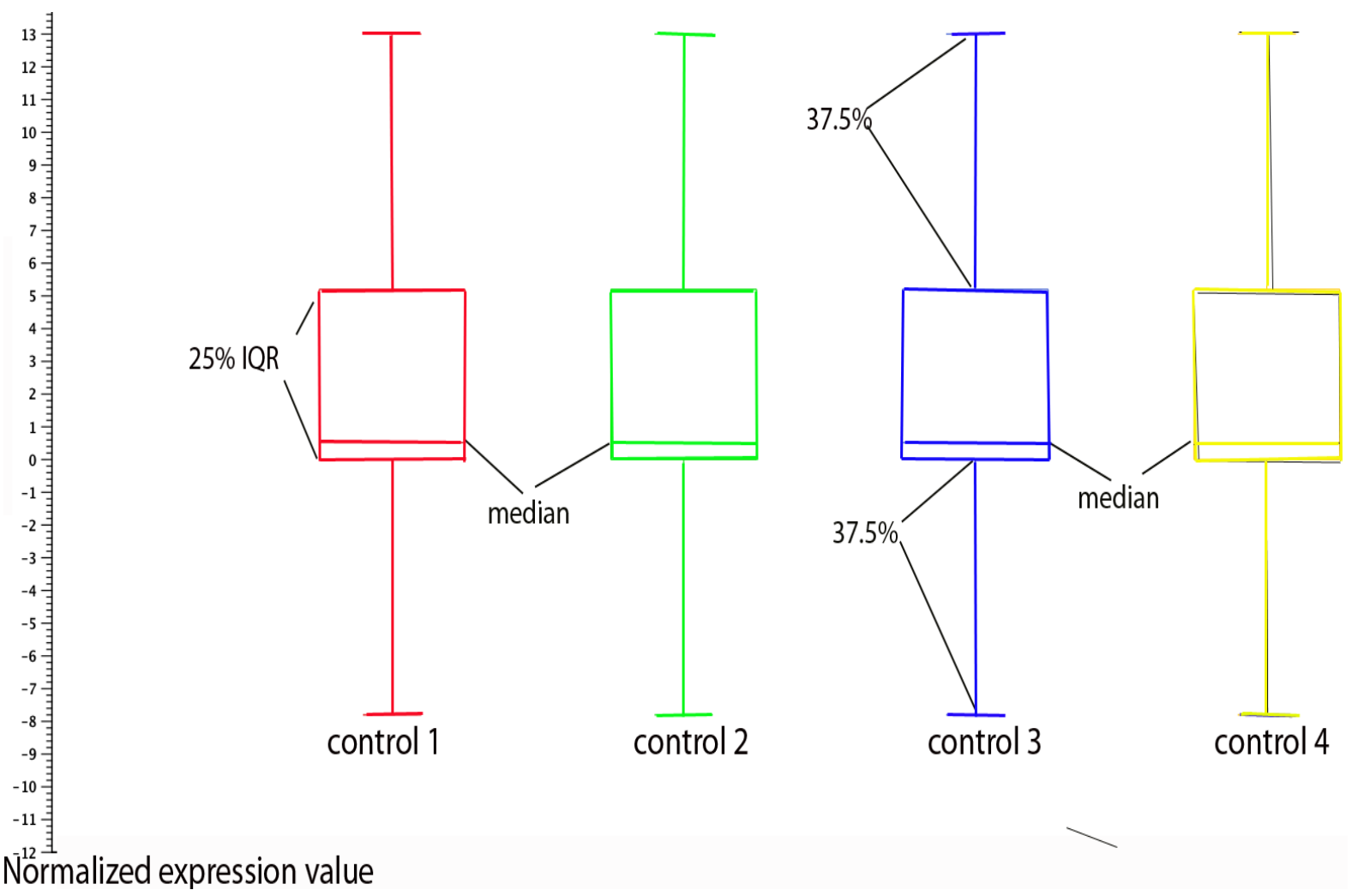

Figure 3.44 Analysing distributions of the control data. Four box plots of the normalised expression values of each of the 4 samples from control livers of F-344 fisher rats dosed with corn oil for 3 hours. Each box plot refers to the distribution of the data, and includes a square box indecating the IQR (Inter quartile Range $25 \%$ ) value for each sample's distribution (from the lower to the upper quartile), the lines displayed in the square boxes are the median and the upper and lower bars extend $1.5(75 \%)$ the height of the box.(Software used The CLC Genomics Workbench). 


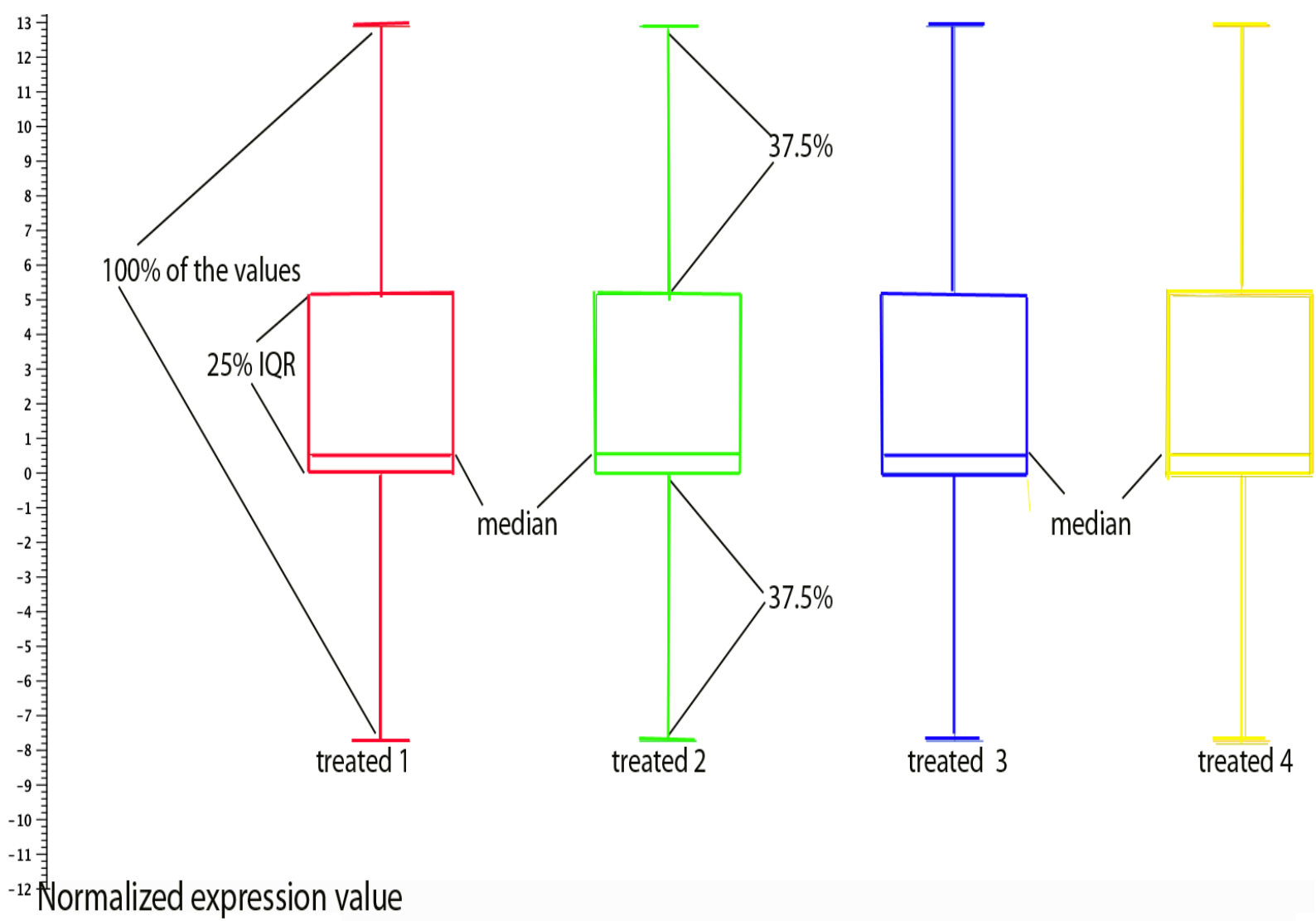

Figure 3.45 Analysing distributions of the treated data. Four box plots of the normalised expression values of each of the 4 samples from livers of F-344 fisher rats treated with $50 \mathrm{mg} \mathrm{kg}^{-1}$ ciprofibrate for 3 hours. Each box plot refers to the distribution of the data, and includes a square box indecating the IQR (Inter quartile Range 25\%) value for each sample's distribution (from the lower to the upper quartile), the lines displayed in the square boxes are the median and the upper and lower bars extend 1.5 (75\%) the height of the box (Software used The CLC Genomics Workbench). 


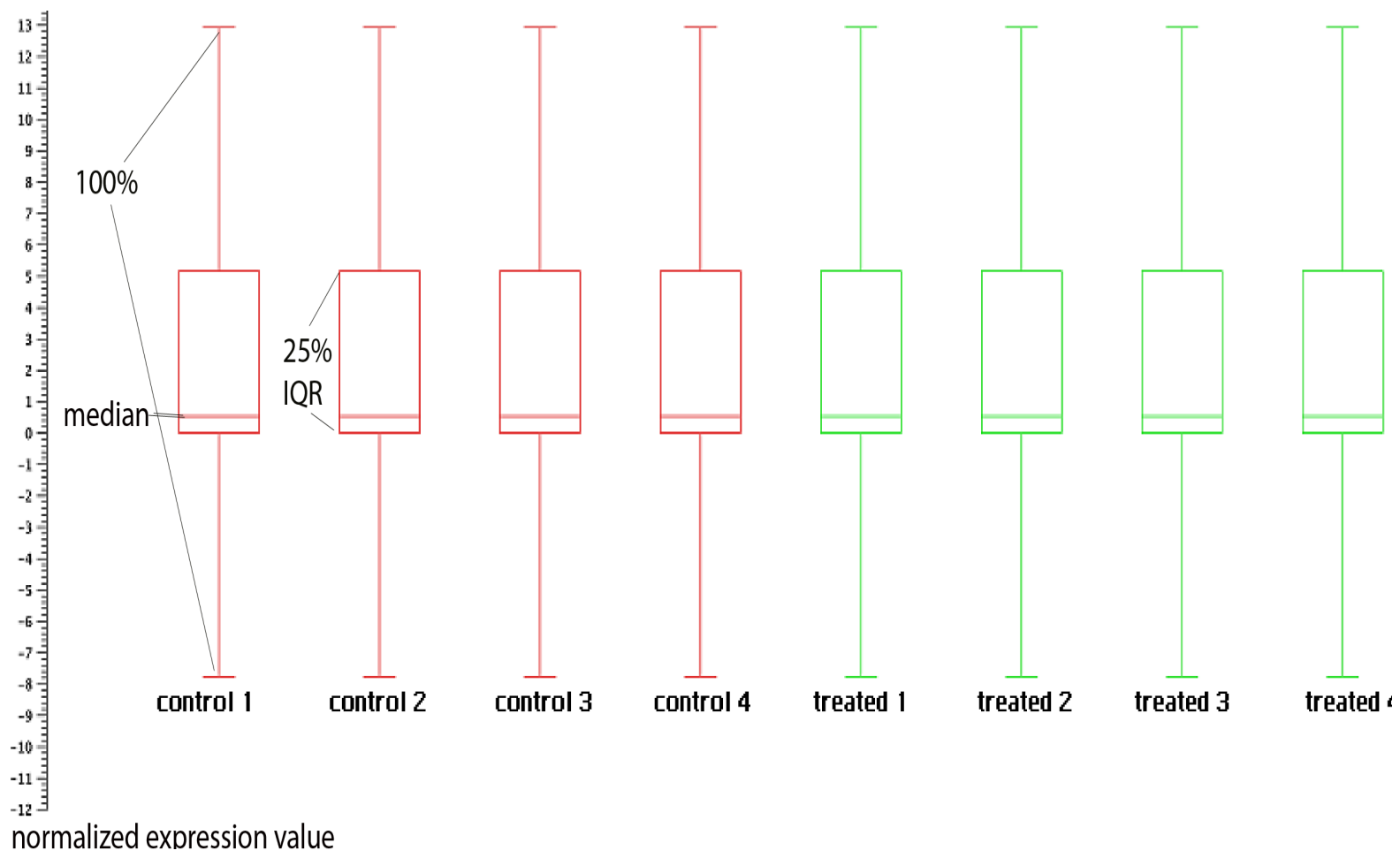

Figure 3.46 Analysing distributions of all the transcriptome data. 8 box plots of the normalised expression values of all 8 samples from livers of F344 fisher rats treated with $50 \mathrm{mg} \mathrm{kg}^{-1}$ ciprofibrate/corn oil for 3 hours. Red are the 4 control (corn oil) samples and green are the 4 treated samples. Each box plot refers to the distribution of the data, and includes a square box indecating the IQR (Inter quartile Range 25\%) value for each sample's distribution (from the lower to the upper quartile), the lines displayed in the square boxes are the median and the upper and lower bars extend 1.5 (75\%) the height of the box. (Software used The CLC Genomics Workbench).

\section{Section 3.4.3 A volcano plot view of the data}

This was done to see the genes on the basis of the p-value and the fold change differences between the control and the ciprofibrate treated samples for 3 hours, by applying the volcano plot view of the data.

A volcano plot of the results from the RNAseq analysis is illustrated in Figure 3.47 showing the $\log 10$ of the p-value (of the Student's t- test of the difference between the control and treated samples) and the $\log 2$ of the fold change difference between the control and treated samples. The plots closest to the zero value for $\log 2$ fold change are the genes with least change in expression, while the genes with significantly changed expression are indicated within the plots in 
red (statistics done was with Students' t- test) data used, and had a false discovery rates FDR pvalues of $<0.05$, and a fold change of \pm 2 .

The volcano plot shows the relationship between the p-values and the variation in expression values of the control and treated groups. Points for gene expressions with statistically significant differences will be positioned in the upper left and upper right of the volcano plot specified in red in Figure 3.47. This shows that the samples are mostly similar with only a small number of genes that are differently (up or down) regulated. These genes are the genes of interest for this study.

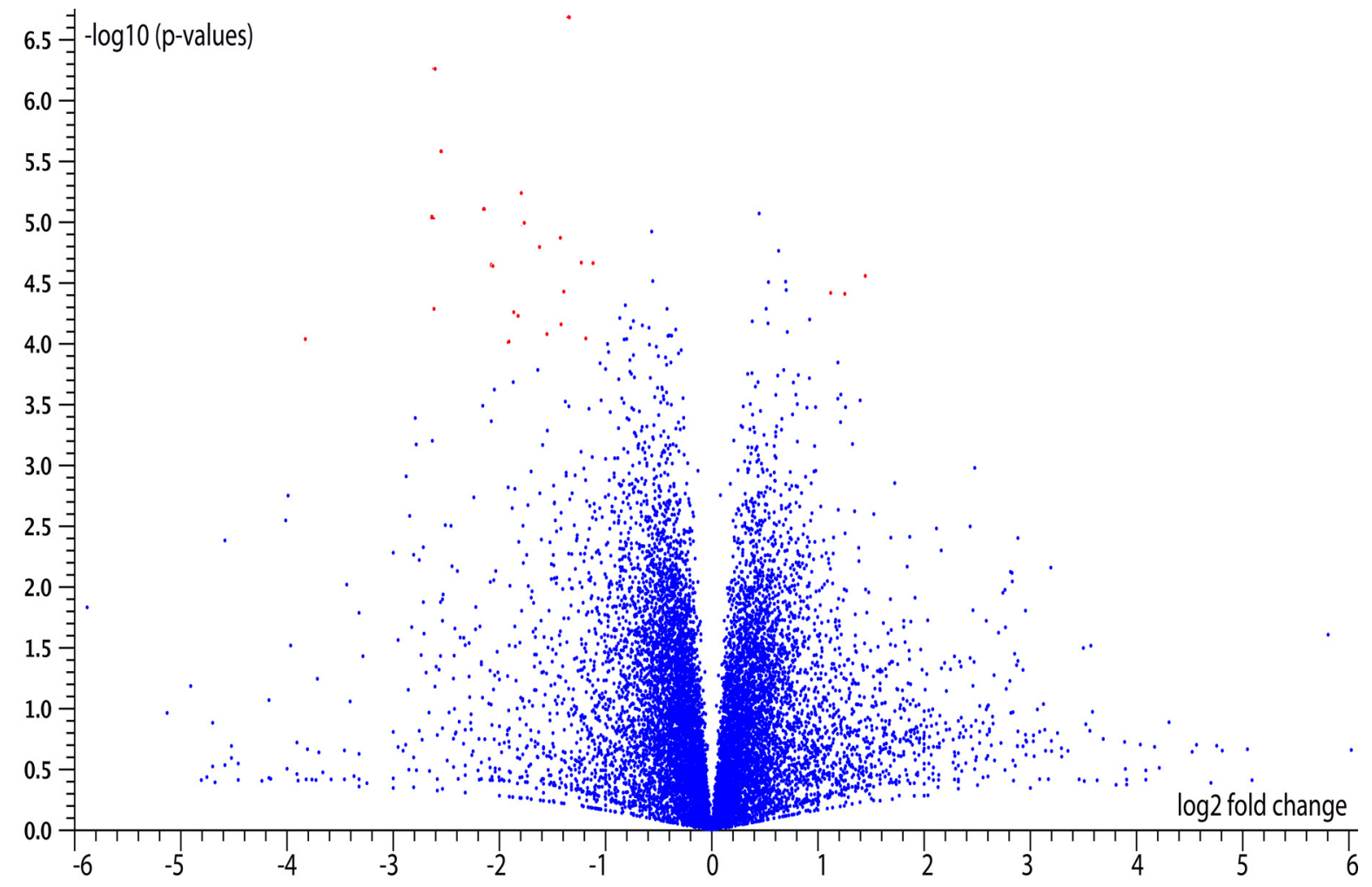

Figure 3.47 volcano plot view of transcriptome data (Student's t- test). A volcano plot view of the $\log 10 \mathrm{p}$ value versus the $\log 2$ fold change difference between the control and treated samples, from the hepatic RNA of F$344 \mathrm{NHsd}$ fisher rats dosed with $50 \mathrm{mg} \mathrm{kg}^{-1}$ ciprofibrate (or corn oil) for 3 hours. Red points are the features with false discovery rates (FDR) p-values of $<0.05$, and a fold change of \pm 2 . (Software used The CLC Genomics Workbench). 


\section{Section 3.4.4 Hierarchical clustering of samples}

Hierarchical clustering was presented to see the comparative similarities of the control and treated samples, and to check if they cluster homogeneously or not.

The hierarchical cluster is a heat map with the clustering of the samples at the bottom. The tree was arranged by placing each group of related genes as a cluster and calculating the pair-wise space between all clusters, then combining each two closest clusters to be made into one new cluster and then the next closest joined and so on until there was only one cluster left (which contains all samples). In the tree the spaces between the clusters reflect the distance of the branches in the tree. Therefore, samples that have closely resembled gene expressions have short distances between them, and those that are more different are separated further.

In Figure 3.48 the samples on the left are the treated samples and the samples on the right are the controls, the red and blue colours express the induction of the genes in the groups (red indicates high gene expression and blue presents low expression of the genes), the hierarchical clustering of the samples clarifies the relationship in between the groups, and shows that the treatment has affected the gene induction and that it is different from the untreated.

The tree cluster at the bottom of Figure 3.48 shows that the samples similar in their gene expression are together, and also indicates that the ciprofibrate treatment replicates had a similar effect on the genes at 3 hours (the red colour is more abundant than the blue). This is different from the control replicates that are all clustered together.

As a conclusion the treated replicates show similar effects on genes that appear highly induced, and the same for the control replicates, which also show a difference between the treated and control groups. 


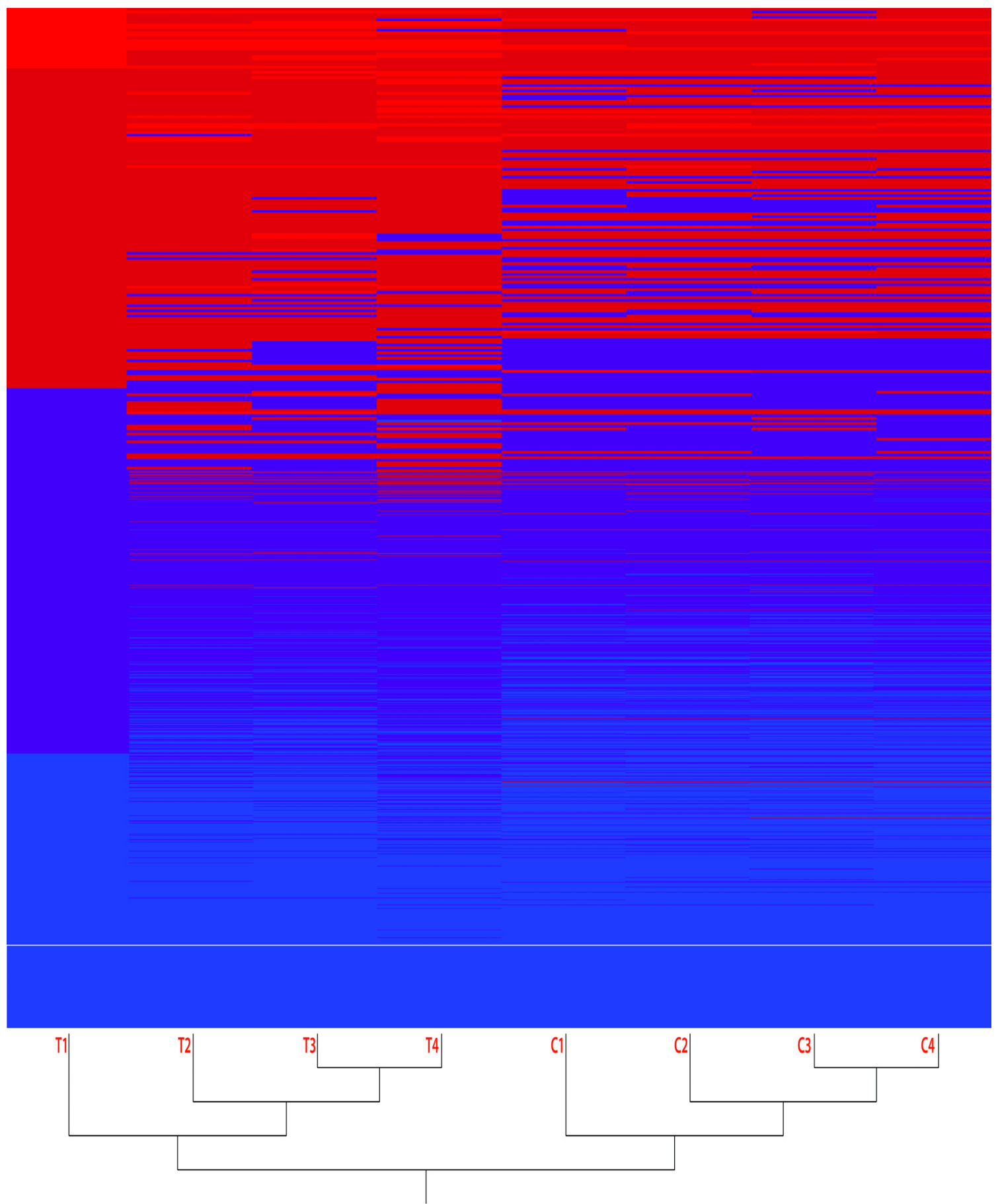

Figure 3.48 A hierarchical cluster of samples. Male Fisher rats were treated with $50 \mathrm{mg} \mathrm{kg}^{-1}$ ciprofibrate or corn oil for 3 hours, then RNAseq analysis was applied on the hepatic RNA samples as described in Section 2.2.6. At the top of the figure are listed the names of the samples the treatments (4 groups) on the left and the controls (4 groups) on the right. The horizontal lines present the features (genes) and are coloured according to the expression level. Red presents the maximum level of expression and blue shows the minimal level of expression. The tree at the bottom of the heatmap visualizes the clustering. The features are sorted by the expression intensity in the first sample on the left. (Software used The CLC Genomics Workbench). 


\section{Section 3.4.5 Hierarchical and K-means clusters of features}

Feature clustering was performed with the results from the RNAseq analysis to recognize and cluster together genes with related gene expression values from the controls or samples treated with $50 \mathrm{mg} \mathrm{kg}^{-1}$ ciprofibrate for 3 hours. Features that are clustered together are expected to be involved in similar biological procedures.

Hierarchical clustering of features was a tree arrangement of the similar expressed genes over the set of control and treated samples (or groups). In the hierarchical cluster each feature is a cluster. Then the pairwise distance between the clusters was evaluated and the two closest clusters combined into one new cluster. Then the clusters were grouped together depending on the relationship of the gene induction until there was only one cluster left. This feature clustering was performed on a subset of the data after filtering away the genes that have low fold difference values or have little difference between the samples (large p-value).

With the hierarchical clustering a number of the genes were found by the feature clustering to be more expressed in the treated than that in the control group, e.g. Cyp $4 A 1, G 0 / G 1$ switch 2 and Scd1 genes (sterol-Coenzyme A desaturase 1), and the last two genes are more closely clustered together than the Cyp4A1 gene.

The feature clustering was also performed as a k-means clustering, where the features (gene expressions) are clustered together in groups depending on the expression response to the control and treated samples. This clustering resulted in presenting how some genes were down-regulated in the control samples and up-regulated in the treated samples, or presenting how the gene expression behaves in a different way, where the genes were up-regulated in the control samples then the same gene expression goes down in the treated samples, or how the gene expression in the control and treated samples have similar expression values. 


\section{Section 3.4.6 Induced genes by ciprofibrate after 3 hours with RNAseq}

The objective from this is to find genes that are differential expressed in hepatic cells of F344NHsd Fisher rats dosed with $50 \mathrm{mg} \mathrm{kg}^{-1}$ ciprofibrate after 3 hours see (Section 2.2.1). This should highlight genes whose expression is correlated with the hepatic DNA synthesis that occurs at 24 hours.

This was done by Transcriptome Sequencing analysis of the hepatic RNA detailed in Section 2.2.6. Stastical analysis was done with Student t- test and genes were defined as significant if the FDR p-value was $<0.05$. A whole list of all the $\sim 25000$ genes and associated data analysis is provided in the $\mathrm{CD}$ at the end of this thesis.

\section{Section 3.4.6.1 Down- regulated genes with RNAseq}

Genes were considered down- regulated if the FDR p-value was $>0.05$ and there was a fold change in expression of $<-1.5$ ( 0.67 fold). Table 3.18 shows a list of down- regulated known (named) genes (e.g. Igfbp2, ppargcla, Cypla2, AhR....), and in Table 3.19 is a list of the novel genes that have not been named to date. 
Table 3.18 Named down- regulated genes in ciprofibrate dosed rats treated for 3 hours. A list of downregulated genes for male F-344NHsd rats aged 14-15 weeks dosed with $50 \mathrm{mg} \mathrm{kg}^{-1}$ ciprofibrate then killed after 3 hours. RNAseq analysis was done as described in Section 2.2.6. Expressed genes with a fold change of $<-1.5$ and a FDR p-value of $<0.05$ were listed.

\begin{tabular}{|c|c|c|c|c|}
\hline Description & $\begin{array}{l}\text { Gene } \\
\text { name }\end{array}$ & $\begin{array}{c}\text { Ensembl } \\
\text { Feature ID }\end{array}$ & $\begin{array}{c}\text { Fold } \\
\text { Change } \\
<-1.5\end{array}$ & $\begin{array}{c}\text { FDR } \\
\text { p- } \\
\text { value } \\
<0.05\end{array}$ \\
\hline $\begin{array}{l}\text { Insulin-like growth factor-binding protein } 2 \text { Precursor } \\
\text { (IGF-binding protein 2) }\end{array}$ & $\operatorname{lgfbp} 2$ & ENSRNOT00000023068 & -5.0 & 0.01 \\
\hline $\begin{array}{l}\text { Peroxisome proliferator-activated receptor gamma, } \\
\text { coactivator } 1 \text { alpha }\end{array}$ & Ppargcla & ENSRNOT00000006071 & -2.1 & 0.01 \\
\hline $\begin{array}{l}\text { Cytochrome P450, family } 1 \text {, subfamily a, polypeptide } 2 \\
\text { Gene }\end{array}$ & Cyp1a2 & ENSRNOT00000058571 & -1.7 & 0.03 \\
\hline Acyl-CoA synthetase medium-chain family member 2 & Acsm2 & ENSRNOT00000020587 & -3.3 & 0.02 \\
\hline $\begin{array}{l}\text { Hepatocyte nuclear factor } 6 \text { (One cut domain family } \\
\text { member } 1 \text { ) }\end{array}$ & HNF-6 & ENSRNOT00000010738 & -2.2 & 0.03 \\
\hline Aryl hydrocarbon receptor & Ahr & ENSRNOT00000006618 & -2.0 & 0.04 \\
\hline $\begin{array}{l}\text { Immediate early response } 2 \text { - immediate early response } \\
\text { gene } 2 \text { protein }\end{array}$ & Ier2 & ENSRNOT00000003793 & -1.8 & 0.02 \\
\hline $\begin{array}{l}\text { Forkhead box D1 (mediates the coordinated expression } \\
\text { of hepatocyte-specific genes) }\end{array}$ & Foxd1 & ENSRNOT00000010201 & -1.9 & 0.04 \\
\hline Death-associated kinase 2 & dapk2 & ENSRNOT00000023372 & -1.7 & 0.04 \\
\hline $\begin{array}{l}\text { Solute carrier family } 2 \text { (facilitated glucose transporter), } \\
\text { member } 1\end{array}$ & Slc2a1 & ENSRNOT00000064452 & -2.4 & 0.04 \\
\hline Protein kinase-like protein $\mathrm{SgK} 493$ & Sgk493 & ENSRNOT00000005664 & -2.2 & 0.04 \\
\hline Oncogene-serine threonine protein kinase & pim-1 & ENSRNOT00000000637 & -2.0 & 0.03 \\
\hline Claudin 9 (predicted); LOC287099; protein-coding & Cldn9 & ENSRNOT00000004848 & -2.1 & 0.03 \\
\hline Claudin 6 (protein binding) & Cldn6 & ENSRNOT00000004845 & -1.9 & 0.03 \\
\hline Claudin 4 & Cldn4 & ENSRNOT00000002003 & -2.0 & 0.04 \\
\hline
\end{tabular}


Table 3.18 Named down- regulated genes in ciprofibrate dosed rats treated for 3 hours. A list of downregulated genes for male F-344NHsd rats aged 14-15 weeks dosed with $50 \mathrm{mg} \mathrm{kg}^{-1}$ ciprofibrate then killed after 3 hours. RNAseq analysis was done as described in Section 2.2.6. Expressed genes with a fold change of $<-1.5$ and a FDR p-value of $<0.05$ were listed.

\begin{tabular}{|c|c|c|c|c|}
\hline Description & $\begin{array}{l}\text { Gene } \\
\text { name }\end{array}$ & $\begin{array}{c}\text { Ensembl } \\
\text { Feature ID }\end{array}$ & $\begin{array}{l}\text { Fold } \\
\text { Change } \\
<-1.5\end{array}$ & $\begin{array}{c}\text { FDR } \\
\text { p- } \\
\text { value } \\
<0.05\end{array}$ \\
\hline $\begin{array}{l}\text { Sialidase } 2 \text { (cytosolic enzyme that cleaves sialic acid; } \\
\text { involved in the degradation of glycolipids and glycopro- } \\
\text { teins) }\end{array}$ & Neu2 & ENSRNOT00000022818 & -2.1 & 0.02 \\
\hline $\begin{array}{l}\text { Proline rich } 16 \text { similar to mesenchymal stem cell protein } \\
\text { DSC54 (predicted) }\end{array}$ & Prr16 & ENSRNOT00000026724 & -1.9 & 0.04 \\
\hline Zink finger protein 36 -acts as a transcriptional activator & Zfp36 & ENSRNOT00000026661 & -1.9 & 0.03 \\
\hline $\begin{array}{l}\text { SH3-domain binding protein } 5 \text { (BTK-associated)-may } \\
\text { bind c-Jun N-terminal kinase (JNK); may play a role in } \\
\text { JNK and Bruton's tyrosine kinase (Btk) mediated signal- } \\
\text { ling pathways }\end{array}$ & Sh3bp5 & ENSRNOT00000026389 & -1.8 & 0.03 \\
\hline $\begin{array}{l}\text { UDP-Gal:betaGlcNAc beta 1,3-galactosyl transferase, } \\
\text { polypeptide } 1\end{array}$ & B3galt1 & ENSRNOT00000010018 & -1.8 & 0.01 \\
\hline $\begin{array}{l}\text { Lipopolysaccharide binding protein-binds lipopolysac- } \\
\text { charide on outer membrane of gram negative bacteria; } \\
\text { involved in immune response }\end{array}$ & Lbp & ENSRNOT00000019787 & -1.8 & 0.04 \\
\hline Leukocyte cell-derived chemotaxin 2 & Lect2 & ENSRNOT00000016252 & -1.8 & 0.04 \\
\hline Small nuclear ribonucleoprotein 25 (U11/U12) & Snrnp25 & ENSRNOT00000067079 & -1.8 & 0.03 \\
\hline Tripartite motif-containing 36 & Trim36 & ENSRNOT00000022294 & -1.8 & 0.04 \\
\hline Sprouty homolog 2 (Drosophila) & Spry2 & ENSRNOT00000013342 & -1.7 & 0.04 \\
\hline $\begin{array}{l}\text { Sec61 gamma subunit, pseudogene } 1 \text { gama subunit-like } \\
\text { Q7Tq10_RAT }\end{array}$ & $\begin{array}{l}\text { SEC61g- } \\
\text { ps1 }\end{array}$ & ENSRNOT00000043104 & -1.7 & 0.02 \\
\hline $\begin{array}{l}\text { Phosphodiesterase } 4 \mathrm{C} \text {, cAMP-specific (phosphodi- } \\
\text { esterase E1 dunce homolog, Drosophila- putative nucle- } \\
\text { otide phosphodlerase E1 dunce homolog, drosophila) }\end{array}$ & Pde4c & ENSRNOT00000026457 & -1.6 & 0.04 \\
\hline UDP-N-acteylglucosamine pyrophosphorylase 1-like 1. & Uap1/1 & ENSRNOT00000017373 & -1.6 & 0.02 \\
\hline
\end{tabular}


Table 3.18 Named down- regulated genes in ciprofibrate dosed rats treated for 3 hours. A list of downregulated genes for male F-344NHsd rats aged 14-15 weeks dosed with $50 \mathrm{mg} \mathrm{kg}^{-1}$ ciprofibrate then killed after 3 hours. RNAseq analysis was done as described in Section 2.2.6. Expressed genes with a fold change of $<-1.5$ and a FDR p-value of $<0.05$ were listed.

\begin{tabular}{|c|c|c|c|c|}
\hline Description & $\begin{array}{l}\text { Gene } \\
\text { name }\end{array}$ & $\begin{array}{c}\text { Ensembl } \\
\text { Feature ID }\end{array}$ & $\begin{array}{l}\text { Fold } \\
\text { Change } \\
<-1.5\end{array}$ & $\begin{array}{c}\text { FDR } \\
\text { p- } \\
\text { value } \\
<0.05\end{array}$ \\
\hline $\begin{array}{l}\text { Hermansky-Pudlak syndrome } 4 \text { homolog (human)- } \\
\text { human homolog is involved in the biogenesis of lyso- } \\
\text { somes and related cellular vesicles; mutations in the } \\
\text { human gene are associated with Hermansky-Pudlak syn- } \\
\text { drome }\end{array}$ & Hps4 & ENSRNOT00000000824 & -1.6 & 0.02 \\
\hline Sodium-dependent phosphate transport protein 1 & Slc17a1 & ENSRNOT00000066313 & -1.6 & 0.04 \\
\hline $\begin{array}{l}\text { Translocase of outer mitochondrial membrane } 7 \text { homolog } \\
\text { (yeast) }\end{array}$ & Tomm7 & ENSRNOT00000065962 & -1.6 & 0.02 \\
\hline Transmembrane protein $38 \mathrm{a}$ & Tmem38a & ENSRNOT00000015877 & -1.5 & 0.01 \\
\hline High mobility group uncleosomeal binding domain 3 & Hmgn3 & ENSRNOT00000039917 & -1.5 & 0.04 \\
\hline $\begin{array}{l}\text { ADP- ribosylation factor- like } 4 \mathrm{~A} \text { - may play role in GTP } \\
\text { binding and hydrolysis }\end{array}$ & $\operatorname{arl} 4 \mathrm{a}$ & ENSRNOT00000005800 & -1.6 & 0.04 \\
\hline ADP- ribosylation factor-like & $\operatorname{arl11}$ & ENSRNOT00000019646 & -1.5 & 0.04 \\
\hline Ribosomal protein S27-ribosomal protein subunit & Rps27 & ENSRNOT00000022897 & -1.7 & 0.02 \\
\hline $\begin{array}{l}\text { Ribosomal protein S14-structural component of the } 40 \mathrm{~S} \\
\text { subunit of the ribosome, the organelle responsible for } \\
\text { protein synthesis }\end{array}$ & Rps14 & ENSRNOT00000059501 & -1.8 & 0.05 \\
\hline Ribosomal protein L10A 60S ribosomal subunit protein & Rpl10a & ENSRNOT00000000603 & -1.5 & 0.02 \\
\hline Ribosomal protein L11 & Rpl11 & ENSRNOT00000030043 & -1.5 & 0.01 \\
\hline Ribosomal protein L23a & Rpl23a & ENSRNOT00000035657 & -1.5 & 0.03 \\
\hline SnoRNA no protein product & U8 & ENSRNOT00000054056 & -5.3 & 0.01 \\
\hline
\end{tabular}


Table 3.19 Novel down- regulated genes in rats dosed with ciprofibrate for 3 hours. A list of novel downregulated genes for male F-344NHsd rats aged 14-15 weeks, dosed with $50 \mathrm{mg} \mathrm{kg}^{-1}$ ciprofibrate then killed after 24 hours. RNAseq analysis was done as described in Section 2.2.6. Expressed genes with a fold change of $<-1.5$ and a FDR p-value of $<0.05$ are shown.

\begin{tabular}{|c|c|c|c|c|}
\hline Description & Gene name & $\begin{array}{c}\text { Ensembl } \\
\text { Feature ID }\end{array}$ & $\begin{array}{l}\text { Fold } \\
\text { change } \\
>1.5\end{array}$ & $\begin{array}{c}\text { FDR } \\
\text { p- } \\
\text { value } \\
<0.05\end{array}$ \\
\hline $\begin{array}{l}\text { Pseudogene (a noncoding sequence similar to an } \\
\text { active protein) no protein product }\end{array}$ & novel & ENSRNOT00000011532 & -9.0 & 0.05 \\
\hline Pseudogene (no protein product) & novel & ENSRNOT00000025854 & -1.9 & 0.04 \\
\hline $\begin{array}{l}\text { Novel MiRNA microarray (a single-stranded } \\
\text { RNA, typically } 21-23 \text { base pairs long), thought to } \\
\text { be involved in gene regulation (especially inhibi- } \\
\text { tion of protein expression) }\end{array}$ & novel & ENSRNOT00000054415 & -1.7 & 0.04 \\
\hline $\begin{array}{l}\text { Protein coding- a protein coding transcript is a } \\
\text { spliced mRNA that leads to a protein product }\end{array}$ & novel & ENSRNOT00000002046 & -1.8 & 0.05 \\
\hline Protein coding & novel & ENSRNOT00000065817 & -1.6 & 0.03 \\
\hline Protein coding & novel & ENSRNOT00000060517 & -1.6 & 0.04 \\
\hline Protein coding & novel & ENSRNOT00000004213 & -1.5 & 0.03 \\
\hline Protein coding transcript & RGD1563551 & ENSRNOT00000047507 & -3.1 & 0.04 \\
\hline Protein coding transcript & RGD1562755 & ENSRNOT00000051559 & -2.5 & 0.01 \\
\hline Protein coding transcript & LOC691255 & ENSRNOT00000036330 & -1.9 & 0.03 \\
\hline $\begin{array}{l}\text { Pseudogene gene a noncoding sequence similar to } \\
\text { an active protein (no protein product) }\end{array}$ & LOC365595 & ENSRNOT00000000346 & -2.1 & 0.03 \\
\hline Pseudogene & LOC367016 & ENSRNOT00000030115 & -1.8 & 0.05 \\
\hline Ribosomal protein P1-like & LOC 10036522 & ENSRNOT00000015893 & -1.5 & 0.03 \\
\hline Similar to ribosomal protein $\mathrm{L} 30$ & RGD1562397 & ENSRNOT00000044756 & -1.5 & 0.04 \\
\hline Similar to $60 \mathrm{~S}$ acidic ribosomal protein $\mathrm{P} 1$ & RGD1565054 & ENSRNOT00000034714 & -1.6 & 0.01 \\
\hline
\end{tabular}


Table 3.19 Novel down- regulated genes in rats dosed with ciprofibrate for 3 hours. A list of novel downregulated genes for male F-344NHsd rats aged 14-15 weeks, dosed with $50 \mathrm{mg} \mathrm{kg}^{-1}$ ciprofibrate then killed after 24 hours. RNAseq analysis was done as described in Section 2.2.6. Expressed genes with a fold change of $<-1.5$ and a FDR p-value of $<0.05$ are shown.

\begin{tabular}{|c|c|c|c|c|}
\hline Description & Gene name & $\begin{array}{c}\text { Ensembl } \\
\text { Feature ID }\end{array}$ & $\begin{array}{l}\text { Fold } \\
\text { change } \\
>1.5\end{array}$ & $\begin{array}{c}\text { FDR } \\
\text { p- } \\
\text { value } \\
<0.05\end{array}$ \\
\hline Similar to dystonin isoform 1 & LOC680875 & ENSRNOT00000014191 & -1.5 & 0.04 \\
\hline Similar to $60 \mathrm{~S}$ ribosomal protein $\mathrm{L} 23 \mathrm{a}$ & LOC689899 & ENSRNOT00000040647 & -1.5 & 0.01 \\
\hline Similar to ribosomal protein $\mathrm{S} 27 \mathrm{a}$ & RGD1564290 & ENSRNOT00000027780 & -1.6 & 0.03 \\
\hline Similar to ribosomal protein $\mathrm{S} 27 \mathrm{a}$ & RGD1560997 & ENSRNOT00000051805 & -1.6 & 0.01 \\
\hline
\end{tabular}

\section{Section 3.4.6.2 Up- regulated genes with RNAseq}

Genes were considered up- regulated if the FDR p-value was more than 0.05 and there was a fold change in expression of $>2.5$ (because the interest is in the up-regulated genes). Table 3.20 shows a list of up- regulated known (named) genes and in Table 3.21 is a list of the novel genes that have not been named to date. 
Table 3.20 Named up- regulated genes in ciprofibrate dosed rats treated for 3 hours. A list of up-regulated genes for male F-344NHsd rats aged 14-15 weeks dosed with $50 \mathrm{mg} \mathrm{kg}^{-1}$ ciprofibrate then killed after 3 hours. RNAseq analysis was done as described in Section 2.2.6. Expressed genes with a fold change of $>2.5$ and a FDR p-value of $<0.05$ were listed.

\begin{tabular}{|c|c|c|c|c|}
\hline Description & $\begin{array}{l}\text { Gene } \\
\text { name }\end{array}$ & $\begin{array}{c}\text { Ensembl } \\
\text { Feature ID }\end{array}$ & $\begin{array}{l}\text { Fold } \\
\text { Change } \\
>2.5\end{array}$ & $\begin{array}{l}\text { FDR } \\
\text { p- } \\
\text { value } \\
<0.05\end{array}$ \\
\hline $\begin{array}{l}\text { Cytochrome P450, family 4, subfamily a, polypeptide } \\
10 \text {-member of the cytochrome P } 450 \text { monoxygenase } \\
\text { enzyme superfamily; plays a role in lipid metabolism; } \\
\text { involved in androgen mediated signalling }\end{array}$ & Cyp4a10 & ENSRNOT00000051385 & 3.2 & 0.01 \\
\hline $\begin{array}{l}\text { Cytochrome } \mathrm{P} 4504 \mathrm{X} 1 \text { cytochrome } \mathrm{P} 450 \text { protein; may } \\
\text { play a role in neurovascular function cytochrome } \mathrm{P} 450 \text {, } \\
\text { family } 4 \text {, subfamily } \mathrm{x} \text {, polypeptide } 1 \text { - cytochrome } \mathrm{P} 450 \\
\text { protein; may play a role in neurovascular function }\end{array}$ & Сур4x1 & ENSRNOT00000011985 & 3.1 & 0.04 \\
\hline $\begin{array}{l}\text { Peroxisome proliferator-activated receptor gamma, } \\
\text { coactivator } 1 \text { beta }\end{array}$ & Ppargc $1 b$ & ENSRNOT00000023661 & 2.9 & 0.03 \\
\hline G0/G1 switch 2 & G0s2 & ENSRNOT00000007879 & 5.8 & 0.01 \\
\hline $\begin{array}{l}\text { Arylacetamide deacetylase-like } 1 \text { - exhibits catalytic } \\
\text { activity and hydrolase activity; involved in metabolism }\end{array}$ & Aadacl1 & ENSRNOT00000017805 & 6.1 & 0.02 \\
\hline Acyl-CoA thioesterase 5 & Acot5 & ENSRNOT00000013760 & 2.8 & 0.01 \\
\hline Acyl-CoA thioesterase 6 & Acot6 & ENSRNOT00000058101 & 4.0 & 0.01 \\
\hline Acid phosphatase, prostate- & Acpp & ENSRNOT00000016222 & 3.2 & 0.03 \\
\hline $\begin{array}{l}\text { Angiopoietin-like } 4 \text {-a circulating protein which causes } \\
\text { an increase in plasma very low density lipoprotein by } \\
\text { inhibition of lipoprotein lipase activity }\end{array}$ & Angptl4 & ENSRNOT00000010031 & 2.7 & 0.01 \\
\hline Apolipoprotein L 9a & Apol9a & ENSRNOT00000031951 & 2.8 & 0.02 \\
\hline Arrestin domain containing 4 & Arrdc & ENSRNOT00000051402 & 3.5 & 0.01 \\
\hline $\begin{array}{l}\text { Calcium channel, voltage-dependent, alpha } 2 / \text { delta sub- } \\
\text { unit } 4\end{array}$ & Cacna2d4 & ENSRNOT00000010746 & 3.3 & 0.01 \\
\hline $\begin{array}{l}\text { Chemokine binding protein } 2 \mathrm{CC} \text {-chemokine receptor; } \\
\text { may have a role in placental immunity or hematopoiesis }\end{array}$ & Ccbp & ENSRNOT00000026343 & 4.5 & 0.05 \\
\hline
\end{tabular}


Table 3.20 Named up- regulated genes in ciprofibrate dosed rats treated for 3 hours. A list of up-regulated genes for male F-344NHsd rats aged 14-15 weeks dosed with $50 \mathrm{mg} \mathrm{kg}^{-1}$ ciprofibrate then killed after 3 hours. RNAseq analysis was done as described in Section 2.2.6. Expressed genes with a fold change of $>2.5$ and a FDR p-value of $<0.05$ were listed.

\begin{tabular}{|c|c|c|c|c|}
\hline Description & $\begin{array}{l}\text { Gene } \\
\text { name }\end{array}$ & $\begin{array}{c}\text { Ensembl } \\
\text { Feature ID }\end{array}$ & $\begin{array}{l}\text { Fold } \\
\text { Change } \\
>2.5\end{array}$ & $\begin{array}{c}\text { FDR } \\
\text { p- } \\
\text { value } \\
<0.05\end{array}$ \\
\hline $\begin{array}{l}\text { Cyclin D1 a cell cycle protein involved in the regulation } \\
\text { of cell proliferation; associated with many cancers and } \\
\text { other diseases }\end{array}$ & Cend1 & ENSRNOT00000028411 & 2.9 & 0.03 \\
\hline $\begin{array}{l}\text { Carnitine palmitoyltansferase } 1 \mathrm{~b} \text {, muscle - muscle iso- } \\
\text { form of enzyme that catalyses the transfer of long chain } \\
\text { fatty acids to carnitine for translocation across the mito- } \\
\text { chondrial inner membrane }\end{array}$ & Cpt1b & ENSRNOT00000013985 & 4.2 & 0.02 \\
\hline $\begin{array}{l}\text { Carnitine palmitoyltransferase } 2 \text { - inner mitochondrial } \\
\text { membrane protein that converts acylcarnitine to acyl- } \\
\text { CoA }\end{array}$ & Cpt2 & ENSRNOT00000016954 & 2.6 & 0.01 \\
\hline Eph receptor A2 & Epha2 & ENSRNOT00000066072 & 3.3 & 0.04 \\
\hline Ets variant 3-like & Etv3I & ENSRNOT00000057490 & 2.9 & 0.04 \\
\hline $\begin{array}{l}\text { Ets variant } 6 \text { human homolog is an ETS family tran- } \\
\text { scription factor; may be involved in hematopoiesis and } \\
\text { maintenance of the vascular network }\end{array}$ & Etv6 & ENSRNOT00000007889 & 4.6 & 0.01 \\
\hline Fin bud initiation factor homolog (zebra fish) & Fiin & ENSRNOT00000006203 & 3.2 & 0.04 \\
\hline $\begin{array}{l}\text { Inhibin beta E cytokine; involved in cell fate determina- } \\
\text { tion }\end{array}$ & Inhbe & ENSRNOT00000010106 & 3.7 & 0.03 \\
\hline Kelch repeat and BTB (POZ) domain containing 11 & Kbtbd11 & ENSRNOT00000016420 & 6.5 & 0.01 \\
\hline $\begin{array}{l}\text { Known pseudogene potassium channel tetramerisation } \\
\text { domain containing } 12\end{array}$ & Kctd12 & ENSRNOT00000037179 & 2.9 & 0.02 \\
\hline Keratin 23 (histone deacetylase inducible) & Krt23 & ENSRNOT00000016657 & 3.9 & 0.01 \\
\hline MHC I like leukocyte 2 & Mill2 & ENSRNOT00000048149 & 3.7 & 0.01 \\
\hline Myotubularin related protein 7 & Mtmr7 & ENSRNOT00000065327 & 4.2 & 0.03 \\
\hline Myeloblastosis oncogene-like 1 & Mybl1 & ENSRNOT00000066911 & 2.6 & 0.01 \\
\hline
\end{tabular}


Table 3.20 Named up- regulated genes in ciprofibrate dosed rats treated for 3 hours. A list of up-regulated genes for male F-344NHsd rats aged 14-15 weeks dosed with $50 \mathrm{mg} \mathrm{kg}^{-1}$ ciprofibrate then killed after 3 hours. RNAseq analysis was done as described in Section 2.2.6. Expressed genes with a fold change of $>2.5$ and a FDR p-value of $<0.05$ were listed.

\begin{tabular}{|c|c|c|c|c|}
\hline Description & $\begin{array}{l}\text { Gene } \\
\text { name }\end{array}$ & $\begin{array}{c}\text { Ensembl } \\
\text { Feature ID }\end{array}$ & $\begin{array}{l}\text { Fold } \\
\text { Change } \\
>2.5\end{array}$ & $\begin{array}{l}\text { FDR } \\
\text { p- } \\
\text { value } \\
<0.05\end{array}$ \\
\hline $\begin{array}{l}\text { Myc myelocytomatosis viral oncogene homolog } 1 \text {, lung } \\
\text { carcinoma derived (avian) mouse lung carcinoma myc } \\
\text { related oncogene } 1 \text { (Lmyc1) is a DNA binding protein } \\
\text { with cell cycle related transcriptional activities }\end{array}$ & Mycl1 v & ENSRNOT00000019101 & 3.6 & 0.02 \\
\hline $\begin{array}{l}\text { Nuclear receptor subfamily } 4 \text {, group A, member } 2 \text { - } \\
\text { nuclear receptor and transcription factor; plays a role in } \\
\text { development and maintenance of neurons synthesizing } \\
\text { the neurotransmitter dopamine }\end{array}$ & $\mathrm{Nr} 4 \mathrm{a} 2$ & ENSRNOT00000041394 & 2.8 & 0.01 \\
\hline Progestin and adipo Q receptor family member VII & Paqr7 & ENSRNOT00000022713 & 5.7 & 0.01 \\
\hline $\begin{array}{l}\text { Peptidase M20 domain containing 2; aminoacylase 1- } \\
\text { like 2; aminoacylase 1-like } 2 \text { (predicted); acy112; } \\
\text { LOC313130; Acy112; Acy112_predicted }\end{array}$ & $\operatorname{Pm} 20 \mathrm{~d} 2$ & ENSRNOT00000060914 & 3.8 & 0.05 \\
\hline Protein phosphatase $1 \mathrm{~K}$ (PP2C domain containing) & Ppm1k & ENSRNOT00000009202 & 2.5 & 0.03 \\
\hline PR domain containing 6 & Prdm6 & ENSRNOT00000047755 & 2.6 & 0.03 \\
\hline Prospero homeobox 2 & Prox 2 & ENSRNOT00000006704 & 3.2 & 0.04 \\
\hline $\begin{array}{l}\text { Proline rich Gla (G-carboxyglutamic acid) } 4 \text { (trans } \\
\text { membrane) }\end{array}$ & Prrg4 & ENSRNOT00000038464 & 7.9 & 0.02 \\
\hline Putative neuronal cell adhesion molecule & Punc & ENSRNOT00000051353 & 6.3 & 0.04 \\
\hline $\begin{array}{l}\text { RAS, dexamethasone-induced } 1 \text { - interacts with neuronal } \\
\text { NO synthase adaptor protein CAPON and is involved in } \\
\text { nitric oxide mediated signalling }\end{array}$ & Rasd1 & ENSRNOT00000004475 & 2.6 & 0.03 \\
\hline Ras responsive element binding protein 1 & Rreb1 & ENSRNOT00000021007 & 2.5 & 0.02 \\
\hline Sterile alpha and TIR motif containing 1 & Sarm1 & ENSRNOT00000013639 & 2.8 & 0.04 \\
\hline $\begin{array}{l}\text { Stearoyl-Coenzyme A desaturase 1-enzyme involved in } \\
\text { the synthesis and regulation of unsaturated fatty acids }\end{array}$ & Scd1 & ENSRNOT00000051086 & 13.2 & 0.01 \\
\hline Stearoyl-coenzyme A desaturase 4 & Scd4 & ENSRNOT00000017834 & 15.6 & 0.02 \\
\hline
\end{tabular}


Table 3.20 Named up- regulated genes in ciprofibrate dosed rats treated for 3 hours. A list of up-regulated genes for male F-344NHsd rats aged 14-15 weeks dosed with $50 \mathrm{mg} \mathrm{kg}^{-1}$ ciprofibrate then killed after 3 hours. RNAseq analysis was done as described in Section 2.2.6. Expressed genes with a fold change of $>2.5$ and a FDR p-value of $<0.05$ were listed.

\begin{tabular}{|c|c|c|c|c|}
\hline Description & $\begin{array}{l}\text { Gene } \\
\text { name }\end{array}$ & $\begin{array}{c}\text { Ensembl } \\
\text { Feature ID }\end{array}$ & $\begin{array}{l}\text { Fold } \\
\text { Change } \\
>2.5\end{array}$ & $\begin{array}{c}\text { FDR } \\
\text { p- } \\
\text { value } \\
<0.05\end{array}$ \\
\hline $\begin{array}{l}\text { Solute carrier family } 16 \text {, member } 6 \text { (monocarboxylic } \\
\text { acid transporter } 7 \text { ) - human homolog is a monocarboxy- } \\
\text { late transporter }\end{array}$ & Slc16a6 & ENSRNOT00000000262 & 6.4 & 0.03 \\
\hline $\begin{array}{l}\text { Solute carrier family } 22 \text { (organic cation/carnitine trans- } \\
\text { porter), member } 5 \text { mediates high-affinity sodium-depen- } \\
\text { dent carnitine transport and sodium-independent organic } \\
\text { cation transport }\end{array}$ & Slc22a5 & ENSRNOT00000011340 & 2.7 & 0.01 \\
\hline $\begin{array}{l}\text { Solute carrier family } 25 \text {, member } 30 \text { kidney mitochon- } \\
\text { drial carrier protein } 1 \text {; solute carrier family } 25 \text { member } \\
30 \text {; solute carrier family } 25 \text {, member } 30 \text {, Kidney mito- } \\
\text { chondrial carrier protein } 1\end{array}$ & $\begin{array}{l}\text { Slc25a30 / } \\
\text { KMCP1_r } \\
\text { at }\end{array}$ & ENSRNOT00000040316 & 3.0 & 0.04 \\
\hline $\begin{array}{l}\text { Solute carrier family } 34 \text { (sodium phosphate), member } 2- \\
\text { a sodium dependent phosphate transporter that may pro- } \\
\text { vide inorganic phosphate for the synthesis of lung sur- } \\
\text { factant and is associated with aging }\end{array}$ & Slc34a2 & ENSRNOT00000048509 & 5.6 & 0.04 \\
\hline $\begin{array}{l}\text { T-box } 3 \text { - human homolog acts as a transcriptional } \\
\text { repressor and plays a role in the development of several } \\
\text { organ systems }\end{array}$ & Tbx3 & ENSRNOT00000011552 & 3.1 & 0.03 \\
\hline
\end{tabular}


Table 3.21 Novel up- regulated genes in rats dosed with ciprofibrate for 3 hours with RNAseq analysis. A list of novel down- regulated genes for male F-344NHsd rats aged 14-15 weeks, dosed with $50 \mathrm{mg} \mathrm{kg}^{-1}$ ciprofibrate then killed after 24 hours. RNAseq analysis was done as described in Section 2.2.6. Expressed genes with a fold change of $>2.5$ and a FDR p-value of $<0.05$ are shown.

\begin{tabular}{|c|c|c|c|c|}
\hline Description & Gene name & $\begin{array}{c}\text { Ensembl } \\
\text { Feature ID }\end{array}$ & $\begin{array}{l}\text { Fold } \\
\text { Change } \\
>2.5\end{array}$ & $\begin{array}{l}\text { FDR p- } \\
\text { value } \\
<0.05\end{array}$ \\
\hline Fer-1-like 5 (C. elegans) Gene & novel & ENSRNOT00000059806 & 2.6 & 0.03 \\
\hline XIAP associated factor 1 Gene & novel & ENSRNOT00000056551 & 2.6 & 0.04 \\
\hline Known protein coding & novel & ENSRNOT00000061062 & 3.5 & 0.02 \\
\hline Known protein coding & novel & ENSRNOT00000041253 & 2.6 & 0.02 \\
\hline Protein coding & novel & ENSRNOT00000061064 & 3.1 & 0.04 \\
\hline Protein coding & novel & ENSRNOT00000061065 & 3.1 & 0.04 \\
\hline Protein coding & novel & ENSRNOT00000016611 & 3.5 & 0.03 \\
\hline $\begin{array}{l}\text { Known protein coding similar to serine/threonine } \\
\text { kinase Synonyms: LOC } 296256 \text {; } \\
\text { RGD1565143_predicted; similar to serine/threonine } \\
\text { kinase (predicted); }\end{array}$ & RGD1565143 & ENSRNOT00000065773 & 3.3 & 0.05 \\
\hline rCG62747-like & $\begin{array}{l}\text { LOC } 1003615 \\
82\end{array}$ & ENSRNOT00000050476 & 3.3 & 0.01 \\
\hline mCG140381-like & $\begin{array}{l}\text { LOC } 1003630 \\
13\end{array}$ & ENSRNOT00000005583 & 2.9 & 0.03 \\
\hline Similar to ras homolog gene family, member $\mathrm{f}$ & LOC690130 & ENSRNOT00000064390 & 2.8 & 0.03 \\
\hline Similar to hypothetical protein MGC42105 & RGD1308116 & ENSRNOT00000021964 & 2.9 & 0.01 \\
\hline $\mathrm{Ab} 2-060$ & LOC501038 & ENSRNOT00000045455 & 2.7 & 0.04 \\
\hline RGD1560010 & RGD1560010 & ENSRNOT00000013356 & 3.6 & 0.02 \\
\hline
\end{tabular}




\section{Section 3.4.7 Pathways for over-representative genes}

The identification of a number of up- regulated genes calls for characterisation of common pathways or functions in this gene subset. This was achieved by manual comparison of the up-regulated genes with pathways found at these websites http://rgd.mcw.edu/wg/pathway?100 and http://www.ensembl.org/Rattus_norvegicus/Info/Index.

The pathways with relationship with DNA synthesis, cell cycle or PPAR signalling were studied. 16 genes were induced out of 73 PPAR signalling pathway genes (21.9\%), when compared with KEGG website. Also, 12 up-regulated genes out of 43 fatty acid metabolic pathway genes $(27.9 \%)$, and 10 out of 103 genes $(9.7 \%)$ were engaged in the cell cycle. Other smaller groups of genes (5-6 genes) were involved in sodium ion transport, oxidation reduction and palmitoylCoA hydrolase activity as demonstrated in Table 3.22.

Pathways that are not listed in the table but have a number of up- regulated genes are metabolic process and bioactivation pathway via cytochrome $\mathrm{P} 450$. 
Table 3.22 Some pathways represented by named up- regulated genes in ciprofibrate dosed rats for 3 hours. A list of pathways and the related genes are shown for up- regulated genes for male F-344NHsd rats aged 14-15 weeks dosed with $50 \mathrm{mg} \mathrm{kg}^{-1}$ ciprofibrate then killed after 3 hours. RNAseq analysis was done as described in Section 2.2.6. Expressed genes with a fold change of $>1.5$ and a FDR $p$-value of $<0.05$ were listed.

\begin{tabular}{|c|c|c|}
\hline Description & $\begin{array}{l}\text { gene } \\
\text { name }\end{array}$ & $\begin{array}{l}\text { fold } \\
\text { change }\end{array}$ \\
\hline \multicolumn{3}{|l|}{ PPAR signalling pathway: } \\
\hline $\begin{array}{l}\text { Acetyl-Coenzyme A acyl transferase 1/peroxisomal 3-ketoacyl-CoA } \\
\text { thiolase }\end{array}$ & Acaa1 & 1.9 \\
\hline Acyl-CoA synthetase long-chain family member 1 & Acsl1 & 1.8 \\
\hline Acyl-CoA synthetase long-chain family member 3 & $\operatorname{Acs} 13$ & 2.0 \\
\hline Angiopoietin-like 4 & Angptl4 & 2.7 \\
\hline Apolipoprotein L 9a & Apol9a & 2.8 \\
\hline Carnitine palmitoyltransferase $1 \mathrm{a}$, liver & Cpt1a & 1.7 \\
\hline Carnitine palmitoyltansferase $1 \mathrm{~b}$, muscle & Cpt1b & 4.2 \\
\hline Carnitine palmitoyltransferase 2 & Cpt2 & 2.6 \\
\hline Cytochrome P450, family 4, subfamily a, polypeptide 1 & Cyp4a1 & 3.3 \\
\hline Cytochrome P450, family 4, subfamily a, polypeptide 2 & Сур4a2 & 2.3 \\
\hline Cytochrome P450, family 4, subfamily a, polypeptide 3 & Сур4a3 & 2.3 \\
\hline Cytochrome $\mathrm{P} 450$, family 4 , subfamily $\mathrm{b}$, polypeptide 1 & Cyp4b1 & 1.8 \\
\hline 3-hydroxy-3-methylglutaryl-Coenzyme A synthase 2 & Hmgcs2 & 1.7 \\
\hline Peroxisome proliferator-activated receptor gamma, coactivator 1 beta & $\begin{array}{l}\text { Ppargc } \\
1 b\end{array}$ & 2.9 \\
\hline
\end{tabular}


Table 3.22 Some pathways represented by named up- regulated genes in ciprofibrate dosed rats for 3 hours. A list of pathways and the related genes are shown for up- regulated genes for male F-344NHsd rats aged 14-15 weeks dosed with $50 \mathrm{mg} \mathrm{kg}^{-1}$ ciprofibrate then killed after 3 hours. RNAseq analysis was done as described in Section 2.2.6. Expressed genes with a fold change of $>1.5$ and a FDR $p$-value of $<0.05$ were listed.

\begin{tabular}{|c|c|c|}
\hline Description & $\begin{array}{l}\text { gene } \\
\text { name }\end{array}$ & $\begin{array}{l}\text { fold } \\
\text { change }\end{array}$ \\
\hline Stearoyl-Coenzyme A desaturase 1 & Scd 1 & 13.2 \\
\hline Stearoyl-coenzyme A desaturase 4 & Scd4 & 15.6 \\
\hline \multicolumn{3}{|l|}{ Fatty acid metabolic pathway: } \\
\hline Acetyl-Coenzyme A acyltransferase 1 & Acaa1 & 1.9 \\
\hline Acyl-CoA synthetase long-chain family member 1 & Acsl1 & 1.8 \\
\hline Acyl-CoA synthetase long-chain family member 3 & Acsl3 & 2.0 \\
\hline Aldehyde dehydrogenase 3 family, member A2 & Aldh3a2 & 1.7 \\
\hline Carnitine palmitoyltransferase $1 \mathrm{a}$, liver & Cptla & 1.7 \\
\hline Carnitine palmitoyltansferase $1 \mathrm{~b}$, muscle & Cptlb & 4.2 \\
\hline Carnitine palmitoyltransferase 2 & Cpt2 & 2.6 \\
\hline Cytochrome P450, family 4, subfamily a, polypeptide 10 & Cyp4a10 & 3.3 \\
\hline Cytochrome P450, family 4, subfamily a, polypeptide 2 & Cyp4a2 & 2.3 \\
\hline Cytochrome P450, family 4, subfamily b, polypeptide 1 & Cyp4b1 & 1.8 \\
\hline Hydroxyacyl-Coenzyme A dehydrogenase, alpha subunit & Hadha & 1.6 \\
\hline Stearoyl-Coenzyme A desaturase 1 & Scd 1 & 13.2 \\
\hline
\end{tabular}


Table 3.22 Some pathways represented by named up- regulated genes in ciprofibrate dosed rats for 3 hours. A list of pathways and the related genes are shown for up- regulated genes for male F-344NHsd rats aged 14-15 weeks dosed with $50 \mathrm{mg} \mathrm{kg}^{-1}$ ciprofibrate then killed after 3 hours. RNAseq analysis was done as described in Section 2.2.6. Expressed genes with a fold change of $>1.5$ and a FDR $p$-value of $<0.05$ were listed.

\begin{tabular}{|c|c|c|}
\hline Description & $\begin{array}{l}\text { gene } \\
\text { name }\end{array}$ & $\begin{array}{c}\text { fold } \\
\text { change }\end{array}$ \\
\hline \multicolumn{3}{|l|}{ Cell cycle: } \\
\hline Cell cycle associated protein 1 Gene & Caprin 1 & 1.8 \\
\hline CC-chemokine receptor & Ccbp & 4.5 \\
\hline Cyclin D1 & Ccnd1 & 2.9 \\
\hline Cyclin T1 & Ccnt1 & 1.8 \\
\hline G0/G1 switch 2 & G0s2 & 5.8 \\
\hline Nicotinamide phosphoribosyltransferase & Nampt & 2.3 \\
\hline Nibrin & $\mathrm{Nbn}$ & 2.0 \\
\hline Par-6 (partitioning defective 6) homolog beta & Pard6b & 2.0 \\
\hline Retinoblastoma 1 & $\mathrm{Rb} 1$ & 1.6 \\
\hline Salt-inducible kinase 1 & Sik1 & 2.2 \\
\hline \multicolumn{3}{|l|}{ Sodium ion transport: } \\
\hline Solute carrier family 13 (sodium/sulfate symporters), member 4 & Slc13a4 & 2.2 \\
\hline $\begin{array}{l}\text { Solute carrier family } 22 \text { (organic cation/carnitine transporter), member } \\
5\end{array}$ & Slc22a5 & 2.7 \\
\hline Solute carrier family 23 (nucleobase transporters), member 2 & Slc $23 \mathrm{a} 2$ & 2.0 \\
\hline Solute carrier family 34 (sodium phosphate), member 2 & Slc34a2 & 5.6 \\
\hline
\end{tabular}


Table 3.22 Some pathways represented by named up- regulated genes in ciprofibrate dosed rats for 3 hours. A list of pathways and the related genes are shown for up- regulated genes for male F-344NHsd rats aged 14-15 weeks dosed with $50 \mathrm{mg} \mathrm{kg}^{-1}$ ciprofibrate then killed after 3 hours. RNAseq analysis was done as described in Section 2.2.6. Expressed genes with a fold change of $>1.5$ and a FDR $p$-value of $<0.05$ were listed.

\begin{tabular}{|c|c|c|}
\hline Description & $\begin{array}{l}\text { gene } \\
\text { name }\end{array}$ & $\begin{array}{c}\text { fold } \\
\text { change }\end{array}$ \\
\hline Solute carrier family 4 (anion exchanger), member 4 & Slc4a4 & 1.8 \\
\hline \multicolumn{3}{|l|}{ Palmitoyl-CoA hydrolase activity: } \\
\hline Acyl-CoA thioesterase 5 & Acot5 & 2.8 \\
\hline Acyl-CoA thioesterase 6 & Acot6 & 4.0 \\
\hline Acyl-CoA thioesterase 7 & Acot7 & 1.6 \\
\hline Acyl-CoA synthetase long-chain family member 1 & Acaal & 1.8 \\
\hline Acyl-CoA synthetase long-chain family member 3 & $\operatorname{Acs} 13$ & 2.0 \\
\hline Acetyl-Coenzyme A acyltransferase 1 & Acaa1 & 1.9 \\
\hline \multicolumn{3}{|l|}{ Oxidation reduction: } \\
\hline Cytochrome P450, family 4, subfamily a, polypeptide 10 & Cyp4a1 & 3.3 \\
\hline Cytochrome P450, family 4, subfamily a, polypeptide 2 & Cyp4a2 & 2.3 \\
\hline Cytochrome P450, family 4, subfamily a, polypeptide 3 & Cyp4a3 & 2.3 \\
\hline Cytochrome P450, family 4, subfamily b, polypeptide 1 & Cyp4b1 & 1.8 \\
\hline Jumonji domain containing $1 \mathrm{C}$ & Jmjd1c & 1.5 \\
\hline
\end{tabular}




\section{Section 3.5 Confirmation of results with real- time PCR}

This section was set out to confirm the results found by the RNAseq and microarray analysis with real- time PCR by choosing some genes and measuring the levels of mRNA. Samples from male F-344 fisher rats treated with $50 \mathrm{mg} \mathrm{kg}^{-1}$ ciprofibrate, $100 \mathrm{mg} \mathrm{kg}^{-1} \mathrm{CPA}$ and the control/ vehicle corn oil for 1, 3, 5 and 24 hours were analysed with real- time PCR as shown in Section 2.2.7. These samples were in 4 biological replicates and 2 technical replicates.

Primers and probes were designed for chosen genes. The genes used were $C Y P 4 A 1, C Y P 3 A 1$, G0s2, Ccnd1, AhR, $\beta$-actin and Scd1. AhR and $\beta$-actin genes were chosen as normalization genes as they were found to have a minimal induction change with the RNAseq results and they are also well known housekeeping genes regularly used for this purpose (Bazzi et al., 2009).

Cytochrome P450, family 4, subfamily a, polypeptide 1 (CYP4A1) was used as a positive control for the samples treated with ciprofibrate, as it is known to be induced by PPAR $\alpha$ agonists (Bell et al., 1991)(Bars et al., 1993)(Morris and Davila, 1996). The induction of CYP4A1 was also noted in the microarray analysis for the 24 hour samples. Cytochrome P450, family 3 , subfamily a, polypeptide 1 (CYP3A1) was used as a positive control for CPA treated samples, as this is known to be highly induced by PXR agonists (Lehmann et al., 1998)(Hosoe et al., 2005).

The other genes tested were G0/G1 switch $2(G 0 s 2)$ and cyclin D1 (Ccnd1) as they are involved in cell cycle pathway. Stearoyl-Coenzyme A desaturase $1(S c d 1)$ is involved in the PPAR signalling pathway. As for the Aryl hydrocarbon receptor $(A h R)$ it was found to be down- regulated in the ciprofibrate samples treated for 3 hours. 


\section{Section 3.5.1 Efficiency of primers and probes}

To test the efficiency of the real- time PCR primers and probes, standard curves were produced for the CYP4A1, CYP3A1, G0s2, Ccnd1, AhR, $\beta$-actin and $S c d 1$ genes by amplifying a 5 fold serial dilution of cDNA prepared from the rat samples treated with corn oil. This was done in triplicate and the negative controls used were NTC, -RT and -RNA as explained in Section 2.2.7.2.

Figure 3.49 shows the Cycle-Threshold $(\mathrm{Ct})$ (the cycle at which the fluorescence from the samples cross the threshold) against the $\log 10$ cDNA concentrations for the genes $A h R$, Scdl and CYP3A1. Figure 3.50 shows the standard curves for the genes Ccnd1, CYP4A1 and G0s2. While the standard curves for the gene $\beta$-actin are shown in Figure 3.51.

The amplification efficiency $(\%)$ and regression coefficient $\left(\mathrm{r}^{2}\right)$ of the standard curves for the genes are represented in Table 3.23. Amplification efficiencies of the standard curves for all seven genes (CYP4A1, CYP3A1, G0s2, Ccnd1, AhR, $\beta$-actin and Scd1) were within $9 \%$ of $100 \%$ and a regression coefficient of $0.996 \pm 0.003$. This is ideal, as the amplification efficiency for PCR reactions should be $100 \% \pm 10 \%$, and the $\mathrm{r}^{2}$ should be close to 1 .

These results show that the genes and the method used, as described in Section 2.2.7, are reliable and can be applied to analyse the samples from male F-344 fisher rats treated with $50 \mathrm{mg} \mathrm{kg}^{-1}$ ciprofibrate, $100 \mathrm{mg} \mathrm{kg}^{-1} \mathrm{CPA}$ and the control/vehicle corn oil for 1, 3, 5 and 24 hours. 


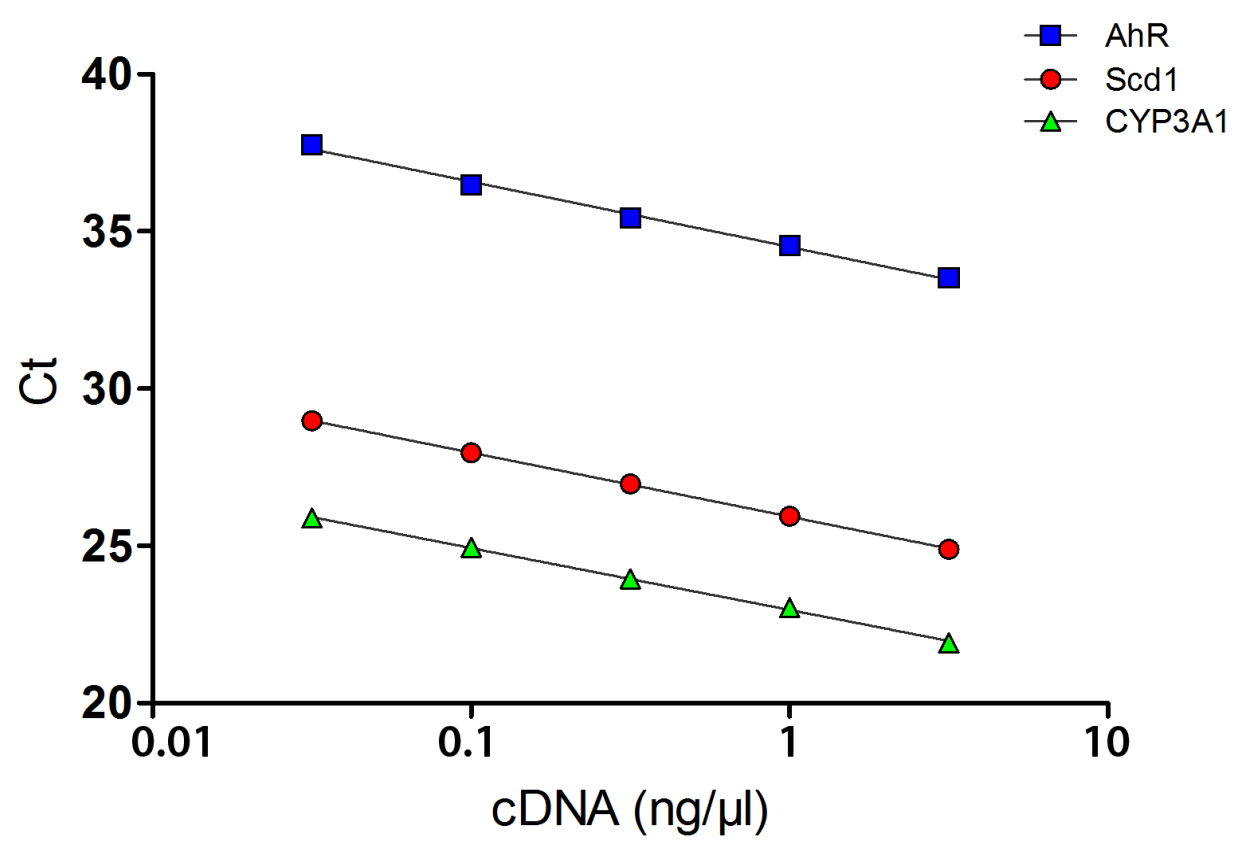

Figure 3.49 Amplification efficiencies for $A \boldsymbol{h} R, \boldsymbol{S c d} 1$ and $\boldsymbol{C Y P 3 A 1}$. cDNA from rat hepatic RNA treated with corn oil for 30 hours was diluted 5 fold and amplified separately with each of $A h R$-with dye HEX (blue squares), $S c d 1$-with dye HEX (red circles) and CYP3A1- with dye FAM (green triangles), then detected with real-time RT-PCR using TaqMan probe as described in Section 2.2.7. Each point represents the mean for triplicate samples. The efficiencies of each of the genes were obtained separately. 


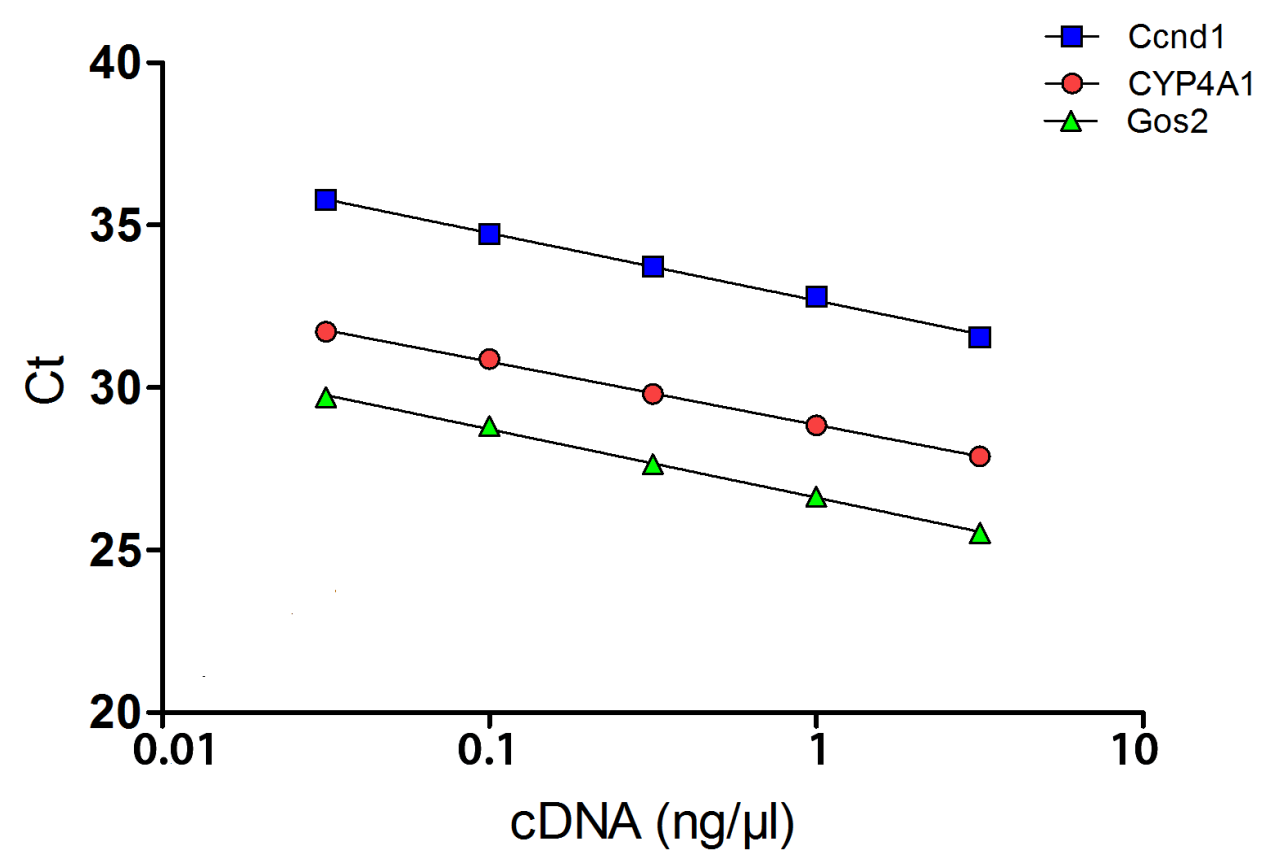

Figure 3.50 Amplification efficiencies for Ccnd1, CYP4A1 and G0s2. cDNA from rat hepatic RNA treated with corn oil for 30 hours was diluted to 5 fold and amplified separately with each of $C c n d 1$-with dye HEX (blue squares), CYP4A1- with dye FAM (red circles) and G0s2- with dye At0647N (green triangles), then detected with realtime RT-PCR using TaqMan probe as described in Section 2.2.7. Each point represents the mean for triplicate samples. The efficiencies of each of the genes were obtained separately.

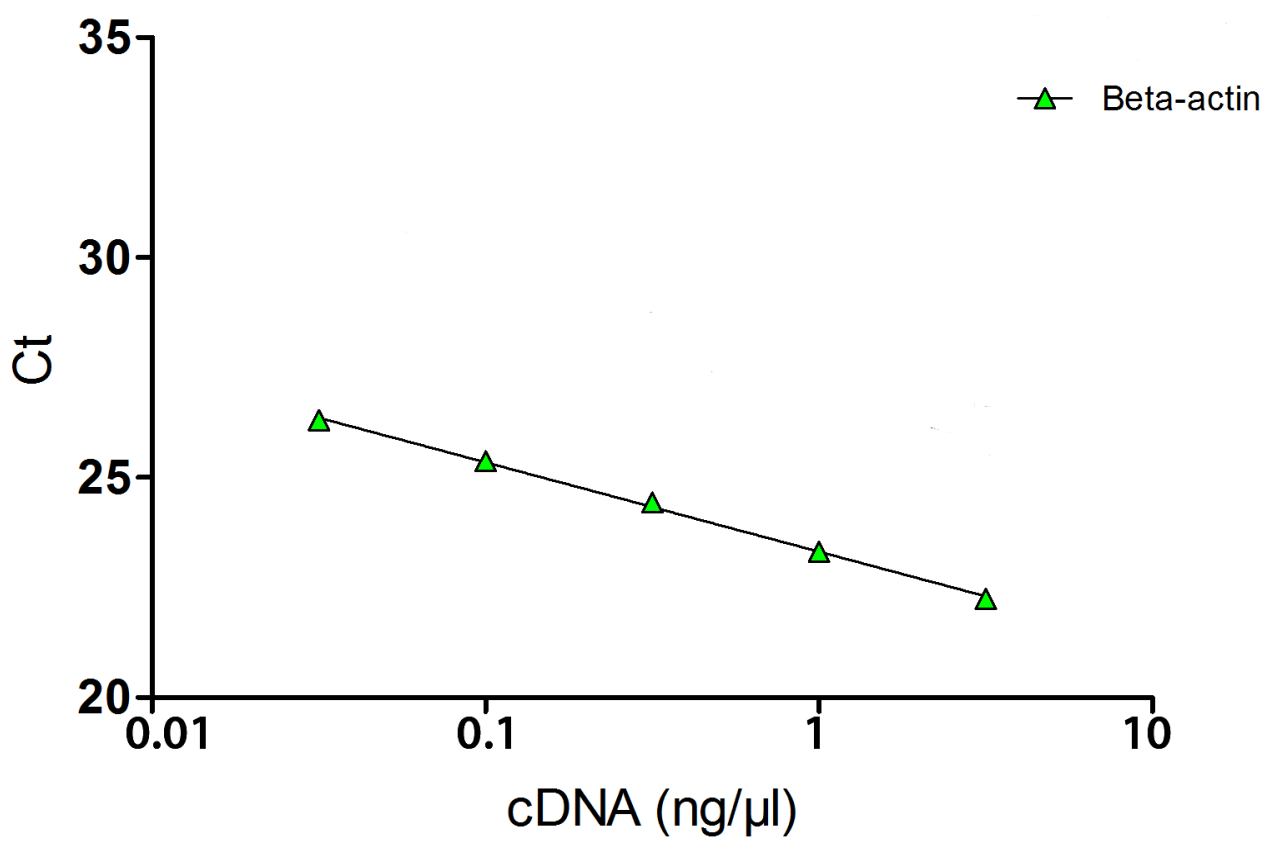

Figure 3.51 Amplification efficiencies for $\beta$-actin. cDNA from rat hepatic RNA treated with corn oil for 30 hours was diluted to 5 fold and amplified with $\beta$-actin- with dye Cy 5 (green triangles), then detected with realtime RT-PCR using TaqMan probe as described in Section 2.2.7. Each point represents the mean for triplicate samples. 
Table 3.23 Quantitation data of real- time RT-PCR for the genes used. Regression and efficiencies of CYP4A1, CYP3A1, G0s2, Ccnd1, AhR, beta actin and Scd1. The regression correlation coefficient value $\mathrm{r}^{2}$ were determined from the equation line. The amplification efficiencies were derived as percentages and were calculated from the slope.

\begin{tabular}{l|l|l}
\hline \multicolumn{1}{c|}{ Gene } & \multicolumn{1}{|c|}{$\mathbf{r}^{2}$} & \multicolumn{1}{c}{ Efficiency\% } \\
\hline CYP3A1 & 0.998 & 102.3 \\
\hline CYP4A1 & 0.997 & 104.1 \\
\hline G0s2 & 0.998 & 93.4 \\
\hline Scd1 & 1.0 & 97.7 \\
\hline Ccnd1 & 0.992 & 94.98 \\
\hline AhR & & 95.1 \\
\hline$\beta$-actin & 0.992 & 97.9 \\
\hline
\end{tabular}

\section{Section 3.5.2 Real- time PCR analysis of the samples}

The aim of this section was to measure the levels of mRNA of the genes CYP4A1, CYP3A1, G0s2, Ccnd 1 and Scd 1 with real- time PCR. To correct for loading differences, AhR and $\beta$-actin were both used as reference genes to normalise the measurements of mRNA.

F344 Fisher rats were treated with $50 \mathrm{mg} \mathrm{kg}^{-1}$ ciprofibrate, $100 \mathrm{mg} \mathrm{kg}^{-1} \mathrm{CPA}$ or corn oil/vehicle for 1, 3, 5 and 24 hours. Hepatic RNA was extracted from frozen livers and reverse transcribed into cDNA as explained in Section 2.2.5.1 and. The cDNA was amplified with real- time PCR and the Ct levels were determined as shown in Section 2.2.7.3. 


\section{Section 3.5.2.1 Effects of ciprofibrate and CPA on CYP4A1}

This experiment was done to test the induction levels of CYP4A1 mRNA at different time points on ciprofibrate/CPA treated samples in comparison with controls, the CYP4A1 was used as a positive control because it was known to be one of the first markers to the induction with PPAR $\alpha$ agonists (Bell et al., 1991)(Bars et al., 1993)(Morris and Davila, 1996).

The results for the samples treated with ciprofibrate showed statistically significant induction of CYP4A1 after 3, 5 and 24 hours of treatment, as shown in the time course in Figure 3.52 (red line). The samples from the 24 hour treatment showed a mean of $\sim 30$ fold induction higher than the control at the same time point. These results were consistent with the results from RNAseq analysis of the 3 hour samples treated with ciprofibrate which showed 3.2 fold induction of CYP4A1, while the real- time PCR gave a 2.4 fold induction at 3 hours (Section 3.4.6.2).

The induction of CYP4A1 in fisher rats treated with CPA was not affected at all the time points as demonstrated as a blue line in Figure 3.52. Statistics was done with one-way analysis of variance (Bonferroni's multiple comparison test), $\mathrm{P}<0.05$. 


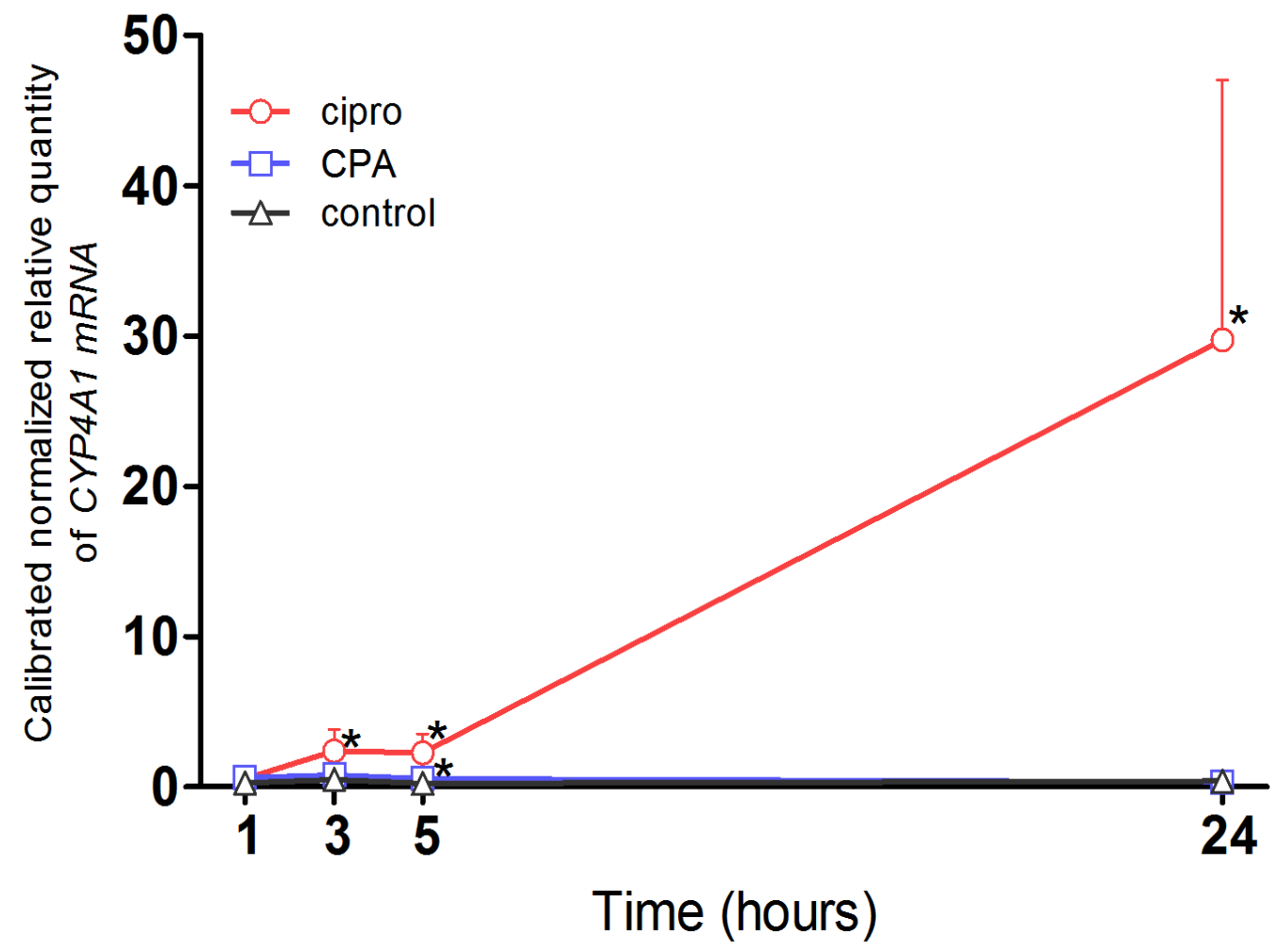

Figure 3.52 Effect of treatments on CYP4A1 mRNA expression. The effects of treatments on CYP4A1 mRNA expression, on cDNA from hepatic RNA of rats treated for 1, 3, 5 and 24 hours with $50 \mathrm{mg} \mathrm{kg}^{-1}$ ciprofibrate (red circles), $100 \mathrm{mg} \mathrm{kg}^{-1} \mathrm{CPA}$ (blue squares) or corn oil (black triangles). Real- time PCR was performed as in Section 2.2.7.3 and analysed as in Section 2.2.7.4. Points are the mean value, and the error bars depict one standard deviation. Statistically significant difference from the control group was indicated by an asterisk. Statistics was done with one-way analysis of variance (Bonferroni's multiple comparison test), $\mathrm{P}<0.05$. 


\section{Section 3.5.2.2 Effects of ciprofibrate and CPA on CYP3A1}

The objective of this section was to test the induction levels of CYP3A1 in ciprofibrate and CPA treated samples in comparison with control samples at different time points. CYP3A1 was used as a positive control for CPA treated samples, because the $C Y P 3 A 1$ was reported to be highly induced by PXR agonists (Lehmann et al., 1998)(Hosoe et al., 2005).

The results for the samples treated with CPA showed a statistically significant induction of CYP3A1 after 24 hours treatment; > 30 fold difference as shown in Figure 3.53/ blue line.

In contrast, the expression of $C Y P 3 A 1$ in Fisher rats treated with ciprofibrate was not different from the control at any of the 1, 3, 5 and 24 hour samples. 


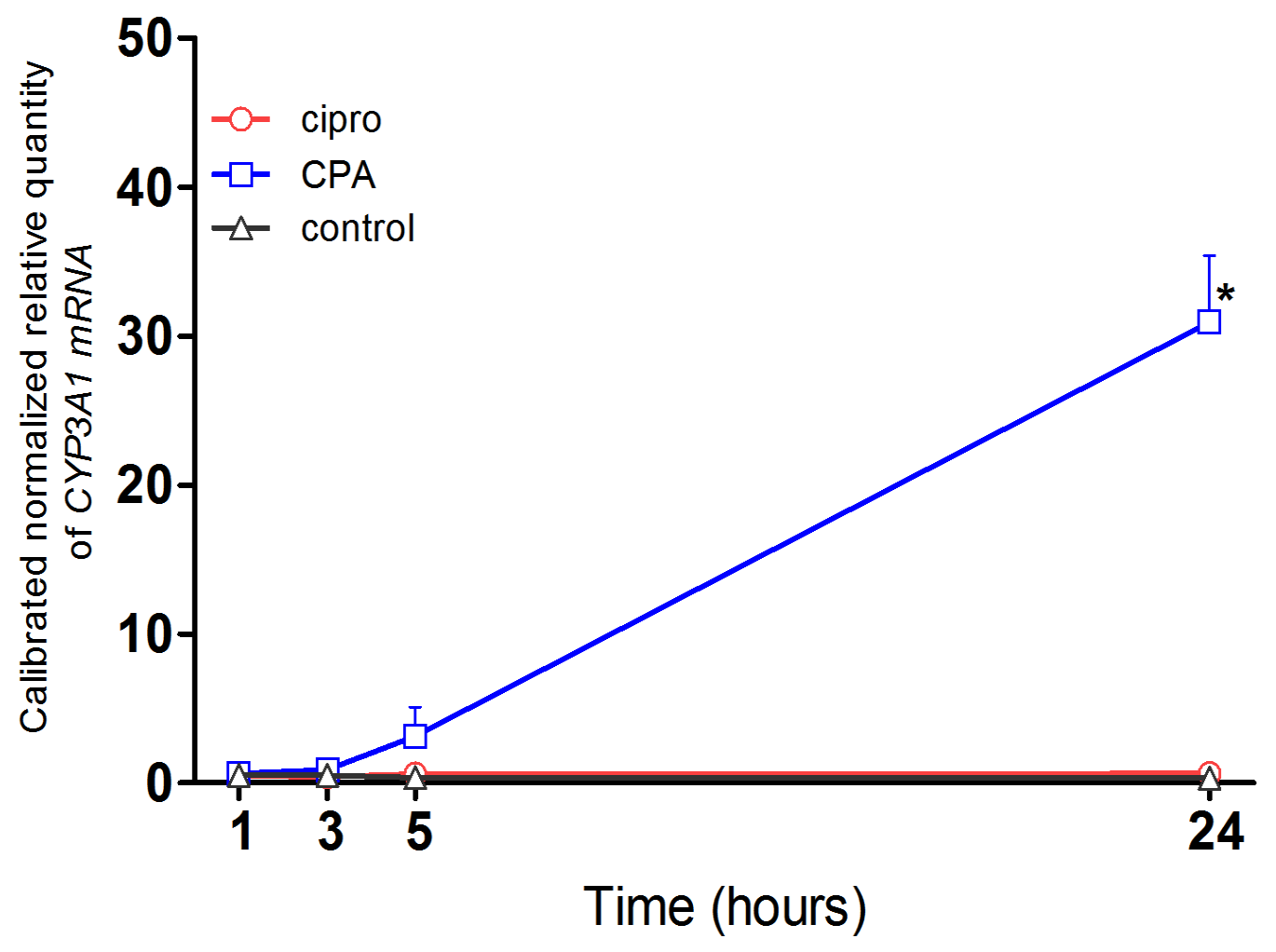

Figure 3.53 Effect of treatments on CYP3A1 mRNA expression. The effects of treatments on CYP3A1 mRNA expression, on cDNA from hepatic RNA of rats treated for 1, 3, 5 and 24 hours with $50 \mathrm{mg} \mathrm{kg}^{-1}$ ciprofibrate (red circles), $100 \mathrm{mg} \mathrm{kg}^{-1} \mathrm{CPA}$ (blue squares) or corn oil (black triangles). Real- time PCR was performed as in Section 2.2.7.3 and analysed as in Section 2.2.7.4. Points are the mean value, and the error bars depict one standard deviation. Statistically significant difference from the control group is indicated by an asterisk. Statistics was done with one-way analysis of variance (Bonferroni's multiple comparison test), $\mathrm{P}<0.05$. 


\section{Section 3.5.2.3 Effects of ciprofibrate and CPA on G0s2}

This experiment was carried out to test the effects of ciprofibrate/CPA on the induction levels of G0/G1 switch 2 (G0s2) mRNA (involved in cell cycle control), at the early time points and at 24 hours after treatment in comparision with the control samples.

Figure 3.54 shows the results for the samples treated with ciprofibrate (in red) where the expression of $G 0 s 2$ at 3 hours was significantly higher (5.4- fold) than the control at the same time point but declines by 24 hours. This result was similar to the results from RNAseq at 3 hours where the G0s 2 gene was found to be 5.8 fold higher than control samples (Section 3.4.6.2).

The induction of G0s 2 in fisher rats treated with CPA showed no significant difference from the control in all the samples treated at 1, 3 and 5 hours, as shown in Figure 3.54 blue line. Statistics was done with one-way analysis of variance (Bonferroni's multiple comparison test), $\mathrm{P}<0.05$. 


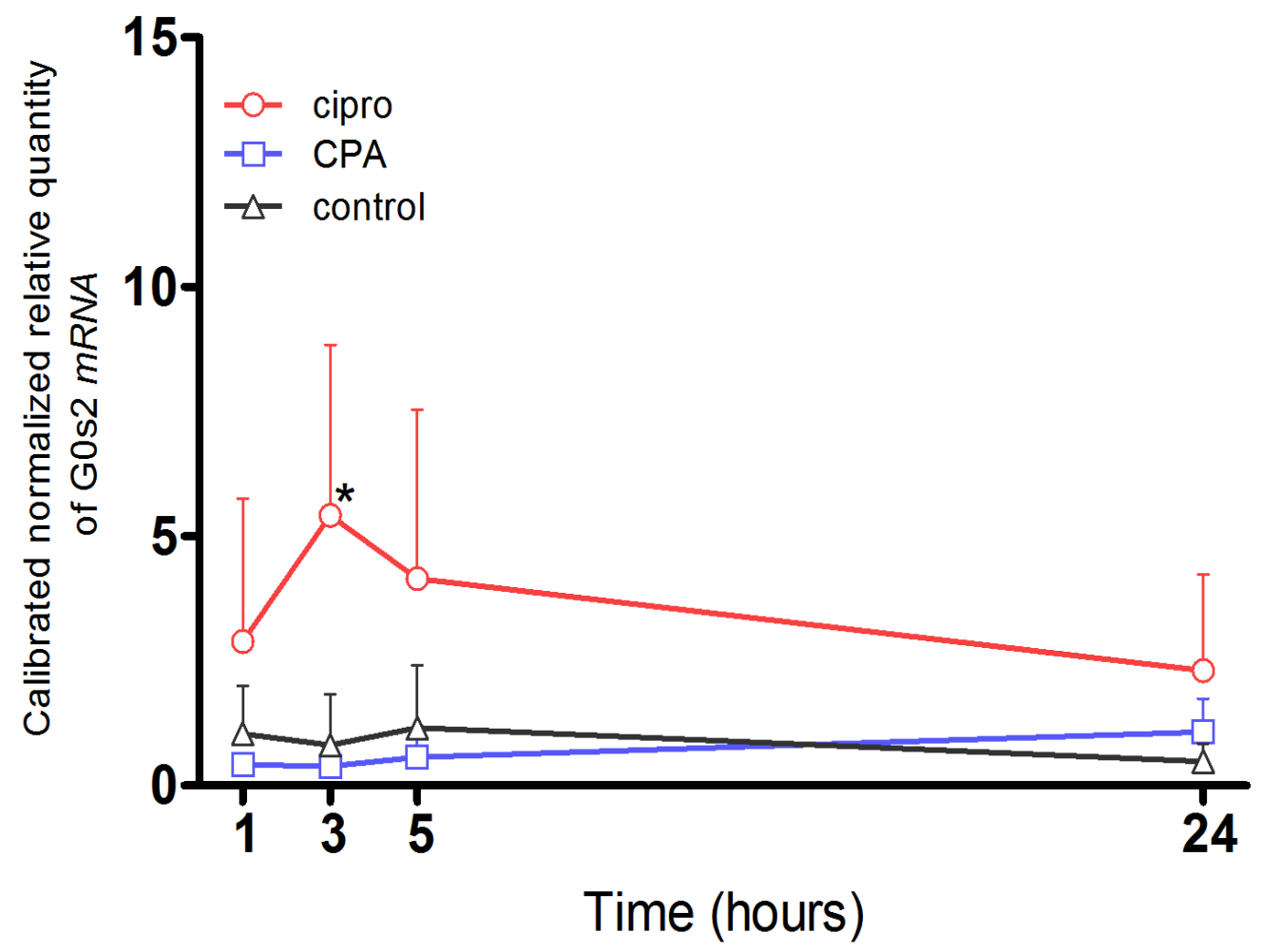

Figure 3.54 Effect of treatments on G0s2 mRNA expression. The effects of treatments on G0s 2 mRNA expression, on cDNA from hepatic RNA of rats treated for $1,3,5$ and 24 hours with $50 \mathrm{mg} \mathrm{kg}^{-1}$ ciprofibrate (red circles), $100 \mathrm{mg} \mathrm{kg}^{-1} \mathrm{CPA}$ (blue squares) or corn oil (black triangles). Real- time PCR was performed as in Section 2.2.7.3 and analysed as in Section 2.2.7.4. Points are the mean value, and the error bars depict one standard deviation. Statistically significant difference from the control group is indicated by an asterisk. Statistics was done with one-way analysis of variance (Bonferroni's multiple comparison test), $\mathrm{P}<0.05$. 


\section{Section 3.5.2.4 Effects of ciprofibrate and CPA on Ccnd1}

This part of the experiment was prepared to determine the effects of ciprofibrate and CPA on the induction levels of cyclin D1 (Ccnd1) (also involved in the cell cycle), with real- time PCR analysis.

The results for the samples treated with ciprofibrate, show a significant induction of $C$ cnd 1 at 3 hours (1.8 fold change) when compared with the control at the same time point (Figure 3.55/ red line). This result is comparable with the results from RNAseq at 3 hours where the Ccndl gene was induced 2.9 fold (Section 3.4.6.2).

The induction of Ccndl in Fisher rats treated with CPA is significantly higher than the control at 5 hours, while the 1, 3 and 24 hour samples treated with CPA have no significant difference when compared with the control as shown in (Figure 3.55). 


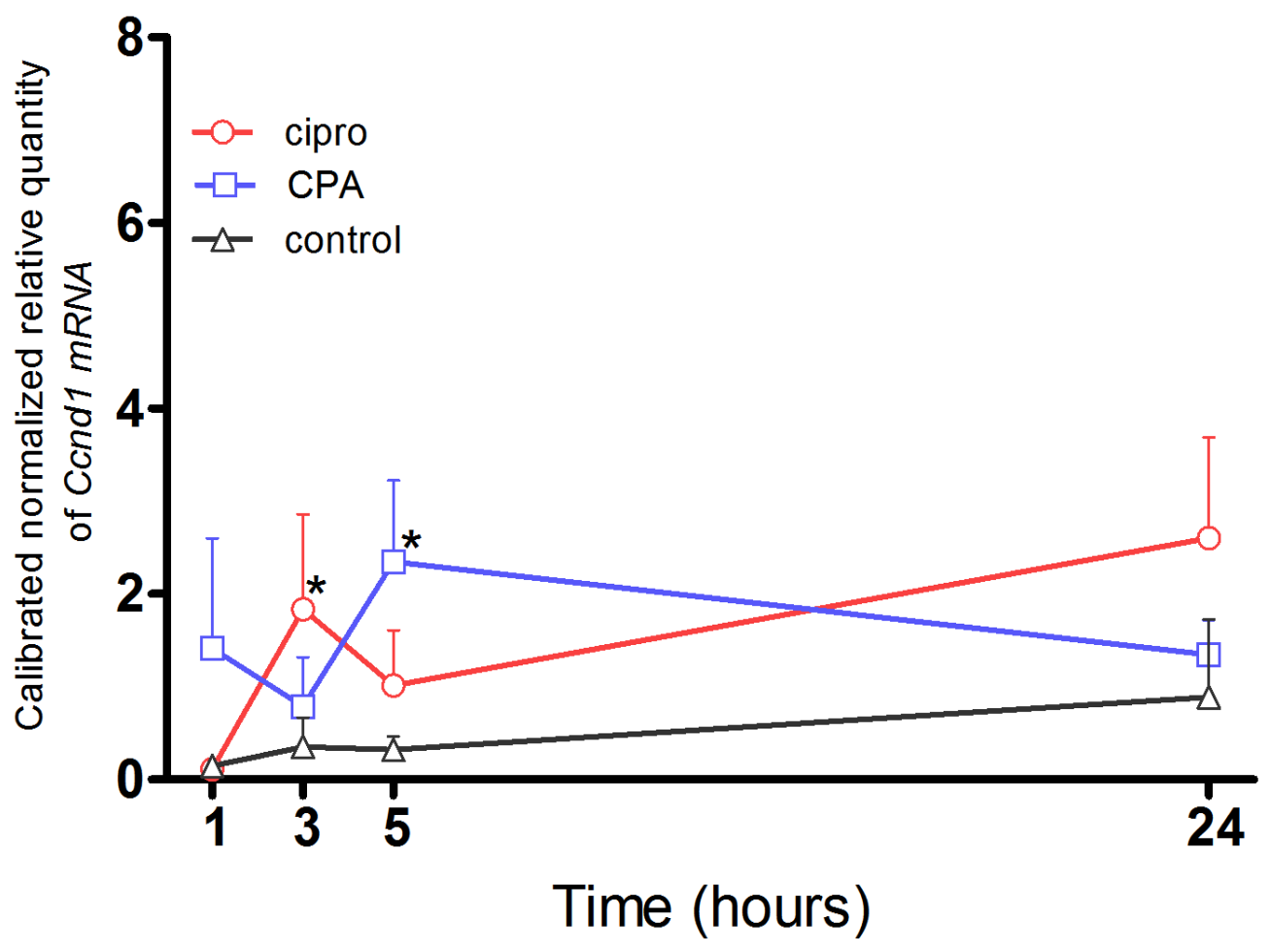

Figure 3.55 Effect of treatments on Ccnd1 mRNA expression. The effects of treatments on Ccndl mRNA expression, on cDNA from hepatic RNA of rats treated for $1,3,5$ and 24 hours with $50 \mathrm{mg} \mathrm{kg}^{-1}$ ciprofibrate (red circles), $100 \mathrm{mg} \mathrm{kg}^{-1} \mathrm{CPA}$ (blue squares) or corn oil (black triangles). Real- time PCR was performed as in Section 2.2.7.3 and analysed as in Section 2.2.7.4. Points are the mean value, and the error bars depict one standard deviation. Statistically significant difference from the control group is indicated by an asterisk. Statistics was done with one-way analysis of variance (Bonferroni's multiple comparison test), $\mathrm{P}<0.05$. 


\section{Section 3.5.2.5 Effects of ciprofibrate and CPA on Scd1}

This experiment was done to test the induction levels of the $S c d 1$ gene expression, which encodes stearoyl-coenzyme A desaturase 1 engaged in the PPAR $\alpha$ pathway) with real- time PCR. The results for the samples treated with ciprofibrate (Figure 3.56) showed a significant induction of $S c d 1$ at 1 hour, and at other time points $S c d 1$ expression in the ciprofibrate samples was slightly higher than in the control.

On the other hand the expression of $S c d 1$ in CPA- treated Fisher rats was lower than in the control albeit not significantly different (Figure 3.56). 


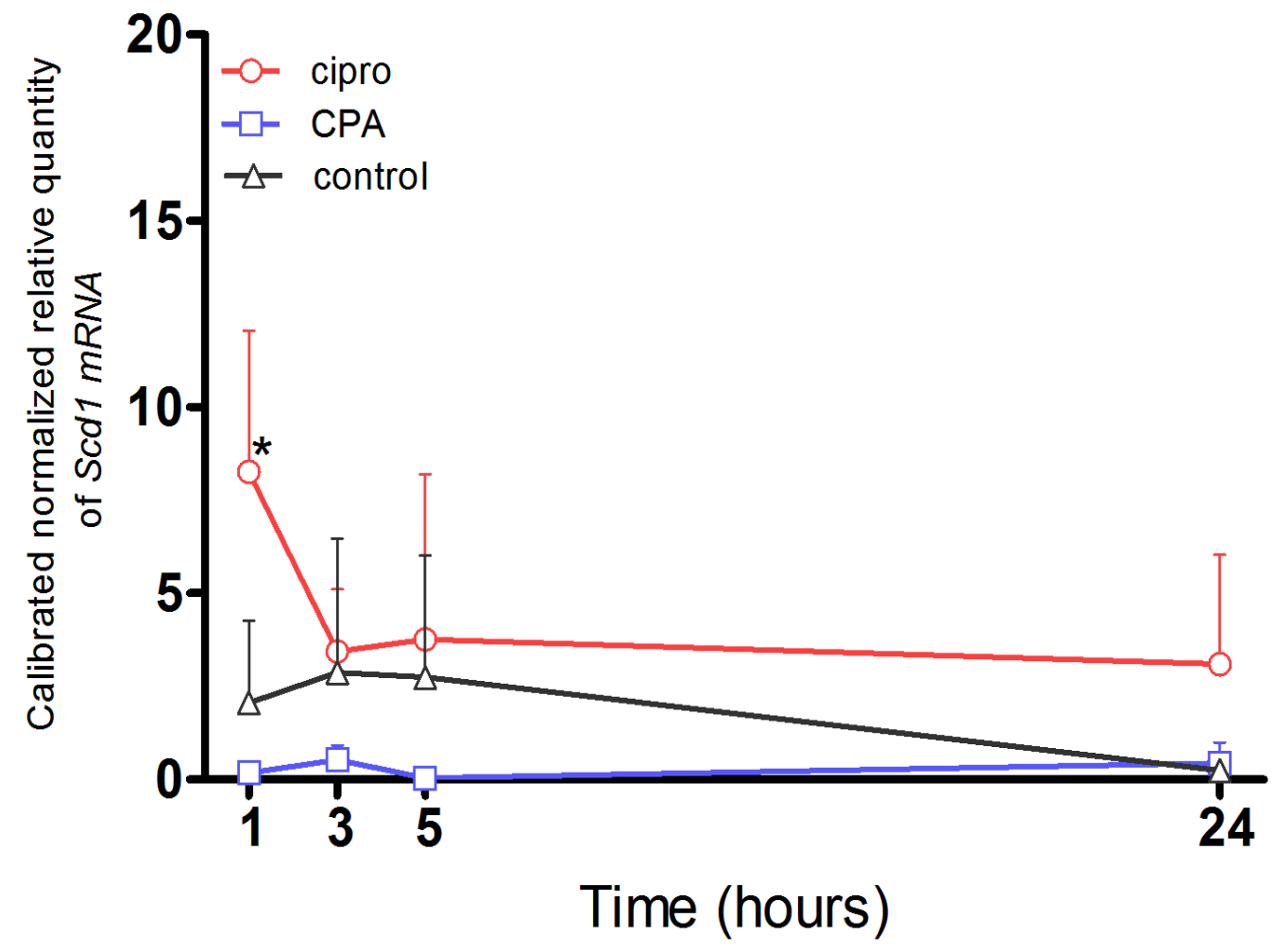

Figure 3.56 Effect of treatments on $\boldsymbol{S c d} 1 \mathrm{mRNA}$ expression. The effects of treatments on $S c d 1 \mathrm{mRNA}$ expression, on cDNA from hepatic RNA of rats treated for 1, 3, 5 and 24 hours with $50 \mathrm{mg} \mathrm{kg}^{-1}$ ciprofibrate (red circles), $100 \mathrm{mg} \mathrm{kg}^{-1} \mathrm{CPA}$ (blue squares) or corn oil (black triangles). Real- time PCR was performed as in Section 2.2.7.3 and analysed as in Section 2.2.7.4. Points are the mean value, and the error bars depict one standard deviation. Statistically significant difference from the control group is indicated by an asterisk. Statistics was done with one-way analysis of variance (Bonferroni's multiple comparison test), $\mathrm{P}<0.05$. 


\section{Chapter 4 Discussion}

\section{Section 4.1 Induction of hepatic DNA synthesis}

The main goal of this thesis was to identify the genes induced by peroxisome proliferators (primarily ciprofibrate), which may be involved in the induction of hepatic DNA synthesis, and consequently, play an important role in hepato-carcinogenesis. First it was essential to demonstrate the effects of ciprofibrate on hepatic DNA synthesis.

\section{Section 4.1.1 Effect of ciprofibrate on hepatic DNA synthesis in mice}

To study the hepatic response to ciprofibrate in different strains of mice, two inbred strains of mice were chosen: $\mathrm{C} 57 \mathrm{BL} / 6 \mathrm{JCrl}$ which is a strain resistant to liver carcinogenesis and DBA/ 2JCrl which is fairly vulnerable to liver carcinogenesis (Diwan et al., 1986).

This was done with an immunohistochemical protocol, as has been used by many in the detection of proliferating cells in vivo with BrdU (deFazio et al., 1987)(Beyer et al., 2008)(Menegazzi et al., 1997)(Peters et al., 1997a). The validity of the immunohistochemical procedure in the detection of incorporated BrdU in the replicating hepatocytes has been broadly tested (e.g., (Eldridge et al., 1990) (Ledda-Columbano et al., 2003)).

The toxicity of BrdU to the DBA/2JCrl mouse strain was assessed by testing the gross effect on the animals' body weight, which showed there was no negative effect from the BrdU on the mice for the duration of the experiment (Section 3.1.1.2.1). This was consistent with results of (A1 Kholaifi, 2008).

Also, the results showed there was no toxic effect from the ciprofibrate indicated by the body weight study, and that the induction of hepatic DNA synthesis did not start until after 4 days of 
exposure to ciprofibrate in DBA/2JCrl mice (Figure 3.5). This was substantively the same as previous results established by (Al Kholaifi et al., 2008) with MCP in 129S4/SvJae mice, where he found that induction of hepatic DNA synthesis occurs 3- 4 days after dosing.

On the contrary, (Styles et al., 1990) showed that when dosing C57BL/6J mice with MCP, the induction of hepatic DNA synthesis started at 24 hours. This discrepancy could be the result of strain differences as this could affect liver function (Akiyama et al., 2001), although no previous evidence indicates that strain differences affect the response to peroxisome proliferators (Budroe et al., 1992).

Because of the above issues, the same experiment was repeated in C57BL/6JCrl mouse strain (Section 3.1.1.3), and this established that there were no toxic effects from the ciprofibrate or BrdU, and the induction of hepatic DNA synthesis did not start until after 4 days of exposure to ciprofibrate. The C57BL/6JCrl mice are inbred mice, so genetic variability is very small. Consequently, the difference between this study and the Styles study is less likely to relate to genetic differences. The present result was consistent with the findings for DBA/2JCrl mice (Section 3.1.1.2.2) AP mice and 129S4/SvJae mice (Al Kholaifi et al., 2008).

The difference in the kinetics of induction of DNA synthesis between this and the Styles study could be due to the fact that this and the Al Kholaifi studies (Al Kholaifi et al., 2008) used an immunohistochemical detection of incorporated BrdU protocol, whereas Styles detected incorporated BrdU by isolation of hepatocytes and flow cytometry (Styles et al., 1987).

Miller (Miller et al., 1996) also tried to reproduce the same results that were from Styles but with the same flow cytometry procedure, and failed to produce the same results indicating that the results produced with the flow cytometry procedure are not fully reproducible. 
As a conclusion, the induction of hepatic DNA synthesis was delayed until after 4 days dosing of ciprofibrate in the $\mathrm{C} 57 \mathrm{BL} / 6 \mathrm{JCrl}$ and the $\mathrm{DBA} / 2 \mathrm{JCrl}$ mouse strain. This result demonstrates a confirmation of earlier studies on other strains with different peroxisome proliferators (LeddaColumbano et al., 2003)(Al Kholaifi et al., 2008).

\section{Section 4.1.2 Effect of ciprofibrate on hepatic DNA synthesis in rats}

The large time window of 4 days between the dosing of the ciprofibrate and the hepatic DNA synthesis makes it difficult to indicate when exactly the regulation of the genes responsible for the induction of DNA synthesis occurred. Thus, it was desirable to try an alternative system, and the rat liver was chosen.

It was known from previous in vivo and in vitro studies in Wistar and Fisher344 rats dosed with peroxisome proliferators (nafenopin and Wyeth-14,643) that the hepatic induction of DNA synthesis starts as early as 24 hours (Miller et al., 1996)(Menegazzi et al., 1997)(Al Kholaifi, 2008) (Al Kholaifi et al., 2008)(Bell and Elcombe, 1991a)(Bell et al., 1991).

In the current study a time course of the hepatic DNA synthesis revealed similar results. Hepatic DNA synthesis in male F-344/NHsd rats was induced by ciprofibrate within 10 to 30 hours, which peaks at 24 hours and again at 48 hours. This was consistent with (Plant et al., 1998) who demonstrated that PPAR $\alpha$ ligands cause rapid induction of DNA synthesis in rat hepatocytes in vitro ( 24 hours). The second peak at 48 hours was probably related to the fact that the dose was given each day, meaning that the first peak would be a response to the first dose and the second peak would be a response to the second dose.

These results were similar to (Aboshofa's data) who also found two peaks of hepatic DNA synthesis at 24 and at 48 hours, using two labelling methods (BrdU and EdU). Aboshofa's data also 
found that the induced hepatocytes at 24 hours are different from the hepatocytes induced at 48 hours (not the exact same hepatocyte). This was achieved by dosing the rats with ciprofibrate at 0 and 24 hours and dosing the animals with BrdU at 22 hours to label the proliferating cells at 22- 26 hours (as a response to the first ciprofibrate dose), and then giving the animals a dose of EdU at 46 hours to label the cells dividing at $46-50$ hours (as a response to the second ciprofibrate dose) (Aboshofa). After examining the hepatocytes with immunohistochemistry (to detect the BrdU labelled cells) and with fluorescent microscopy (to indicate the cells labelled with EdU), the images were merged together. Aboshofa found that the cells labelled with BrdU were different from the cells labelled with EdU, this suggests that the hepatocytes that divide at 24 hours are different from the hepatocytes that divide at 48 hours (Aboshofa personal communications).

Al Kholaifi's (Al Kholaifi et al., 2008) results with F-344/NHsd rats showed that hepatic DNA synthesis started to rise at 24 hours and continued after 48- 96 hours. This was consistent with the results found in this study (Figure 3.9). However, Al Kholaifi used the chronic dosing system for BrdU labelling which gives the cumulative number of BrdU-labelled hepatocytes, whereas this study used the acute dosing system, showing what happened at each time point within a 2- 4 hour window.

It was desirable to determine the optimal dose of ciprofibrate in F-344/NHsd rats that gave the highest hepatic replicative DNA synthesis. Al Kholaifi (Al Kholaifi, 2008) used $50 \mathrm{mg} \mathrm{kg}^{-1} \mathrm{day}^{-}$ ${ }^{1}$ but did not test the effects of higher doses. This information was not available in the literature, so this study demonstrated (with a dose response experiment of $0,50,100,200,300 \mathrm{mg} \mathrm{kg}^{-1}$ body weight for 24 hours), that the liver labelling index increased significantly at 50, 100 and $200 \mathrm{mg} \mathrm{kg}^{-1}$ ciprofibrate, but the labelling index was low at $300 \mathrm{mg} \mathrm{kg}^{-1}$. The reduced response at $300 \mathrm{mg} \mathrm{kg}^{-1}$ suggests a possible toxic reaction suppressing the liver growth response (Section 
3.1.2.1.1). The concentration of $50 \mathrm{mg} \mathrm{kg}^{-1}$ was selected for the assay as an optimal dose of ciprofibrate for F-344NHsd rats, because it was deemed sufficiently low to avoid toxicity but gave a reasonably good labelling index.

(Woods et al., 2007) suggested that PPAR $\alpha$ ligands mediate chronic oxidative DNA damage, therefore, it was of importance to test the serum ALT concentrations as an indicator of liver cell damage. A single dose of 50-300 $\mathrm{mg} \mathrm{kg}^{-1}$ ciprofibrate did not increase serum ALT levels (Figure 3.11), indicating that there is no gross hepatotoxicity, and consequently no potential for regenerative DNA synthesis. Also the body weight of the animals was tested on a daily basis and this showed that there was no growth inhibition, indicating no toxic effects from the ciprofibrate. In addition the examination of histological sections revealed no necrosis in the liver tissue.

The immunohistochemical protocol yielded satisfactory staining of intestinal nuclei with BrdU as a positive control for labelling. Ciprofibrate-induced hepatocyte DNA synthesis was at its peak for rats at 24 hours after dosing, in contrast to the mouse strains where there was no significant induction until 4 days after treatment. These results demonstrate a species difference between mouse and rat in the kinetics of induction of hepatocyte DNA synthesis by PPAR $\alpha$ ligands.

The early induction of hepatic DNA synthesis in rat by PPAR $\alpha$ ligands unlocks doors of opportunity to study the mechanism of induction of the liver growth response, by linking early measurements of altered gene regulation to subsequent hepatic DNA synthesis.

\section{Section 4.1.3 Effects of CPA on hepatic DNA synthesis in rats}

The anti-androgen cyproterone acetate (CPA) is known to cause liver tumours in rats, and it 
strongly enhances hepatic DNA synthesis of male and female Wistar rats (Schulte-Hermann et al., 1980), with it being more strongly inducing in female F-344 rats (Aboshofa). This drug was used to compare the genes that were induced with the CPA (PXR) with those that were induced by ciprofibrate (PPAR- $\alpha)$.

Although female rats gave higher induction than males from the preliminary tests, and from the literature (Topinka et al., 2004a) (Topinka et al., 2004b), it was reasonable to use male rats, as male rats had been used for the ciprofibrate dosing in this study. It might be expected that similar genes are induced in the male and the female rats, just more strongly in the latter (it would be interesting to follow up on this).

The doses used for the CPA (or PCN used in the preliminary experiment) were chosen from the literature (Topinka et al., 2004a) (Topinka et al., 2004b) and (Guzelian et al., 2006), at $100 \mathrm{mg}$ $\mathrm{kg}^{-1}$. The time was fixed to 24 hours so it would be comparable to the ciprofibrate experiment. The results showed a significantly high labelling index in the treated over the control group and over the groups treated with ciprofibrate at 24 hours (Figure 3.13B) and this was similar to results from previous studies (Topinka et al., 2004a). 


\section{Section 4.2 Zonal distribution of DNA synthesis in liver}

The fact that the zonal distribution of DNA synthesis in the rat liver is known (Barrass et al., 1993) and that Barrass has established a reliable method to study this, gave reason to make similar studies on mouse liver, as there are no directly comparable data in mice (Burkhardt et al., 2004).

The main objective was to study the hepatic zonal distribution of cell proliferation in the liver of mice treated with ciprofibrate. Rats liver (used as a positive control) treated with ciprofibrate or CPA or corn oil (control) showed a significant zonal distribution of the labelled nuclei, with $\sim 20$ fold more labelled cells in the periportal region than in the perivenous region. This was in agreement with the literature (Barrass et al., 1993). Equally, the preferential periportal distribution of hepatic labelling in ciprofibrate treated rats was consistent over a dose range of 50-200 $\mathrm{mg} \mathrm{kg}^{-1}$ body weight (because of the low number of labelled cells in the $300 \mathrm{mg} \mathrm{kg}^{-1}$ it was not possible to study the zonation in these slides.).

The zonal distribution of hepatic labelling index in male mouse showed no statistically significant difference between the periportal or perivenous zones in most of the mouse strains studied (1294S/SvJae wild type, PPAR $\alpha$ null male mice, C57BL/6JCrl and DBA/2JCrl), with the different doses of PPAR agonist, or choice of drug PPAR $\alpha$ (ciprofibrate, methylclofenapate) or CAR (TCPOBOP) (Section 3.2.2).

Exceptions were female 129S4/SvJae mice when treated with TCPOBOP as they showed a significantly perivenous preference (Figure 3.20), but the magnitude of the effect is relatively small, with the number of labelled cells in the perivenous region less than two times greater than those in the periportal region. Also AP mice when treated with MCP showed a similar zonal reaction to the rats, as the control and the group treated for 4 days had a periportal preference, 
but for the group treated for 3 days the difference was not significant.

Of the total liver volume, $20 \%$ is made up of non-parenchymal cells, which are stellate cells, Kupffer cells, pit cells and endothelial cells (Oinonen and Lindros, 1998). These types of cells display modest quantitative zonal differentiation, in general being more abundant in the periportal area (Sasse, 1986). This could be related to the periportal/perivenous zonal behaviour noticed in the hepatic DNA induction in the liver population. It is observed furthermore that the periportal zonation of the hepatic labelling index in rat is different from the centrilobular induction of peroxisomal enzymes, cytochrome P450 and acyl CoA oxidase induced by PPAR $\alpha$ ligands, suggesting that the factors that mediate the induction mechanisms are located to specific zones of the liver lobule (Bell and Elcombe, 1991b)(Bars et al., 1993).

However, the induction of both enzymes and DNA synthesis are dependent on the PPAR $\alpha$, this suggests that the zonation of the peroxisomal enzymes is via a PPAR $\alpha$ independent means (Al Kholaifi et al., 2008). Candidates that may intervene with these PPAR $\alpha$-independent zonal effects are the zonal distribution of the PPAR $\alpha$-associated microRNAs, or co-activators that are known to be required for the induction of hepatic DNA synthesis (Matsumoto et al., 2007) (Shah et al., 2007a).

Whereas it is acknowledged in mice that the $A p c$ gene is the liver zonation keeper (Benhamouche et al., 2006), it is unknown if similar pathways apply for rat hepatocytes. Generally, however, the zonation of the hepatic induction of DNA synthesis is less studied, especially in mice.

These results illustrate species differences in zonation and kinetics of liver growth between rat and mouse, and predict species differences in zonation and timing of the regulatory factors responsible for the liver growth. These differences are similar in extent to those seen in extensive 
zonation studies on the induction of enzymes by various xenobiotics in isolated rat cells (Oinonen et al., 1994).

Bars (Bars et al., 1992) reported that the induction and expression of the cytochrome P4502B1/ 2 iso enzyme has a hepatic zonal pattern in the intact liver, whereas different reaction to PPAR $\alpha$ occurred in vitro, where they found that $\mathrm{P} 4502 \mathrm{~B} 1 / 2$ hepatic immunostaining was stronger in cells isolated from the perivenous liver region than in hepatocytes isolated from the periportal region. They also suggested that periportal and perivenous hepatocytes are assigned differentially to maintain regio- specific factors.

The diversity in inter species and inter strain response to the peroxisome proliferators could be most likely as a result of a difference in PPAR and/or PPRE structure, but this needs to be studied further and more data is required (Aldridge et al., 1995). 


\section{Section 4.3 Gene expression analysis}

It has been acknowledged that the hepatic DNA synthesis induced by ciprofibrate in rat occurs after 24 hours (Section 3.1.2), and it is known that cells need $\sim 19$ hours to undergo hepatic DNA synthesis (Alberts et al., 2002). This implies that the RNA signal is increased within the first five hours after dosing. To determine the immediate early genes that may be induced the first 15 hours post induction were examined, as these genes could be responsible for the hepatic DNA synthesis at 24 hours.

This was done with cDNA microarray, RNA transcriptome sequencing and quantitative realtime PCR. Studies have shown that two or more different methodologies used to measure gene expression change have a tendency to agree when the magnitude of change in gene expression is large (Draghici et al., 2006).

cDNA microarrays can concurrently measure the expression intensity of thousands of genes within a specific mRNA sample (Schena et al., 1995)(Schena et al., 1998). The microarray analysis was applied to measure the expression levels of genes induced by $50 \mathrm{mg} \mathrm{kg}^{-1}$ ciprofibrate in livers of F-344NHsd rats after 1, 3, 5 and 24 hours in comparison with the control.

The microarray analysis was carefully controlled with usage of: (1) vehicle/ corn oil as a negative control, (2) rats dosed with PXR ligands (CPA) as positive controls, to compare genes that are involved in hepatic DNA synthesis, but which might not be specific for the PPAR ligands (ciprofibrate), (3) the 24 hour samples were used to exclude the genes that are generally regulated by ciprofibrate but might not be specifically related to the early-immediate reaction that might be involved in the hepatic DNA synthesis, (4) a common reference/control (a sample containing an aliquot from each of the corn oil, CPA and ciprofibrate samples) was used which is the most commonly used design of microarray experiments, for a complete comparison of sam- 
ples and to remove any bias from the 555 and 647 Alexa dyes (Cherkaoui-Malki et al., 2001).

The cDNA microarray analysis was optimized and each step controlled and assessed, beginning with the RNA quality and quantity measurements (Section 3.3.1). The incorporation of Alexa dyes 555 and 647 in the cDNA were also made with a negative control (sample with no RNA) and a positive control (RNA supplied in the kit).

\section{Section 4.3.1 Optimization of the microarray technique}

Optimization of the microarray technique was essential to ensure the results are reliable and repeatable. So, the following issues were addressed: (1) reproducibility of the scanning, (2) reproducibility of hybridization, and (3) the testing of different concentrations of cDNA. The reproducibility of scanning (60-90\%) was good (Section 3.3.3.1). However, initial experiments on the reproducibility of hybridization were not as successful, since the same cDNA when hybridized on three different sets of slides did not give repeatable results. This was a problem, and results from these hybridizations were not reliable. Therefore, it was essential to address this issue before being able to consider using the microarray technique for further analysis (Section 3.3.3.2). Subsequently, by considering all the microarray procedures systematically, it was revealed that the gene names were misplaced on the gene spots of the slides (human error) when placing the features from the GAL file on the slides. This issue was resolved by using slides with markers indicating where the genes were situated.

It was also essential that all the hybridizations were replicated at least twice with data giving a minimum of $60 \%$ similarity to be considered in the analysis. A $60 \%$ similarity in the reproducibility of the technical replicates was proposed acceptable in other studies, and it has been reported that the correlation coefficient can range between 0.5 and 0.95 (this corresponds to 50 95\%) (Bammler et al., 2005)(Jarvinen et al., 2004)(Jenssen et al., 2002)(Carter et al, 2005). 
This variability issue with microarrays could be related to the fact that they do not measure with great accuracy the genes expressed at low levels (Tarca et al., 2006). Also fluorescence from the extremely highly induced genes may surpass the saturation limit of the detector. These factors may have contributed to the differences evident in this study between data from the microarray analysis and the transcriptome sequencing, as the latter would detect all the genes.

From this study the measures used to improve the quality of microarray results were to use four biological replicates and two technical replicates with the technical replicates being accepted only where $\mathrm{r}^{2}>0.6$.

\section{Section 4.3.2 Microarray analysis of rats dosed with ciprofibrate}

The 24 hour samples were initially tested to measure the expression levels of genes associated with induction of hepatic DNA synthesis, because this time point has been thoroughly investigated in the literature and a large number of genes have been detected to be highly induced. This was to ensure that the analysis and processing of the data were acceptable and reliable, and that specific genes used as markers were discovered.

Microarray analysis of rats dosed with ciprofibrate after 24 hours revealed 1597 significantly changed genes. In the samples treated with ciprofibrate for 24 hours 39 genes were up- regulated by double or more and 23 genes down- regulated by half or less. Up- regulated genes included Cyp4a1, Cte1, Rab19, Slc9a2, 18A, Ldh3, Narg1 and Polr2a. Genes recently reported to be upregulated after 14 days of orally repeated dosing of WY-14,643 were Apex1, Xrcc5, Gadd45 and A1h1 (Suzuki et al., 2010). Down- regulated genes included Mup2, Zfp598, Fgg, Cyp2c29 and Sepina $3 a$ (a list of all the genes are found in a CD at the end of the Thesis).

Cyp4A1 is a known marker for PPAR $\alpha$ agonists (Morris and Davila, 1996)(Hardwick et al., 
1987)(Bell and Elcombe, 1991a)(Bell and Elcombe, 1991b)(Orton and Parker, 1982)(Baker et al., 2004). The induction of CYP4Al via the PPAR $\alpha$ receptor has been reported in hepatocytes both in vitro (Yaacob et al., 1997) and in vivo (Correia, 1995)(Simpson, 1997). Furthermore, clofibrate exposure induced $C Y P 4 A 1$ with both RNA microarrays and quantitative real-time PCR (Baker et al., 2004). The induction of CYP4A1 with ciprofibrate here, while not proof, supported the validity of the present microarray analyses.

The microarray analysis of ciprofibrate dosed F-344NHsd fisher rats after 1, 3, and 5 hours showed 1377 significant genes analysed for each of the time points. Some of the up- regulated genes were Fxyd2, Igf1, cpa5, Cd68, Abcc2, Mup1, Cmklr1, mmu and Ndrg1 for the 1 hour samples, while Psmb9, Inppl1, Saa3, Serpinalb, Ins 1 and Gsta1 were up- regulated for the 3 hour samples. The genes Gc, Apob, Dusp14 Mug1, Serpina 1b, Kcnhl, Apcs and Gcap15 were upregulated in the 5 hour samples. These are all novelty findings for the immediate early genes. Later genes have been reported to be induced by clofibrate after 3 days of treatment: $H c d$, Cyp4a1, 3kcta, 3kctb, ACox, Cyp17 and Adh1(Baker et al., 2004).

Down- regulated genes can be just as informative as up- regulated genes when studying the mechanism of action of liver growth induced by ciprofibrate. After 1 hour treatment with ciprofibrate a number of the down- regulated genes were Fgf21, Rgsl2, Usp28, Dars, Vnn3 and $F z d 7$, some of the down- regulated genes after 3 hours were Pfkfb2, Wdr10, Clecsf9, Kcnq2, Mylc2pl and Rgsl2, while genes down- regulated at 5 hours were Nedd4, Rem1, Adcy8, Rab40c, $A c a d s b$ and $C c b 3$. Other genes that have been reported to be down- regulated after 24 hours of dosing with ciprofibrate are $A p o-A 1, C Y P 1 A 2, C P T 1$ and tumour necrosis factor receptor 1 (Baker et al., 2004). 


\section{Section 4.3.3 Transcriptome sequencing of rats dosed with ciprofibrate for 3 hours}

Transcriptome sequencing analysis uses high- efficiency high- throughput sequencing to measure gene expression (Marioni et al., 2008). Transcriptome sequencing analysis was used to help find differently expressed genes in hepatic cells of F344/NHsd Fisher rats dosed with $50 \mathrm{mg} \mathrm{kg}^{-}$ ${ }^{1}$ ciprofibrate for 3 hours. A key advantage of the transcriptome sequencing analysis procedure is the number of genes that could be detected in this study, at just under 25000 genes. This was because the transcriptome analysis was sincere and was used against a complete rat genome data base. The microarray analysis had only 5826 genes because a large number of genes were missed when spreading the cDNA on the slides, or the cDNA does not hybridize well enough to be able to be scanned, or just washes off at the washing stages, also the microarray slides were specified for mice, so only the rat genes that match the mouse genome are included.

The different outcomes from the microarray results and the transcriptome sequencing results and real-time PCR measurements are expected, and could reflect the fact that the microarray analysis excluded the extremely high induced genes and the very low expressed genes (Tarca et al., 2006) (Gerhold et al., 2001). While the transcriptome sequencing data were more inclusive, and real- time PCR detects smaller changes in gene expressions, that are undetectable with microarrays (Baker et al., 2004). Hence the recommendation that microarrays are used to screen thousands of genes, whereas quantitative real-time PCR could be used to validate observations with chosen genes of interest (Baker et al., 2004).

The trancriptional sequencing was carefully monitored, with the samples confirmed to be assigned to their original groups and the hierarchical and k-means clustering showing that the control and treatment groups were clustered together. 
Up- regulated genes included $C Y P 4 A 1, G 0 s 2$ (G0/G1 switch 2), Aadacl1, Acot5+ 6 (Acyl-CoA thioesterase 5+6) Acpp, Apol9a, Ccnd1, Epha2, Prrg4, Myc11, Etv6 and Scd1, and the downregulated known/ named genes were Igfbp2, ppargcla, Cypla2, AhR, Acsm2, Cldn9 $+4+6$, Hps 4 and Rps14. These were similar to results found by Peters who revealed that the Aco, and $c-m y c$ alongside other genes were up- regulated when mice were dosed with Wy-14,643 for 5 weeks and 11 months (Peters et al., 1997a). He also concluded that the peroxisome proliferators contribute to the hepato-carcinogenicity effects.

\section{Section 4.3.4 Ciprofibrate pathways of over-represented genes}

The acute phase response pathway was over-represented among the functions of up- regulated genes in both the 3 and 5 hour groups treated with ciprofibrate and analysed with microarray analysis. At 3 hours 4 up- regulated genes out of 23 (of all genes in the genome) that are involved in the acute phase response (17.4\%) and 8 out of 23 genes (34.8\%) in the 5 hour group. The acute inflammatory response and the wounding response were over-represented at 3 and 5 hours post-treatment. These results were not unexpected, as these responses, and especially the acute phase response, are a complex chain of reactions that are known to be the initial response to infections, or malignancy, which prevent further damage to the tissue (Baumann and Gauldie, 1994).

Hierarchical clustering was also used in these experiments to clarify different pathways that were over-represented, among up- regulated genes after ciprofibrate treatment for 24 hours. These functional categories included the fatty acid metabolic process, the monocarboxylic acid metabolic process, the long chain fatty acid metabolic process (100\%), fatty acid $\beta$ oxidation and acyl-CoA metabolic process. Among the changes documented to occur during liver growth after treatment with peroxisome proliferators in rats are $\beta$-oxidation of fatty acids and very long- 
chain fatty acid $\beta$-oxidation (Latruffe et al., 2001)(Hamadeh et al., 2002)(Schoonjans et al., 1996). Therefore, similar results were revealed in this study.

Genes known to be involved in the response to peroxisome proliferators were also up- regulated, including genes responsible for liver fatty acid binding protein and acyl-CoA and growth regulatory genes (c-myc, c-Ha-ras, fos, jun, and egr-1) (Corton et al., 2000).

Over-represented pathways among up- regulated genes from the transcriptome sequencing data included those with relationships to DNA synthesis, cell cycle or PPAR signalling: The PPAR signalling pathway, the fatty acid metabolic pathway and cell cycle regulatory genes. Other smaller groups of genes (5-6 genes) were involved in sodium ion transport, oxidation reduction and palmitoyl-CoA hydrolase activity. Other pathways were the metabolic process and bioactivation pathway via cytochrome P450.

Others reported that in rodents treated acutely with $\mathrm{Wy}-14,643$ a number of the significantly induced genes were Il1 $\beta, I l 1 r 1, H n f 4$ and Stat3, and when they were treated chronically the genes that had increased expression were $I l 1 \beta$, Illr1, Il6 and Ppar $\gamma$ (Anderson et al., 2001). With nullizygous mice for TNF-receptor I, II or both, they also demonstrated that the hepatic carcinogenesis caused by peroxisome proliferators is not mediated through TNF $\alpha$.

A number of the genes identified here were followed up with the quantitative real- time PCR. Chosen pathways were tested in a time course for the ciprofibrate and CPA treatments. These pathways were the DNA synthesis, the cell cycle pathway and PPAR signalling pathway genes as they are related to the hepatic DNA synthesis and so to the liver growth mechanism. The genes were G0/G1 switch $2(G 0 s 2)$, cyclin D1 (Ccnd1), stearoyl-coenzyme A desaturase 1 (Scd1), Cytochrome P450, family 4, subfamily a, polypeptide 1 member CYP4A1 and Cytochrome P450, family 3, subfamily a, polypeptide 1 member CYP3A1. 


\section{Section 4.3.5 Microarray analysis of rats dosed with CPA}

$\mathrm{CPA}$ is an artificial progesterone analogue with progestogenic and antiandrogenic activities, used in the treatment of prostate cancer to resolve androgenisation symptoms in females and to reduce the male hormone testosterone to suppress the sexual drive in males (Neumann, 1994). In rat liver, CPA has shown evidence of genotoxic activity, promoting specific DNA adducts and mutagenesis (Krebs et al., 1998).

Microarray analysis of dosed rats with CPA after 24 hours resulted in 1597 significantly changed genes (up and down- regulated), the 24 hour group was initially studied to specify genes that are know to be induced at this time with PXR ligands, to act as a control for the analysis and processing of the data, and to be able to relate this to the experimental system. This was done by finding specific genes that were used as markers, CYP3A1 (Slatter et al., 2006) or Gstm3 (GstYb4) (Krebs et al., 1998).

Results from rats treated with $100 \mathrm{mg} \mathrm{kg}^{-1} \mathrm{CPA}$ for 24 hours resulted in 21 up- regulated genes and 10 down- regulated genes with Student's t- test. Some of these up- regulated genes included Gsta1, Hspa8, Gstm3 (GstYb4), Ugt1a5, Apoa1, Mup3, Ef1A1 and Rps6, and down- regulated genes included are Mup2, Rnase4, Trf and CYP2d26 (a list of all the genes are found in a CD at the end of the Thesis).

Although CYP3A1 was not found in the initial 24 hour analysis, it is a well known marker for PXR agonists in rats (Slatter et al., 2006), this could be related to the fact that the CYP3A1 is highly induced at 24 hours and the microarray analysis (as reported earlier) can lose the ability to detect the extremely high induced genes and the very low expressed genes (Tarca et al., 2006)(Gerhold et al., 2001). On the other hand, Gstm3 (GstYb4) was found, and this gene was also widely reported in the literature to be induced after 24 hours of dosing with CPA, and could 
also be used as a marker (Slatter et al, 2006)(Krebs et al., 1998).

The microarray analysis of CPA dosed rats at the immediate early hours at 1,3 , and 5 hours, with 1377 significantly up/ down- regulated genes. Some of the up- regulated genes at 1 hour were Sstr4, Cd97, 4930477O03Rik, E2f3, Sirt2, Nrxn3, Trpc4ap and Rnf141. A number of the 3 hour up- regulated genes were Hpxn, Serpina3m, Cops4, E130101E03Rik, Cyp2c29 and Al481316. While the genes up- regulated in the 5 hour group included $m t$, Mugl, Fabpl, Scd1, Adamts1, Gc, Eeflal Fzd7 and Cyp2c29, other reported genes in rats and mice induced after 3 daily doses of PXRs are Gstm3, Abcd3, Abcc2, Amtl, CYP51, Foxa1, Fmo2, Gsta4, Gstt2, Nr2f2, Slc16a6 (Slatter et al., 2006). Shah used qPCR to find that a number of genes were upregulated in guts of mice treated with PXR, Gstal, Gstm1, Gstt1, and Mdrla (Shah et al., 2007b). From this it is noticeable that the Gst's and Gstm's are all up- regulated in this study and in a number of previous studies.

While the down- regulated genes in the 1 hour group included Pla2g2c, Card10, Apom, Sfrs16, Rem1, Racl and Bmp7, the down- regulated genes in the 3 hour group were Axot, Alas1, Ugt1a13, Edem1 and Sifl, and the down- regulated genes in the group treated for 5 hours included Acadsb, Dbil5, Sfrs 16, Inppl1, Cental and Gpx1. Also Shah found that PCN (a PXR) inhibited TNF $\alpha$ activated NF kB luciferase reporter in the colon (Shah et al., 2007b) and in rat liver (Menegazzi et al., 1997).

\section{Section 4.3.6 CPA pathways of over-represented genes}

The glutathione transferase activity pathway was over-represented among the functions of upregulated genes when the rat livers were treated with CPA. These results were similar to the findings of Slatter (Slatter et al., 2006). The process interphase of mitotic cell cycle was also over-represented among up-regulated genes along with the phospholipid metabolic process and 
the steroid metabolic process, as also found by (Slatter et al., 2006).

According to a heatmap from the 3 hour samples treated with CPA, immune responses, a response to chemical stimulus, and a response to organic substance and other pathways were over- represented. Unfortunately, there was not enough data from the analysis to perform a heatmap analysis for the 1 and 5 hour time points. Previous studies have illustrated that citrate cycle, pyruvate metabolism, fatty acid metabolism and bile acid biosynthesis were over- represented among the data for PXR -treated cells suggesting that the PXRs regulate bile and lipid acid metabolism (Slatter et al., 2006).

\section{Section 4.3.7 Quantifying genes with real- time PCR}

To confirm and quantify genes of interest found by the microarray and the RNAseq analysis, real- time PCR was applied. The choice of the genes analysed was based largely on the RNAseq results: $C Y P 4 A 1$ was used as a positive control for ciprofibrate because it is known to be induced by PPAR $\alpha$ agonists (Bell et al., 1991)(Bars et al., 1993)(Morris and Davila, 1996). CYP3A1 was used as a positive control for $C P A$ as this is known to be highly induced by PXR agonists (Lehmann et al., 1998)(Hosoe et al., 2005), and G0s2, Ccnd1, and Scd1 were also detected as genes of interest, to check when their expression is increased and if the ciprofibrate induces similar responses in these genes in comparision to the CPA samples.

Validation of the normalization genes ( $A h R$ and $\beta$-actin genes) was essential to normalise the measurements of mRNA to correct for loading differences, and was performed in each of the experiments. This was done to exclude any sample differences attributable to RNA quality or quantity. $A h R$ and $\beta$-actin genes were found to have a minimal change according to the literature and they are well known housekeeping genes regularly used for this purpose (Bazzi et al., 2009) (Lee et al., 1995). The normalization / housekeeping gene expression is not always stable across 
the treatments (Pohjanvirta et al., 2006), and it is optimal practice to use more than one such normalization/ reference genes (Vandesompele et al., 2002). Thus, two reference genes were used in this study.

\section{Section 4.3.7.1 Effects of ciprofibrate and CPA on CYP4A1}

The rat liver CYP4A1 is induced in rodent livers treated with peroxisome proliferators (Hardwick et al., 1987). This rapid induction is usually followed by liver hyperplasia and hypertrophy (Bell et al., 1991), as liver enlargement of the treated rats was also found in this study.

The induction levels of $C Y P 4 A 1 \mathrm{mRNA}$ at different time points on ciprofibrate or CPA treated samples in comparison with controls were measured. This generated a statistically significant high induction of $C Y P 4 A 1$ after 3, 5 and 24 hours of ciprofibrate treatment with the 24 hour treatment giving an induction of $\sim 30$ - fold. The 3 hour ciprofibrate samples gave results with real- time PCR consistent with the RNAseq analysis, $\sim 2.4$ fold induction and $\sim 3.2$ fold- induction, respectively. As for the microarray data it appears to be less sensitive and unreliable (in particular at early hours), as the CYP4A1 did not correlate with the RT-PCR or the RNAseq, and the genes were not consistent between the time points as expected, also no positive controls were found in the early time points for the treatments. The literature reports $C Y P 4 A 1$ to be highly induced with PPAR $\alpha$ agonists in vivo and in vitro (Bell et al., 1991)(Bars et al., 1993)(Morris and Davila, 1996).

The high induction of CYP4Al that has been seen here and the pathways that have been highlighted earlier in Section 4.3.4 correlate with results that state that induction of CYP4A1 happens at the same time as other genes which are involved in the peroxisomal $\beta$ oxidation pathway $(\mathrm{Fu}-$ ruta et al., 1982). It has been reported that the CYP4A1 is involved in the metabolism of a range of xenobiotics and in the hydroxylation of fatty acids (Aoyama et al., 1990)(Gonzalez and 
Nebert, 1990). The induction of $C Y P 4 A 1$ expression in the fisher rats treated with CPA was not affected in the 1, 3 and 24 hour samples while it was significantly lower than the control at 5 hours.

\section{Section 4.3.7.2 Effects of ciprofibrate and CPA on CYP3A1}

The quantitative real- time PCR results for the CPA treated samples showed a statistically significant $>30$ - fold induction of CYP3A1 after 24 hours. These results were consistent with findings in the literature that found that $C Y P 3 A 1$ was highly induced by PXR agonists (Lehmann et al., 1998)(Hosoe et al., 2005).

It has been reported that PXR mediates the genomic effects of a number of steroid hormones and xenobiotics via the $C Y P 3 A$ gene family (Masuyama et al., 2001), and the difference in the response to PXRs between the males and female rodents could not be overlooked, with the latter having a higher induction of CYP3A1 (Eliasson et al., 1994)(Larsen and Jefcoate, 1995). PXRs activate $C Y P 3 A$ s specifically in hepatic cells because of the need for a hepatic nuclear factor$4 \alpha(\mathrm{HNF} 4 \alpha)$ which apparently is involved in the transcriptional activation of the CYP3As (Tirona et al., 2003). As for the induction of $C Y P 3 A 1$ in ciprofibrate treated fisher rats, there was no difference from the control at any of the time points.

\section{Section 4.3.7.3 Effects of ciprofibrate and CPA on Ccnd1}

Cyclin D1 is involved in the cell cycle and was known to be induced after partial hepatectomy (Boylan and Gruppuso, 2005)(Michalopoulos, 2007). Cyclin D1 is considered an important intracellular mediator for the mitogenic signals that are responsible for hepatocyte proliferation in the regenerating liver (Nelsen et al., 2001). It is also a delayed target of the c-Jun-N-terminal kinase pathway during liver regeneration (Schwabe et al., 2003). Other studies demonstrate that 
the over expression of the cyclin D1 gene results in fast growth of a subset of hepatocellular carcinomas (Nishida et al., 1994).

Real- time PCR analysis of Ccndl showed an up- regulation with ciprofibrate treated samples at 3 hours ( 1.8 fold change) and this was similar to the corresponding RNAseq analysis (2.9 fold change). These results were similar to previous studies that showed a high induction of cyclin D1 mRNA in Wy14643 treated mice (Peters et al., 1998).

Ccnd1 was induced at 5 hours in CPA treated Fisher rats but not at 1, 3 or 24 hour samples. This demonstrates that the Ccndl could be affected by both the ciprofibrate and the CPA at the immediate early time points.

These results demonstrate that $C c n d 1$ might be a common target for the hepatic DNA synthesis, and is not specific for the peroxisome proliferators nor the PXRs. This was also suggested by Pibiri, who found the Ccndl was highly induced at the early hours after a single dose with the thyroid hormone (T3), and also suggested that Ccndl could be responsible for the mitogenic activity of nuclear receptor ligands (Pibiri et al., 2001).

Therefore, conclusions could be drawn in relation to the effects of the Ccndl on the hepatic DNA synthesis, as it is induced after 3 hours presumably stimulating the DNA to enter the cell cycle and so cause the hepatic DNA synthesis that is observed after 24 hours. However, this phenomenon is noticed additionally with the CPA signifying that the Ccndl is not specific to the PPAR $a$ and that the PXRs have the same effects on the Ccndl.

\section{Section 4.3.7.4 Effects of ciprofibrate and CPA on $S c d 1$}

It has been shown previously that poly-unsaturated fatty-acids like linoleic acid repress the expression of $S c d$ gene encoding (stearoyl-coenzyme A desaturase 1) in adipocytes (Sessler et al., 
1996). When mice were fed a high-carbohydrate fat free diet, $S c d 1$ was induced around 50-fold, which could have been caused by carbohydrate or insulin (Waters and Ntambi, 1994)(Ntambi, 1995).

In the present study ciprofibrate significantly induced $S c d 1$ at 1 hour ( $\sim 9$ fold change according to real- timePCR, $\sim 13$ - fold change according to RNAseq analysis) and at the other time points Scdl expression in ciprofibrate samples were slightly higher than the control samples, while Scdl expression in CPA treated rats was slightly lower than the control at all the time points, though this difference was not significant. Research done by Miller showed that peroxisome proliferators induced $S c d 1$ in mouse liver (Miller and Ntambi, 1996).

This is interesting as it suggests that the signals from the $S c d 1$, occurring as soon as 1 hour after dosing with the ciprofibrate, stimulates the hepatocytes to divide. The hepatic DNA synthesis could be seen after 24 hours with the immunohistochemical protocol. Apparently the induction just stops within two hours, and this is reflected on the hepatic DNA synthesis as the cells slow down their dividing within a couple of hours after the 24 hours peck. Furthermore, a noteworthy reality is that the CPA is not involved in this pathway as it is specific for the PPAR $\alpha$, which is as confirmed by the fact that $S c d l$ expression is not induced by CPA.

\section{Section 4.3.7.5 Effects of ciprofibrate and CPA on G0s2}

The $G 0 s 2$ gene was identified by chance during a screen to find differentially expressed genes with links to lectin treatments of lymphocytes, and is involved with cell cycle development from the G0 to the G1 stage (Cristillo et al., 1997). It was also considered that G0s2 is a target gene of the all-trans-retinoic acid (this is an oxidized form of vitamin A used in the treatment of acute leukemia) (Kitareewan et al., 2008). It has been reported that the PPARs agonist WY14,643 induces G0s 2 expression in vivo after 6 hours and in vitro after 5 days (Zandbergen et al., 2005). 
The results for the ciprofibrate samples show that the induction of $G 0 s 2$ at 3 hours was significantly higher than the control (5.4 fold induction). This result is similar to the findings from the RNAseq analysis at 3 hours as the $G 0 s 2$ gene expression was found to be 5.8 fold above control samples (Section 3.4.6.2). The induction then subsided gradually at 5 hours, and then more so at 24 hours. This is very interesting as the timing correlates with the hepatic DNA synthesis results (Section 3.1.2.1.1) which showed the hepatic DNA synthesis peaks at 24 hours before subsequently declining.

The data are consistent with a possible relationship between $G 0 s 2$ expression and hepatic DNA synthesis, as a G0s2 provoked G0 to G1 transition at $\sim 3$ hours, would be expected to give induction of DNA synthesis during the following cell cycle at $\sim 20$ hours later, indicating a close relation between the $G 0 s 2$ and the hepatic DNA synthesis.

The expression of $G 0 s 2$ in fisher rats treated with CPA show no significant difference from the control in all the samples treated at 1, 3, 5 and 24 hours, showing that the CPA promotes a different response from the ciprofibrate, and the $G 0 s 2$ is specific to the PPAR $\alpha$. 


\section{Section 4.4 Concluding remarks}

In this thesis the effects of $50 \mathrm{mg} / \mathrm{kg}$ ciprofibrate treatment for $1,3,5$ and 24 hours on immediate-early liver gene expression in rats was studied. This was done by using cDNA microarrays, transcriptome sequencing and quantitative real- time PCR.

The hepatic DNA synthesis induced by ciprofibrate was initially characterized. This was done with BrdU immunohistochemical detection protocol, and was found to be significantly increased at 24 hours in rat liver, while it was not significantly induced until after 4 days in mice. For rats treated with ciprofibrate, the zonation of the hepatocytes found in S-phase were significantly different between centrilobular and periportal liver regions, being more dominant in the periportal region by $\sim 20$ fold. The zonal distribution of S-phase hepatocytes in mice was not different between the periportal and the perivenous zones, but had a random distribution across the liver tissue. The difference in the period and localization of the hepatic DNA synthesis between mouse and rat liver suggests there is a species difference in the kinetics between the mouse and rat's response to the ciprofibrate.

This study identifies many genes that appear to be up- regulated by ciprofibrate including previously known PPAR $\alpha$ agonist-responsive genes involved in processes such as PPAR signalling pathways, fatty acid metabolic pathway, cell cycle, palmitoyl-coa hydrolase activity, lipid metabolism, inflammatory responses, and stress responses. In addition, the immediate- early gene response shows novel candidate genes, consistent with a link between the genes expression at 1 - 3 hours and the hepatic DNA synthesis at 24 hours. The gene induction was up- regulated at 1- 3 hours, then the induction came to control levels after 5 hours dosing, incorporating the hepatic DNA synthesis that was significantly high at 24 hours and then gradually decreased to control levels at 36 hours. This suggests that these genes were responsible for the hepatic DNA 
synthesis that occurred after 24 hours of dosing with ciprofibrate. This is similar to previous results obtained after partial hepatectomy with the gene expression for cell cycle regulated genes, that peaks after 2-3 hours after partial hepatectomy (Taub, 2004).

Five genes were followed up in ciprofibrate and CPA treated rats with quantitative real- time PCR, these genes were CYP4A1, CYP3A1, Ccnd1, Scd1 and G0s2. CYP4A1 and CYP3A1 were used as positive controls for ciprofibrate and CPA dosed animals, respectively. The Ccndl and G0s 2 genes both had a significantly high induction at 3 hours with ciprofibrate treated animals, but only Ccndl expression was additionally significantly high at 5 hours with the CPA dosed animals. $S c d 1$ expression was induced significantly with the ciprofibrate at 1 hour and not with the CPA. These results suggest that $S c d 1$ and $G 0 s 2$ are affected at the immediate-early hours by ciprofibrate, while they are not affected by the CPA, so they would be expected to be in a different pathway than the CPA. Also, the Ccndl is a common gene that is expressed by both the ciprofibrate and the CPA at the early time points after dosing and apparently it is induced by other DNA inducers e.g. T3.

Finally, this study was able to shed some light on the mechanism of action of hepatic growth induced by ciprofibrate by studying the hepatic DNA synthesis in mouse and rat liver tissue, and by characterizing the immediate early induced genes that are provoked by peroxisome proliferators, and can cause hepatic proliferation, which might be helpful in cancer studies. 


\section{Section 4.5 Prospective work}

A large number of the genes identified here could be interesting to follow up, as the microarray and the transcriptome sequencing analysis both provide a large data base for the immediate early time points and the acute response to ciprofibrate or CPA after a range of time points.

Chosen pathways or particular genes could be tested with real- time PCR at different time points, and in female rats treated with CPA as it is known that female rats give a hepatic DNA synthesis higher than the males that were used in this study, so it would be expected to have much more induction of the same genes, in particular, the DNA synthesis, the cell cycle pathway or PPAR signalling pathway genes, such as G0/G1 switch 2 (G0s2), cyclin D1 (Ccnd1), stearoyl-coenzyme A desaturase 1 (Scd1), carnitine palmitoyltransferase 1a (Cpt1a), cyclin T1(Ccnt1), Myeloblastosis oncogene-like (Myb11), Ets variant 3+6 (Etv31 + Etv6), Kelch repeat and BTB (POZ) domain containing 11 (Kbtbd11), Myc myelocytomatosis viral oncogene homolog 1 (Mycl1 v), Protein phosphatase 1K (Ppm1k) or T-box 3 (Tbx3).

Additionally, the proteins induced by the PPAR could be studied by western blotting. These genes could be tested in other species in particular human tissues for comparison and to predict the level of danger, if any, from the peroxisome proliferators in concern with the hepatocarcinogenesis.

Also, immunohistochemical protocols could be used against specific antigens to indicate, where in the liver zones do particular genes begin their induction (by following the pattern at the different time points) if periportal or perivenous, and this could help to tie groups of genes together and introduce a small view of their mechanism of action in response to both the ciprofibrate and the CPA. 
Furthermore, to prove that the genes identified in this study are actually involved in or required for the hepatic DNA synthesis induction, it would be exciting to follow up with knock-out mice or rats of these genes and test if the induction is affected. It might also be worth checking if the rodents that do not react to peroxisome proliferators have these genes, and to examine if these genes are induced after dosing. 


\section{Appendix I of RNA, cDNA and dye yields of the microarray samples}

\begin{tabular}{|c|c|c|c|}
\hline Sample ID & $\begin{array}{c}\text { RNA yield } \\
\mu \mathrm{g} / \mu \mathrm{l}\end{array}$ & $\begin{array}{l}\text { cDNA yield } \\
\qquad \mathbf{n g} / \boldsymbol{\mu l} \\
\text { for microarray }\end{array}$ & $\begin{array}{c}\text { Alexa flour } 555 \text { dye } \\
\text { attachment to cDNA } \\
\text { pmol } / \mu \mathrm{l}\end{array}$ \\
\hline CIPROFIBRATE & & & \\
\hline Treated cipro $1 \mathrm{~h}-1$ & 10.08 & 79.6 & 4.7 \\
\hline Treated cipro $1 \mathrm{~h}-2$ & 15.66 & 92.7 & 2.5 \\
\hline Treated cipro $1 \mathrm{~h}-3$ & 9.4 & 112.9 & 10.5 \\
\hline Treated cipro $1 \mathrm{~h}-4$ & 8.38 & 159.4 & 12 \\
\hline Treated cipro $3 \mathrm{~h}-1$ & 13.6 & 350.6 & 13.6 \\
\hline Treated cipro $3 \mathrm{~h}-2$ & 11.7 & 144 & 11.7 \\
\hline Treated cipro $3 \mathrm{~h}-3$ & 13.36 & 43.97 & 6.3 \\
\hline Treated cipro $3 \mathrm{~h}-4$ & 11.06 & 35.2 & 5.2 \\
\hline Treated cipro $5 \mathrm{~h}-1$ & 9.14 & 218.1 & 50.1 \\
\hline Treated cipro $5 \mathrm{~h}-2$ & 10.26 & 152.2 & 33.5 \\
\hline Treated cipro 5h-3 & 12.82 & 71.32 & 19.7 \\
\hline Treated cipro $5 \mathrm{~h}-4$ & 13.8 & 129.6 & 15.9 \\
\hline Treated cipro $24 \mathrm{~h}-2$ & 4.88 & 19.8 & 3.6 \\
\hline Treated cipro $24 \mathrm{~h}-3$ & 3.59 & 13 & 1.3 \\
\hline Treated cipro $24 \mathrm{~h}-5$ & 3.06 & 17.3 & 1.7 \\
\hline Treated cipro $24 \mathrm{~h}-6$ & 5.33 & 51 & 8.8 \\
\hline
\end{tabular}




\begin{tabular}{|c|c|c|c|}
\hline $\begin{array}{c}\text { CYROTERONE } \\
\text { ACETATE }\end{array}$ & & & \\
\hline Treated CPA 1h-1 & 3.95 & 99.6 & 11.3 \\
\hline Treated CPA 1h-2 & 5.2 & 60.3 & 5.7 \\
\hline Treated CPA 1h-3 & 7.8 & 77.1 & 16.8 \\
\hline Treated CPA 1h-4 & 9.75 & 69.1 & 7.5 \\
\hline Treated CPA 3h-1 & 8.43 & 12 & 4.9 \\
\hline Treated CPA 3h-2 & 2.93 & 7.9 & 2.3 \\
\hline Treated CPA 3h-3 & 4.67 & 39.9 & 3 \\
\hline Treated CPA 3h-4 & 7.32 & 19.3 & 6.7 \\
\hline Treated CPA 5h-1 & 7.01 & 19.9 & 10.8 \\
\hline Treated CPA 5h-2 & 7.3 & 57.5 & 13 \\
\hline Treated CPA 5h-3 & 4.75 & 34.1 & 11.5 \\
\hline Treated CPA 5h-4 & 3.69 & 5.9 & 4.4 \\
\hline Treated CPA 24h-1 & 8.34 & 84.4 & 11.4 \\
\hline Treated CPA 24h-2 & 8.24 & 140.5 & 10.8 \\
\hline Treated CPA 24h-3 & 12.34 & 62.8 & 9.6 \\
\hline Treated CPA 24h-4 & 4.02 & 140.6 & 44.9 \\
\hline \multicolumn{4}{|l|}{$\begin{array}{l}\text { CORN OIL } \\
\text { (CONTROL) }\end{array}$} \\
\hline control 1h-1 & 15.54 & 153.7 & 14.6 \\
\hline control 1h-2 & 8.08 & 114.4 & 7.6 \\
\hline control 1h-3 & 14.04 & 127.8 & 13 \\
\hline control 1h-4 & 7.46 & 136.5 & 16.7 \\
\hline
\end{tabular}




\begin{tabular}{c|c|c|c}
\hline control 3h-1 & 8.14 & 36 & 4.4 \\
\hline control 3h-2 & 7.56 & 10.7 & 1.5 \\
\hline control 3h-3 & 5.31 & 16.8 & 3.8 \\
\hline control 3h-4 & 4.88 & 12.7 & 2.3 \\
\hline control 5h-1 & 11.2 & 9.8 & 4.6 \\
\hline control 5h-2 & 6.72 & 24 & 2.4 \\
\hline control 5h-3 & 8.14 & 8 & 6.5 \\
\hline control 5h-4 & 7.33 & 18 & 26.9 \\
\hline control 24h-1 & 3.65 & 142.5 & 46.2 \\
\hline control 24h-2 & 6.24 & 373 & 6.7 \\
\hline control 24h-3 & 3.86 & 45.4 & 8.4 \\
\hline control 24h-6 & 5.32 & 71.4 & \\
\hline
\end{tabular}




\title{
Record of Training Courses
}

\author{
Mrs. Abeer H. A. Amer \\ student ID number 4047465
}

Record of Training courses

Institute of genetics courses

Radiation training course

Safety training for postgraduate research student

Biological safety training

Training of Personnel under the Animals (Scientific Procedures) Act 1986

Home office license course (model 1)

Home office license course (model 2)

Home office license course (model 3)

RT-PCR course

Seminars

\section{Graduate School courses}

Library induction and use of software

Exploiting the power of MS word a: for individual chapters and academic papers

Exploiting the power of MS word b: combining chapters into the thesis

MS Excel functionality a: entering, formatting and storing data

MS Power Point: developing a professional presentation

Computer and molecular biology

Further presentation skills

Getting started with research design and statistics 
Introduction to image and photo editing

Nature of the $\mathrm{PhD}$ and the supervision process

Guidelines for planning and formatting theses

Getting going on your thesis

Intensive learning and teaching program

Beginning writing

Academic writing/ synthesis sources

Introductory events to teaching for PG research students and researchers

Training for reading to tape for disabled students

Training for note-taking

Training for invigilation

Training for information technology (IT) support

\section{Presentations at the School Post-Graduate Symposia}

First platform presentation

Second year poster presentation

Third year platform presentation

\section{Demonstrating}

Molecular and development neuroscience (ligand binding practical class)

The manipulating genes and genomes

The genes and cellular control

The C. Elegans practical 


\section{Chapter 5 References}

ABOSHOFA, F. A. (unpublished data) Mechanism of action of Liver growth induced by nongenotoxic carcinogens(peroxisome proliferators). School of Biology. Nottingham, of Nottingham.

AKIYAMA, T. E., NICOL, C. J., FIEVET, C., STAELS, B., WARD, J. M., AUWERX, J., LEE, S. S., GONZALEZ, F. J. \& PETERS, J. M. (2001) Peroxisome proliferatoractivated receptor-alpha regulates lipid homeostasis, but is not associated with obesity: studies with congenic mouse lines. J Biol Chem, 276, 39088-93.

AL KHOLAIFI, A. (2008) The induction of liver growth by perixisome proliferators. School of biology. Nottingham, University of Nottingham.

AL KHOLAIFI, A., AMER, A., JEFFERY, B., GRAY, T. J., ROBERTS, R. A. \& BELL, D. R. (2008) Species-specific kinetics and zonation of hepatic DNA synthesis induced by ligands of PPARalpha. Toxicol Sci, 104, 74-85.

ALBERTS, B., JOHNSON, A., LEWIS, J., RAFF, M., ROBERTS, K. \& WALTER, P. (2002) Molecular Biology of the Cell. New York, Garland Science.

ALDRIDGE, T. C., TUGWOOD, J. D. \& GREEN, S. (1995) Identification and characterization of DNA elements implicated in the regulation of CYP4A1 transcription. Biochem J, 306 ( Pt 2), 473-9.

ALSHEIKH-ALI, A. A., KUVIN, J. T. \& KARAS, R. H. (2004) Risk of adverse events with fibrates. Am J Cardiol, 94, 935-8.

AMACHER, D. E., SCHOMAKER, S. J. \& BURKHARDT, J. E. (1998) The relationship among microsomal enzyme induction, liver weight and histological change in rat toxicology studies. Food Chem Toxicol, 36, 831-9.

ANDERSON, S. P., DUNN, C. S., CATTLEY, R. C. \& CORTON, J. C. (2001) Hepatocellular proliferation in response to a peroxisome proliferator does not require TNFalpha signalling. Carcinogenesis, 22, 1843-51.

AOYAMA, T., HARDWICK, J. P., IMAOKA, S., FUNAE, Y., GELBOIN, H. V. \& GONZALEZ, F. J. (1990) Clofibrate-inducible rat hepatic P450s IVA1 and IVA3 catalyze the omega- and (omega-1)-hydroxylation of fatty acids and the omegahydroxylation of prostaglandins E1 and F2 alpha. J Lipid Res, 31, 1477-82.

ASHBY, J., BRADY, A., ELCOMBE, C. R., ELLIOTT, B. M., ISHMAEL, J., ODUM, J., TUGWOOD, J. D., KETTLE, S. \& PURCHASE, I. F. H. (1994) Mechanistically- 
Based Human Hazard Assessment of Peroxisome Proliferator-Induced Hepatocarcinogenesis. Human \& Experimental Toxicology, 13, S1-S117.

BAKER, V. A., HARRIES, H. M., WARING, J. F., DUGGAN, C. M., NI, H. A., JOLLY, R. A., YOON, L. W., DE SOUZA, A. T., SCHMID, J. E., BROWN, R. H., ULRICH, R. G. \& ROCKETT, J. C. (2004) Clofibrate-induced gene expression changes in rat liver: a cross-laboratory analysis using membrane cDNA arrays. Environ Health Perspect, $112,428-38$.

BAMMLER, T., BEYER, S. BHATTACHARYA, G. A. BOORMAN, A. BOYLES, B. U. BRADFORD, R. E. BUMGARNER, P. R. BUSHEL, K. CHATURVEDI, D. CHOI, M. L. CUNNINGHAM, S. DENG, H. K. DRESSMAN, R. D. FANNIN, F. M. FARIN, J. H. FREEDMAN, R. C. FRY, A. HARPER, M. C. HUMBLE, P. HURBAN, T. J. KAVANAGH, W. K. KAUFMANN, K. F. KERR, L. JING, J. A. LAPIDUS, M. R. LASAREV, J. LI, Y. J. LI, E. K. LOBENHOFER, X. LU, R. L. MALEK, S. MILTON, S. R. NAGALLA, P. O'MALLEY J, V. S. PALMER, P. PATTEE, R. S. PAULES, C. M. PEROU, K. PHILLIPS, L. X. QIN, Y. QIU, S. D. QUIGLEY, M. RODLAND, I. RUSYN, L. D. SAMSON, D. A. SCHWARTZ, Y. SHI, J. L. SHIN, S. O. SIEBER, S. SLIFER, M. C. SPEER, P. S. SPENCER, D. I. SPROLES, J. A. SWENBERG, W. A. SUK, R. C. SULLIVAN, R. TIAN, R. W. TENNANT, S. A. TODD, C. J. TUCKER, B. VAN HOUTEN, B. K. WEIS, S. XUAN, T. \& ZARBL, H. (2005) Standardizing global gene expression analysis between laboratories and across platforms. Nat Methods, 2, 351-6.

BARRASS, N. C., PRICE, R. J., LAKE, B. G. \& ORTON, T. C. (1993) Comparison of the acute and chronic mitogenic effects of the peroxisome proliferators methylclofenapate and clofibric acid in rat liver. Carcinogenesis, 14, 1451-6.

BARS, R. G., BELL, D. R. \& ELCOMBE, C. R. (1993) Induction of cytochrome P450 and peroxisomal enzymes by clofibric acid in vivo and in vitro. Biochem Pharmacol, 45, 2045-53.

BARS, R. G., BELL, D. R., ELCOMBE, C. R., OINONEN, T., JALAVA, T. \& LINDROS, K. O. (1992) Zone-specific inducibility of cytochrome P450 2B1/2 is retained in isolated perivenous hepatocytes. Biochem J, 282 ( Pt 3), 635-8.

BAUMANN, H. \& GAULDIE, J. (1994) The acute phase response. Immunol Today, 15, 7480.

BAZZI, R., BRADSHAW, T. D., ROWLANDS, J. C., STEVENS, M. F. \& BELL, D. R. (2009) 2-(4-Amino-3-methylphenyl)-5-fluorobenzothiazole is a ligand and shows species-specific partial agonism of the aryl hydrocarbon receptor. Toxicol Appl Pharmacol, 237, 102-10. 
BECUWE, P. \& DAUCA, M. (2005) Comparison of cytotoxicity induced by hypolipidemic drugs via reactive oxygen species in human and rodent liver cells. International Journal of Molecular Medicine, 16, 483-92.

BELL, A. R., SAVORY, R., HORLEY, N. J., CHOUDHURY, A. I., DICKINS, M., GRAY, T. J., SALTER, A. M. \& BELL, D. R. (1998) Molecular basis of non-responsiveness to peroxisome proliferators: the guinea-pig PPARalpha is functional and mediates peroxisome proliferator-induced hypolipidaemia. Biochem J, 332 ( Pt 3), 689-93.

BELL, D. R., BARS, R. G., GIBSON, G. G. \& ELCOMBE, C. R. (1991) Localization and differential induction of cytochrome P450IVA and acyl-CoA oxidase in rat liver. Biochem J, 275 ( Pt 1), 247-52.

BELL, D. R. \& ELCOMBE, C. R. (1991a) Induction of acyl-CoA oxidase and cytochrome P450IVA1 RNA in rat primary hepatocyte culture by peroxisome proliferators. Biochem J, 280 ( Pt 1), 249-53.

BELL, D. R. \& ELCOMBE, C. R. (1991b) Regulation of differentially spliced transcripts of acyl-CoA oxidase in the rat. Biochim Biophys Acta, 1090, 211-5.

BENHAMOUCHE, S., DECAENS, T., GODARD, C., CHAMBREY, R., RICKMAN, D. S., MOINARD, C., VASSEUR-COGNET, M., KUO, C. J., KAHN, A., PERRET, C. \& COLNOT, S. (2006) Apc tumour suppressor gene is the "zonation-keeper" of mouse liver. Dev Cell, 10, 759-70.

BENJAMINI, Y. \& HOCHBERG, Y. (1995) Controlling the False Discovery Rate - a Practical and Powerful Approach to Multiple Testing. Journal of the Royal Statistical Society Series B-Methodological, 57, 289-300.

BERNHARD, W. \& ROUILLER, C. (1956) Microbodies and the problem of mitochondrial regeneration in liver cells. J Biophys Biochem Cytol, 2, 355-60.

BEYER, T. A., XU, W., TEUPSER, D., AUF DEM KELLER, U., BUGNON, P., HILDT, E., THIERY, J., KAN, Y. W. \& WERNER, S. (2008) Impaired liver regeneration in Nrf2 knockout mice: role of ROS-mediated insulin/IGF-1 resistance. EMBO J, 27, 212-23.

BLAAUBOER, B. J., VAN HOLSTEIJN, C. W., BLEUMINK, R., MENNES, W. C., VAN PELT, F. N., YAP, S. H., VAN PELT, J. F., VAN IERSEL, A. A., TIMMERMAN, A. \& SCHMID, B. P. (1990) The effect of beclobric acid and clofibric acid on peroxisomal beta-oxidation and peroxisome proliferation in primary cultures of rat, monkey and human hepatocytes. Biochem Pharmacol, 40, 521-8.

BOYLAN, J. M. \& GRUPPUSO, P. A. (2005) D-type cyclins and G1 progression during liver development in the rat. Biochem Biophys Res Commun, 330, 722-30. 
BRIDGMAN, J. F., ROSEN, S. M. \& THORP, J. M. (1972) Complications during clofibrate treatment of nephrotic-syndrome hyperlipoproteinaemia. Lancet, 2, 506-9.

BUDROE, J. D., UMEMURA, T., ANGELOFF, K. \& WILLIAMS, G. M. (1992) Doseresponse relationships of hepatic acyl-CoA oxidase and catalase activity and liver mitogenesis induced by the peroxisome proliferator ciprofibrate in C57BL/6N and BALB/c mice. Toxicol Appl Pharmacol, 113, 192-8.

BURKHARDT, S., BAHNEMANN, R., FAILING, K. \& REINACHER, M. (2004) Zonal distribution of cell proliferation in the liver of untreated B6C3F1 and C57BL mice. Toxicologic Pathology, 32, 100-5.

CAROLI-BOSC, F. X., LE GALL, P., PUGliese, P., DELABRE, B., CAROLI-BOSC, C., DEMARQUAY, J. F., DELMONT, J. P., RAMPAL, P. \& MONTET, J. C. (2001) Role of fibrates and HMG-CoA reductase inhibitors in gallstone formation: epidemiological study in an unselected population. Dig Dis Sci, 46, 540-4.

CARTER, D. E., ROBINSON, J. F., ROBINSON, E. M., ALLISTER, M. W., HUFF, A. F. AND HEGELE, R. A. (2005) Quality assessment of microarray experiments. Clin Biochem, 38, 639-42.

CATTLEY, R. C. (2003) Regulation of cell proliferation and cell death by peroxisome proliferators. Microscopy Research and Technique, 61, 179-84.

CATTLEY, R. C., MARSMAN, D. S. \& POPP, J. A. (1991) Age-Related Susceptibility to the Carcinogenic Effect of the Peroxisome Proliferator Wy-14,643 in Rat-Liver. Carcinogenesis, 12, 469-73.

CHERKAOUI-MALKI, M., MEYER, C. M., CAO, W. Q., LATRUFFE, N., YELDANDI, A. V., RAO, M. S., BRADFIELD, C. A. \& REDDY, J. K. (2001) Identification of novel peroxisome proliferator-activated receptor alpha (PRAR alpha) target genes in mouse liver using cDNA microarray analysis. Gene Expression, 9, 291-304.

CHEUNG, C., AKIYAMA, T. E., WARD, J. M., NICOL, C. J., FEIGENBAUM, L., VINSON, C. \& GONZALEZ, F. J. (2004) Diminished hepatocellular proliferation in mice humanized for the nuclear receptor peroxisome proliferator-activated receptor alpha. Cancer Res, 64, 3849-54.

CIBELli, A., STEFANINI, S. \& CERU, M. P. (1988) Peroxisomal Beta-Oxidation and Catalase Activities in Fetal-Rat Liver - Effect of Maternal Treatment with Clofibrate. Cellular and Molecular Biology, 34, 191-205.

CORREIA, M. A. (1995) Rat and human liver cytochromes P450 IN PR, O. D. M. (Ed.) Cytochrome P450s, Structure, Metabolism and Biochemistery. 2nd ed. New York. 
CORTON, J. C., ANDERSON, S. P. \& STAUBER, A. (2000) Central role of peroxisome proliferator-activated receptors in the actions of peroxisome proliferators. Annual Review of Pharmacology and Toxicology, 40, 491-518.

CORTON, J. C., FAN, L. Q., BROWN, S., ANDERSON, S. P., BOCOS, C., CATTLEY, R. C., MODE, A. \& GUSTAFSSON, J. A. (1998) Down-regulation of cytochrome P450 $2 \mathrm{C}$ family members and positive acute-phase response gene expression by peroxisome proliferator chemicals. Mol Pharmacol, 54, 463-73.

CORTON, J. C. \& LAPINSKAS, P. J. (2005) Peroxisome proliferator-activated receptors: mediators of phthalate ester-induced effects in the male reproductive tract? Toxicol Sci, 83, 4-17.

CRESSMAN, D. E., GREENBAUM, L. E., DEANGELIS, R. A., CILIBERTO, G., FURTH, E. E., POLI, V. \& TAUB, R. (1996) Liver failure and defective hepatocyte regeneration in interleukin-6-deficient mice. Science, 274, 1379-83.

CRISTILlO, A. D., HEXIMER, S. P., RUSSELL, L. \& FORSDYKE, D. R. (1997) Cyclosporin A inhibits early mRNA expression of G0/G1 switch gene 2 (G0S2) in cultured human blood mononuclear cells. DNA Cell Biol, 16, 1449-58.

DAVIS, B. J., MARONPOT, R. R. \& HEINDEL, J. J. (1994) Di-(2-ethylhexyl) phthalate suppresses estradiol and ovulation in cycling rats. Toxicol Appl Pharmacol, 128, 21623.

DEDUVE, C. (1965) Functions of Microbodies (Peroxisomes). Journal of Cell Biology, 27, A25-30.

DEFAZIO, A., LEARY, J. A., HEDLEY, D. W. \& TATTERSALL, M. H. (1987) Immunohistochemical detection of proliferating cells in vivo. J Histochem Cytochem, $35,571-7$.

DESVERGNE, B. \& WAHLI, W. (1999) Peroxisome proliferator-activated receptors: nuclear control of metabolism. Endocr Rev, 20, 649-88.

DIEHL, A. M., MICHAELSON, P. \& YANG, S. Q. (1994) Selective induction of CCAAT/ enhancer binding protein isoforms occurs during rat liver development. Gastroenterology, 106, 1625-37.

DIWAN, B. A., RICE, J. M., OHSHIMA, M. \& WARD, J. M. (1986) Interstrain Differences in Susceptibility to Liver Carcinogenesis Initiated by N-Nitrosodiethylamine and Its Promotion by Phenobarbital in C57bl/6ncr,C3h/Hencrmtv- and Dba/2ncr Mice. Carcinogenesis, 7, 215-220. 
DRAGHICI, S., P. KHATRI, EKLUND, A. C. \& SZALLASI, Z. (2006) Reliability and reproducibility issues in DNA microarray measurements. Trends Genet, 22, 101-109.

DREYER, C., KREY, G., KELLER, H., GIVEL, F., HELFTENBEIN, G. \& WAHLI, W. (1992) Control of the peroxisomal beta-oxidation pathway by a novel family of nuclear hormone receptors. Cell, 68, 879-87.

DUDEK, R. W. (2000) High yeild histology, USA.

ELDRIDGE, S. R., TILBURY, L. F., GOLDSWORTHY, T. L. \& BUTTERWORTH, B. E. (1990) Measurement of chemically induced cell proliferation in rodent liver and kidney: a comparison of 5-bromo-2'-deoxyuridine and [3H]thymidine administered by injection or osmotic pump. Carcinogenesis, 11, 2245-51.

ELIASSON, E., MKRTCHIAN, S., HALPERT, J. R. \& INGELMAN-SUNDBERG, M. (1994) Substrate-regulated, cAMP-dependent phosphorylation, denaturation, and degradation of glucocorticoid-inducible rat liver cytochrome P450 3A1. J Biol Chem, $269,18378-83$.

FAUSTO, N. (2000) Liver regeneration. Journal of Hepatology, 32, 19-31.

FRICK, M. H., ELO, O., HAAPA, K., HEINONEN, O. P., HEINSALMI, P., HELO, P., HUTTUNEN, J. K., KAITANIEMI, P., KOSKINEN, P.\& MANNINEN, V. (1987) Helsinki Heart Study: primary-prevention trial with gemfibrozil in middle-aged men with dyslipidemia. Safety of treatment, changes in risk factors, and incidence of coronary heart disease. $N$ Engl J Med, 317, 1237-45.

FURUTA, S., MIYAZAWA, S. \& HASHIMOTO, T. (1982) Biosynthesis of enzymes of peroxisomal beta-oxidation. J Biochem, 92, 319-26.

GAO, L., LI, Y., PEI, X. \& CHEN, X. (2003) [Effects of Di(2-ethylhexyl) phthalate(DEHP) on mouse embryos development in vitro]. Wei Sheng Yan Jiu, 32, 198-200.

GERHOLD, D., LU, M., XU, J., AUSTIN, C., CASKEY, C. T. \& RUSHMORE, T. (2001) Monitoring expression of genes involved in drug metabolism and toxicology using DNA microarrays. Physiol Genomics, 5, 161-70.

GONZALEZ, F. J. \& NEBERT, D. W. (1990) Evolution of the P450 gene superfamily: animal-plant 'warfare', molecular drive and human genetic differences in drug oxidation. Trends Genet, 6, 182-6.

GREEN, H. J., PAKENHAM, K. I., HEADLEY, B. C., YAXLEY, J., NICOL, D. L., MACTAGGART, P. N., SWANSON, C., WATSON, R. B. \& GARDINER, R. A. (2002) Altered cognitive function in men treated for prostate cancer with luteinizing 
hormone-releasing hormone analogues and cyproterone acetate: a randomized controlled trial. BJU Int, 90, 427-32.

GRILLI, M., CHENTRAN, A. \& LENARDO, M. J. (1993) tumour-Necrosis-Factor-Alpha Mediates a T-Cell Receptor-Independent Induction of the Gene Regulatory Factor NfKappa-B in T-Lymphocytes. Molecular Immunology, 30, 1287-94.

GRISHAM, J. W. (1962) A Morphologic Study of Deoxyribonucleic Acid Synthesis and Cell Proliferation in Regenerating Rat Liver - Autoradiography with Thymidine-H3. Cancer Research, 22, 842-847.

GUJAEVA, E. L., KOBLIAKOV, V. A., ZABOTINA, E. J. RYBALKINA, T. N. \& STRAVROVSKAYA, A. A. (1998) Coordinated regulation of P-glycoprotein activity and cytochrome P-4501A induction in sublines of rat hepatoma McA RH7777 cells with different levels of colchicine resistance. Membr Cell Biol, 12, 481-8.

GUZELIAN, J., BARWICK, J. L., HUNTER, L., PHANG, T. L., QUATTROCHI, L. C. \& GUZELIAN, P. S. (2006) Identification of genes controlled by the pregnane X receptor by microarray analysis of mRNAs from pregnenolone 16alpha-carbonitrile-treated rats. Toxicol Sci, 94, 379-87.

HAMADEH, H. K., BUSHEL, P. R., JAYADEV, S., MARTIN, K., DISORBO, O., SIEBER, S., BENNETT, L., TENNANT, R., STOLL, R., BARRETT, J. C., BLANCHARD, K., PAULES, R. S. \& AFSHARI, C. A. (2002) Gene expression analysis reveals chemicalspecific profiles. Toxicol Sci, 67, 219-31.

HARDWICK, J. P., SONG, B. J., HUBERMAN, E. \& GONZALEZ, F. J. (1987) Isolation, complementary DNA sequence, and regulation of rat hepatic lauric acid omegahydroxylase (cytochrome P-450LA omega). Identification of a new cytochrome P-450 gene family. $J$ Biol Chem, 262, 801-10.

HENRIKSON, R. C., KAYE, G. I., MAZURKIEWICZ, J.E. (1997) NMS Histology. Baltimore, Williams and Wilkins.

HIGGINS, G. (1933) Experimental pathology of the liver XII Effects of feeding desiccated thyroid gland on restoration of the liver. Archives of Pathology, 16, 226-31.

HOLDEN, P. R. \& TUGWOOD, J. D. (1999) Peroxisome proliferator-activated receptor alpha: Role in rodent liver cancer and species differences. Journal of Molecular Endocrinology, 22, 1-8.

HOSOE, T., NAKAHAMA, T. \& INOUYE, Y. (2005) Divergent modes of induction of rat hepatic and pulmonary CYP3A1 by dexamethasone and pregnenolone 16 alphacarbonitrile. Journal of Health Science, 51, 75-9. 
ISSEMANN, I. \& GREEN, S. (1990) Activation of a Member of the Steroid-Hormone Receptor Superfamily by Peroxisome Proliferators. Nature, 347, 645-50.

JARVINEN, A. K., HAUTANIEMI, S., EDGREN, P., AUVINEN, J., SAARELA, O. P., KALLIONIEMI, H. \& MONNI, O. (2004) Are data from different gene expression microarray platforms comparable? Genomics, 83, 1164-8.

JENSSEN, T. K., LANGAAS, M. KUO, B. SMITH-SORENSEN, O. MYKLEBOST, W. P. \& HOVIG, E. (2002) Analysis of repeatability in spotted cDNA microarrays. Nucleic Acids Res, 30, 3235-44.

JPENBERG, I. A., E. JEANNIN, W. WAHLI \& A. DESVERGNE (1997) Polarity and specific sequence requirements of peroxisome proliferator-activated receptor (PPAR)/ retinoid $\mathrm{X}$ receptor heterodimer binding to DNA. A functional analysis of the malic enzyme gene PPAR response element. J Biol Chem, 272, 20108-17.

KASPER, P. \& MUELLER, L. (1999) Sex-specific induction of apoptosis by cyproterone acetate in primary rat hepatocytes. Carcinogenesis, 20, 2185-2188.

KELLER, J. M., COLLET, P., BIANCHI, A., HUIN, C., BOUILLAUD-KREMARIK, P., BECUWE, P., SCHOHN, H.,L. DOMENJOUD, L.\& DAUCA, V. (2000) Implications of peroxisome proliferator-activated receptors (PPARS) in development, cell life status and disease. Int J Dev Biol, 44, 429-42.

KITAREEWAN, S., BLUMEN, S., SEKULA, D., BISSONNETTE, R. P., LAMPH, W. W., CUI, Q., GALLAGHER, R. \& DMITROVSKY, E. (2008) G0S2 is an all-trans-retinoic acid target gene. International Journal of Oncology, 33, 397-404.

KLAUNIG, J. E. (2003) Application of the framework to the PPAR alpha agonist case example. Toxicological Sciences, 72, 170-170.

KLAUNIG, J. E., BABICH, M. A., BAETCKE, K. P., COOK, J. C., CORTON, J. C., DAVID, R. M., DELUCA, J. G., LAI, D. Y., MCKEE, R. H., PETERS, J. M., ROBERTS, R. A. \& FENNER-CRISP, P. A. (2003) PPARalpha agonist-induced rodent tumours: modes of action and human relevance. Crit Rev Toxicol, 33, 655-780.

KLIEWER, S. A., FORMAN, B. M., BLUMBERG, B., ONG, E. S., BORGMEYER, U., MANGELSDORF, D. J., UMESONO, K. \& EVANS, R. M. (1994) Differential expression and activation of a family of murine peroxisome proliferator-activated receptors. Proc Natl Acad Sci US A, 91, 7355-9.

KOBLIAKOV, V. A. (2010) Mechanisms of tumour promotion by reactive oxygen species. Biochemistry (Mosc), 75, 675-85. 
KREBS, O., SCHAFER, B., WOLFF, T., OESTERLE, D., DEML, E., SUND, M. \& FAVOR, J. (1998) The DNA damaging drug cyproterone acetate causes gene mutations and induces glutathione-S-transferase P in the liver of female Big Blue transgenic F344 rats. Carcinogenesis, 19, 241-5.

KÜHNEL, W. (2003) Color atlas of cytology, histology, and microscopic anatomy, George Thieme Verlag.

KURT, E. J. (1991) Histology and cell biology, Maryland USA, William and Wikins.

LAKE, B. G., RUMSBY, P. C., PRICE, R. J. \& CUNNINGHAME, M. E. (2000) Species differences in hepatic peroxisome proliferation, cell replication and transforming growth factor-betal gene expression in the rat, Syrian hamster and guinea pig. Mutat Res, 448, 213-25.

LARSEN, M. C. \& JEFCOATE, C. R. (1995) Phenobarbital induction of CYP2B1, CYP2B2, and CYP3A1 in rat liver: genetic differences in a common regulatory mechanism. Arch Biochem Biophys, 321, 467-76.

LATRUFFE, N., CHERKAOUI MALKI, M., NICOLAS-FRANCES, V., JANNIN, B., CLEMENCET, M. C., HANSMANNEL, F., PASSILLY-DEGRACE, P. \& BERLOT, J. P. (2001) Peroxisome-proliferator-activated receptors as physiological sensors of fatty acid metabolism: molecular regulation in peroxisomes. Biochem Soc Trans, 29, 305-9.

LATRUFFE, N. \& VAMECQ, J. (1997) Peroxisome proliferators and peroxisome proliferator activated receptors (PPARs) as regulators of lipid metabolism. Biochimie, 79, 81-94.

LAU, C., BUTENHOFF, J. L. \& ROGERS, J. M. (2004) The developmental toxicity of perfluoroalkyl acids and their derivatives. Toxicol Appl Pharmacol, 198, 231-41.

LEDDA-COLUMBANO, G. M., PIBIRI, M., CONCAS, D., MOLOTZU, F., SIMBULA, G., COSSU, C. \& COLUMBANO, A. (2003) Sex difference in the proliferative response of mouse hepatocytes to treatment with the CAR ligand, TCPOBOP. Carcinogenesis, $24,1059-65$.

LEE, S. S., PINEAU, T., DRAGO, J., LEE, E. J., OWENS, J. W., KROETZ, D. L., FERNANDEZ-SALGUERO, P. M., WESTPHAL, H. \& GONZALEZ, F. J. (1995) Targeted disruption of the alpha isoform of the peroxisome proliferator-activated receptor gene in mice results in abolishment of the pleiotropic effects of peroxisome proliferators. Mol Cell Biol, 15, 3012-22.

LEHMANN, J. M., MCKEE, D. D., WATSON, M. A., WILLSON, T. M., MOORE, J. T. \& KLIEWER, S. A. (1998) The human orphan nuclear receptor PXR is activated by 
compounds that regulate CYP3A4 gene expression and cause drug interactions. J Clin Invest, 102, 1016-23.

LEIGHTON, F., POOLE, B., BEAUFAY, H., BAUDHUIN, P., COFFEY, J. W., FOWLER, S. \& DE DUVE, C. (1968) The large-scale separation of peroxisomes, mitochondria, and lysosomes from the livers of rats injected with triton WR-1339. Improved isolation procedures, automated analysis, biochemical and morphological properties of fractions. $J$ Cell Biol, 37, 482-513.

LEU, J., CRISSEY, M., LEU, J., CILIBERTO, G. \& TAUB, R. (2001) Interleukin-6-induced STAT3 and AP-1 amplify hepatocyte nuclear factor 1-mediated transactivation of hepatic genes, an adaptive response to liver injury. Mol Cell Biol, 21, 414-24.

LUCI, S., GIEMSA, B., KLUGE, H. \& EDER, K. (2007) Clofibrate causes an upregulation of PPAR-alpha target genes but does not alter expression of SREBP target genes in liver and adipose tissue of pigs. American Journal of Physiology-Regulatory Integrative and Comparative Physiology, 293, R70-R77.

MADER, S. S. (2004) Understanding Human Anatomy \& Physiology.

MANGNALL, D., BIRD, N. C. \& MAJEED, A. W. (2003) The molecular physiology of liver regeneration following partial hepatectomy. Liver Int, 23, 124-38.

MARIONI, J. C., MASON, C. E., MANE, S. M., STEPHENS, M. \& GILAD, Y. (2008) RNAseq: an assessment of technical reproducibility and comparison with gene expression arrays. Genome Res, 18, 1509-17.

MARSMAN, D. S., CATTLEY, R. C., CONWAY, J. G. \& POPP, J. A. (1988) Relationship of hepatic peroxisome proliferation and replicative DNA synthesis to the hepatocarcinogenicity of the peroxisome proliferators di(2-ethylhexyl)phthalate and [4-chloro-6-(2,3-xylidino)-2-pyrimidinylthio]acetic acid (Wy-14,643) in rats. Cancer Res, 48, 6739-44.

MASUYAMA, H., HIRAMATSU, Y., MIZUTANI, Y., INOSHITA, H. \& KUDO, T. (2001) The expression of pregnane $\mathrm{X}$ receptor and its target gene, cytochrome $\mathrm{P} 450$ 3A1, in perinatal mouse. Mol Cell Endocrinol, 172, 47-56.

MATSUMOTO, K., YU, S. T., JIA, Y. Z., AHMED, M. R., VISWAKARMA, N., SARKAR, J., KASHIREDDY, P. V., RAO, M. S., KARPUS, W., GONZALEZ, F. J. \& REDDY, J. K. (2007) Critical role for transcription coactivator peroxisome proliferator-activated receptor (PPAR)-binding protein/TRAP220 in liver regeneration and PPAR alpha ligand-induced liver tumour development. Journal of Biological Chemistry, 282, 17053-17060.

MENEGAZZI, M., CARCERERIDEPRATI, A., SUZUKI, H., SHINOZUKA, H., PIBIRI, M., PIGA, R., COLUMBANO, A. \& LEDDACOLUMBANO, G. M. (1997) Liver cell 
proliferation induced by nafenopin and cyproterone acetate is not associated with increases in activation of transcription factors NF-kappa B and AP-1 or with expression of tumour necrosis factor alpha. Hepatology, 25, 585-592.

MEYER, K., LEE, J. S., DYCK, W. Q., CAO, M. S., RAO, S. S., THORGEIRSSON P. A. \& REDDY J. K. (2003) Molecular profiling of hepatocellular carcinomas developing spontaneously in acyl-CoA oxidase deficient mice: comparison with liver tumours induced in wild-type mice by a peroxisome proliferator and a genotoxic carcinogen. Carcinogenesis, 24, 975-84.

MICHALOPOULOS, G. K. (2007) Liver regeneration. J Cell Physiol, 213, 286-300.

MICHALOPOULOS, G. K. \& DEFRANCES, M. C. (1997) Liver regeneration. Science, 276, 60-6.

MILLER, C. W. \& NTAMBI, J. M. (1996) Peroxisome proliferators induce mouse liver stearoyl-CoA desaturase 1 gene expression. Proc Natl Acad Sci U S A, 93, 9443-8.

MILLER, R. T., SHAH, R. S., CATTLEY, R. C. \& POPP, J. A. (1996) The peroxisome proliferations WY-14,643 and methylclofenapate induce hepatocyte ploidy alterations and ploidy-specific DNA synthesis in F344 rats. Toxicol Appl Pharmacol, 138, 317-23.

MOODY, D. E., REDDY, J. K., LAKE, B. G., POPP, J. A. \& REESE, D. H. (1991) Peroxisome Proliferation and Nongenotoxic Carcinogenesis - Commentary on a Symposium. Fundamental and Applied Toxicology, 16, 233-248.

MORIMURA, K., CHEUNG, C., WARD, J. M., REDDY, J. K. \& GONZALEZ, F. J. (2006) Differential susceptibility of mice humanized for peroxisome proliferator-activated receptor alpha to Wy-14,643-induced liver tumourigenesis. Carcinogenesis, 27, 10741080.

MORRIS, D. L. \& DAVILA, J. C. (1996) Analysis of rat cytochrome P450 isoenzyme expression using semi-quantitative reverse transcriptase-polymerase chain reaction (RT-PCR). Biochem Pharmacol, 52, 781-92.

MUKHERJEE, R., SUN, S., SANTOMENNA, L., MIAO, B., WALTON, B., LIAO, K., LOCKE, J. H., ZHANG, S. H., NGUYEN, L. T., ZHANG, K., MURPHY, H. O., ROSS, M. X., XIA, C., TELEHA, S. Y., CHEN, B., SELLING, R., WYNN, T., BURN H., \& YOUNG, P. R. (2002) Ligand and coactivator recruitment preferences of peroxisome proliferator activated receptor alpha. J Steroid Biochem Mol Biol, 81, 217 25 .

NELSEN, C. J., RICKHEIM, D. G., TIMCHENKO, N. A., STANLEY, M. W. \& ALBRECHT, J. H. (2001) Transient expression of cyclin D1 is sufficient to promote hepatocyte replication and liver growth in vivo. Cancer Res, 61, 8564-8. 
NEUMANN, F. (1994) The antiandrogen cyproterone acetate: discovery, chemistry, basic pharmacology, clinical use and tool in basic research. Exp Clin Endocrinol, 102, 1-32.

NISHIDA, N., FUKUDA, Y., KOMEDA, T., KITA, R., SANDO, T., FURUKAWA, M., AMENOMORI, M., SHIBAGAKI, I., NAKAO, K.\& IKENAGA, M. (1994) Amplification and overexpression of the cyclin D1 gene in aggressive human hepatocellular carcinoma. Cancer Res, 54, 3107-10.

NTAMBI, J. M. (1995) Cellular differentiation and dietary regulation of gene expression. Prostaglandins Leukot Essent Fatty Acids, 52, 117-20.

OINONEN, T. \& LINDROS, K. O. (1998) Zonation of hepatic cytochrome P-450 expression and regulation. Biochem $J, 329$ ( Pt 1), 17-35.

OINONEN, T., SAARIKOSKI, S., HUSGAFVEL-PURSIAINEN, K., HIRVONEN, A. \& LINDROS, K. O. (1994) Pretranslational induction of cytochrome P4501A enzymes by beta-naphthoflavone and 3-methylcholanthrene occurs in different liver zones. Biochem Pharmacol, 48, 2189-97.

ORTON, T. C. \& PARKER, G. L. (1982) The effect of hypolipidemic agents on the hepatic microsomal drug-metabolizing enzyme system of the rat. Induction of cytochrome(s) P-450 with specificity toward terminal hydroxylation of lauric acid. Drug Metab Dispos, 10, 110-5.

PARZEFALL, W., BERGER, W., KAINZBAUER, E., TEUFELHOFER, O., SCHULTEHERMANN, R. \& THURMAN, R. G. (2001) Peroxisome proliferators do not increase DNA synthesis in purified rat hepatocytes. Carcinogenesis, 22, 519-523.

PERAZA, M. A., BURDICK, A. D., MARIN, H. E., GONZALEZ, F. J. \& PETERS, J. M. (2006) The toxicology of ligands for peroxisome proliferator-activated receptors (PPAR). Toxicological Sciences, 90, 269-295.

PETERS, J. M., AOYAMA, T., CATTLEY, R. C., NOBUMITSU, U., HASHIMOTO, T. \& GONZALEZ, F. J. (1998) Role of peroxisome proliferator-activated receptor alpha in altered cell cycle regulation in mouse liver. Carcinogenesis, 19, 1989-94.

PETERS, J. M., CATTLEY, R. C. \& GONZALEZ, F. J. (1997a) Role of PPAR alpha in the mechanism of action of the nongenotoxic carcinogen and peroxisome proliferator $\mathrm{Wy}-$ 14,643. Carcinogenesis, 18, 2029-2033.

PETERS, J. M., CHEUNG, C. \& GONZALEZ, F. J. (2005) Peroxisome proliferator-activated receptor-alpha and liver cancer: where do we stand? Journal of Molecular MedicineJmm, 83, 774-785. 
PETERS, J. M., TAUBENECK, M. W., KEEN, C. L. \& GONZALEZ, F. J. (1997b) Di(2ethylhexyl) phthalate induces a functional zinc deficiency during pregnancy and teratogenesis that is independent of peroxisome proliferator-activated receptor-alpha. Teratology, 56, 311-6.

PETERS, J. W. \& COOK, R. M. (1973) Effect of phthalate esters on reproduction in rats. Environ Health Perspect, 3, 91-4.

PIBIRI, M., LEDDA-COLUMBANO, G. M., COSSU, C., SIMBULA, G., MENEGAZZI, M., SHINOZUKA, H. \& COLUMBANO, A. (2001) Cyclin D1 is an early target in hepatocyte proliferation induced by thyroid hormone (T3). FASEB J, 15, 1006-13.

PLANT, N. J., HORLEY, N. J., SAVORY, R. L., ELCOMBE, C. R., GRAY, T. J. B. \& BELL, D. R. (1998) The peroxisome proliferators are hepatocyte mitogens in chemically-defined media: glucocorticoid-induced PPAR alpha is linked to peroxisome proliferator mitogenesis. Carcinogenesis, 19, 925-931.

POHJANVIRTA, R., NIITTYNEN, M., LINDEN, J., BOUTROS, P. C., MOFFAT, I. D. \& OKEY, A. B. (2006) Evaluation of various housekeeping genes for their applicability for normalization of mRNA expression in dioxin-treated rats. Chem Biol Interact, 160, 134-49.

RADISKY, D. C., LEVY, D. D., LITTLEPAGE, L. E., LIU, H., NELSON, C. M., FATA, J. E., LEAKE, D., GODDEN, E. L., ALBERTSON, D. G., NIETO, M. A., WERB, Z. \& BISSELL, M. J. (2005) Rac1b and reactive oxygen species mediate MMP-3-induced EMT and genomic instability. Nature, 436, 123-7.

RAEDSCH, R., PLACHKY, J., WOLF, N. \& SIMONIS, G. (1995) Biliary lipids, lithogenic index and biliary drug concentrations during etofibrate and bezafibrate treatment. Eur $J$ Drug Metab Pharmacokinet, 20, 113-8.

REDDY, J. K. (2004) Peroxisome proliferators and peroxisome proliferator-activated receptor alpha: biotic and xenobiotic sensing. Am J Pathol, 164, 2305-21.

REDDY, J. K., AZARNOFF, D. L. \& HIGNITE, C. E. (1980) Hypolipidaemic hepatic peroxisome proliferators form a novel class of chemical carcinogens. Nature, 283, 3978.

REDDY, J. K., GOEL, S. K., NEMALI, M. R., CARRINO, J. J., LAFFLER, T. G., REDDY, M. K., SPERBECK, S. J., OSUMI, T., HASHIMOTO, T., LALWANI, N. D. \& ET AL. (1986) Transcription regulation of peroxisomal fatty acyl-CoA oxidase and enoylCoA hydratase/3-hydroxyacyl-CoA dehydrogenase in rat liver by peroxisome proliferators. Proc Natl Acad Sci U S A, 83, 1747-51.

RHODIN, J. (1954) Correlation of ultrastructural organization and function in normal and 
experimentally changed proximal convoluted tubule cells of the mouse kidney. Stocklhom: Aktiebologet Godvil.

RININGER, J. A., WHEELOCK, G. D., MA, X. \& BABISH, J. G. (1996) Discordant expression of the cyclin-dependent kinases and cyclins in rat liver following acute administration of the hepatocarcinogen [4-chloro-6-(2,3-xylidino)-2-pyrimidinylthio] acetic acid (WY14,643). Biochem Pharmacol, 52, 1749-55.

RITTER, E. J., SCOTT, W. J., JR., RANDALL, J. L. \& RITTER, J. M. (1985) Teratogenicity of dimethoxyethyl phthalate and its metabolites methoxyethanol and methoxyacetic acid in the rat. Teratology, 32, 25-31.

ROKOS, C. L. \& LEDWITH, B. J. (1997) Peroxisome proliferators activate extracellular signal-regulated kinases in immortalized mouse liver cells. J Biol Chem, 272, 13452-7.

ROSS, M. H., \& KAYE, G. I. (2003) Histology a text and atlas, Lippincott williams\& Wilkins.

SASSE, D. (1986) Metabolic Zonation of the Liver. Experientia, 42, 646-646.

SCEARCE, L. M., LEE, J., NAJI, L., GREENBAUM, L., CRESSMAN, D. E. \& TAUB, R. (1996) Rapid activation of latent transcription factor complexes reflects initiating signals in liver regeneration. Cell Death and Differentiation, 3, 47-55.

SCHENA, M., SHALON, D., DAVIS, R. W. \& BROWN, P. O. (1995) Quantitative monitoring of gene expression patterns with a complementary DNA microarray. Science, 270, 467-70.

SCHENA, M., HELLER, R. A., THERIAULT, T. P., KONRAD, K., LACHENMEIER, P. \& DAVIS, R. W. (1998). Microarrays: biotechnology's discovery platform for functional genomics. Trends Biotechnol, 16, 301-6.

SCHOONJANS, K., STAELS, B. \& AUWERX, J. (1996) Role of the peroxisome proliferatoractivated receptor (PPAR) in mediating the effects of fibrates and fatty acids on gene expression. J Lipid Res, 37, 907-25.

SCHULTE-HERMANN, R., HOFFMAN, V., PARZEFALL, W., KALLENBACH, M., GERHARDT, A. \& SCHUPPLER, J. (1980) Adaptive responses of rat liver to the gestagen and anti-androgen cyproterone acetate and other inducers. II. Induction of growth. Chem Biol Interact, 31, 287-300.

SCHWABE, R. F., BRADHAM, C. A., UEHARA, T., HATANO, E., BENNETT, B. L., SCHOONHOVEN, R. \& BRENNER, D. A. (2003) c-Jun-N-terminal kinase drives cyclin D1 expression and proliferation during liver regeneration. Hepatology, 37, 82432 . 
SESSLER, A. M., KAUR, N., PALTA, J. P. \& NTAMBI, J. M. (1996) Regulation of stearoylCoA desaturase 1 mRNA stability by polyunsaturated fatty acids in 3T3-L1 adipocytes. J Biol Chem, 271, 29854-8.

SHAH, Y. A., MORIMURA, K., YANG, Q., TANABE, T., TAKAGI, M. \& GONZALEZ, F. J. (2007a) Peroxisome proliferator-activated receptor alpha regulates a microRNAmediated signalling cascade responsible for hepatocellular proliferation. Molecular and Cellular Biology, 27, 4238-4247.

SHAH, Y. M., MA, X. C., MORIMURA, K., KIM, I. \& GONZALEZ, F. J. (2007b) Pregnane $\mathrm{X}$ receptor activation ameliorates DSS-induced inflammatory bowel disease via inhibition of NF-kappa B target gene expression. American Journal of PhysiologyGastrointestinal and Liver Physiology, 292, G1114-G1122.

SIGAL, S. H., RAJVANSHI, P., GORLA, G. R., SOKHI, R. P., SAXENA, R., GEBHARD, D. R., REID, L. M. \& GUPTA, S. (1999) Partial hepatectomy-induced polyploidy attenuates hepatocyte replication and activates cell aging events. American Journal of Physiology-Gastrointestinal and Liver Physiology, 276, G1260-G1272.

SIMPSON, A. E. (1997) The cytochrome P450 4 (CYP4) family. Gen Pharmacol, 28, 351-9.

SINGH, A. R., LAWRENCE, W. H. \& AUTIAN, J. (1974) Mutagenic and antifertility sensitivities of mice to di-2-ethylhexyl phthalate (DEHP) and dimethoxyethyl phthalate (DMEP). Toxicol Appl Pharmacol, 29, 35-46.

SKALETSKY, S. R. (2000). Primer3 on the WWW for general users and for biologist programmers. Krawetz S, Misener S (eds) Bioinformatics Methods and Protocols: Methods in Molecular Biology. Humana Press, Totowa, NJ, 365-386.

SLATTER, J. G., CHENG, O. CORNWELL, P. D. DE SOUZA, J. ROCKETT, T. RUSHMORE, D. HARTLEY, R. EVERS, Y. HE, X. DAI, R. HU, M. CAGUYONG, C. J. ROBERTS, J. CASTLE, A. \& ULRICH, R. G. (2006) Microarray-based compendium of hepatic gene expression profiles for prototypical ADME geneinducing compounds in rats and mice in vivo. Xenobiotica, 36, 902-37.

STEFANINI, S., MAURIELlO, A., FARRACE, M. G., CIBELLI, A. \& CERU, M. P. (1989) Proliferative response of foetal liver peroxisomes to clofibrate treatment of pregnant rats. A quantitative evaluation. Biol Cell, 67, 299-305.

STYLES, J. A., KELLY, M. \& ELCOMBE, C. R. (1987) A cytological comparison between regeneration, hyperplasia and early neoplasia in the rat-liver. Carcinogenesis, 8, 391399.

STYLES, J. A., KELLY, M. D., PRITCHARD, N. R. \& FOSTER, J. R. (1990) Effects produced by the non-genotoxic hepatocarcinogen methylclofenapate in dwarf mice - 
peroxisome induction uncoupled from dna-synthesis and nuclearity changes. Carcinogenesis, 11, 387-391.

SUCHANEK, K. M., MAY, F. J., ROBINSON, J. A., LEE, W. J., HOLMAN, N. A., MONTEITH, G. R. \& ROBERTS-THOMSON, S. J. (2002) Peroxisome proliferatoractivated receptor alpha in the human breast cancer cell lines MCF-7 and MDA-MB231. Mol Carcinog, 34, 165-71.

SUZUKI, T., JIN, M., DEWA, Y., ICHIMURA, R., SHIMADA, Y., MIZUKAMI, S., SHIBUTANI, M. \& MITSUMORI, K. (2010) Evaluation of in vivo liver genotoxic potential of Wy-14,643 and piperonyl butoxide in rats subjected to two-week repeated oral administration. Arch Toxicol, 84, 493-500.

TALARMIN, H., RESCAN, C. CARIOU, S. GLAISE, D. ZANNINELLI, G. BILODEAU, M. LOYER, P. GUGUEN-GUILLOUZO, C. \& BAFFET G. (1999) The mitogenactivated protein kinase kinase/extracellular signal-regulated kinase cascade activation is a key signalling pathway involved in the regulation of $\mathrm{G}(1)$ phase progression in proliferating hepatocytes. Mol Cell Biol, 19, 6003-11.

TARCA, A. L., ROMERO, R. \& DRAGHICI, S. (2006) Analysis of microarray experiments of gene expression profiling. Am J Obstet Gynecol, 195, 373-88.

TAUB, R. (2004) Liver regeneration: From myth to mechanism. Nature Reviews Molecular Cell Biology, 5, 836-847.

TAUB, R., GREENBAUM, L. E. \& PENG, Y. (1999) Transcriptional regulatory signals define cytokine-dependent and -independent pathways in liver regeneration. Semin Liver Dis, 19, 117-27.

TEWARI, M., DOBRZANSKI, P., MOHN, K. L., CRESSMAN, D. E., HSU, J. C., BRAVO, R. \& TAUB, R. (1992) Rapid Induction in Regenerating Liver of R1/If-1 (an I-Kappa-B That Inhibits Nf-Kappa-B, Relb-P50, and C-Rel-P50) and Phf, a Novel Kappa-B SiteBinding Complex. Molecular and Cellular Biology, 12, 2898-2908.

TIRONA, R. G., LEE, W., LEAKE, B. F., LAN, L. B., CLINE, C. B., LAMBA, V., PARVIZ, F., DUNCAN, S. A., INOUE, Y., GONZALEZ, F. J., SCHUETZ, E. G. \& KIM, R. B. (2003) The orphan nuclear receptor HNF4alpha determines PXR- and CAR-mediated xenobiotic induction of CYP3A4. Nat Med, 9, 220-4.

TOPINKA, J., OESTERLE, D., REIMANN, R. \& WOLFF, T. (2004a) No-effect level in the mutagenic activity of the drug cyproterone acetate in rat liver. Part I. Single dose treatment. Mutat Res, 550, 89-99. 
TOPINKA, J., OESTERLE, D., REIMANN, R. \& WOLFF, T. (2004b) No-effect level in the mutagenic activity of the drug cyproterone acetate in rat liver. Part II. Multiple dose treatment. Mutat Res, 550, 101-8.

TUGWOOD, J. D., ISSEMANN, I., ANDERSON, R. G., BUNDELL, K. R., MCPHEAT, W. L. \& GREEN, S. (1992) The Mouse Peroxisome Proliferator Activated Receptor Recognizes a Response Element in the 5' Flanking Sequence of the Rat Acyl Coa Oxidase Gene. Embo Journal, 11, 433-9.

VAN VLOTEN, W. A., VAN HASELEN, C. W., VAN ZUUREN, E. J., GERLINGER, C. \& HEITHECKER, R. (2002) The effect of 2 combined oral Contraceptives containing either drospirenone or cyproterone acetate on acne and seborrhea. Cutis, 69, 2-15.

VANDESOMPELE, J., DE PRETER, K., PATTYN, F., POPPE, B., VAN ROY, N., DE PAEPE, A. \& SPELEMAN, F. (2002) Accurate normalization of real-time quantitative RT-PCR data by geometric averaging of multiple internal control genes. Genome Biol, 3, RESEARCH0034.

WATERS, K. M. \& NTAMBI, J. M. (1994) Insulin and dietary fructose induce stearoyl-CoA desaturase 1 gene expression of diabetic mice. J Biol Chem, 269, 27773-7.

WEIBEL, E. R., STAUBLI, W., GNAGI, H. R. \& HESS, F. A. (1969) Correlated morphometric and biochemical studies on the liver cell. I. Morphometric model, stereologic methods, and normal morphometric data for rat liver. J Cell Biol, 42, 68-91.

WEISBURGER, J. H. \& WILLIAMS, G. M. (2000) The distinction between genotoxic and epigenetic carcinogens and implication for cancer risk. Toxicol Sci, 57, 4-5.

WILlE, A. C., OLIVEIRA, F. A., SOARES, M. A. \& GOMES, J. R. (2004) Cell cycle time and rate of entry of cells into mitosis in the small intestine of young rats. Cell Prolif, 37, 189-94.

WILSON, G. N., KING, T., ARGYLE, J. C. \& GARCIA, R. F. (1991) Maternal clofibrate administration amplifies fetal peroxisomes. Pediatr Res, 29, 256-62.

WOODS, C. G., BURNS, A. M., BRADFORD, B. U., ROSS, P. K., KOSYK, O., SWENBERG, J. A., CUNNINGHAM, M. L. \& RUSYN, I. (2007) WY-14,643induced cell proliferation and oxidative stress in mouse liver are independent of NADPH oxidase. Toxicological Sciences, 98, 366-74.

WU, F. Y., WANG, S. E., SANDERS, I., SHIN, F., ROJO, J., BASELGA, M. E. \& ARTEAGA, C. L. (2006). Reduction of cytosolic p27(Kip1) inhibits cancer cell motility, survival, and tumourigenicity. Cancer Res, 66, 2162-2172. 
YAACOB, N. S., NORAZMI, M. N., KASS, G. E. \& GIBSON, G. G. (1997) Use of competitive RT-PCR in the molecular analysis of peroxisome proliferation. Eur J Drug Metab Pharmacokinet, 22, 321-4.

YADETIE, F., LAEGREID, A., BAKKE, I., KUSNIERCZYK, W., KOMOROWSKI, J., WALDUM, H. L. \& SANDVIK, A. K. (2003) Liver gene expression in rats in response to the peroxisome proliferator-activated receptor-alpha agonist ciprofibrate.

Physiological Genomics, 15, 9-19.

YAMAMOTO, Y., MOORE, R., GOLDSWORTHY, M., NEGISHI, T. L. \& MARONPOT, R. R. (2004) The orphan nuclear receptor constitutive active/androstane receptor is essential for liver tumour promotion by phenobarbital in mice. Cancer Res, 64, 7197 200.

YELDANDI, A. V., RAO, M. S. \& REDDY, J. K. (2000) Hydrogen peroxide generation in peroxisome proliferator-induced oncogenesis. Mutation Research-Fundamental and Molecular Mechanisms of Mutagenesis, 448, 159-177.

ZANDBERGEN, F., MANDARD, S., ESCHER, P., TAN, N. S., PATSOURIS, D., JATKOE, T., ROJAS-CARO, S., MADORE, S., WAHLI, W., TAFURI, S., MULLER, M. \& KERSTEN, S. (2005) The G0/G1 switch gene 2 is a novel PPAR target gene. Biochem $J, 392,313-24$.

ZEEBERG, B. R., HAIYING QIN, SUDARSHAN NARASIMHAN, MARGOT SUNSHINE, HONG CAO, DAVID W. KANE, MARK REIMERS, ROBERT STEPHENS, DAVID BRYANT, STANLEY K. BURT, ELDAD ELNEKAVE, DANIELLE M. HARI, THOMAS A. WYNN, CHARLOTTE CUNNINGHAM-RUNDLES, DONN M. STEWART, DAVID NELSON \& JOHN N. WEINSTEIN. (2005) High-Throughput GoMiner, an 'industrial-strength' integrative Gene Ontology tool for interpretation of multiple-microarray experiments, with application to studies of Common Variable Immune Deficiency (CVID). <http://www.biomedcentral.com/1471-2105/6/168> BMC Bioinformatics <http://www.biomedcentral.com/bmcbioinformatics/>, 168. 